DESIGN AND PERFORMANCE ANALYSIS OF DOUBLE-FLUX

SUPERSONIC AIR EJECTOR

A THESIS SUBMITTED TO

THE GRADUATE SCHOOL OF NATURAL AND APPLIED SCIENCES

OF

MIDDLE EAST TECHNICAL UNIVERSITY

BY

BERK BOZKIR

IN PARTIAL FULFILLMENT OF THE REQUIREMENTS

FOR

THE DEGREE OF MASTER OF SCIENCE

IN

AEROSPACE ENGINEERING

MAY 2018 

Approval of the thesis:

\section{DESIGN AND PERFORMANCE ANALYSIS OF DOUBLE-FLUX SUPERSONIC AIR EJECTOR}

submitted by BERK BOZKIR in partial fulfillment of the requirements for the degree of Master of Science in Aerospace Engineering Department, Middle East Technical University by,

Prof. Dr. Halil Kalıpçılar

Dean, Graduate School of Natural and Applied Sciences

Prof. Dr. Ozan Tekinalp

Head of Department, Aerospace Engineering

Prof. Dr. Hüseyin Nafiz Alemdaroğlu

Supervisor, Aerospace Engineering Dept., METU

\section{Examining Committee Members:}

Prof. Dr. Yusuf Özyörük

Aerospace Engineering Dept., METU

Prof. Dr. Hüseyin Nafiz Alemdaroğlu

Aerospace Engineering Dept., METU

Prof. Dr. Serkan Özgen

Aerospace Engineering Dept., METU

Assoc. Prof. Dr. Dilek Funda Kurtuluş

Aerospace Engineering Dept., METU

Asst. Prof. Dr. Durmuş Sinan Körpe

Aeronautical Engineering Dept., THK

Date: 11.05 .2018 
I hereby declare that all information in this document has been obtained and presented in accordance with academic rules and ethical conduct. I also declare that, as required by these rules and conduct, I have fully cited and referenced all material and results that are not original to this work.

Name, Last name:

Signature 


\title{
ABSTRACT \\ DESIGN AND PERFORMANCE ANALYSIS OF DOUBLE-FLUX SUPERSONIC AIR EJECTOR
}

\author{
BOZKIR, Berk \\ M. S., Department of Aerospace Engineering \\ Supervisor: Prof. Dr. Hüseyin Nafiz ALEMDAROĞLU
}

May 2018, 116 pages

The main purpose of this study is to design a double-flux supersonic ejector and to evaluate its performance associated with its entrainment ratio by employing Computational Fluid Dynamics methods as well as one-dimensional approach. Since the performance of the ejector systems is strongly dependent on the design, this study concentrates on maximizing the entrainment ratio by varying the corresponding angles and the lengths of the critical segments such as mixing angle, divergence angle, mixing throat length etc., while keeping the operational parameters unaltered. Numerically computed results and the one-dimensional calculations have been compared. It is found that the proper design is mandatory for achieving efficient entrainment ratios, and has prominent effect on the operation of the system. It is found that almost $20 \%$ of enhancement on entrainment performance can be obtained solely by modifying the lengths and angles of the ejector's critical segments without changing the operating conditions. It is also deduced that during these modifications, the complex flow structure through the system, should not be disregarded for a thoroughly maximization of the performance and an efficient operation of the ejector.

Keywords: Supersonic Ejector Design, CFD, Ejector Performance Maximization, Entrainment Ratio, One Dimensional Approach 


\title{
ÇIFT AKILI SESÜSTÜ HAVA EJEKTÖR SISTEMININ TASARIM VE PERFORMANS ANALIZI
}

\author{
BOZKIR, Berk \\ Yüksek Lisans, Havacılık ve Uzay Mühendisliği Bölümü \\ Tez Yöneticisi: Prof. Dr. Hüseyin Nafiz ALEMDAROĞLU
}

Mayıs 2018, 116 sayfa

$\mathrm{Bu}$ çalışmada öncelikli amaç, çift akı sesüstü hava ejektör sisteminin dizaynı ve Hesaplamalı Akışkanlar Dinamiği metodunun yanı sıra tek boyutlu yaklaşım ile ejektör performansın geometrik parametrelere bağlı olarak değerlendirilmesidir. Ejektör sistemi performansının tasarım ile ilişkisi dikkate alınarak, ejektör sürükleme performansı maksimizasyonuna odaklanılmış, bu doğrultuda her bir geometrik parametre ayrı ayrı değerlendirilerek, elde edilen sonuçlar ortaya çıkarılmıştır. Aynı zamanda, akış yapısı ile akış dahilinde meydana gelen değişimler ve olası sebepleri belirtilmiş ve tartışılmıştır. Nümerik olarak elde edilen sonuçlar, tek boyutlu sonuçlar ile birlikte değerlendirilmiş, verimli sürükleme oranları elde edilmesi ve iyileştirilmesi için uygun bir tasarımın zorunluluğu saptanmıştır. Çalışma neticesinde \%20'ye yakın sürükleme performans artışı ejektör'ün çalışma koşulları sabit tutulup sadece kritik geometrik parametreler değiştirilerek elde edilmiştir. Bu çalışma ayrıca göstermiştir ki; özellikle karışma bölgesi başta olmak üzere tüm sistem boyunca oluşan karmaşık akış yapısı, sistem verimi açısından kesinlikle göz ardı edilmemelidir.

Anahtar Kelimeler: Süpersonik Ejektör Tasarımı, HAD, Ejektör Performansı Maksimizasyonu, Sürükleme Oranı, Tek Boyutlu Yaklaşım 
To my love and my family... 


\section{ACKNOWLEDGEMENT}

I would like to express my gratitude to Prof. Dr. Hüseyin Nafiz ALEMDAROĞLU for his great help to my work.

I also would like to state that this study could not be accomplished without the support and guidance of my colleagues, Mr. Tuğrul AKPOLAT, Mr. Ümit POYRAZ, Mr. Taylan KARPUZCU, Mr. Oğuz EREN and Mr. Cihan EROĞLU. I thank them all.

I especially thank to my love, Ms. Berna BAŞDOĞAN BOZKIR; to my friends; Mr. Tuğcan SELİMHOCAOĞLU, Mr. Berkan ZİRAMAN, Mr. Boray DEĞERLIYYURT, Mr. Volkan ACUN, Mr. Arda ERGÖNEN, Mr. Cenk TÜRKOĞLU, Mr. Mert DOĞAN, Mr. Kerem ALPTEKİN, Mr. Serdar YILDIZ, Mr. Sıtkı ÇÖRTOĞLU, Mr. Murat SÜMBÜL, Mr. Toygar BAKKALOĞLU, Mr. Eldem UZUN as well as my pet (dog) Mr. ODIN for always being there for me and for giving me a life full of beautiful moments and happiness.

Above all, I would like to offer the most and my sincere gratitude to my mother Mrs. Hayat BOZKIR, my father Mr. Hasan BOZKIR and my sister Ms. Ece BOZKIR and my whole relatives as for sure I cannot come this far in this journey without them. 


\section{TABLE OF CONTENTS}

ABSTRACT

ACKNOWLEDGEMENT ….............................................................................. vii

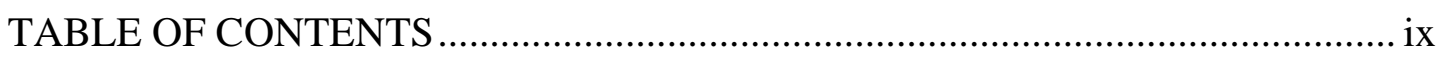

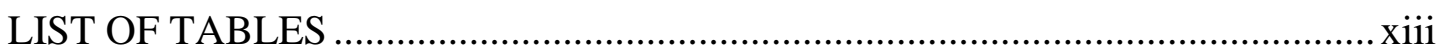

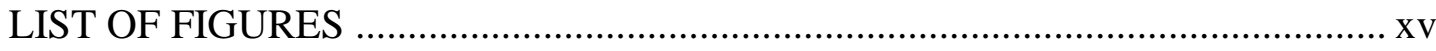

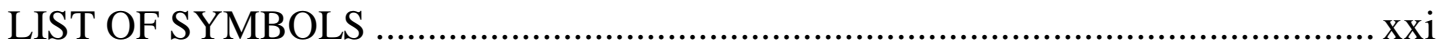

\section{CHAPTERS}

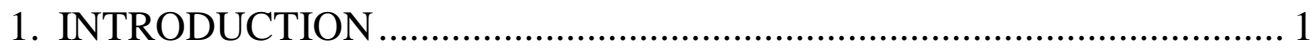

1.1. Objective of the Thesis ................................................................... 1

1.2. Literature Survey …………………………………………..... 1

1.2.1. Definition of the Ejector Systems .......................................... 1

1.2.2. Applications and Investigations of the Ejector Systems...... 4

1.3. Motivation of the Study ............................................................... 7

2. THEORETICAL INVESTIGATION OF AN EJECTOR AND ONE DIMENSIONAL APPROACH..............................................................

2.1. Theoretical Investigation of an Ejector.......................................... 9

2.1.1. Components of an Ejector................................................... 9

2.1.1.1. Converging-Diverging Nozzle .............................. 9 
2.1.1.2. Vacuum Region 10

2.1.1.3. Mixing Region 11

2.1.1.4. Diffuser Region 13

2.1.2. Entrainment Ratio 14

2.2. One Dimensional Approach 14

2.2.1. Converging-Diverging Nozzle Calculations 15

2.2.2. Secondary Inlet Branch Calculations 16

2.2.3. Mixing Chamber Calculations 17

2.2.4. Mixing Throat Calculations 18

2.2.5. Diffuser Calculations 19

2.2.6. Length of the Segments Pre-estimation 20

2.3. Theoretical Evaluation and the Outcomes 21

3. COMPUTATIONAL METHODS AND TOOLS FOR THE

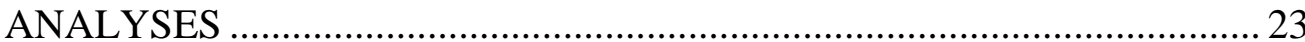

3.1. Validation of the Computational Methods and Tools - Part I....... 23

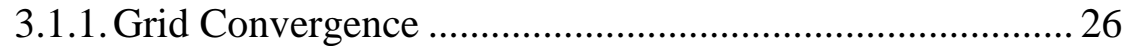

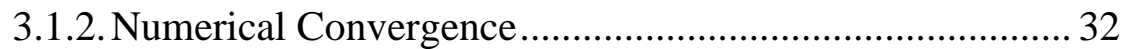

3.1.3. Present Study and the Comparison ................................. 34

3.2. Validation of the Computational Methods and Tools - Part II...... 39

4. RESULTS AND DISCUSSION 45 
4.2.1. Convergent-Divergent Nozzle Divergence Angle Analysis $(\psi)$.

4.2.1.1. Entrainment Ratio Analysis. 49

4.2.1.2. Mach Number and Pressure Distribution 50

4.2.1.3. Conclusion. 53

4.2.2. Secondary Inlet Inner-wall Angle Analysis ( $\alpha$ ) 54

4.2.2.1. Entrainment Ratio Analysis 54

4.2.2.2. Mach Number and Pressure Distribution 55

4.2.2.3. Conclusion. 59

4.2.3. Secondary Inlet Outer-wall Angle Analysis ( $\beta)$ 59

4.2.3.1. Entrainment Ratio Analysis. 59

4.2.3.2. Mach Number and Pressure Distribution 61

4.2.3.3. Conclusion 64

4.2.4. Gap Length Analysis ( $\left.\mathrm{L}_{\mathrm{gap}}\right)$ 64

4.2.4.1. Entrainment Ratio Analysis 65

4.2.4.2. Mach Number and Pressure Distribution 67

4.2.4.3. Conclusion 69

4.2.5. Mixing Convergence Angle Analysis $(\theta)$ 70 
4.2.5.1. Entrainment Ratio Analysis 71

4.2.5.2. Mach Number and Pressure Distribution 72

4.2.5.3. Conclusion 76

4.2.6. Length of Mixing Throat Section Analysis $\left(\mathrm{L}_{\mathrm{t} 2}\right)$ .77

4.2.6.1. Entrainment Ratio Analysis 77

4.2.6.2. Mach Number and Pressure Distribution 79

4.2.6.3. Conclusion 82

4.2.7. Diffuser Divergence Angle Analysis ( $\Phi)$ 83

4.2.7.1. Entrainment Ratio Analysis 83

4.2.7.2. Mach Number and Pressure Distribution 85

4.2.7.3. Conclusion 88

4.3. Outcomes of the Study..... 89

5. CONCLUSION AND FUTURE WORK 91

5.1. Conclusion 91

5.2. Future Work 93

REFERENCES 95

\section{APPENDICES}

A: TEMPERATURE AND PRESSURE EFFECTS ON THE ENTRAINMENT PERFORMANCE 99

B: 1-D FORTRAN CODE AND THE INPUT FILE 107 


\section{LIST OF TABLES}

\section{TABLES}

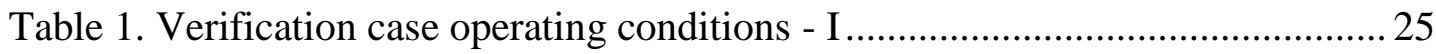

Table 2. Verification case non-dimensional parameters - I ................................ 25

Table 3. Grid resolution for corresponding flow simulations - I............................. 32

Table 4. Verification case study and analyses results - I..................................... 34

Table 5. Verification case study and analyses error table - I.................................. 35

Table 6. Verification case operating conditions - II ........................................... 40

Table 7 . Verification case study and analyses results - II ................................... 41

Table 8. Entrainment ratio results for the corresponding nozzle divergence angles

Table 9. Entrainment ratio results for the corresponding secondary inlet inner-wall angles

Table 10. Entrainment ratio results for the corresponding secondary inlet outer-wall angles 60

Table 11. Entrainment ratio results for the corresponding gap lengths 65

Table 12. Entrainment ratio results for the corresponding mixing convergence angles.

Table 13. Entrainment ratio results for the corresponding mixing throat lengths

Table 14. Entrainment ratio results for the corresponding diffuser divergence angles. 
Table 15. Overall ejector performance enhancement.

Table 16. Entrainment ratio results for the corresponding temperature ratios......... 100

Table 17. Entrainment ratio results for the corresponding pressure ratio values -

primary stagnation pressure (Po1) varied 102

Table 18. Entrainment ratio results for the corresponding pressure ratios - secondary stagnation pressure (Po2) varied. 104 


\section{LIST OF FIGURES}

\section{FIGURES}

Figure 1. A generic supersonic ejector scheme and its main components

Figure 2. A generic supersonic ejector scheme, its components along with the descriptions 3

Figure 3. A generic supersonic ejector geometry and velocity contribution 4

Figure 4. A generic scheme of a blow-down wind tunnel with an ejector system ...... 5

Figure 5. Test envelope of the DLR-Cologne Trisonic Wind Tunnel [10] 6

Figure 6. A typical converging-diverging nozzle scheme 10

Figure 7. Vacuum region and the process description 10

Figure 8. Constant-pressure mixing (top) versus constant-area mixing (bottom) ..... 11

Figure 9. Mixing patterns - shock cells visualization 12

Figure 10. Instantaneous Shilieren image of shock cells. [25] 12

Figure 11. Diffuser region and the explanation 13

Figure 12. Ejector geometry with the assigned stations 14

Figure 13. Zoomed view of the nozzle exit and the secondary flow intersection...... 16

Figure 14. Zoomed view of the upstream and downstream mixing region 17

Figure 15. Mixing throat section and NSW 18

Figure 16. Diffuser section and stations 
Figure 17. Lengths of the corresponding elements along with the convergence

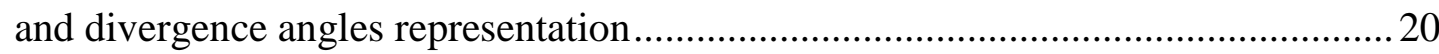

Figure 18. Cross sectional view of the verification case geometry - I [39]..............224

Figure 19. Grid convergence plot for FloEFD simulation ...................................... 27

Figure 20. A sectional view of the selected grid for the FloEFD simulations,

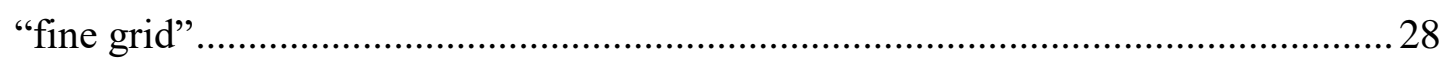

Figure 21. Grid distribution effects on the flow structure with comparison [39] ......28

Figure 22. Grid convergence plot for the ANSYS Fluent with k-epsilon realizable turbulence model implementation .29

Figure 23. A view of the selected grid\#3 for the ANSYS Fluent simulations with k-epsilon realizable turbulence model implementation, "fine grid" 30

Figure 24. A cross-sectional view of the selected grid\#3 for the ANSYS Fluent simulations with SST k-omega turbulence model implementation, "fine grid" 30

Figure 25. Grid convergence plot for the ANSYS Fluent with SST k-omega turbulence model implementation

Figure 26. Numerical convergence plot for the computation performed by FloEFD 32

Figure 27. Residual plot for the computation performed by ANSYS Fluent with SST k-omega turbulence model implementation .33

Figure 28. Residual plot for the computation performed by ANSYS Fluent with k-epsilon realizable turbulence model implementation .33

Figure 29. Comparison of the computational results and the numerical literature data (top) [39] and the zoomed view in the mixing region (bottom) 36 
Figure 30. Supersonic region $(M>1)$ Mach contours; (upper five; reference cases [34], [38] - lower three; real wall study(viscous), k-epsilon and SST k-omega turbulence model implementations respectively).................................................. 38

Figure 31. CFD results for viscous solution of FloEFD, Mach number contour 39

Figure 32. Velocity vectors within the mixing region (vector spacing $=0.15 \mathrm{~mm}$ ) for the present study (viscous FloEFD solution) 39

Figure 33. Verification case geometry - II [12] (dimensions in m)

Figure 34. Axial streamline pressure comparison of $\mathrm{P} 1=4 \mathrm{~atm}$ test case \#1 with that of the literature values [12] and the corresponding pressure iso-contour...

Figure 35. Axial streamline pressure comparison of $\mathrm{P} 1=6 \mathrm{~atm}$ test case \#3 with that of the literature values [12] and the corresponding pressure iso-contour

Figure 36. A generic supersonic ejector scheme with study parameters 45

Figure 37. Computational mesh cross-sectional view a. overall view b. crosssectional views of corresponding locations c. mixing + inlets d. inlets + nozzle + upstream mixing e. mixing throat + upstream diffuser

Figure 38. Nozzle divergence angle illustration

Figure 39. Change of entrainment ratio with nozzle divergence angle.

Figure 40. Mach number contours for the given nozzle divergence angles. 50

Figure 41. Effects of nozzle divergence angle on Mach number variation along the centerline

Figure 42. Pressure iso-contours for the corresponding nozzle divergence angles ... 52

Figure 43. Effects of nozzle divergence angle on pressure variation along the centerline..... 
Figure 44. Secondary inlet inner-wall angle illustration

Figure 45. Change of entrainment ratio with secondary inlet inner-wall angle 55

Figure 46. Mach number contours for the corresponding secondary inlet inner-wall angles..... 56

Figure 47. Effects of secondary inlet inner-wall angle on Mach number variation along the centerline

Figure 48. Pressure iso-contours for the corresponding secondary inlet inner-wall angles.....

Figure 49. Effects of secondary inlet inner-wall angle along the centerline pressure variation

Figure 50. Secondary inlet outer-wall angle illustration 59

Figure 51. Change of entrainment ratio with secondary inlet outer-wall angle 60

Figure 52. Mach number contours for the corresponding secondary inlet outer-wall angles

Figure 53. Effects of secondary inlet outer-wall angle on Mach number variation along the centerline

Figure 54. Pressure iso-contours for the corresponding secondary inlet outer-wall angles

Figure 55. Effects of secondary inlet outer-wall angle along the centerline pressure variation

Figure 56. Gap length illustration 65

Figure 57. Change of entrainment ratio with gap length for both 1-D calculations and the viscous (real wall) results 
Figure 58. Mach number contours for the indicated ratio values for the corresponding gap lengths

Figure 59. Effects of gap length on Mach number variation along the centerline..... 68

Figure 60. Pressure iso-contours for the corresponding gap lengths

Figure 61. Effects of gap length on pressure variation along the centerline .70

Figure 62. Mixing convergence angle illustration

Figure 63. Change of entrainment ratio with mixing convergence angle

Figure 64. Mach number contours for the corresponding mixing convergence angles.

Figure 65. Effects of mixing convergence angle on Mach number variation along the centerline

Figure 66. Pressure iso-contours for the corresponding mixing convergence angles

Figure 67. Effects of mixing convergence angle on pressure variation along the centerline

Figure 68. Mixing throat length illustration

Figure 69. Change of entrainment ratio with the mixing throat length .78

Figure 70. Mach number contours for the corresponding mixing throat lengths .79

Figure 71. Effects of the mixing throat length on Mach number variation along the centerline 80

Figure 72. Pressure iso-contours for the ratio values indicated for the corresponding mixing throat lengths .81 
Figure 73. Effects of mixing throat length on pressure variation along the centerline

Figure 74. Diffuser divergence angle illustration 83

Figure 75. Change of entrainment ratio with diffuser divergence angle. 84

Figure 76. Mach number contours for the corresponding diffuser divergence angles.

Figure 77. Effects of diffuser divergence angle on Mach number variation along the centerline 86

Figure 78. Pressure iso-contours for the corresponding diffuser divergence angles.....

Figure 79. Effects of diffuser divergence angle on pressure variation along the centerline 88

Figure 80. Operation illustration - additional study I - stagnation temperatures of the corresponding working fluids 99

Figure 81. Change of entrainment ratio with the primary fluid temperature 100

Figure 82. Operation illustration - additional study II - stagnation pressures of the corresponding working fluids 101

Figure 83. Change of entrainment ratio with the pressure ratio $\pi$ (Po1 altered) ..... 103

Figure 84. Change of entrainment ratio with the pressure ratio $\pi$ (Po2 altered) ..... 105 Figure 85. Streamlines for $\pi=7.59$ (upper) and $\pi=9.52$ (lower) 104

Figure 86. Entrainment performance versus pressure ratio $(\pi)$ comparison for both $P o 1$ and $P o 2$ altered cases 


\section{LIST OF SYMBOLS}

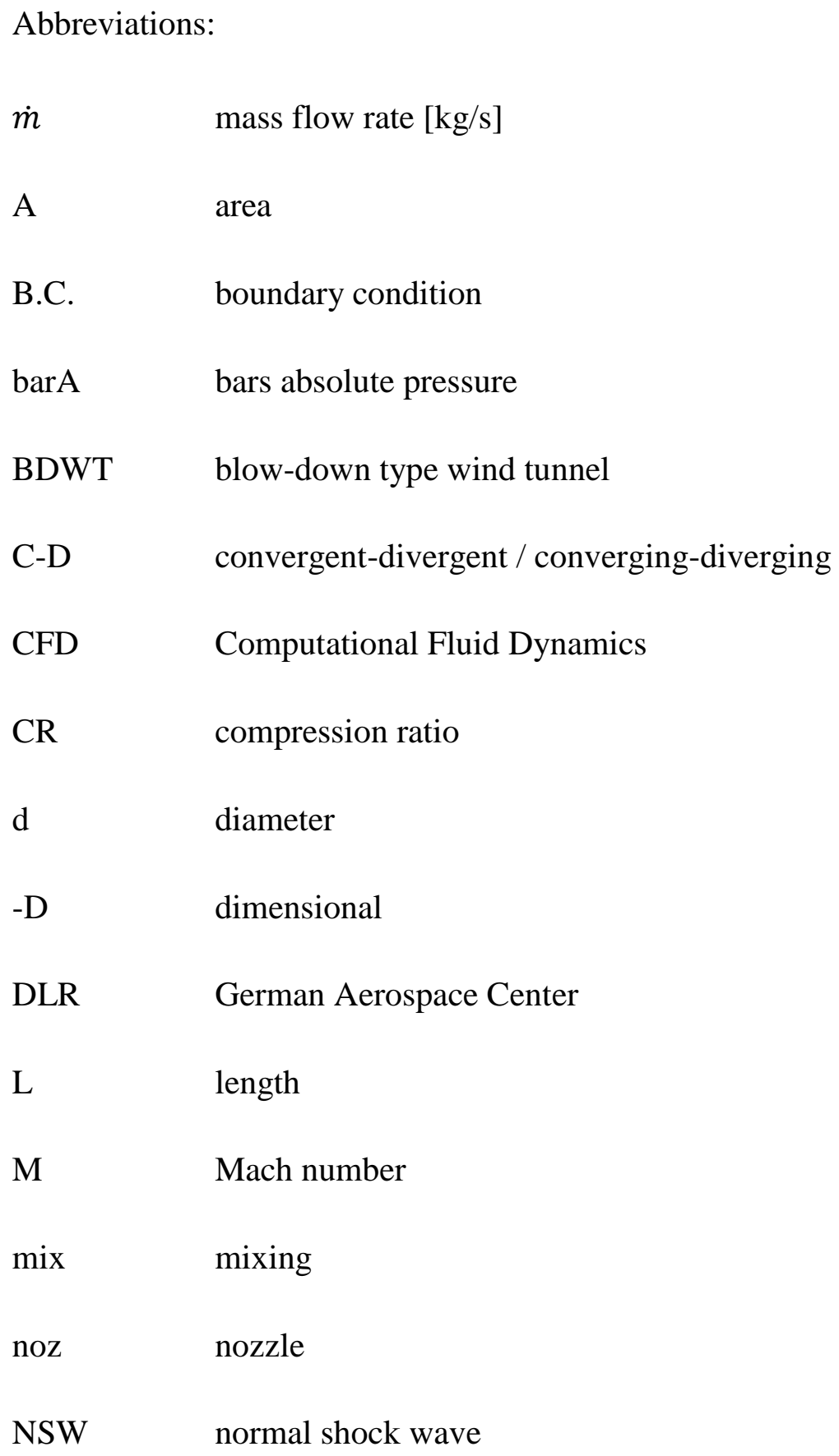




$\begin{array}{ll}\mathrm{P} & \text { pressure }[\mathrm{Pa}] \\ \mathrm{T} & \text { temperature }[\mathrm{K}] \\ \mathrm{u} & \mathrm{X} \text {-component of velocity }[\mathrm{m} / \mathrm{s}] \\ \mathrm{V} & \text { velocity }[\mathrm{m} / \mathrm{s}] \\ \mathrm{W}-\mathrm{ER} & \text { entrainment ratio }\end{array}$

Greek Symbols:

$\begin{array}{ll}\alpha & \text { secondary inlet inner-wall angle } \\ \beta & \text { secondary inlet outer-wall angle } \\ \psi & \text { nozzle divergence angle } \\ \theta & \text { mixing convergence angle } \\ \phi & \text { diffuser divergence angle } \\ \tau & \text { temperature ratio of the primary and the secondary fluid } \\ \pi & \text { pressure ratio of the primary and the secondary fluid } \\ \gamma & \text { ratio of specific heat at constant pressure to that of at constant volume } \\ \rho & \text { density }\left[\mathrm{kg} / \mathrm{m}^{3}\right] \\ \xi & \text { coefficient of flow friction }\end{array}$

Subscripts / Superscripts:
( ) total/stagnation state
( ) atm at atmospheric condition
( ) out at outlet / discharge 


$\begin{array}{ll}\text { ( )gap } & \text { at gap } \\ ()_{1} & \text { primary (working fluid) } \\ ()_{2} & \text { secondary (working fluid) } \\ \mathrm{t} & \text { throat } \\ \mathrm{t} 2 & \text { mixing (second) throat } \\ * & \text { sonic state } \\ \mathrm{i} & \text { inlet } \\ \mathrm{e} & \text { exit }\end{array}$




\section{CHAPTER 1}

\section{INTRODUCTION}

\subsection{Objective of the Thesis}

The main purpose of this thesis is to design a double-flux supersonic air ejector system with air-air as the working fluids and to evaluate its performance associated with its entrainment ratio. Study concentrates on the maximization of the entrainment ratio by varying the geometrical parameters of the ejector system, while keeping the operational parameters unaltered since the ejector systems are strongly dependent on the design.

In this context, the operational parameters of an ejector system along with the geometrical aspects will be introduced and investigated in detail, including the effects of these aspects on the performance of an ejector system.

\subsection{Literature Survey}

\subsubsection{Definition of the Ejector Systems}

The ejector system can be defined as an alternative jet pump or a vacuum system which is used for removing or relocating any fluid from a given location. Type of the operating fluid is referred to "working fluid", and at large; air, steam, water and several refrigerants are among the most used as working fluids using this system.

The system mainly composes of a primary and a secondary inlet, a nozzle section, a mixing region, a diffuser section and a discharge outlet. The design and the geometrical properties of such regions vary depending on the desired operation or 
operational conditions. Nozzle section can be designed as a converging nozzle (i.e. Ejector system) or a converging-diverging nozzle (i.e. Supersonic ejector system), depending on the desired vacuum level or the pressures of the fluid inlets in order to achieve the desired operation. A generic scheme of a supersonic ejector system is shown in Figure 1.

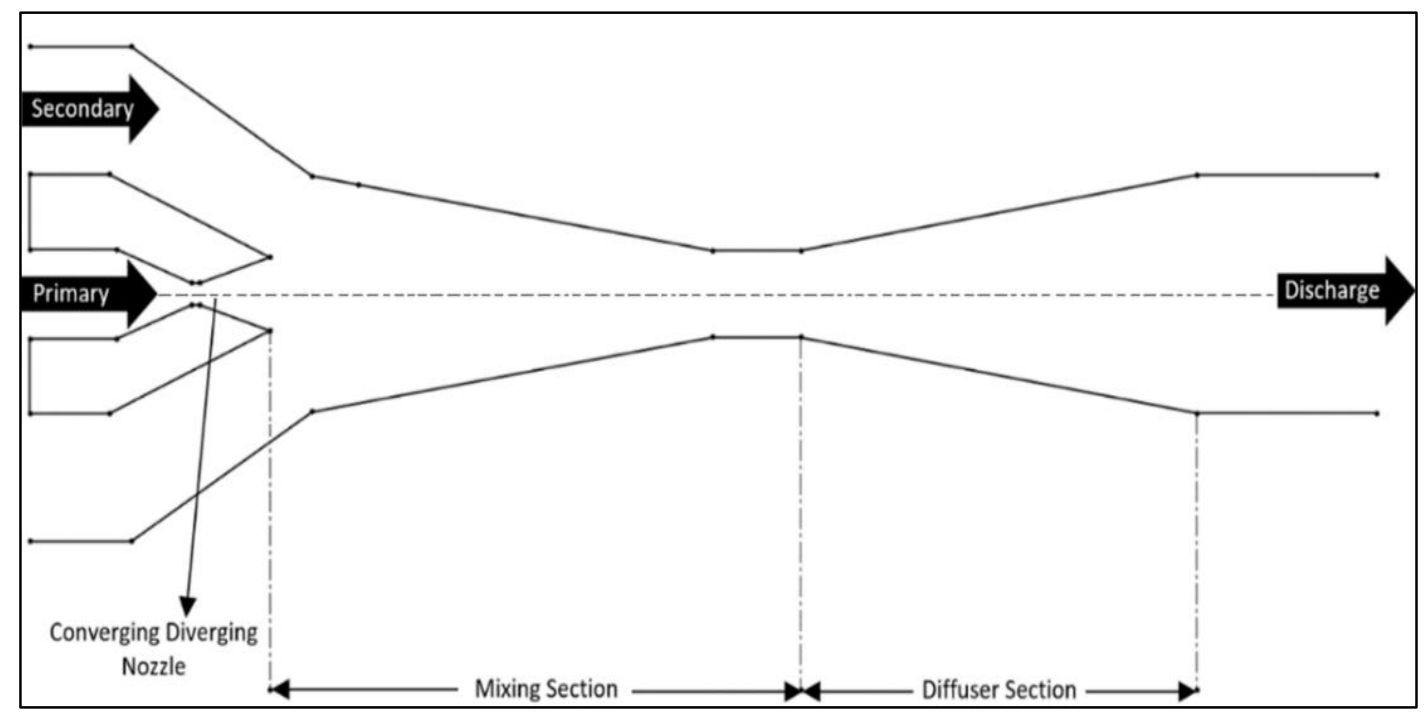

Figure 1. A generic supersonic ejector scheme and its main components

The generic scheme of an ejector system given in Figure 2 describes the ejector system is composed of a "primary fluid" that is the supplied, high-energy, high-pressure and so called the "motive fluid" and a "secondary fluid" that is the low-energy, lowpressure fluid which is desired to be vacuumed-out and that is called the "entrained fluid". The "discharge fluid" is and should be (considering the conservations) the total of the primary and the secondary fluids after which the two streams are well-mixed, and the pressure is balanced out with what the ambient pressure is. The design or the geometrical properties of the system is substantial by means of the desired level of vacuum as well as the mixing of such two streams and the pressure recovery throughout the ejector [1].

The high pressure primary fluid's pressure energy is transformed into kinetic energy with the help of the nozzle system so that the pressure of such stream is reduced and a "vacuum region" is formed just after the nozzle exit (downstream location of the 
nozzle) as shown in Figure 2. If the pressure of this vacuum region is lower than that of the secondary fluid's pressure, the system drives this secondary fluid out of its location, through this vacuum region, and such two streams meet at this zone.

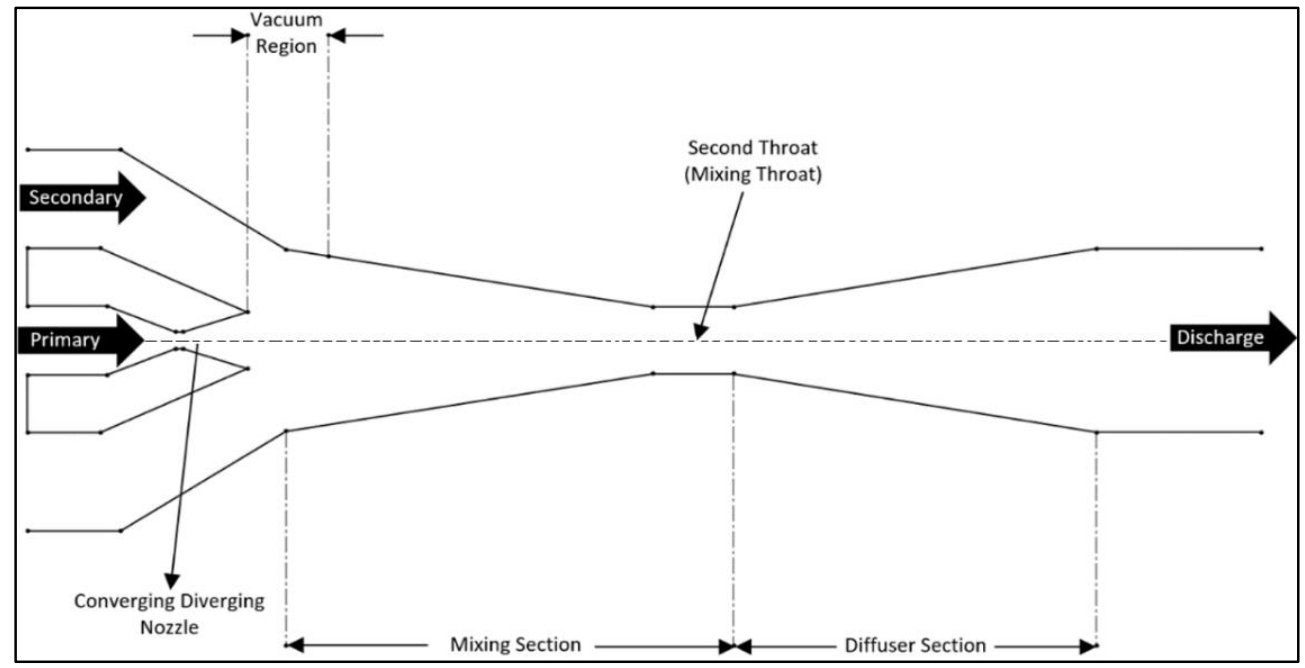

Figure 2. A generic supersonic ejector scheme, its components along with the descriptions

Subsequently, the mixing operation within the so-called mixing region commences, which is one of the most influential phenomenon held within the geometry. [2] While designing such a system, a proper mixing of such two streams should be considered and ensured, in order to achieve efficient and smooth operation of the ejector system.

During mixing process, the velocity of the flow is "diminished (i.e. for supersonic ejector, the velocity of the flow is reduced to subsonic flow at the downstream-end of the mixing region), thus the static pressure of flow is increased with the help of the frictional forces, turbulent shear layer formed between such two different streams, and even the shocks formed within and during the operation which will be investigated in more detail at the following chapters.

As it is pointed out in Figure 3, Mach number of the flow varies through the system itself. This Mach number variation can shortly and simply be commentated as; acceleration of the primary flow through the nozzle and of the secondary flow as a consequence of the low-pressure vacuum region created at the nozzle exit, deceleration of the flow through the mixing region due to the frictional forces and shocks within, 
and further deceleration through the diffuser section, followed by an equalization of the flow pressure at the downstream location. Through the upstream of the diffuser, the flow is subsonic; however, the pressure of the flow is still lower than that of the ambient pressure at the downstream-end of the ejector. Therefore, further decrease in velocity, thus the increase in pressure, is essential in order the flow to attain the backpressure value. In a sense, the process from upstream locations of the vacuum region (Figure 3) to the downstream locations of the diffuser is often called "pressure recovery".

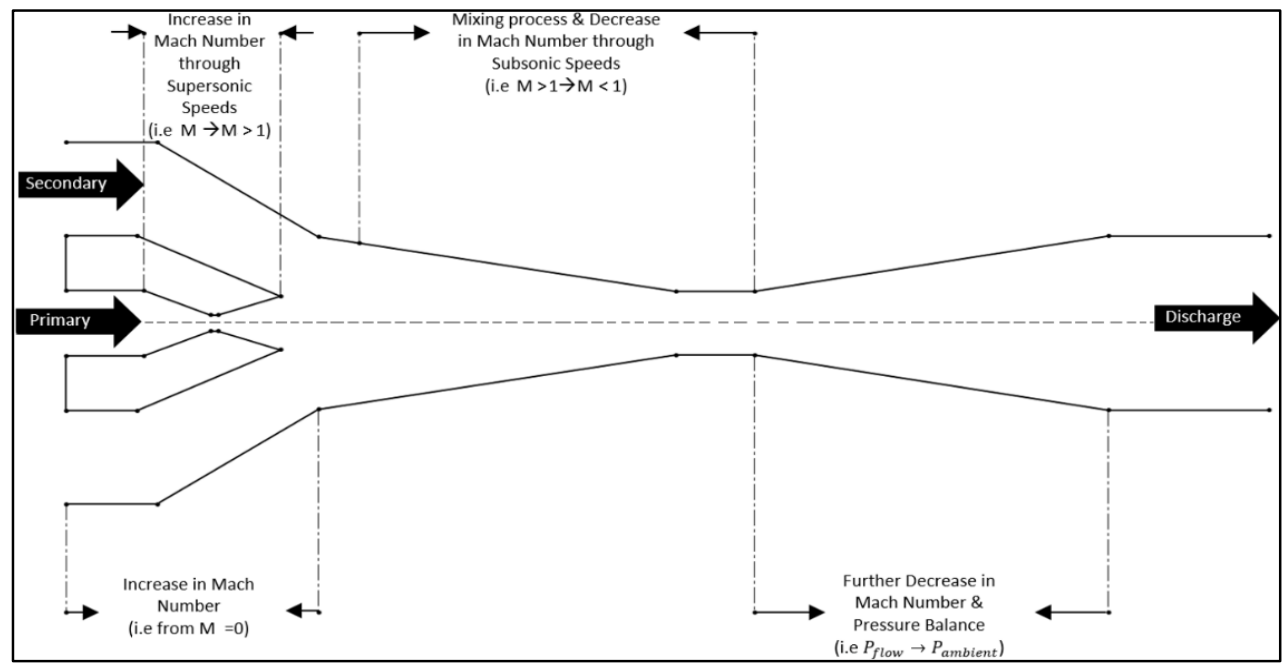

Figure 3. A generic supersonic ejector geometry and velocity contribution

The main advantage of an ejector system is that; it has no moving parts, elements or sections and due to this fact, maintenance or suchlike operations are not necessary as the system only uses the pressure energies of primary-secondary inlets and discharge outlet. Once the geometry/contour is properly set, the system is reliable and operates trouble-freely. In this respect, an ejector is a very low-cost system and is a simple solution for creating vacuum.

\subsubsection{Applications and Investigations of the Ejector Systems}

Ejector systems have usage in the backpressure control of a blow-down wind tunnel test section (Figure 4), in a closed return type supersonic or subsonic wind tunnel applications, and in refrigeration systems etc. with various corresponding types of 
working fluids [3] as well as various number of stages that is, a number of operating ejectors consecutively [4].

The ejector configuration of which the current thesis study is focused on where the working fluids are air, is generally used for controlling the backpressure of essentially the blow-down type wind tunnels (BDWT). In order to simulate high altitude flow conditions at these facilities ([5], [6]) the pressure of the test section has to be controlled accordingly, and this has to be achieved with a vacuum system ([7], [8]). As blow-down type wind tunnels include air storage tanks (air reservoir) that have sufficient amount of pressurized air within, the primary fluid of the ejector system is usually supplied from these air storage tanks as shown in Figure 4. Considering these, ejector systems are widely used for purposes of creating vacuum [9].

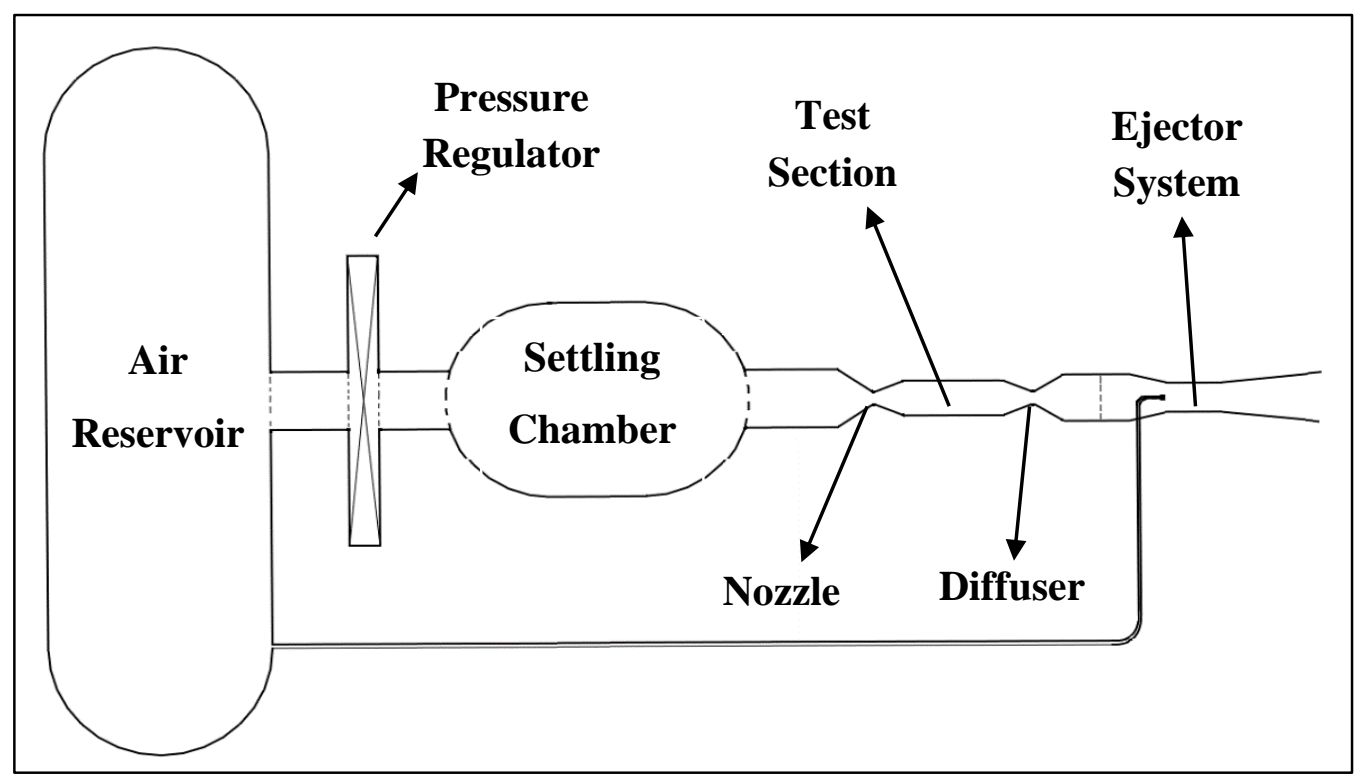

Figure 4. A generic scheme of a blow-down wind tunnel with an ejector system

The utilization of ejector systems improves the test envelope of such test facilities as can be seen in Figure 5 showing the capabilities of the DLR-Cologne Trisonic Wind Tunnel [10]. This plot shows the abilities of the facility with or without an ejector, and it can apparently be observed that, in order to achieve mainly the high altitude, high Mach number flight conditions as well as the low Reynolds number conditions, the use of an ejector system is necessary. 


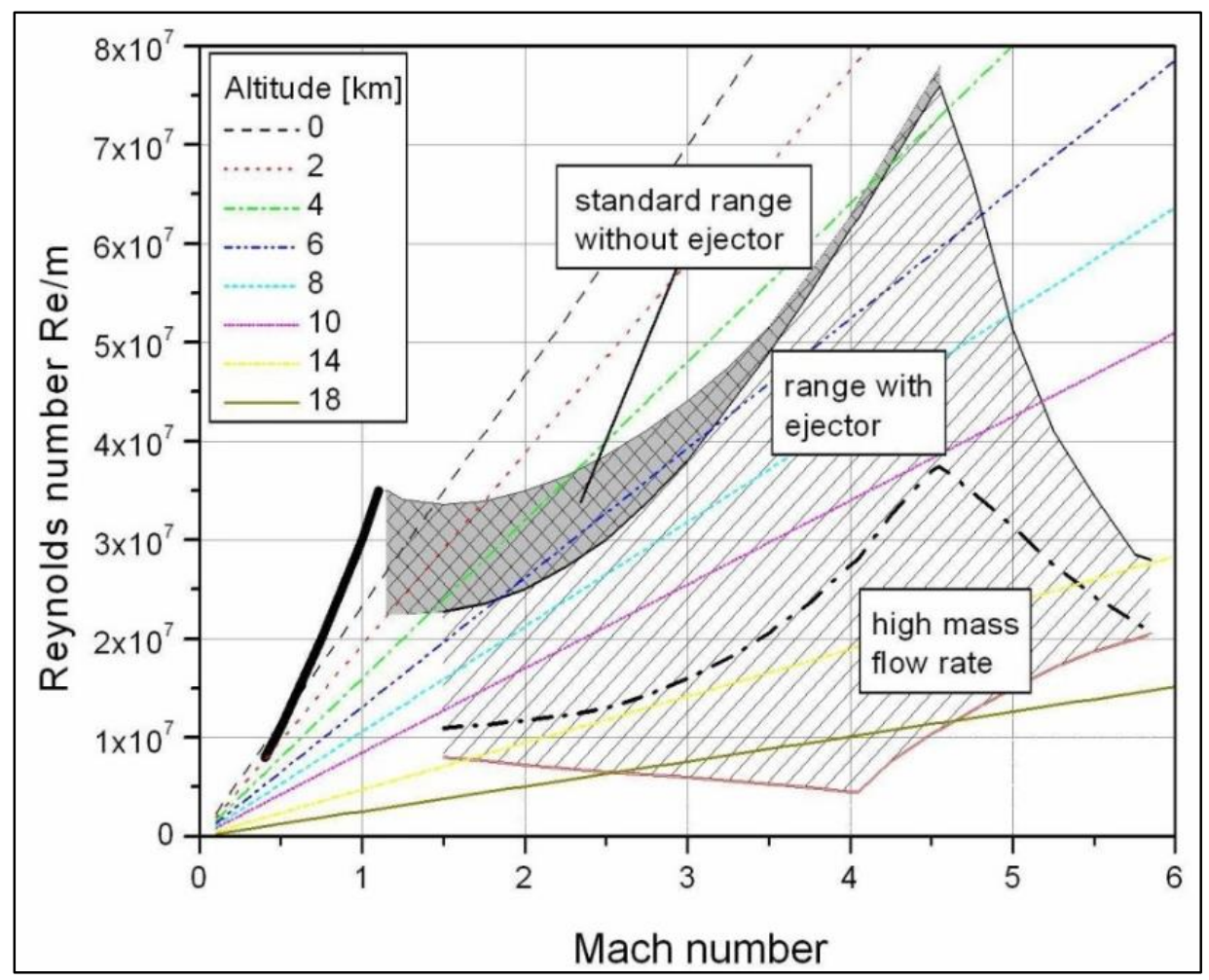

Figure 5. Test envelope of the DLR-Cologne Trisonic Wind Tunnel [10]

Ejector systems are firstly introduced in early $20^{\text {th }}$ century and are in use for purposes of vacuum since then. Several investigations aiming the improvement of the ejector performance as Dutton and Carrol [11] and Bartosiewicz et al. [12] have performed, considerations of the cost-efficiency [13], optimization of the ejector operation as Manikanda et al. [8] and Mattos and Medronho [14] have carried out, different approaches on the operation or design as Croquer et al. [15], Gagan et al. [16], Maghsoodi et al. [17] and Yamamoto et al. [18] have accomplished and suchlike studies regarding the ejector systems have been carried out so far that are available in the literature and proper references are cited along the study where a guidance is applicable.

However, investigation of the ejector systems is not quite popular and obtaining a specific desired information related to such systems can be challenging. In this regard, a study informing the ejector operation, the modifications of the ejector parameters and its effects on the ejector performance is carried out along this study. 


\subsection{Motivation of the Study}

Even though an ejector system is considered an effective, maintenance-free and a convenient vacuum implementation tool, it has several drawbacks to consider. Since the geometry itself is the key for the operation, these issues must be considered along with the design process.

Apparently, the contour itself shall be designed such that, the accelerated primary flow carves out enough vacuum levels at the corresponding locations in order to properly draw the secondary flow in, and the complications that may possibly arise due to the complexity of the flow structure should not be disregarded [19]. The main aspect to consider is to maximize the performance which is to drain the highest possible amount of secondary fluid through the system with the least amount of resources i.e. primary fluid, which is also associated with mostly the entrainment ratio [20]. One may not provide a certain mass flow or a pressure energy in order operate the system at the desired suction level, or may operate inefficiently which would obviously be a waste of resources, if the geometry is not designed properly [11].

On the other hand, while maximizing the performance of the system, the reasonable lengths, openings, diverging or converging angles, cross-sectional areas; simply the overall layout of the geometry should be designed. In order to eliminate the possible troubles [21] that may arise due to for instance separation, choking, blockage, vortex formation, improper mixing, inadequate recovery of pressure, or any kind of flow obstacles during the operation which may dramatically affect the performance of the system [22].

Therefore, this study basically originates from such considerations of maximizing the performance while observing the flow characteristics of corresponding designs [23]. 


\section{CHAPTER 2}

\section{THEORETICAL INVESTIGATION OF AN EJECTOR}

AND

\section{ONE DIMENSIONAL APPROACH}

In this chapter, a theoretical investigation of an ejector system is detailed and a onedimensional approach for the evaluation of the ejector operation as well as its performance is presented.

\subsection{Theoretical Investigation of an Ejector}

The operation through an ejector system is informed including the aspects to be considered while designing such a system within this section. As the current study is concentrated on the evaluation and the maximization of the ejector performance, the main components of an ejector as well as the entrainment ratio that defines the performance of such systems are detailed.

\subsubsection{Components of an Ejector}

\subsubsection{Converging-Diverging Nozzle}

The converging-diverging type of nozzle has a variety of usage, especially, in applications where supersonic velocities are to be created. (Oppositely, deceleration of the supersonic flows into subsonic velocities.) The basic scheme and the operational demonstration of a convergent-divergent nozzle is shown in Figure 6.

Convergent-divergent nozzle operates as accelerating the subsonic flow first to sonic then to supersonic velocities (or the exact opposite) with the help of the three distinct 
segments which are called ; converging section, throat section and diverging section, as shown in Figure 6.

In a supersonic ejector system, a convergent-divergent nozzle is used for accelerating the high-energy, high-pressurized fluid to supersonic velocities, thus and so, the pressure of the stream is dropped into very low values by generating a vacuum region at the exit section.

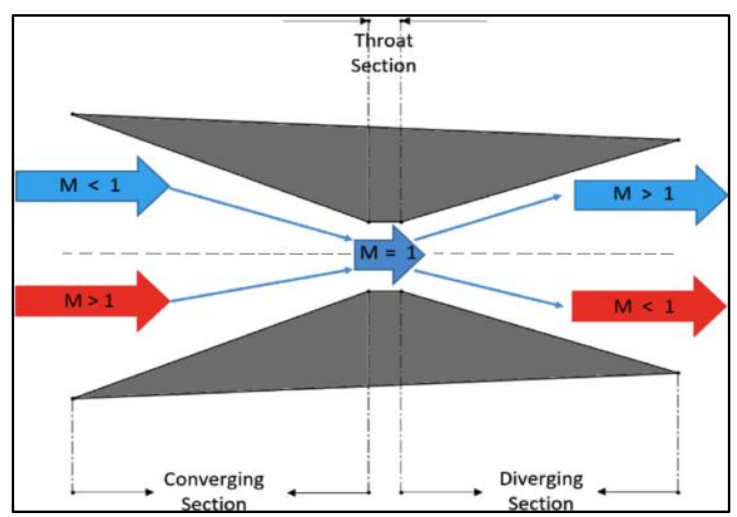

Figure 6. A typical converging-diverging nozzle scheme

\subsubsection{Vacuum Region}

The most prominent part of an ejector system is the "vacuum region" through which the high-pressure primary flow is accelerated and the pressure of the fluid is far reduced (Figure 7).

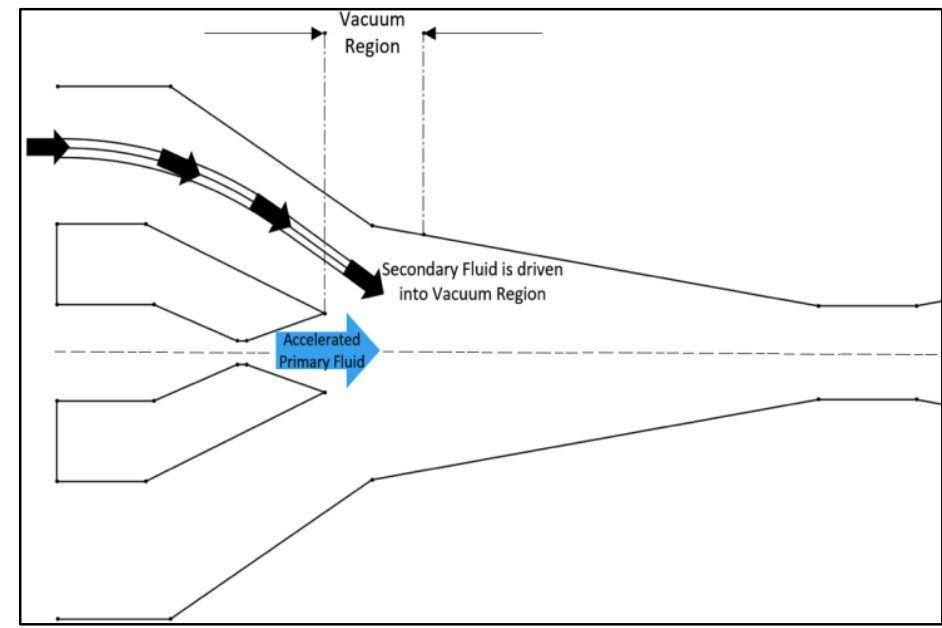

Figure 7. Vacuum region and the process description 
If the pressure of the accelerated primary flow is lower enough, then the system drives the "secondary fluid" surrounding the primary fluid at this location, as shown in Figure 7.

\subsubsection{Mixing Region}

Mixing region (or chamber) is the section in which two incoming streams (primary and secondary) meet each other and the process of mixing is taking place at the downstream location. By means of performance, the sizing and the geometrical properties of the mixing chamber has important effect over the flow itself. Two different mixing behaviors and corresponding geometries are widely used in the literature. These are called "constant - pressure mixing chamber" and "constant - area mixing chamber" that are shown in Figure 8. There are no apparent advantages of one approach to the other, and the choice varies from condition to condition. Current study focusses on the constant-pressure mixing approach.

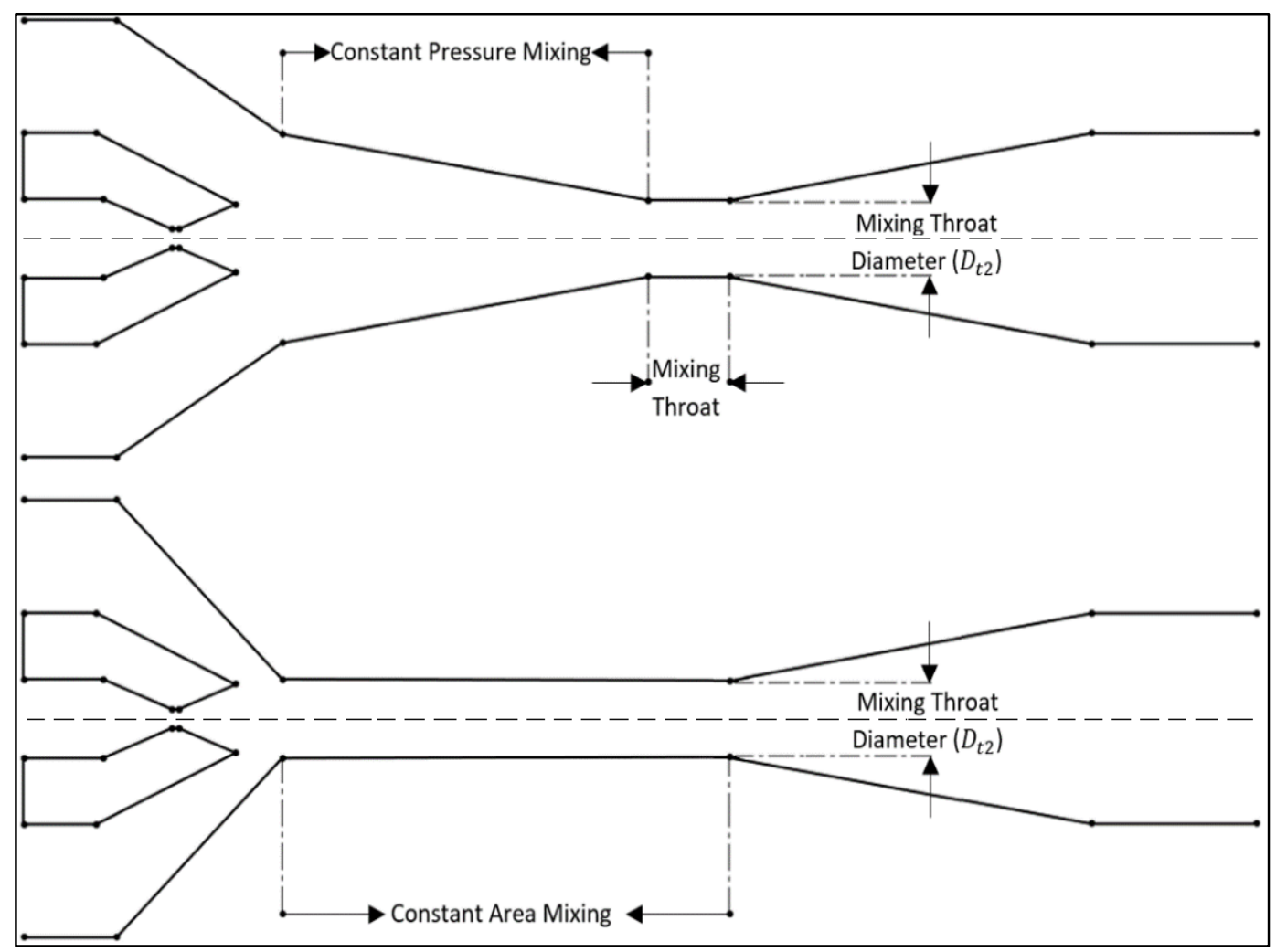

Figure 8. Constant-pressure mixing (top) versus constant-area mixing (bottom) 
Within the mixing chamber, some important incidents take place. As the flow exiting from nozzle has less pressure value than that of the secondary flow, there forms a boundary as shown by the dashed lines (Figure 9) which gets narrower (radially) through the downstream of the chamber (as the flow mixes).

Flow exiting from the nozzle has a tendency to further expand its area but as it meets with this jet boundary, an oblique shock is formed. Such nozzle configuration is called “over-expanded nozzle" [24].

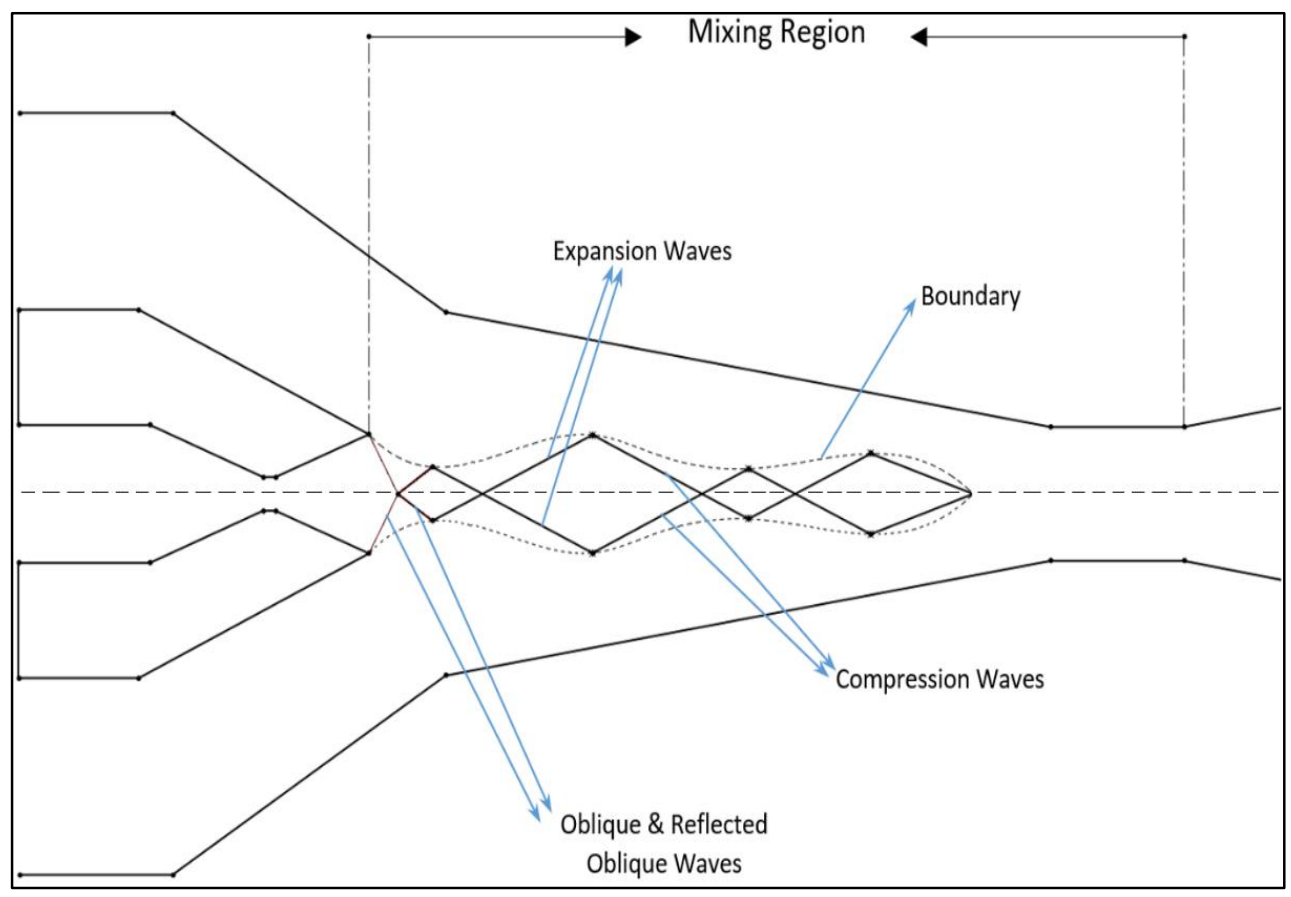

Figure 9. Mixing patterns - shock cells visualization

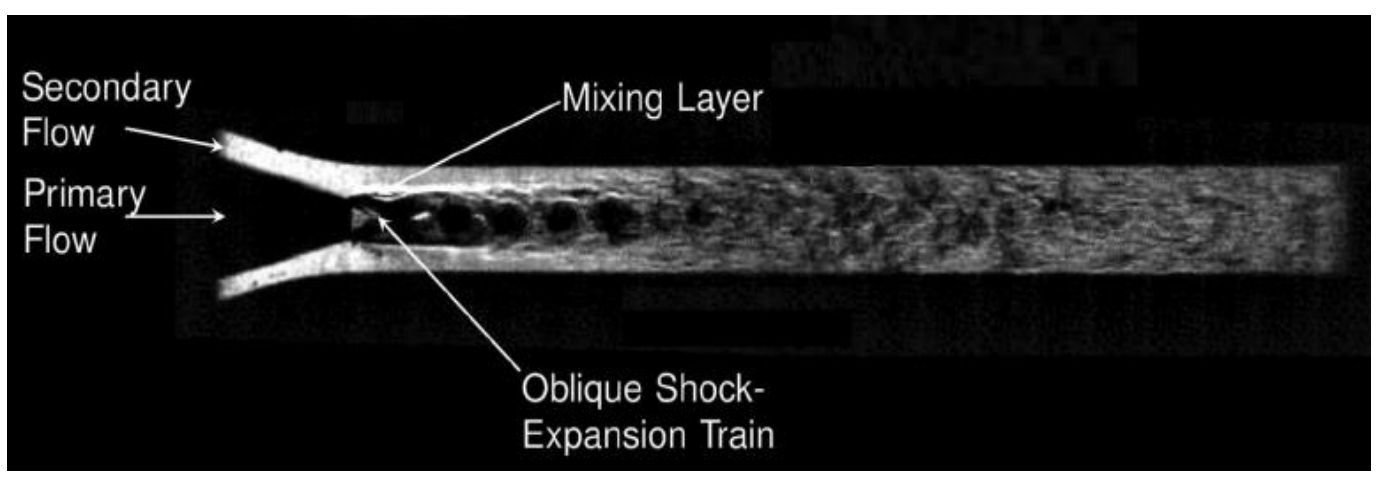

Figure 10. Instantaneous Shilieren image of shock cells. [25] 
The oblique shock meets its twin coming from the opposite side and both are reflected back outwards. The pressure of the flow passing through the oblique shock increases, but this time, it exceeds the pressure of the surrounding flow so a series of expansion waves from both sides is formed. Flow passing through these expansion waves, expands, resulting a decrease in pressure again. But for this time the pressure of the fluid becomes lower than the surrounding fluid so this time a series of compression waves are formed from both sides and flow passing through these, turns through the centerline and its pressure increases again [26]. Also, an example of flow visualization of such series of shock patterns are also shown in Figure 10, where these are called shock-cells ([25], [27]).

So this series of compression and expansion waves goes on until the pressure is balanced and the streams are totally mixed. At the end of this mixing, if the flow is still supersonic, a normal shock wave is formed. The mixing throat (which also refers as the second throat) shown in Figure 2 is where the flow is expected to be mixed and the transition (or jump) to subsonic velocity is occurred.

\subsubsection{Diffuser Region}

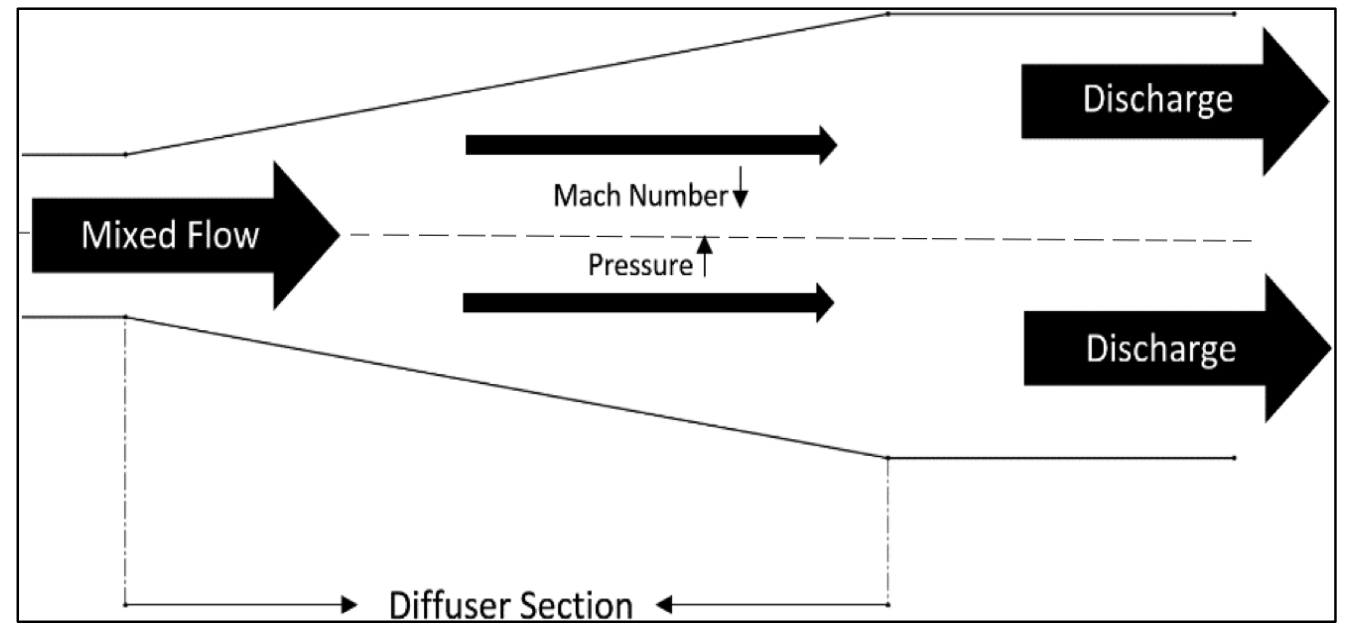

Figure 11. Diffuser region and the explanation

Diffuser section is the region where velocity of the mixed flow is further reduced and the pressure of the mixed flow is balanced with that of the ambient air in order not to 
disturb the smooth operation [28]. The effect of the ambient pressure (also refers as backpressure) will be investigated in the following chapters. It is known that the backpressure is another remarkable fact for the vacuum operation as its presence is one of the main causes for the fluid motion within [29]. A view of an example diffuser region, including its operational behaviors is shown in Figure 11.

\subsubsection{Entrainment Ratio}

The most important aspect considering the performance of an ejector is the so called "entrainment ratio" and mostly denoted as "w" or "ER" and the performance of the ejector is associated with this ratio.

Entrainment Ratio $=\frac{\text { Secondary Mass Flow Rate }}{\text { Primary Mass Flow Rate }}$

It is basically the ratio of secondary fluid's mass flow rate to the primary fluid's mass flow rate and describes how much of the secondary fluid, the system is able to vacuumout or drain for a unit of supplied primary fluid.

\subsection{One Dimensional Approach}

In order to examine the flow within an ejector system (one-dimensionally), several assumptions are implemented to choose the appropriate method ([30], [31]). The system is divided into segments and the stations are assigned as seen in Figure 12.

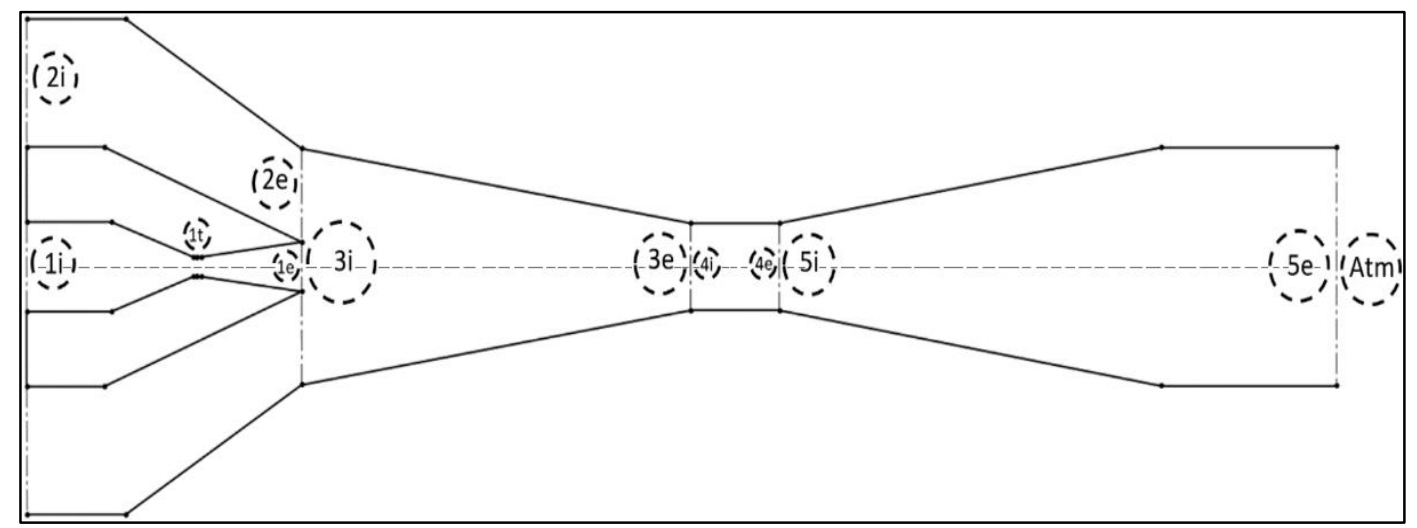

Figure 12. Ejector geometry with the assigned stations 
The indices "i" refers to state "in", "e" refers to state at "exit", "t" refers the state at "throat" at the corresponding stations shown in Figure 12 and are arranged as follows;

Segment $\{1\} \rightarrow$ converging - diverging nozzle

Segment $\{2\} \rightarrow$ secondary inlet branch

Segment $\{3\} \rightarrow$ mixing chamber

Segment $\{4\} \rightarrow$ mixing throat

Segment $\{5\} \rightarrow$ diffuser

So, within the corresponding segments, the conservation equations are applied in order to acquire [13] 1-D aero-thermodynamic properties of the flow ([23], [32]).

$\frac{\partial \rho u}{\partial x}=0 \rightarrow \rightarrow \rightarrow \dot{m}_{\text {in }}=\dot{m}_{\text {out }}$

$u \frac{\partial \rho u}{\partial x}=-\frac{d p}{d x}$

Conservation equations and isentropic relations are used to get the corresponding 1-D calculations to get a FORTRAN code. The flow is assumed to be steady, inviscid, adiabatic, compressible and one-dimensional [33] and the fluid is assumed to be calorically perfects gas.

\subsubsection{Converging-Diverging Nozzle Calculations}

As a first step, such calculations are based on the assumption of isentropic flow for which the flow is assumed to be ideal and shock-free, thus change in flow variables is negligibly small.

The desired operation is fulfilled with the area - Mach number relation between sonic (throat) region and desired region (can be both upstream- or downstream- end), and the remaining flow variables can be calculated by the help of [33] isentropic flow equations. These equations (Equations 4-7) considered are as follows; 
$\frac{A^{*}}{A}=\left(\left(\frac{\gamma+1}{2}\right)^{-\frac{\gamma+1}{2(\gamma-1)}} \frac{\left(1+\frac{\gamma-1}{2} M^{2}\right)^{\frac{\gamma+1}{2(\gamma-1)}}}{M}\right)^{-1}$

$\frac{P_{o}}{P}=\left(1+\frac{\gamma-1}{2} M^{2}\right)^{\frac{\gamma}{\gamma-1}}$

$\frac{T_{o}}{T}=\left(1+\frac{\gamma-1}{2} M^{2}\right)$

$\frac{\rho_{o}}{\rho}=\left(1+\frac{\gamma-1}{2} M^{2}\right)^{\frac{1}{\gamma-1}}$

By use of these equations/relations, aero-thermodynamic flow properties at the inlet, exit and throat (sonic, *) locations within convergent-divergent nozzle can be calculated with ease within the knowledge of stagnation (total) state properties of the fluids [34].

\subsubsection{Secondary Inlet Branch Calculations}

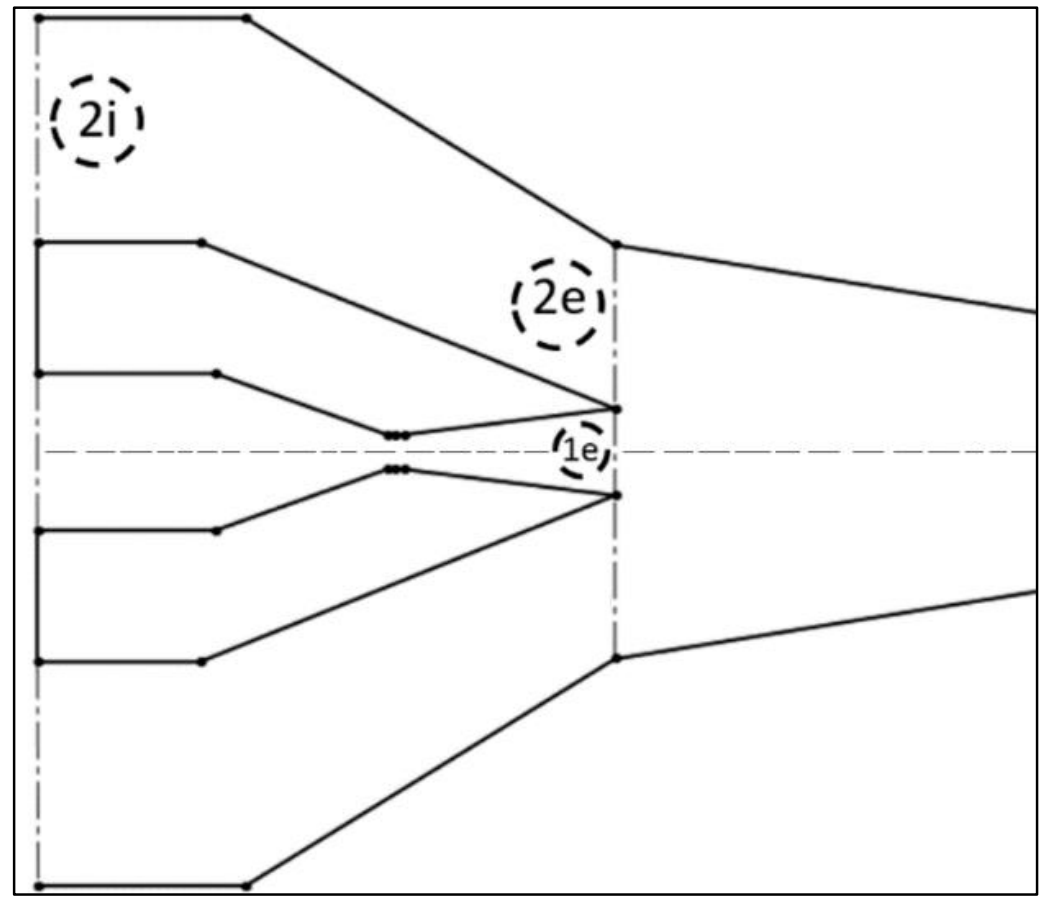

Figure 13. Zoomed view of the nozzle exit and the secondary flow intersection 
Throughout the investigation of the flow along the secondary inlet branch, several assumptions should be taken into consideration. Inlet properties are taken as, ambient conditions from where the fluid is to be drained, and ideal, isentropic flow assumptions; the pressure of the convergent-divergent nozzle exit (station-1e) and the secondary pipe exit (station-2e) is also taken as being equal at the intersection line (i.e. $P_{1 e}=P_{2 e}$ ) shown in Figure 13. In this manner, the whole initial (inlet) properties as well as the exit pressure is determined, which simplifies the process [30].

\subsubsection{Mixing Chamber Calculations}

Similar to the previous section, assuming the pressure of the mixing inlet (station-3i), convergent-divergent nozzle exit (station-1e) and the secondary branch exit (station2e) equal (i.e. $P_{3 i}=P_{1 e}=P_{2 e}$ ) (Figure 13 and Figure 14), and the individual flow properties of primary and secondary streams are already determined.

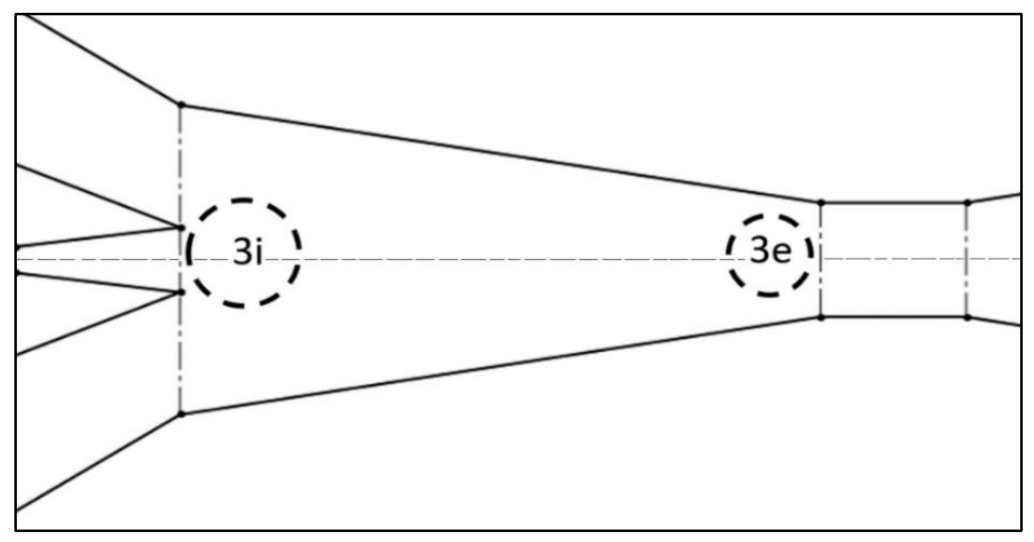

Figure 14. Zoomed view of the upstream and downstream mixing region

Another assumption is the "constant-pressure mixing" approach which is discussed within previous chapters [35]. In a sense, this assumption uncovers the pressure at the exit of the mixing segment i.e. $P_{3 e}=P_{3 i}$ which is also obtained as $P_{3 i}=P_{1 e}=P_{2 e}$ (Figure 13 and Figure 14).

In addition, similar to the previous two sections, the flow is assumed to be ideal and isentropic, without any oblique-expansion-compression patterns/shocks, and the mixing of primary and secondary streams realizes ideally. 
During the mixing process, the velocity of the flow is assumed to be gradually decreased in consequence of flow friction or resistance between streams depending on the Reynolds number of the flow itself, corresponding area ratios, flow rates and velocities of the streams [36]. Such relations are determined from the following formulations that are acquired from the literature [17], where $\xi_{m}$ refers as the coefficient of flow friction between the two mixing streams.

$$
\begin{array}{lll}
\left\{A_{3 i} / A_{\text {throat }}<6.9\right\} & \rightarrow & \xi_{m} \cong 0.850 \\
\left\{6.9<{ }^{A_{3 i}} / A_{\text {throat }} \leq 7.5\right\} & \rightarrow & \xi_{m} \cong 0.845 \\
\left\{7.5<{ }^{A_{3 i}} / A_{\text {throat }} \leq 8.3\right\} & \rightarrow & \xi_{m} \cong 0.840 \\
\left\{8.3<{ }^{A_{3 i}} / A_{\text {throat }} \leq 8.8\right\} & \rightarrow & \xi_{m} \cong 0.825 \\
\left\{8.8<A_{3 i} / A_{\text {throat }}\right\} & \rightarrow & \xi_{m} \cong 0.810
\end{array}
$$

where Mach number of the mixed flow can be calculated using one dimensional and ideal mixing be calculated as;

$M_{4 i}=\xi_{m} \frac{\dot{m}_{\text {prim }} M_{1 e}+\dot{m}_{\text {sec }} M_{2 e}}{\dot{m}_{\text {prim }}+\dot{m}_{\text {sec }}}$

The flow is assumed to be perfectly mixed with constant flow properties in the downstream section of the mixing region.

\subsubsection{Mixing Throat Calculations}

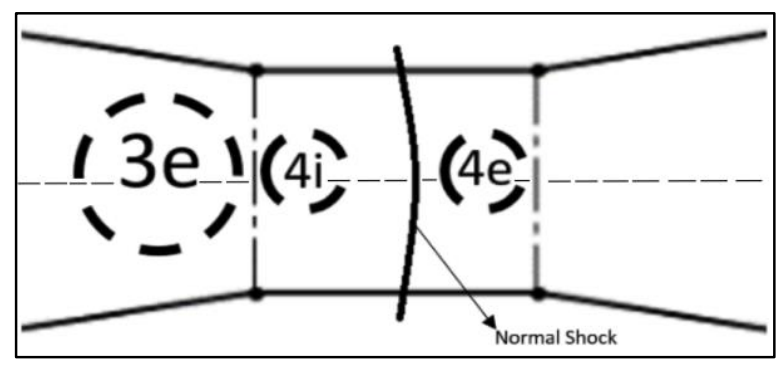

Figure 15. Mixing throat section and NSW 
Flow in the mixing throat segment is assumed to be stabilized if the velocity is subsonic, however, if the flow in this section is supersonic, then it is expected (desired) that a normal shock to be formed there.

In order to obtain the flow properties at the downstream of normal shock wave i.e. $X X_{4 e}$, following equations [37] are utilized;

$$
\begin{aligned}
& \frac{P_{4 e}}{P_{4 i}}=\frac{2 \gamma M^{2}-(\gamma-1)}{\gamma+1} \\
& \frac{T_{4 e}}{T_{4 i}}=\frac{\left[2 \gamma M^{2}-(\gamma-1)\right]\left[(\gamma-1) M^{2}+2\right]}{(\gamma+1)^{2} M^{2}} \\
& M_{4 e}=\sqrt{\frac{(\gamma-1) M^{2}+2}{2 \gamma M^{2}-(\gamma-1)}} \\
& \frac{\rho_{4 e}}{\rho_{4 i}}=\frac{(\gamma+1) M^{2}}{(\gamma-1) M^{2}+2} \\
& \frac{P_{04 e}}{P_{04 i}}=\left\{\left[\frac{(\gamma+1) M^{2}}{(\gamma-1) M^{2}+2}\right]^{\gamma}\left[\frac{(\gamma+1)}{2 \gamma M^{2}+(1-\gamma)}\right]\right\}^{\frac{1}{\gamma-1}} \\
& T_{0_{4 e}}=T_{04 i}
\end{aligned}
$$

where $M=M_{4 i}$ and state $4 \mathrm{i}$ is upstream, $4 \mathrm{e}$ is downstream of the normal shock.

\subsubsection{Diffuser Calculations}

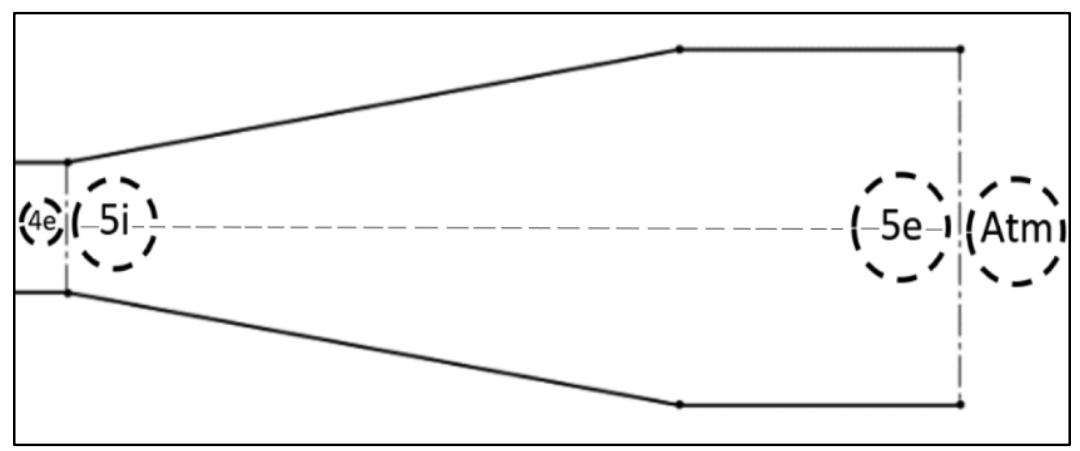

Figure 16. Diffuser section and stations 
Along this segment, the objective is to balance, level the pressure of the flow which passes through the normal shock wave (NSW) to that of the flow to be discharged (i.e. $\left.P_{4 e}=P_{5 i} \rightarrow P_{5 e}\right)$ (Figure 16).

The pressure at downstream of the diffuser section can be acquired from the ambient pressure (i.e. $P_{5 e}=P_{a t m}$ ), and geometrical formalizing of such can be arranged accordingly.

\subsubsection{Length of the Segments Pre-estimation}

There exists several length-ratios which provides efficient operation of the ejector system that can be determined from literature surveys. However, these ranges depend strongly on the operational conditions, and therefore may vary significantly dependently on the conditions of the operation.

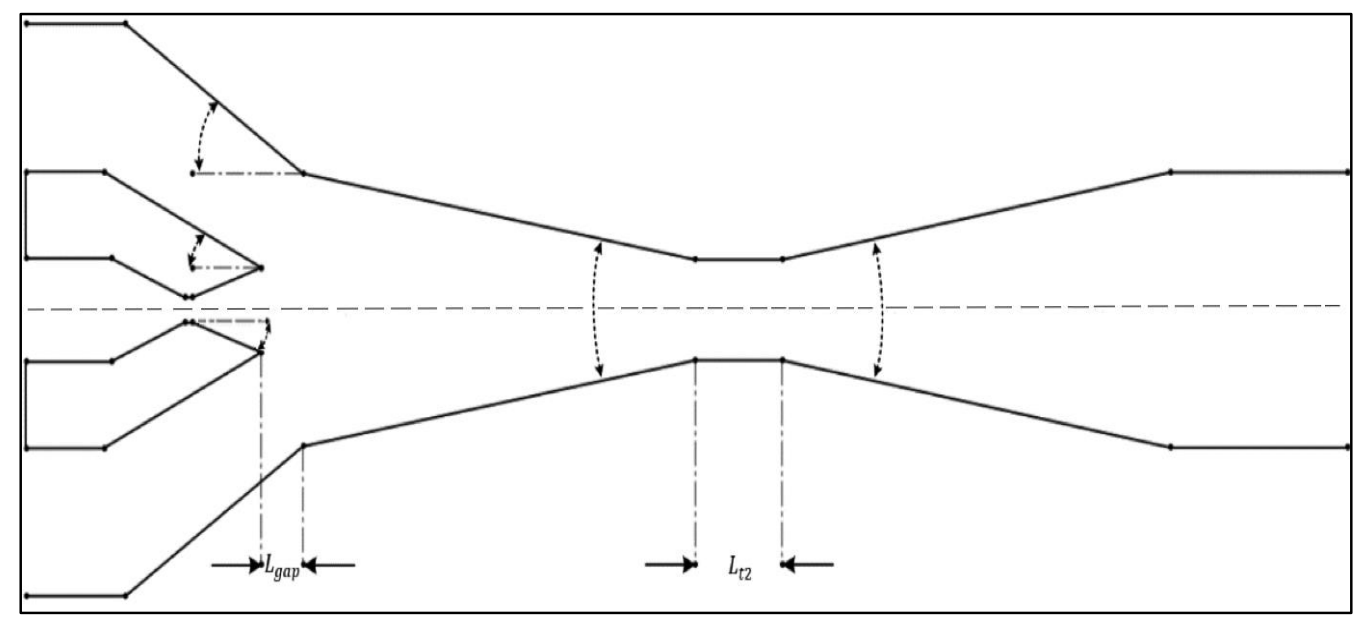

Figure 17. Lengths of the corresponding elements along with the convergence and divergence angles representation

Therefore, the length of each section of the ejector should be studied in detail. In order to obtain a better performant ejector, a parametric study must be realized [38].

In this context, by keeping the cross-sectional area of the stations (Figure 17) constant, the convergence angles of mixing region and secondary inlet dimensions and the divergence angles of the nozzle and the diffuser sections should be altered. These 
geometrical parameters as well as the length of the gap $\left(L_{\text {gap }}\right)$ and the mixing throat section $\left(L_{t 2}\right)$ can be visualized as a whole from the model shown in Figure 17.

Therefore, a specific geometry for an efficient ejector operation can be obtained [14].

\subsection{Theoretical Evaluation and the Outcomes}

Discovering the operation of the ejector and obtaining 1-D calculations, a preliminary ejector geometry, aero-thermodynamic properties at the critical locations and the most of all; the entrainment ratio are acquired for the given conditions of the operation. This output provides sufficient information for an initial evaluation of the system as well as leads detailed analyses of ejector performance maximizations which will be performed in the following sections. 


\section{CHAPTER 3}

\section{COMPUTATIONAL METHODS AND TOOLS FOR THE ANALYSES}

In order to determine the distribution of the pressure and the flow field within the geometry of the ejector, computational fluid dynamics (CFD) methods are used. Two popular commercial CFD codes, ANSYS Fluent and FloEFD, are used for this purpose. Furthermore, the CFD results obtained by using these codes are also compared with the 1-D FORTRAN code results written within the scope of the thesis.

This section presents the method and the computer programs that are used to validate the computational results for the present study. As a validation of the methods and tools, two different geometries are taken from the literature [12] and [39]. Then the 1$\mathrm{D}$ and the CFD results are compared with the corresponding results given in [12], [15], [16], [39] and [40]. These two different geometries are evaluated within the separate sections and named as "Validation Part I" and "Validation Part II".

\subsection{Validation of the Computational Methods and Tools - Part I}

In the first instance, a geometry / a supersonic ejector model is taken from the literature, [39] which is shown in Figure 18 indicating the dimensions and geometry of the ejector used for this study [16].

In addition to dimensional and geometrical properties (Figure 18), operating conditions as well as the non-dimensional design parameters of the present system is also given in Table 1 and Table 2. For the test case used in this study, the system operates with a primary flow of pressure $743000 \mathrm{~Pa}$, a secondary flow of pressure 
86300 Pascal and a discharge pressure of $137000 \mathrm{~Pa}$, same as used in the literature [39].

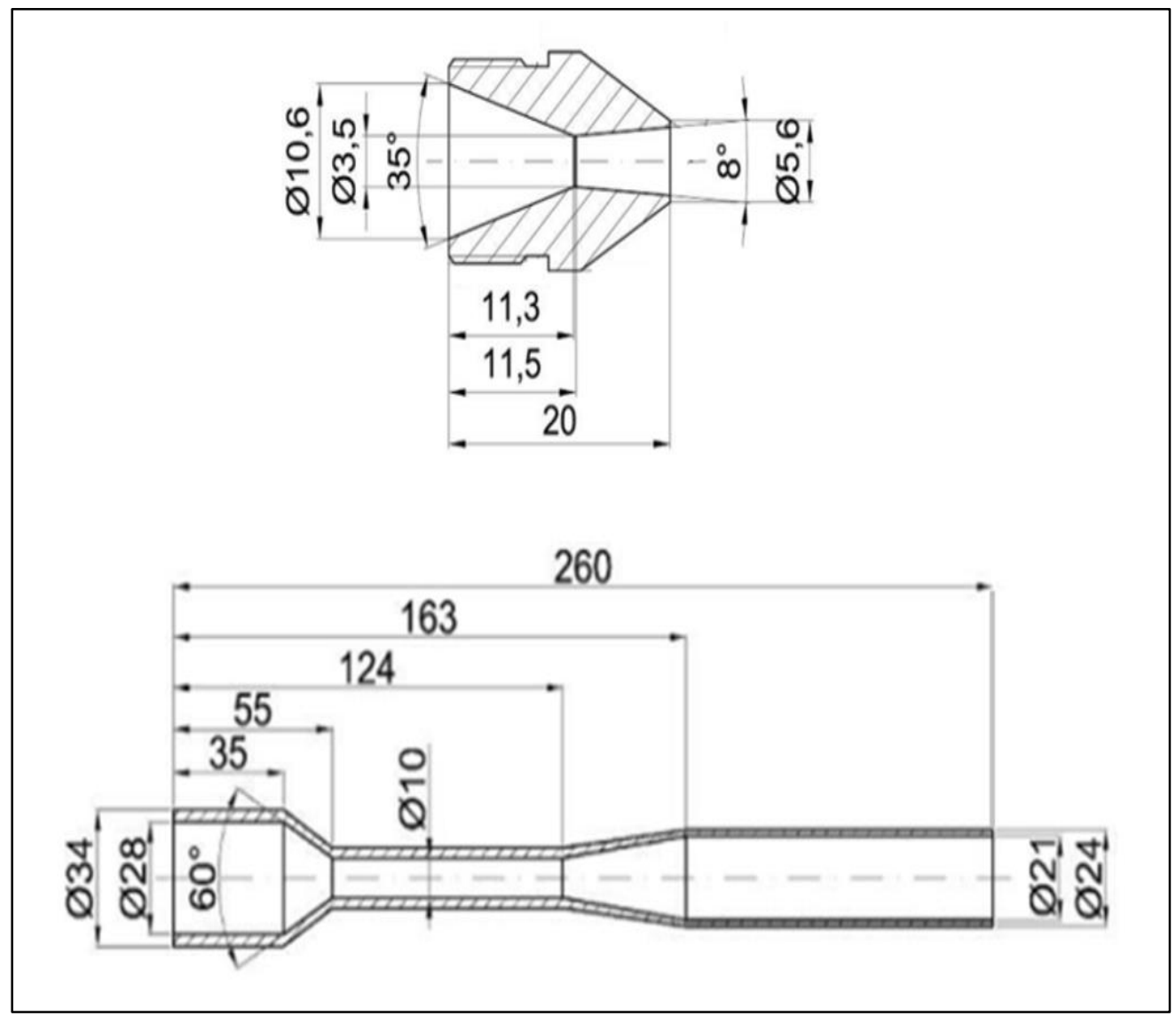

Figure 18. Cross sectional view of the verification case geometry - I [39]

This verification case is explained in detail, and the 1-D Fortran code developed is used for calculating the pressures and other flow parameters along the various components of the same ejector as used in the literature [39]. Then a more comprehensive computational study is initiated by using a commercial CFD code, FloEFD, including the "ideal wall" analysis in which walls are neglected ideally (i.e. Euler computations, inviscid solution), and "real wall" analysis in which the no-slip boundary conditions are applied (i.e. N-S computations, viscous solution).

The use of a CFD code requires an appropriate geometry and to help generating the geometry, first a commercial CAD design package, SolidWorks is used. CFD analysis 
is performed by setting pressure boundary conditions to the flow-openings. (i.e. pressure inlet B.C. to primary/secondary and pressure outlet B.C. to discharge)

Table 1. Verification case operating conditions - I

\begin{tabular}{|c|c|}
\hline & Static Pressure \\
\hline Primary Fluid (Inlet) & $\mathrm{P}_{1}==743000 \mathrm{~Pa}$ \\
\hline Secondary Fluid (Inlet) & $\mathrm{P}_{2}==86300 \mathrm{~Pa}$ \\
\hline Discharge (Outlet) & $\mathrm{P}_{\text {out }}==137000 \mathrm{~Pa}$ \\
\hline
\end{tabular}

Table 2. Verification case non-dimensional parameters - I

\begin{tabular}{|c|c|c|c|c|}
\hline & $\begin{array}{c}\text { Secondary/ } \\
\text { Primary }\end{array}$ & $\begin{array}{c}\text { Secondary/ } \\
\text { Nozzle Throat }\end{array}$ & $\begin{array}{c}\text { Mixing throat/ } \\
\text { Nozzle Throat }\end{array}$ & $\begin{array}{c}\text { Nozzle Exit/ } \\
\text { Nozzle Throat }\end{array}$ \\
\hline Area Ratio & 2.19 & 5.77 & 8.54 & 2.637 \\
\hline & $\begin{array}{c}\text { Secondary/ } \\
\text { Primary }\end{array}$ & $\begin{array}{c}\text { Discharge/ } \\
\text { Secondary }\end{array}$ & Nozzle Exit/Primary \\
\hline $\begin{array}{c}\text { Pressure } \\
\text { Ratio }\end{array}$ & 0.116 & 1.65 & 0.058 \\
\hline
\end{tabular}

In addition to this, the same ejector geometry is investigated implementing the two well-known turbulence models which are k- $\varepsilon$ realizable and SST (shear stress transport) k-omega, for the simulations performed using the commercial ANSYS Fluent code in order for the elaboration of the study and determination of the proper solver code with pros and cons evaluation for the study. Same procedure mentioned previously for setting the boundary conditions are performed together with the axis boundary condition is set to the $\mathrm{x}$-axis.

For the entire flow simulations, the grid convergence is checked as a first instance. In order to be certain if the grid is capable of capturing the solution accurately and costeffectively, a grid convergence study is performed. Several grid densities and distributions are arranged for each tool to be taken benefit of and corresponding results are analyzed. For the studies, a coarse, a medium, a fine and a very fine grids are 
generated, named as "grid\#1", "grid\#2", "grid\#3" and "grid\#4" respectively and the corresponding results are evaluated and presented.

The problem is computed in such a way that, firstly a converged solution of only the primary flow is obtained, then the secondary flow is enabled for both FloEFD and ANSYS Fluent analyses. Besides, converged solutions for the inviscid (ideal wall) and viscous (real wall) approaches of FloEFD, $1^{\text {st }}$ and $2^{\text {nd }}$ order methods of ANSYS Fluent are obtained step by step for each analysis in order to obtain the final solution of the problem. Therefore, series of steps are carried out for an ultimate result at each analysis. This yields a minimum solution time of $\sim 3$ to $\sim 4$ hours as well as a maximum solution time of $\sim 62$ to $\sim 63$ hours for each result over the course of this thesis, including the grid convergence study.

\subsubsection{Grid Convergence}

For generating the grids to be performed for FloEFD, a grid convergence study is performed. These grids that are to be observed for this study has cell sizes as follows;

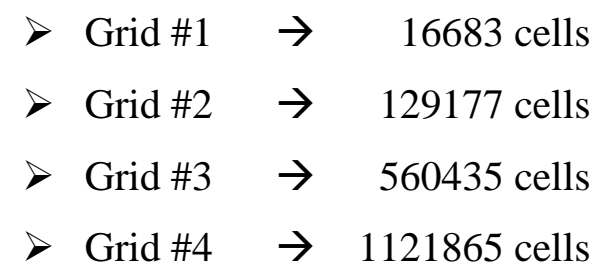

The problem is solved with the indicated grid sizes which refer to "coarse", "medium", "fine" and "very fine" cartesian meshes respectively and the results for the entrainment ratio corresponding to each grid size are analyzed. The behavior of the analyses and how the solutions vary with further refinement of the grid is compared and shown in Figure 19.

As it can clearly be observed from Figure 19, following the medium grid (\#2), the variation of the entrainment ratio has cruised to the converged value of 0.57 . At this point it can be decided that further refinement of the grid would not worth the effort, meaning that the variation in the solution is minor whereas the computational time is 
increasing dramatically. This value is taken as the convergence criteria for the fineness of the grid used in the computations. We can see clearly from the graph in Figure 19 that with increasing mesh size, the entrainment ratio approaches asymptotically the limited value of the entrainment. It is decided therefore that fine grid (grid \#3) is selected to be used for the further analyses as shown and marked in the plot, Figure 19.

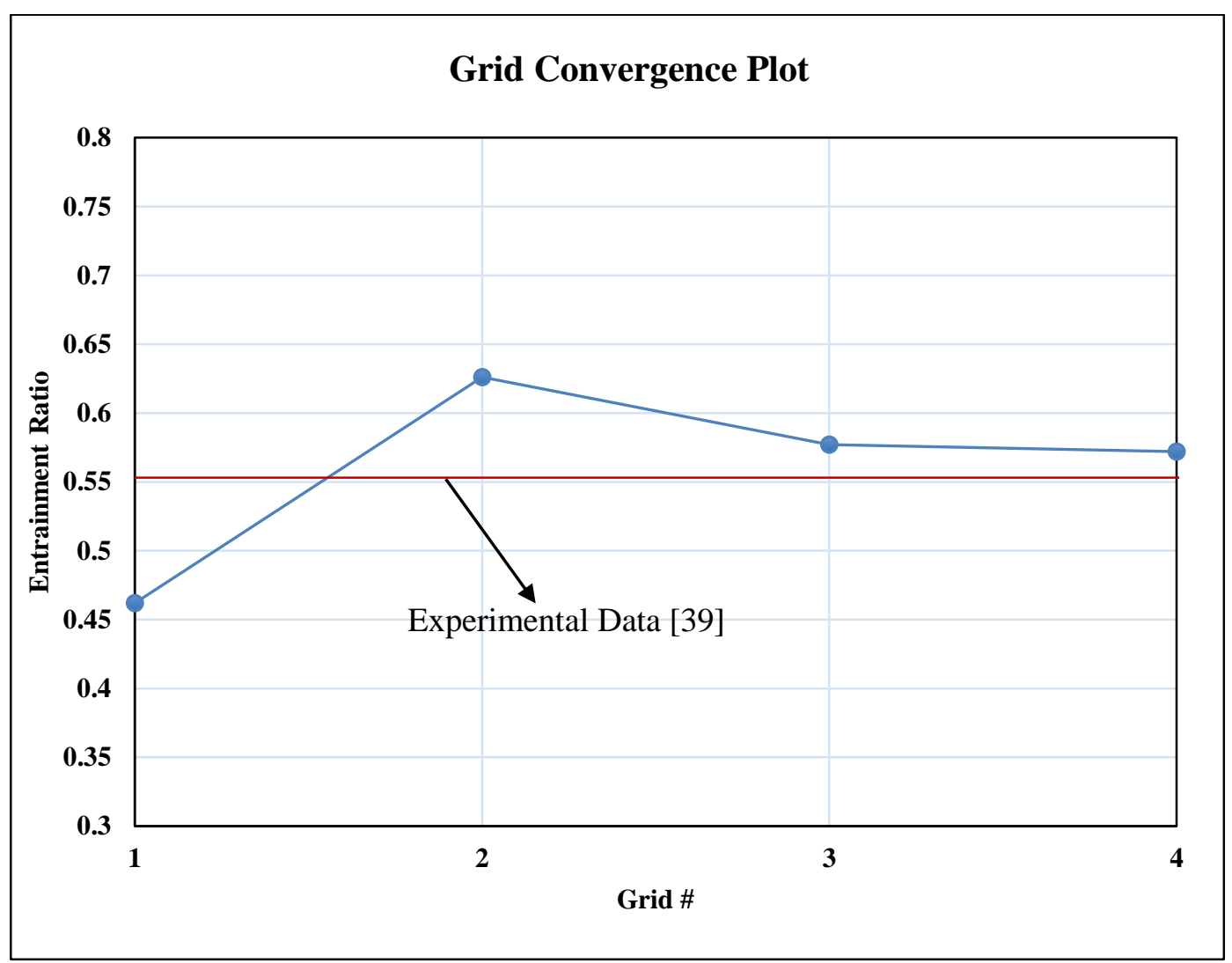

Figure 19. Grid convergence plot for FloEFD simulation

Moreover, the effect of these separate grid densities on the axial pressure distribution are compared and the results are shown in Figure 21. Thus, the grid dependency of not only the entrainment ratio but also the flow characteristics through the system is sifted. The grids are indicated as \#1, \#2, \#3 and \#4 and their comparison with those that of the literature [39] data are shown in Figure 21. Looking at the results, grid \#1 defined as coarse mesh, could not be able to capture the pressure oscillations, whereas the remaining grids defined as medium, fine and very fine mesh respectively, all match 
the pattern. One can observe from grid \#3 and \#4 (Figure 21) that, refining the grid will not worth the effort from that point on so that grid \#3, the fine grid, is selected to be used for such operation and is presented in Figure 20.

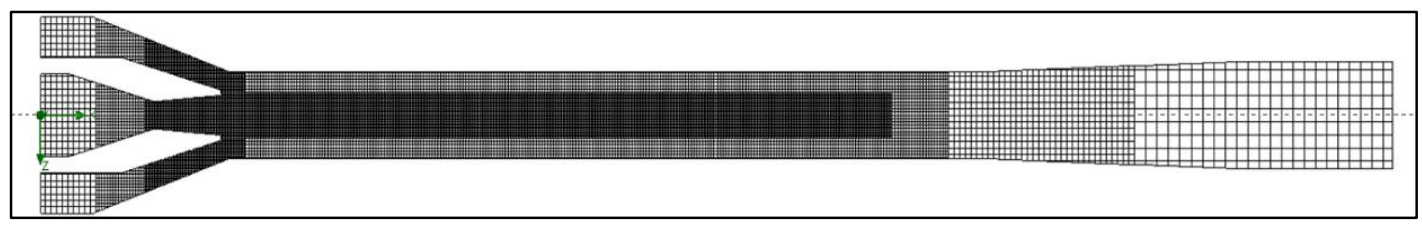

Figure 20. A sectional view of the selected grid for the FloEFD simulations, "fine grid"

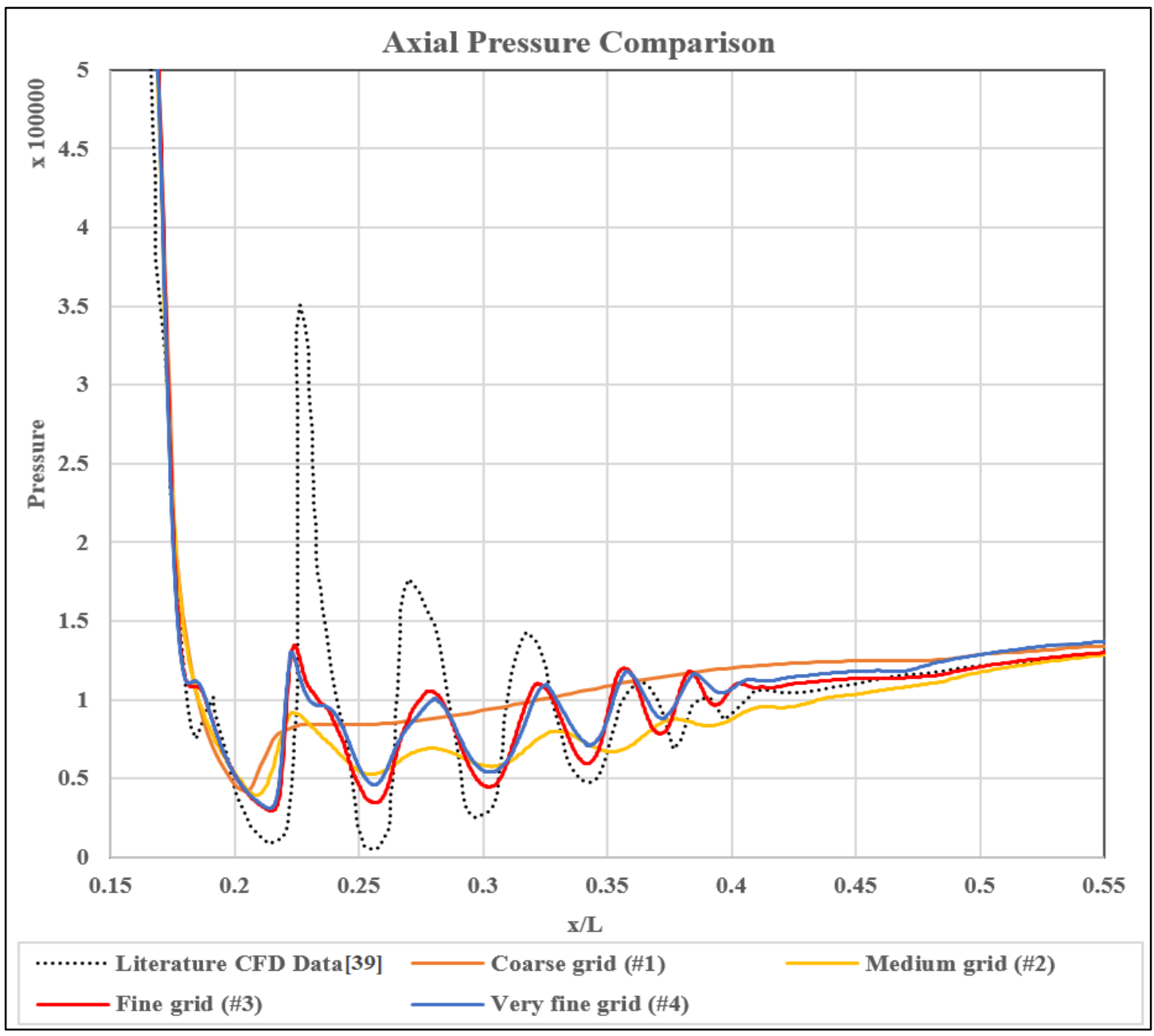

Figure 21. Grid distribution effects on the flow structure with comparison [39]

Secondly, ANSYS Fluent CFD tool is also used including two different turbulence models. For the k-epsilon realizable turbulence model and assuming that the grid 
density be enough for resolving the flow within the domain, a study is carried out. The method uses axisymmetric approach and solves the 2-D geometry, the number of the cells are fewer relative to a 3-D geometry, and corresponding grids are prepared as follows;

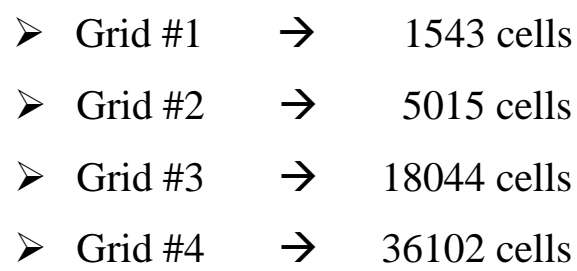

The problem is solved with these grid densities and the computed entrainment ratios for the corresponding quadrilateral grids are plotted in Figure 22. As it can explicitly observed from Figure 22, the entrainment ratio progression with refining the grid is approaching a limiting value.

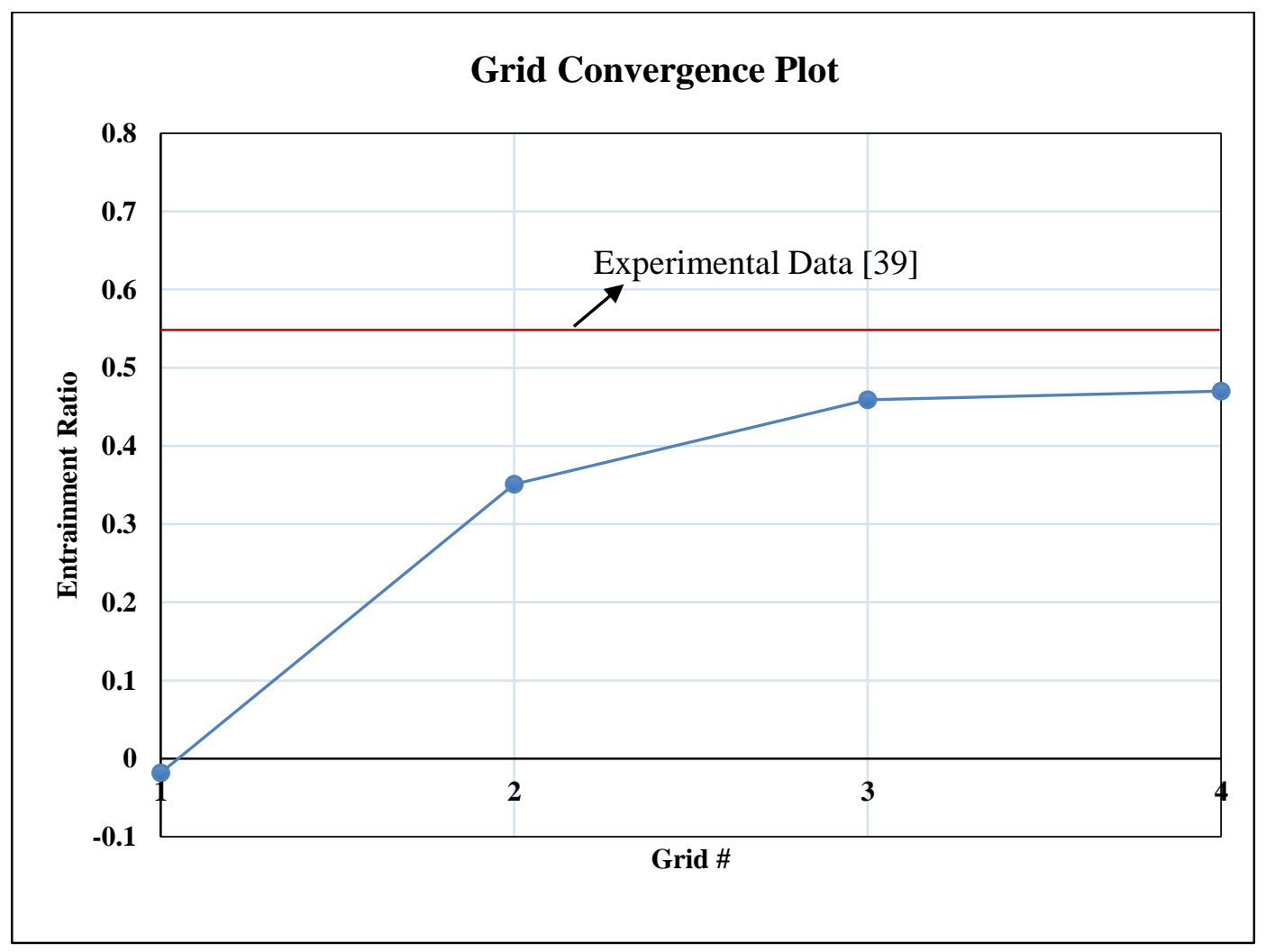

Figure 22. Grid convergence plot for the ANSYS Fluent with k-epsilon realizable turbulence model implementation 


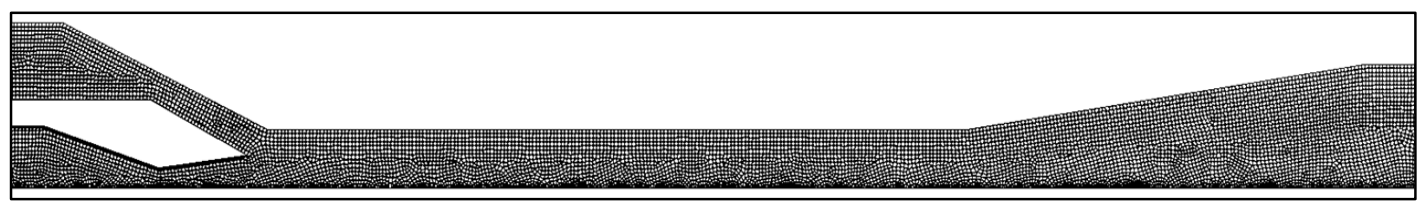

Figure 23. A view of the selected grid\#3 for the ANSYS Fluent simulations with k-epsilon realizable turbulence model implementation, "fine grid"

The variation over the solution is obtained to be up to $105 \%$ and followed by the fluctuations within the range of $\sim 3 \%$ to $\sim 30 \%$. For the third grid referring to "fine grid", containing 18044 cells, these fluctuations are diminished as low as $\sim 0.18 \%$ $\sim 1.50 \%$. Once it is concluded that the limiting value is reached for the entrainment value, no further refinement of the grid would be necessary. Therefore, grid \#3 that is the fine grid, is selected as the appropriate grid size and no further refinement was necessary as shown in Figure 22.

Following these, computations performed by ANSYS Fluent CFD tool, another turbulence model using the SST k-omega turbulence model are implemented, in order to make sure that the grid density is adequate enough to resolve the flow details, multiple grid distributions are used in the computations indicated as follows;

\begin{tabular}{|c|c|c|}
\hline Grid \#1 & $\rightarrow$ & 6045 cells \\
\hline Grid \#2 & & 17743 cells \\
\hline Grid \#3 & & $56284 \mathrm{ce}$ \\
\hline 7 & & 156673 \\
\hline
\end{tabular}

The problem is solved with the corresponding grid densities and the computed entrainment ratios are shown in Figure 25.

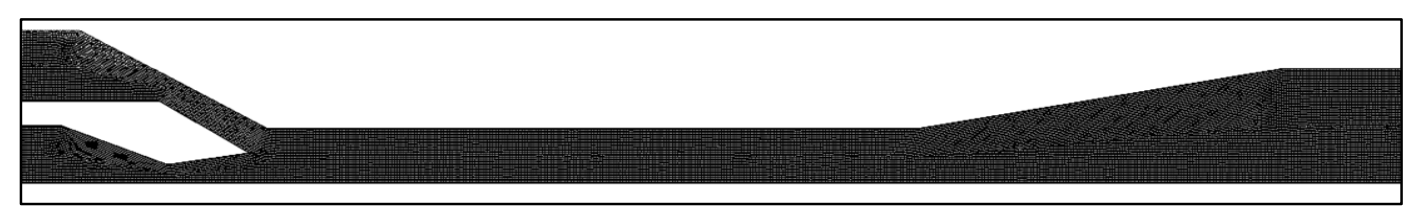

Figure 24. A cross-sectional view of the selected grid\#3 for the ANSYS Fluent simulations with SST k-omega turbulence model implementation, "fine grid" 


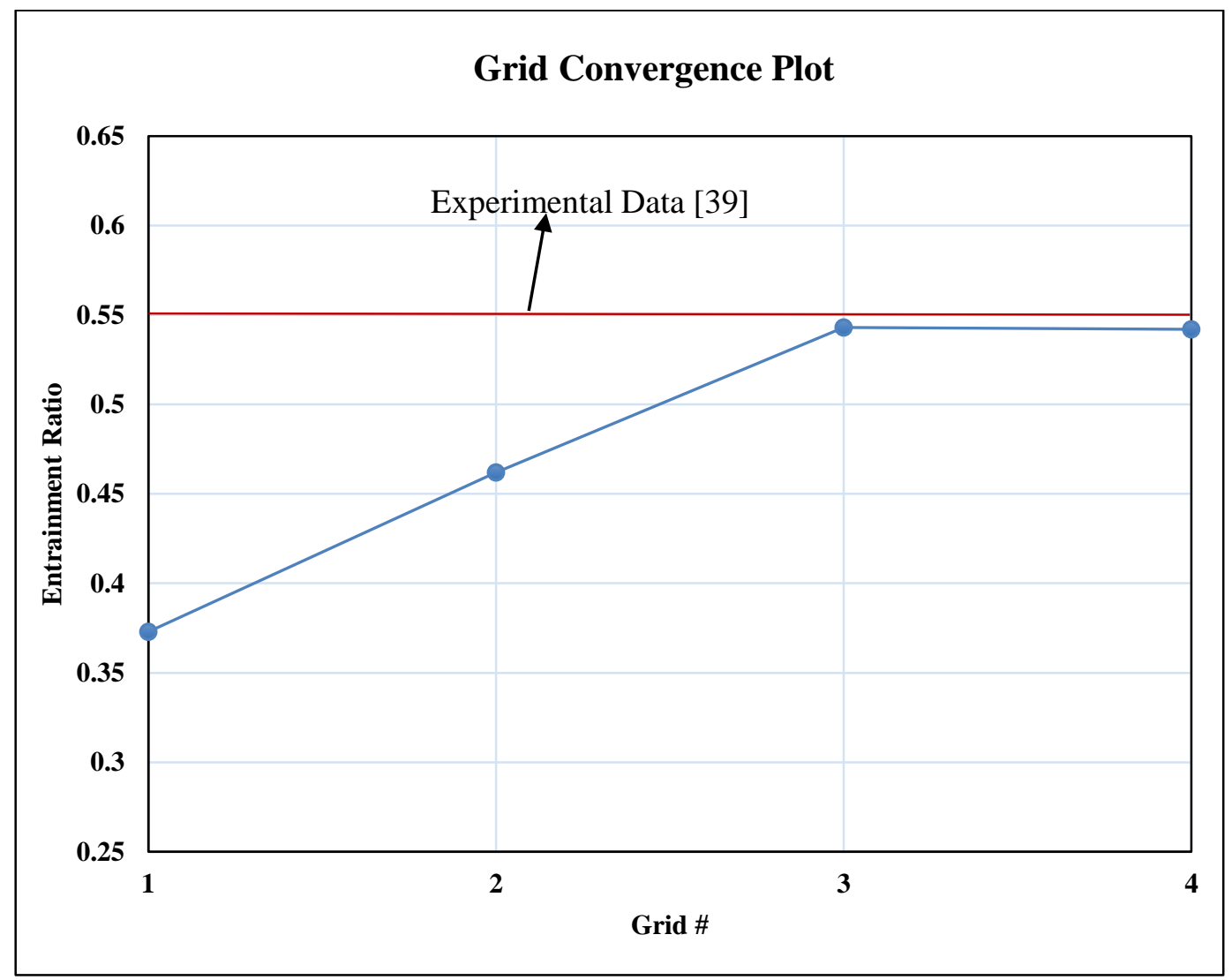

Figure 25. Grid convergence plot for the ANSYS Fluent with SST k-omega turbulence model implementation

Looking at the plot, it is observed that as of the third grid referring to the fine grid, the entrainment value is reached to an almost constant value. Since further refinement does not worth the effort, grid\#3 with 56284 cells is selected as the grid density for the analysis, as can be viewed in Figure 24.

For the k-epsilon realizable turbulence model implementation in ANSYS Fluent solver, the first cell height near the wall is specified in such a way that to $y+$ value shall remain within the range of from $\sim 30$ to $\sim 300$ whereas for the SST k-omega turbulence model implementation, $\mathrm{y}^{+}$is appointed as low as $\mathrm{y}^{+\leq} \sim 1$. On the other hand, for the simulations performed with FloEFD, no such methods are performed as the solver automatically determines the near-wall regions, and resolves such regions with modified k-epsilon 2-equation model. Also, local refinement of meshes are performed for the critical regions of the system such as; the convergent-divergent nozzle, flow 
intersections and regions where the shocks are expected to be formed. Stable solutions are achieved for each analysis, with the grid resolution shown in Table 3.

Table 3. Grid resolution for corresponding flow simulations - I

\begin{tabular}{|c|c|c|c|}
\hline & FloEFD & $\begin{array}{c}\text { FLUENT } \\
\text { k- } \varepsilon \text { realizable turbulence } \\
\text { model, } y+=\text { from } \sim 30 \text { to } \\
\sim 300\end{array}$ & $\begin{array}{c}\text { FLUENT } \\
\text { SST k- } \omega \text { turbulence } \\
\text { model, } y+=\sim 1\end{array}$ \\
\hline \# of cells & 560435 & 18044 & 56284 \\
\hline
\end{tabular}

\subsubsection{Numerical Convergence}

Numerical convergence of the solutions is achieved, and the variation of the parameters of interest are monitored during the computations. Along the analyses performed by FloEFD, mass flow rate through the inlets together with the entrainment ratio is additionally set to be judged for the convergence of the solution apart from the flow variables.

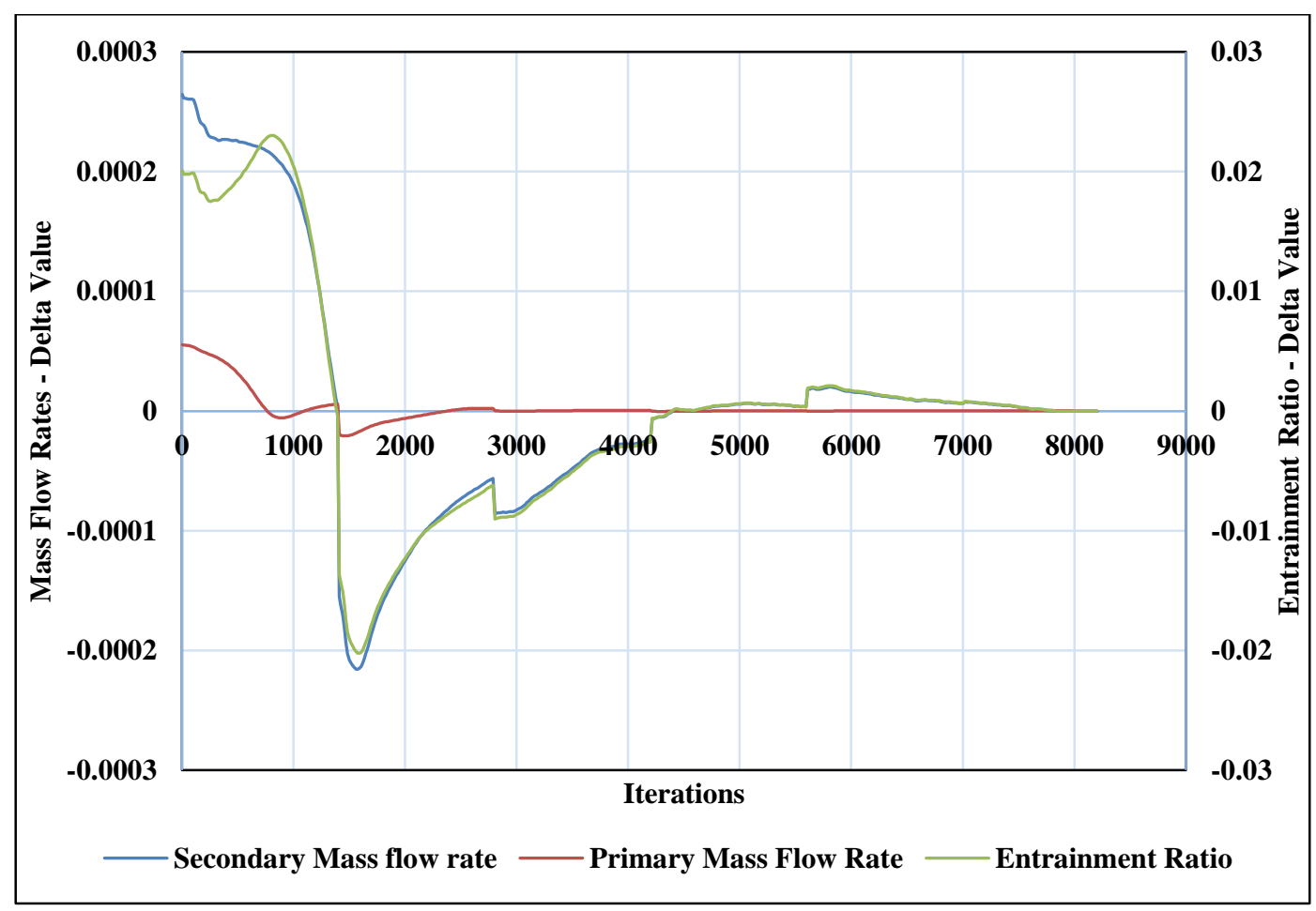

Figure 26. Numerical convergence plot for the computation performed by FloEFD 
The numerical convergence of the mass flow rates together with the entrainment ratio as described in Figure 26 is obtained. As it can clearly be observed, primary mass flow rate is converged to its value after 2000 iterations and almost no change can be observed for both on the entrainment ratio value and the secondary mass flow rate after 5000 iterations and through 8000 iterations.

In a similar manner, besides the flow variables, primary and secondary mass flow rates are monitored throughout the analyses performed by ANSYS Fluent. For both turbulence models implementations, convergence criterion for the entire parameters are set to be $10^{-5}$ and the results are shown in Figure 27 andFigure 28, confirming the convergence of the computed solutions.

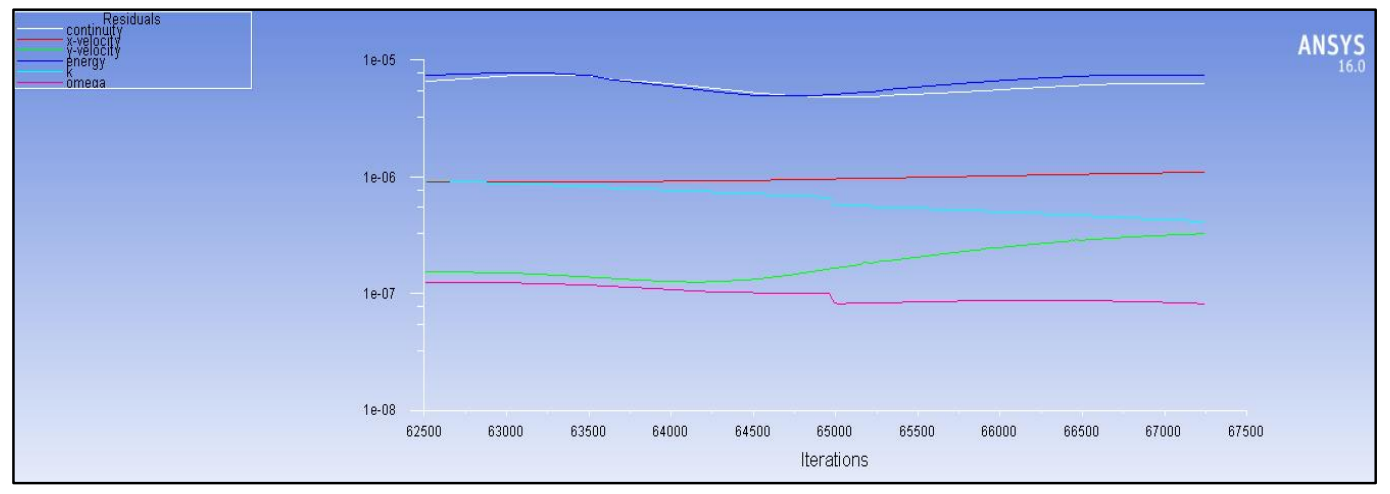

Figure 27. Residual plot for the computation performed by ANSYS Fluent with SST komega turbulence model implementation

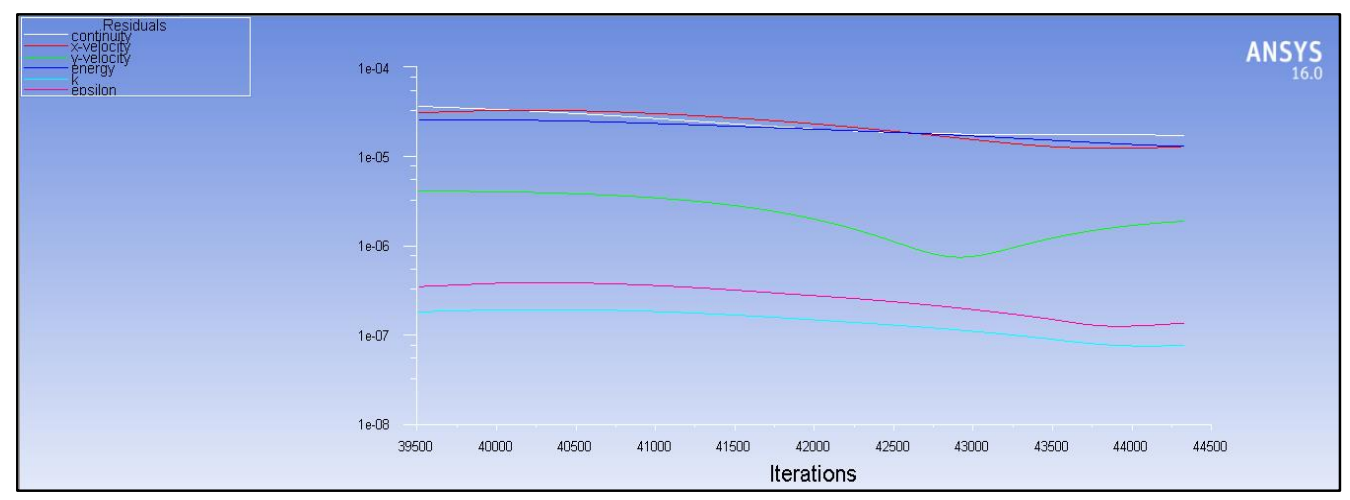

Figure 28. Residual plot for the computation performed by ANSYS Fluent with k-epsilon realizable turbulence model implementation 


\subsubsection{Present Study and the Comparison}

These computations are compared each with each other as well as both CFD results [39] and experimental results [16] available in the literature, as the mass flow rates, entrainment ratio as well as the axial pressure and Mach number of the flow contours later on.

Table 4. Verification case study and analyses results - I

\begin{tabular}{|c|c|c|c|}
\hline & $\begin{array}{l}\text { Primary Mass } \\
\text { Flow Rate }\end{array}$ & $\begin{array}{l}\text { Secondary } \\
\text { Mass Flow } \\
\text { Rate }\end{array}$ & $\begin{array}{c}\text { Entrainment } \\
\text { Ratio (w) }\end{array}$ \\
\hline $\begin{array}{c}\text { Experiment } \\
\text { [39], [16] }\end{array}$ & - & - & 0.553 \\
\hline $\begin{array}{c}\text { CFD Results } \\
\text { [39] }\end{array}$ & $\begin{array}{c}16.43 \\
\text { grams/sec }\end{array}$ & 9.30 grams $/ \mathrm{sec}$ & 0.566 \\
\hline $\begin{array}{l}\text { One-Dimensional } \\
\text { FORTRAN Code } \\
\text { Prediction }\end{array}$ & $\begin{array}{c}16.83 \\
\text { grams/sec }\end{array}$ & $\begin{array}{c}10.78 \\
\text { grams/sec }\end{array}$ & 0.641 \\
\hline $\begin{array}{l}\text { CFD Results (FloEFD / } \\
\text { Inviscid Solution) }\end{array}$ & $\begin{array}{c}16.95 \\
\text { grams/sec }\end{array}$ & $\begin{array}{c}11.96 \\
\text { grams/sec }\end{array}$ & 0.705 \\
\hline $\begin{array}{l}\text { CFD Results (FloEFD / } \\
\text { Viscous Solution) }\end{array}$ & $\begin{array}{c}16.42 \\
\text { grams/sec }\end{array}$ & $9.47 \mathrm{grams} / \mathrm{sec}$ & 0.577 \\
\hline $\begin{array}{l}\text { CFD Results (FLUENT / } \\
\text { k- } \varepsilon \text { realizable) }\end{array}$ & $\begin{array}{c}16.04 \\
\text { grams/sec }\end{array}$ & $9.05 \mathrm{grams} / \mathrm{sec}$ & 0.564 \\
\hline $\begin{array}{c}\text { CFD Results } \\
\text { ( FLUENT / SST k- } \omega)\end{array}$ & $\begin{array}{c}16.17 \\
\text { grams/sec }\end{array}$ & 8.76 grams $/ \mathrm{sec}$ & 0.542 \\
\hline
\end{tabular}

So the acquired results and the literature data are shown in Table 4 and Table 5 including the percentage of errors as a separate table.

Looking at the results involving the 1-D approach, 3-D inviscid and viscous CFD solutions of FloEFD as well as the 2-D axisymmetric approaches using ANSYS Fluent seems to be in agreement with the expectations and stay within the acceptable ranges. Only the result for inviscid solution has an error percentage of $25 \%$. Even 1-D calculation seems to be good method for quick pre-study for designing and analyzing 
such a system. Results acquired from 3-D real wall CFD analysis and 2-D axisymmetric analysis with implementation of turbulence models appear to stay within the acceptable accuracy limits. $(\sim 5 \%)$

Table 5. Verification case study and analyses error table - I

\begin{tabular}{|c|c|c|c|}
\hline & $\begin{array}{c}\text { Primary } \\
\text { Mass Flow } \\
\text { Rate }\end{array}$ & $\begin{array}{c}\text { Secondary } \\
\text { Mass Flow } \\
\text { Rate }\end{array}$ & $\begin{array}{c}\text { Entrainment } \\
\text { Ratio (w) }\end{array}$ \\
\hline $\begin{array}{c}\text { CFD Results } \\
\text { [39], [16] }\end{array}$ & - & - & $2.35 \%$ \\
\hline $\begin{array}{c}\text { One-Dimensional FORTRAN } \\
\text { Code Prediction }\end{array}$ & $2.43 \%$ & $5.91 \%$ & $13.17 \%$ \\
$15.83 \%$
\end{tabular}

Reviewing the literature, it is observed that, the percentage of error (accuracy) of such kind of analysis should be below 20\%. It can be said that the error below $20 \%$ is acceptable, below $10 \%$ is good [41] but as the computational ability and power is improving rapidly, nowadays this accuracy of the computations can be obtained around or below $\sim 5 \%$.

Moreover, in order to investigate these methods in details, pressure variation along the centerline of the ejector (axial pressure variation) is computed and compared with the CFD results acquired from the literature. A computed pressure values obtained from 
the paper [39] is digitized, and the resulting data is plotted with the current computed values on the same graph, Figure 29.

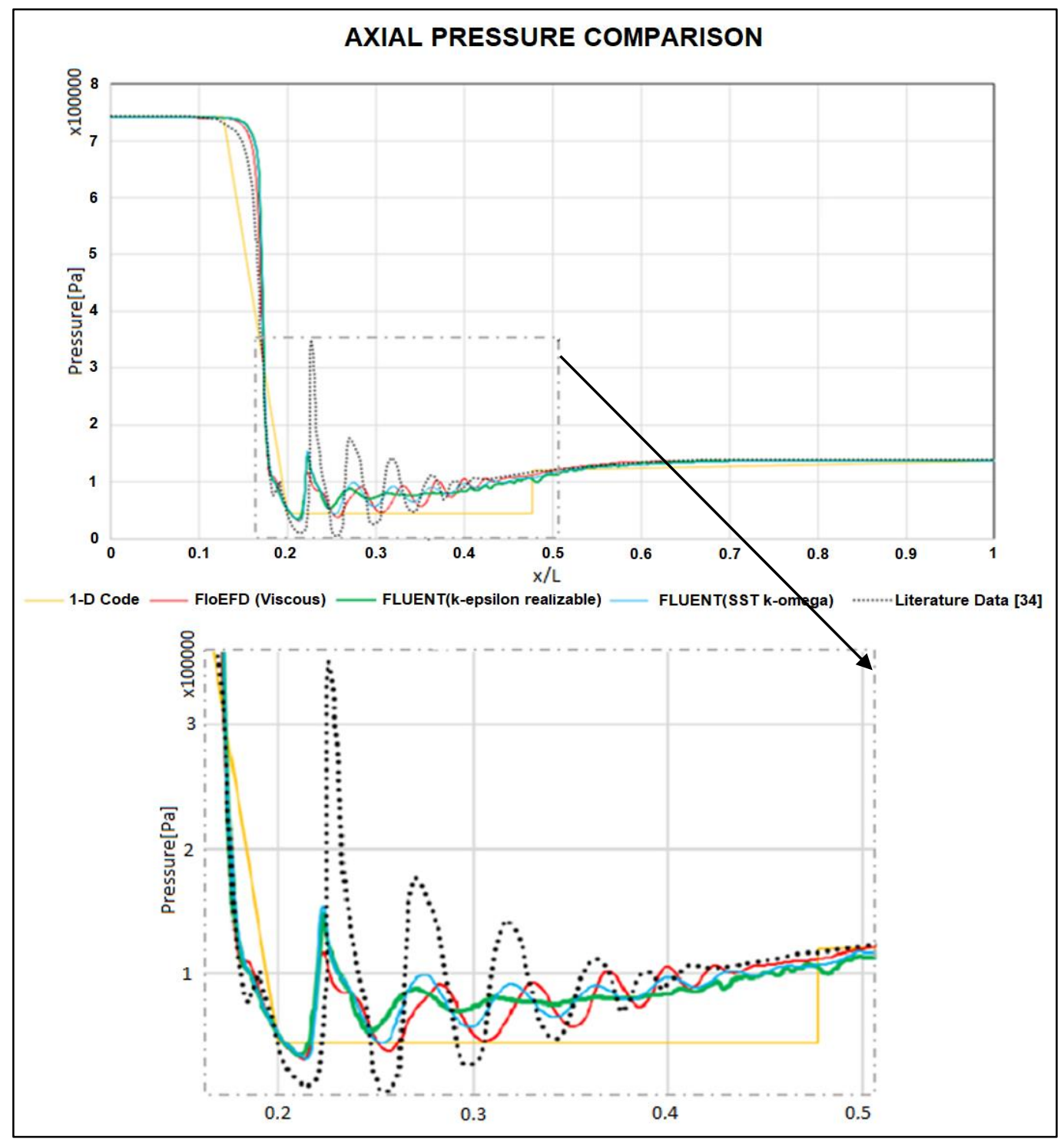

Figure 29. Comparison of the computational results and the numerical literature data (top) [39] and the zoomed view in the mixing region (bottom)

Looking at the results, 1-D predictions seems to act like a trend-line of the pressure variation throughout the system. 1-D code only calculates the flow at the stations as discussed in previous chapters and assumes that the mixing to be ideal and shock-free, it can be treated as acceptable, as the pressure values at the defined stations are well 
captured (Figure 29). However, the code is incapable of obtaining the oblique shocks and expansion wave patterns if that is the matter of concern.

The whole remaining approaches of CFD cases are able to capture the expansion and compression patterns, however, the k-epsilon realizable turbulence model implementation appears to reflect results that do not agree through the downstream locations of the mixing region. Moreover, such computational methods seem to be inadequate especially for capturing the locations following the second pressure peak.

As it can be clearly observed from the pressure plot (Figure 29), both the viscous CFD analysis (FloEFD) and the SST k-omega turbulence model implementation, the locations of the oscillations caused by the expansion-compression patterns are successfully captured whereas the pressure values are under predicted especially for the first two patterns with slight shifts for the locations of pressure peaks.

Thus, both the viscous CFD analysis results and the SST k-omega approach results apparently come out to be applicable (with each having its advantages on separate concerns) in terms of locating the axial pressure oscillations and expansioncompression wave patterns formations, throughout the system.

As also shown in the literature [39], supersonic region $(M \geq 1)$ within the given geometry is investigated using several turbulence models, and corresponding Mach contours are plotted. Therefore, for comparison, same procedures are performed in the present study cases (Figure 30), and the results are shown and compared with the literature.

Although, the results obtained using the SST k-omega approach is slightly more accurate than the FloEFD analysis, it is decided that the use of the commercial software package Solidworks Flow Simulation (FloEFD) together with the CAD tool are found to be more convenient since the geometrical and operational aspects of the system will be investigated as a whole package throughout the study. Using such a tool makes the preparation of the model geometry, performing the computational analyses and the 
overall study, advantageous when considering the effort and the computational rapidity.

The variation of the Mach number (acquired from the FloEFD - viscous study) as a pseudo-colored visualization through the whole system is presented and shown in Figure 31 .

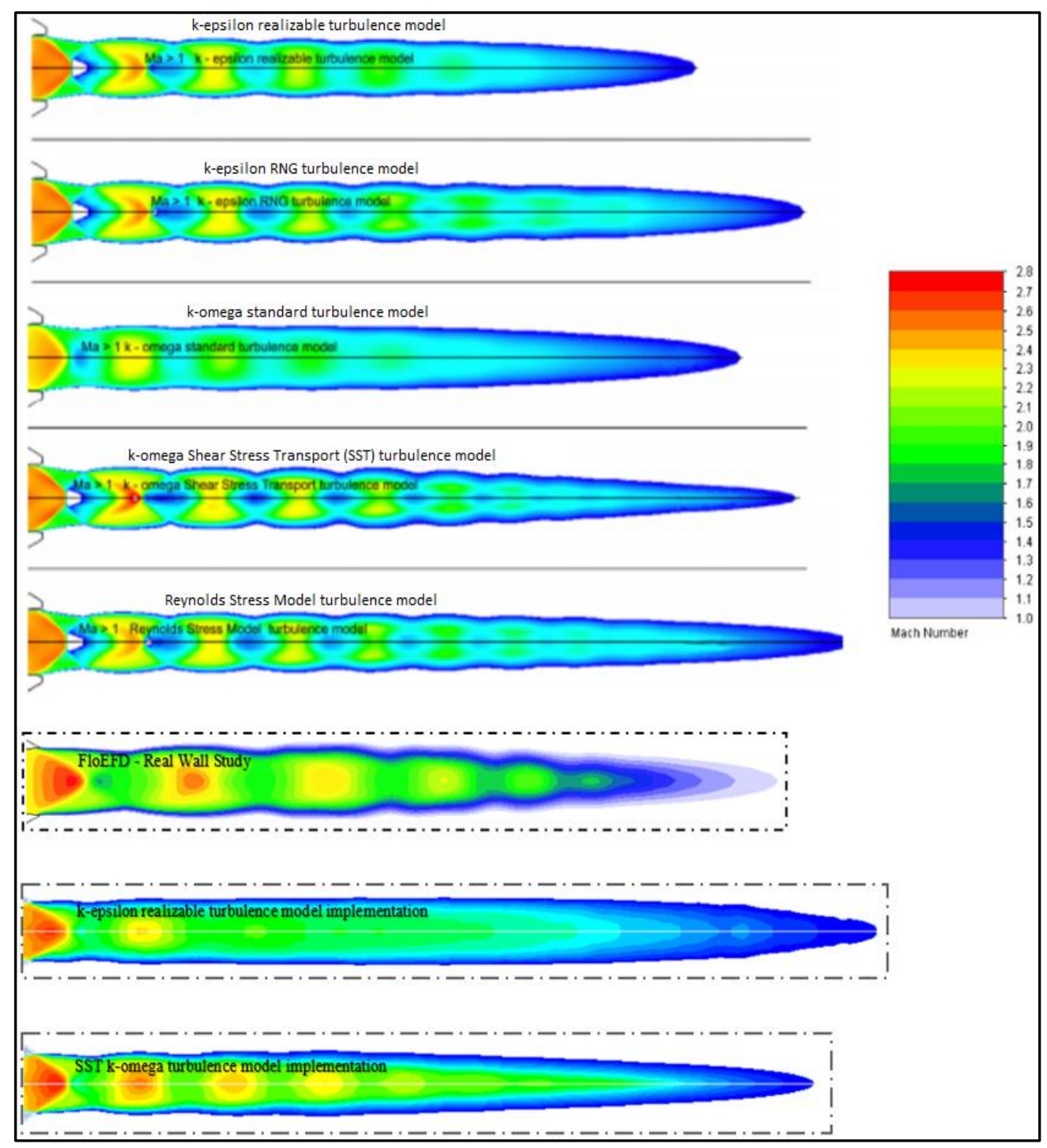

Figure 30. Supersonic region ( $M>1$ ) Mach contours; (upper five; reference cases [34], [38] lower three; real wall study(viscous), k-epsilon and SST k-omega turbulence model implementations respectively) 


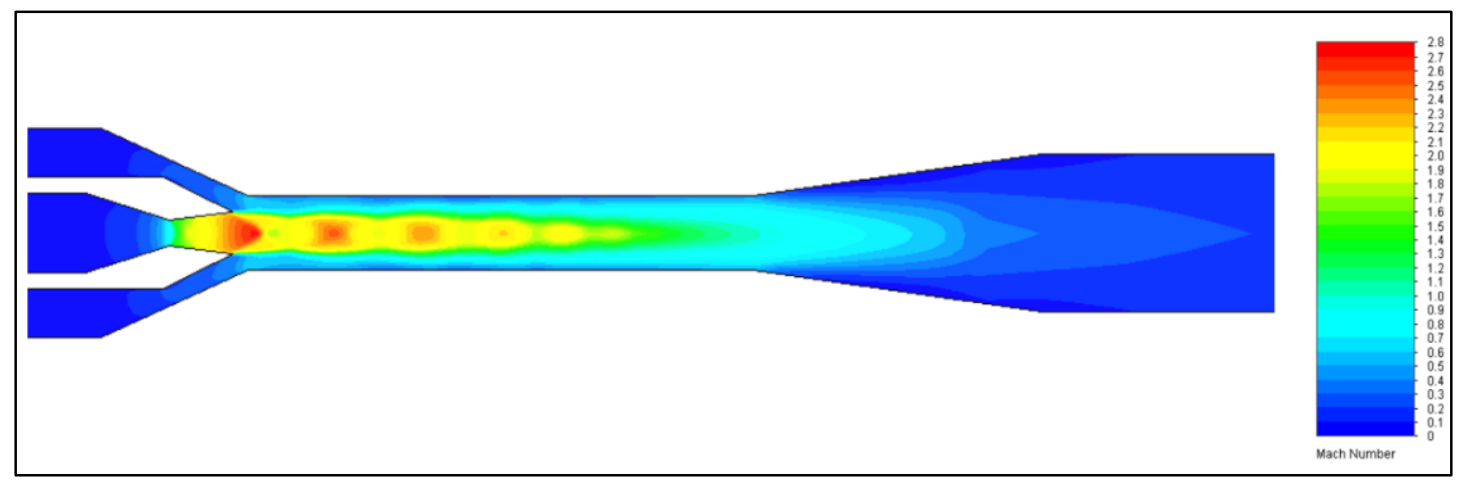

Figure 31. CFD results for viscous solution of FloEFD, Mach number contour

The oblique shock-expansion-compression patterns for such a case can also be observed clearly from the velocity vectors plotted for the viscous FloEFD analysis. (Figure 32)

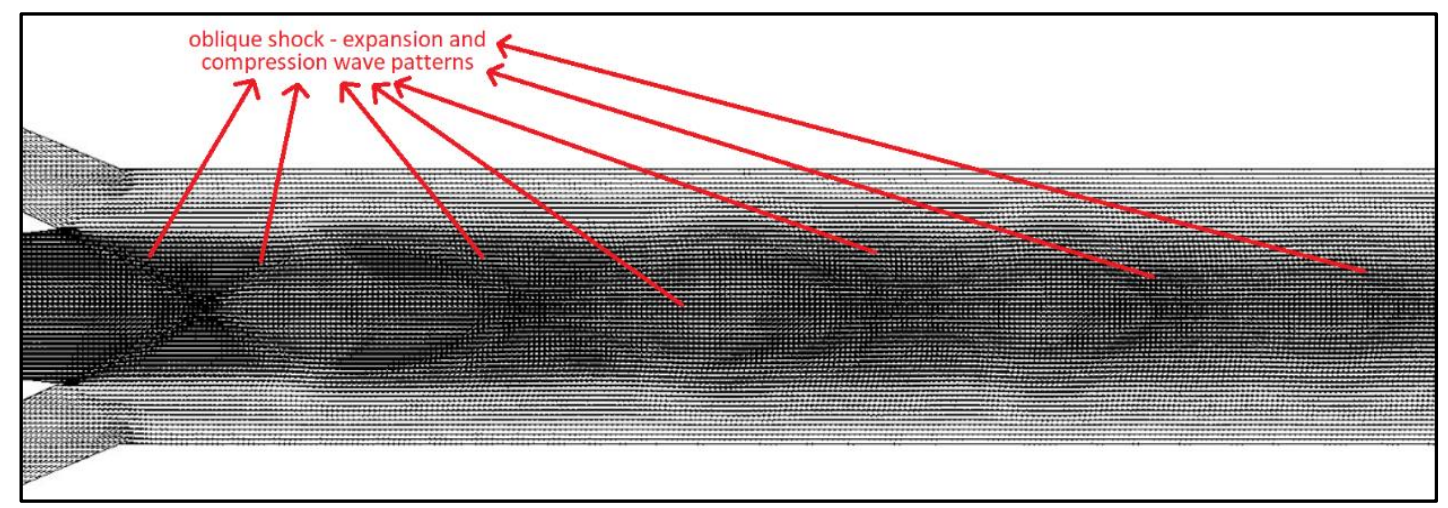

Figure 32. Velocity vectors within the mixing region (vector spacing $=0.15 \mathrm{~mm}$ ) for the present study (viscous FloEFD solution)

\subsection{Validation of the Computational Methods and Tools - Part II}

For further verification of the present methods of analysis used in this study, another geometry is obtained from the literature [12].

The ejector model is obtained from literature paper [12], which is shown in Figure 33 indicating the ejector geometry and the dimensions.

As opposed to the previous geometry, this ejector model is operated at three different flow conditions [12]. Therefore, this test case is in fact more than one test case so one 
can benefit from the results available for further validating the methods used in the analysis within the scope of the present thesis.

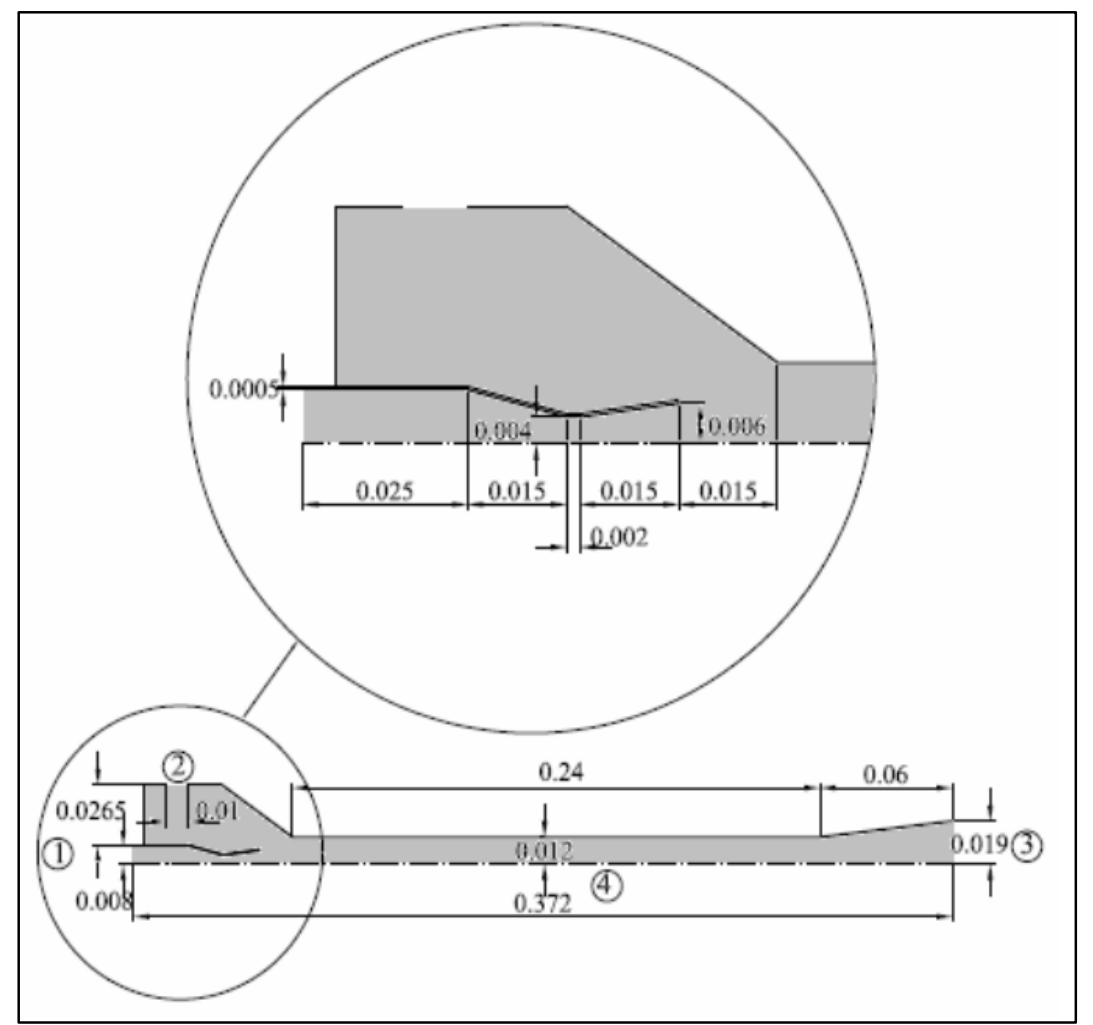

Figure 33. Verification case geometry - II [12] (dimensions in m)

Table 6. Verification case operating conditions - II

\begin{tabular}{|c|c|c|c|}
\hline & $\underline{\text { Case \#1 }}$ & $\underline{\text { Case \#2 }}$ & $\underline{\text { Case \#3 }}$ \\
\hline Primary Fluid (Inlet) & $\begin{array}{c}\mathrm{P}_{1}=405300 \mathrm{~Pa} \\
\text { or } \\
\mathrm{P}_{1}=4 \mathrm{~atm}\end{array}$ & $\begin{array}{c}\mathrm{P}_{1}=506625 \mathrm{~Pa} \\
\text { or } \\
\mathrm{P}_{1}=5 \mathrm{~atm}\end{array}$ & $\begin{array}{c}\mathrm{P}_{1}=607950 \mathrm{~Pa} \\
\text { or } \\
\mathrm{P}_{1}=6 \mathrm{~atm}\end{array}$ \\
\hline $\begin{array}{c}\text { Secondary Fluid } \\
\text { (Inlet) }\end{array}$ & $\dot{m}_{\mathrm{sec}}=0.028 \mathrm{~kg} / \mathrm{s}$ & $\dot{m}_{\mathrm{sec}}=0.028 \mathrm{~kg} / \mathrm{s}$ & $\dot{m}_{\mathrm{sec}}=0.028 \mathrm{~kg} / \mathrm{s}$ \\
\hline Discharge (Outlet) & $\begin{array}{c}\mathrm{P}_{\mathrm{out}}=101325 \mathrm{~Pa} \\
\text { or } \\
\mathrm{P}_{\text {out }}=1 \mathrm{~atm}\end{array}$ & $\begin{array}{c}\mathrm{P}_{\text {out }}=101325 \mathrm{~Pa} \\
\text { or } \\
\mathrm{P}_{\text {out }}=1 \mathrm{~atm}\end{array}$ & $\begin{array}{c}\mathrm{P}_{\text {out }}==101325 \mathrm{~Pa} \\
\text { or } \\
\mathrm{P}_{\text {out }}=1 \mathrm{~atm}\end{array}$ \\
\hline
\end{tabular}

Similar approaches are implemented as in the previous case. The only difference this time is the fact that, the secondary mass flow rate is kept fixed as in the literature case 
[12]. Thus, instead of implementing the fixed pressure boundary conditions to all of the flow openings, the secondary pressure is varied, by trial and error, until the mass flow rate of $0.028 \mathrm{~kg} / \mathrm{s}$ is reached. This includes the one-dimensional Fortran code as well as the numerical flow simulations which are performed using the commercial SolidWorks FloEFD / Flow Simulation program for all three circumstances. These simulations are realized to determine how accurately the mass flow rates are calculated and discussed.

The three cases explained previously are first implemented into 1-D Fortran code, then corresponding 3-D geometry is generated with the help of SolidWorks CAD program and the resulting secondary pressure is calculated for the secondary mass flow rate of $0.028 \mathrm{~kg} / \mathrm{s}$. CFD analysis is performed by setting the pressure boundary conditions to the flow-openings. (i.e. pressure inlet B.C. to primary/secondary and pressure outlet B.C. to discharge)

Table 7. Verification case study and analyses results - II

\begin{tabular}{|c|c|c|c|}
\hline Case \# & $\begin{array}{c}P_{2} \\
(\mathbf{C F D})\end{array}$ & $\begin{array}{c}\boldsymbol{P}_{2} \text { (Experimental } \\
[12])\end{array}$ & Error \% \\
\hline$\# 1-P_{1}=405300 \mathrm{~Pa}$ & $73950 \mathrm{~Pa}$ & $79034 \mathrm{~Pa}$ & $6.43 \%$ \\
\hline$\# 2-P_{1}=506625 \mathrm{~Pa}$ & $59570 \mathrm{~Pa}$ & $68901 \mathrm{~Pa}$ & $13.54 \%$ \\
\hline$\# 3-P_{1}=607950 \mathrm{~Pa}$ & $43700 \mathrm{~Pa}$ & $40530 \mathrm{~Pa}$ & $7.82 \%$ \\
\hline Case \# & $\begin{array}{c}P_{2} \\
\text { (1-D Code) }\end{array}$ & $\frac{\boldsymbol{P}_{\mathbf{2}}}{\text { (Experimental [12]) }}$ & Error \% \\
\hline$\# 1-P_{1}=405300 \mathrm{~Pa}$ & $45579 \mathrm{~Pa}$ & $79034 \mathrm{~Pa}$ & $42.33 \%$ \\
\hline$\# 2-P_{1}=506625 \mathrm{~Pa}$ & $52634 \mathrm{~Pa}$ & $68901 \mathrm{~Pa}$ & $23.61 \%$ \\
\hline$\# 3-P_{1}=607950 \mathrm{~Pa}$ & $59524 \mathrm{~Pa}$ & $40530 \mathrm{~Pa}$ & $46.86 \%$ \\
\hline
\end{tabular}

Similar to the previous test case, the grid convergence and the numerical convergence of the solutions are achieved and the flow parameters are monitored during the analyses. Along the analyses performed by FloEFD, mass flow rates through the flow inlets and the entrainment ratio are additionally set to be judged for the convergence 
of the solution apart from the flow variables. Therefore, these information provides evidence that the results are converged to expected values.

Looking at Table 7, which shows the corresponding errors, one-dimensional approach seems to yield the solution with an error of around $\sim 40 \%$. Since the code approximates the flow ideally and as shock-free; except a single normal shock; as well as inviscid and free of any disturbances, it is normal to have such a large difference in computations. Despite these assumptions, initial guessing of the flow characteristics with this percentage of accuracy for such a complex flow structure can be considered as acceptable. On the other hand, the numerical simulations show an error to be around $\sim 10 \%$ and it can be concluded that the errors appear to be within the acceptable ranges.

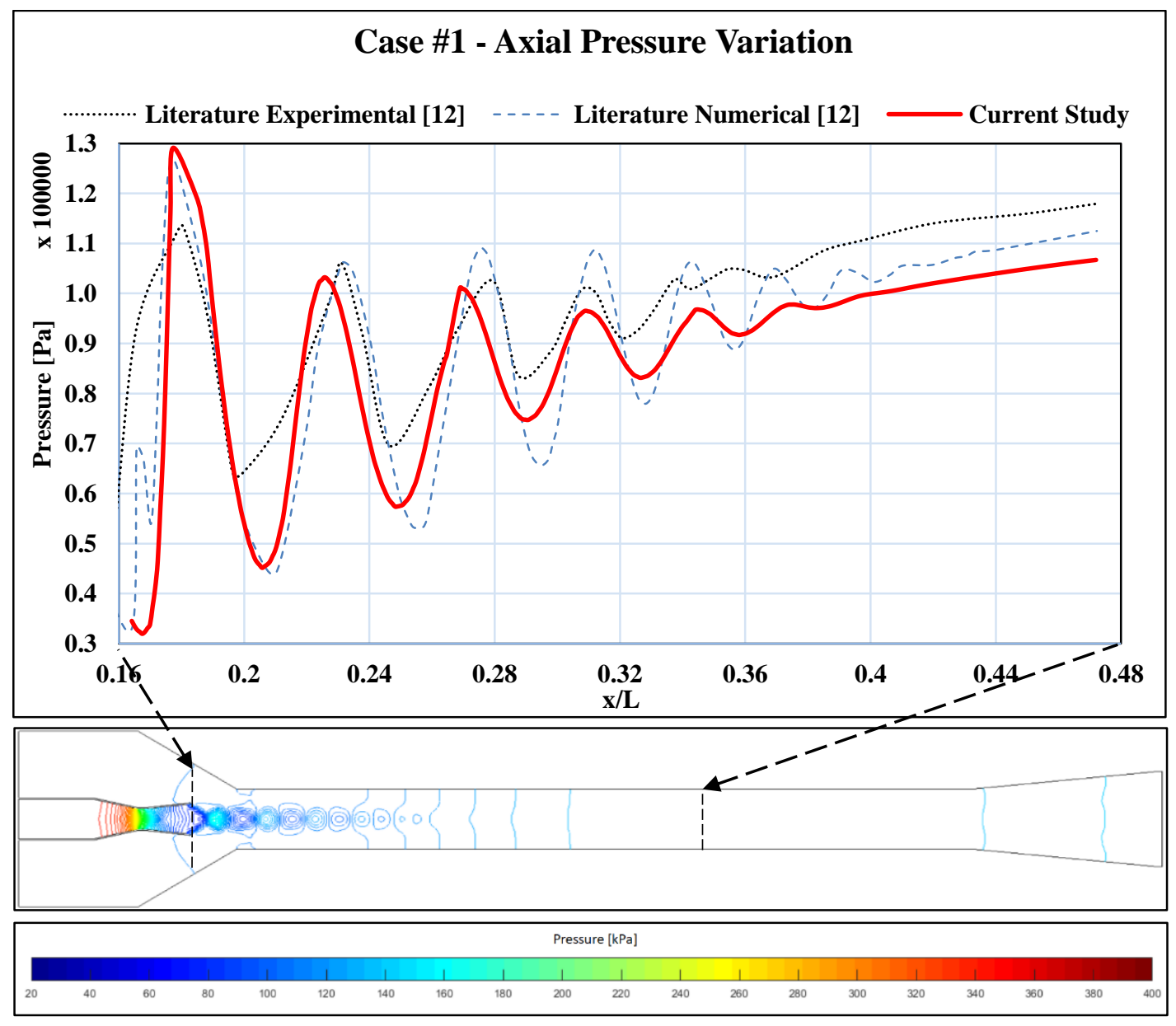

Figure 34. Axial streamline pressure comparison of $P 1=4$ atm test case $\# 1$ with that of the literature values [12] and the corresponding pressure iso-contour 
Furthermore, detailed variations of pressure along the axial direction are presented in in Figure 34 and Figure 35. These figures indicate how the pressure changes with axial direction and compare the present computational results with those of numerical and experimental results of [12]. Looking at the plots (Figure 34 andFigure 35) which shows the comparison of the CFD study with that of the experimental and numerical results from the literature, indicate good agreement with both the data with some minor differences. Such differences can be considered as acceptable which are due to several causes such as, numerical errors and grid distribution that has already been discussed previously.

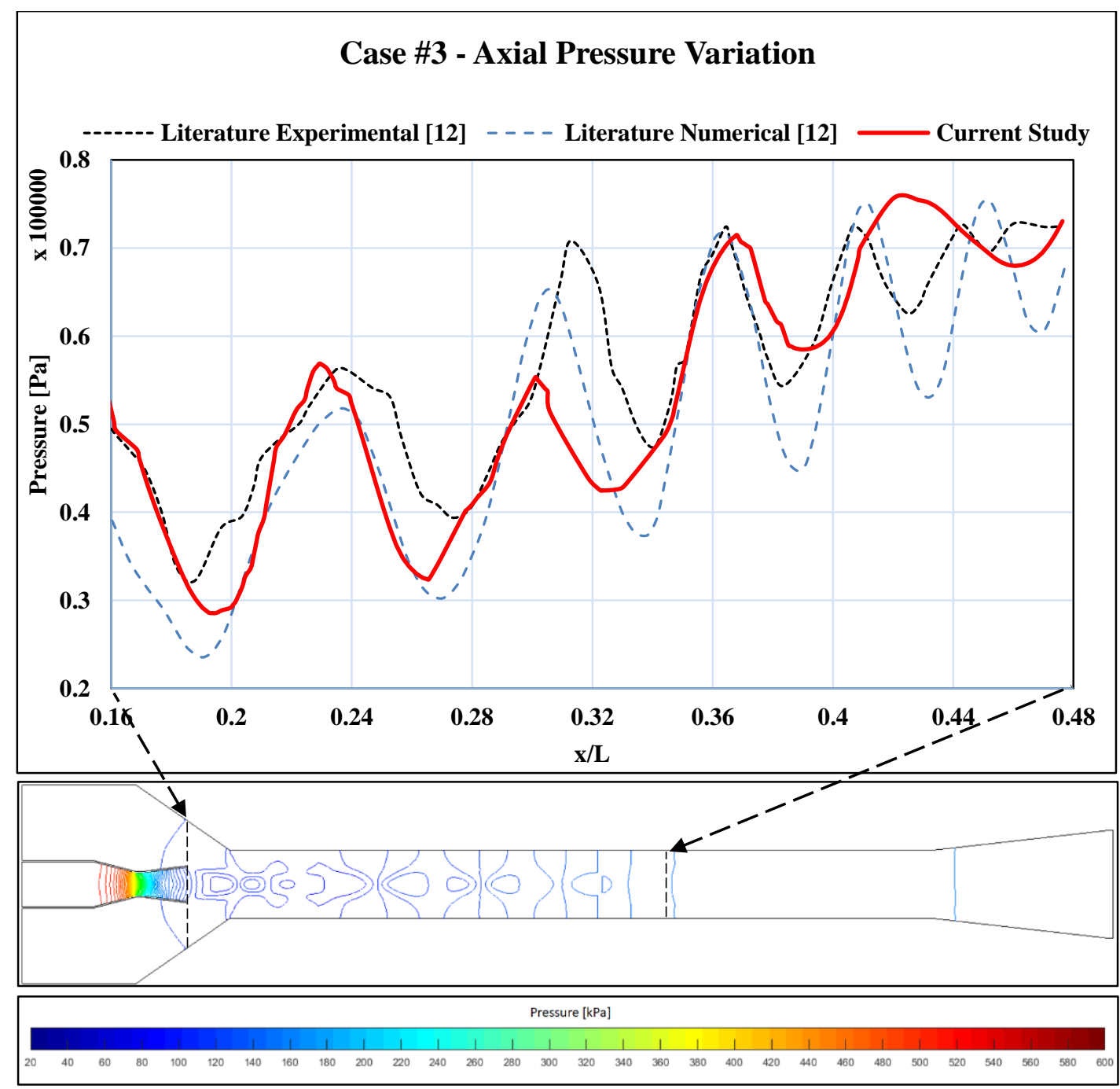

Figure 35. Axial streamline pressure comparison of $P 1=6$ atm test case $\# 3$ with that of the literature values [12] and the corresponding pressure iso-contour 
As a result, one can conclude that, the locations and the magnitude of oscillations for pressure values are captured accurately-enough with only minor shifts and variations. It reveals the practicability of the method for predicting the flow within a supersonic ejector system. 


\section{CHAPTER 4}

\section{RESULTS AND DISCUSSION}

In order to achieve an efficient operation for the ejector, several adjustments to the geometry should (or can) be incorporated [42]. Such adjustments include arranging the proper angles for the diverging or converging sections or proper lengths of corresponding segments of the geometry itself. In this way, effective operation can be reached and performance of the system can be maximized.

Multiple design options are examined and the effect of these variations on the are observed. These design options include the divergence and convergence angles and the lengths of the segments as indicated in Figure 36.

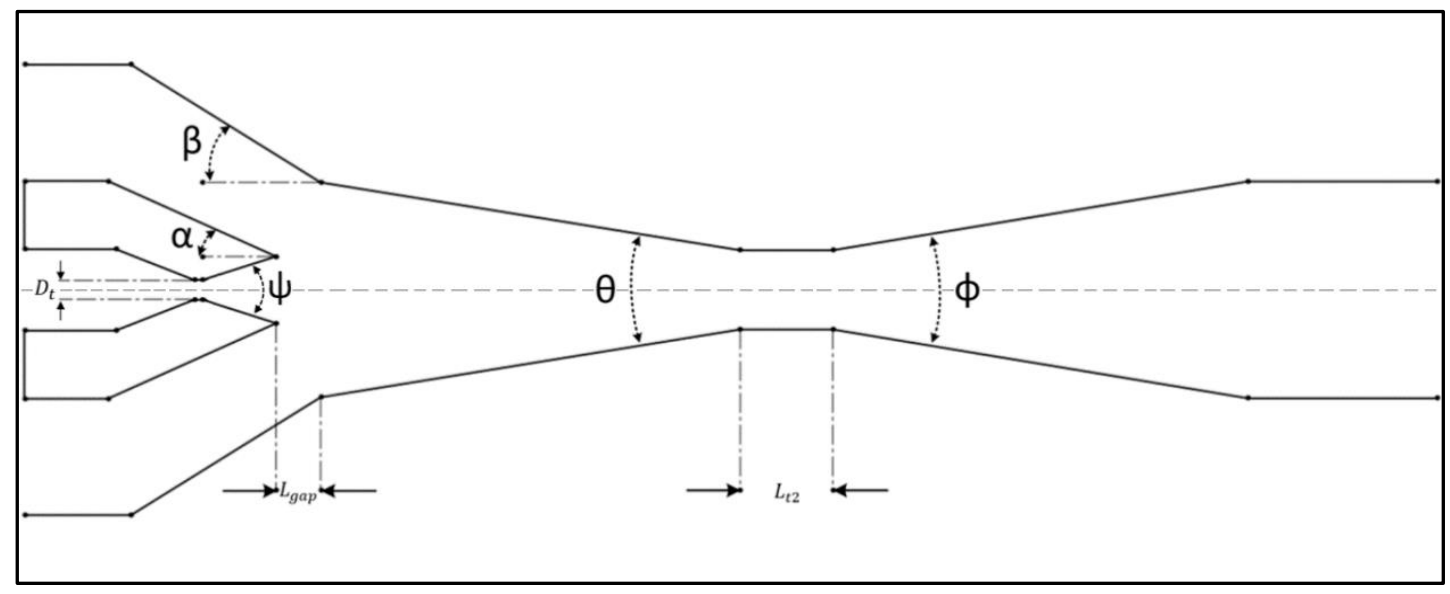

Figure 36. A generic supersonic ejector scheme with study parameters

As it can clearly be observed from Figure 36, these parameters include;

- " $\alpha$ " the "secondary inlet inner-wall angle", 
- " $\beta$ " the "secondary inlet outer-wall angle",

- " $\psi$ " the "nozzle divergence angle",

- " $\theta$ " the "mixing convergence angle",

- " $\phi$ " the "diffuser divergence angle",

- " $L_{g a p}$ " the "gap length" and refers the distance between convergent-divergent nozzle outlet and mixing section inlet,

- " $L_{t 2}$ " the "second throat length" and refers the length of the mixing (second) throat.

- " $D_{t}$ " shows the "diameter of convergent-divergent nozzle throat" and is used for non-dimensionalization (or to obtain relative length ratios).

The parameters are separately varied and their effect on the performance of the system are analyzed to obtain the efficiency of the ejector configuration and in the meantime, to determine the effects of these design parameters on the flow characteristics which primarily can be investigated and commented with the help of the resulting entrainment ratio value and by the Mach contours as well as the pressure iso-contours.

Each parameter is varied keeping the remaining parameters fixed and their individual effects are analyzed. Study is followed by selecting the best case of each modification and analyses of performance including improving the computational cost.

Throughout the study, following ranges of variables are analyzed;

- " $\alpha " \rightarrow$ from $8.91^{\circ}$ to $33.16^{\circ}$

- " $\beta " \rightarrow$ from $16.13^{\circ}$ to $47.94^{\circ}$

- “ $\psi$ " $\rightarrow$ from $21.29^{\circ}$ to $36.01^{\circ}$

- " $\theta$ " $\rightarrow$ from $0.06^{\circ}$ to $0.11^{\circ}$

- “ $\phi " \rightarrow$ from $1.03^{\circ}$ to $5.14^{\circ}$

- “ $\frac{L_{\text {gap }}}{D_{t}}$ ” $\rightarrow$ from 0.30 to 1.48

- “ $\frac{L_{t 2}}{D_{t}}$ ” $\rightarrow$ from 0.59 to 23.67 
These ranges are selected considering the resultant entrainment ratio of the ejector system from the CFD analyses.

\subsection{Computational Mesh Properties}

The properties of the general and the local meshes are presented within the scope of this chapter.

The cross-sectional view of the computational mesh in which a general view as well as the locational zoomed view are presented in Figure 37.

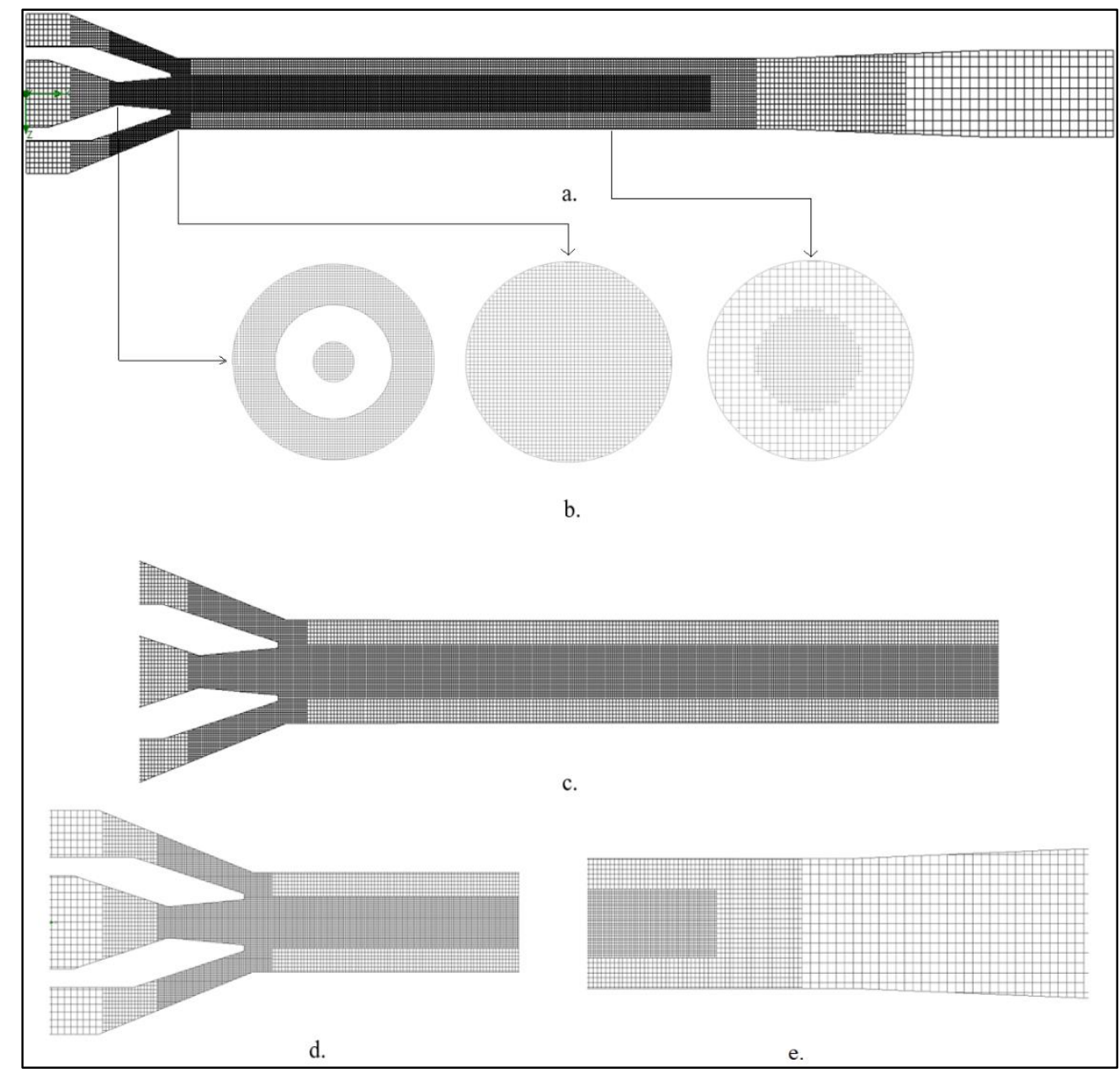

Figure 37. Computational mesh cross-sectional view a. overall view b. cross-sectional views of corresponding locations c. mixing + inlets d. inlets + nozzle + upstream mixing e. mixing throat + upstream diffuser 
Mesh distribution in the system is as shown and the objective geometry is taken from gap length analysis, $1 \mathrm{~mm}$ of gap length trial. As the length/size of the geometry, thus, the mesh distribution varies from case to case, a particular case is selected to demonstrate the computation mesh properties, however, the mesh density of the sections is kept constant. (Though the number of cells vary.) Through this study, the numbers of computational cells are changed between 700000 to 900000 cells during the trials.

The local refinements are implemented to the critical regions of the geometry such as the primary and the secondary inlets, the mixing region. Further refinements in the region where the expansion-compression-oblique waves are pre-expected to be formed (tube-like local refinement, that can be spotted in Figure 37), and the diffuser region.

\subsection{Analyses Results}

In this chapter, effects of the parameters over the performance (entrainment ratio) is investigated both by comparisons of the corresponding Mach number and pressure graphs as well as contours. The study involves both one-dimensional approach and viscous CFD studies.

\subsubsection{Convergent-divergent Nozzle Divergence Angle Analysis $(\Psi)$}

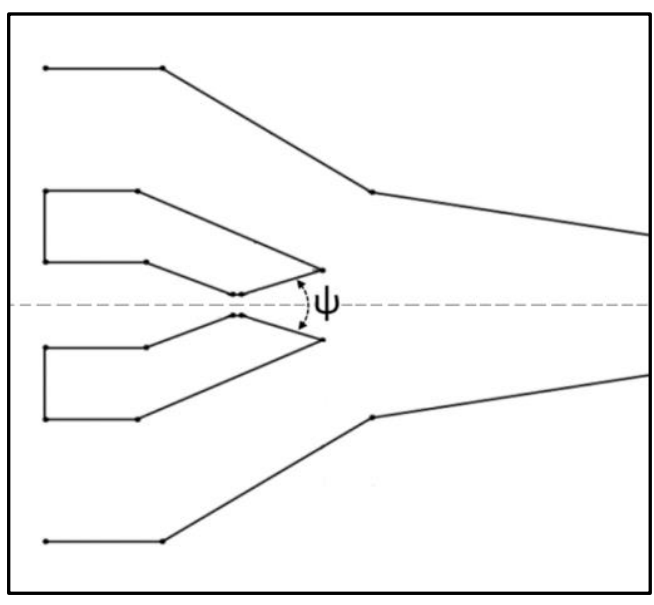

Figure 38. Nozzle divergence angle illustration 
This chapter includes the detailed investigation of convergent-divergent nozzle divergence angle effects over the flow and the performance of the supersonic ejector system, which is shown in Figure 38.

\subsubsection{Entrainment Ratio Analysis}

The resultant entrainment ratio values for corresponding angles is presented as table in Table 8.

Table 8. Entrainment ratio results for the corresponding nozzle divergence angles

\begin{tabular}{|c|c|c|}
\hline $\boldsymbol{\Psi}$ & $\begin{array}{c}\text { CFD Analyses } \\
\text { Entrainment } \\
\text { Ratio (w) }\end{array}$ & $\begin{array}{c}\text { 1-D Approach } \\
\text { Entrainment } \\
\text { Ratio (w) }\end{array}$ \\
\hline $\mathbf{2 1 . 2 9}^{\circ}$ & 1.282 & \multirow{2}{*}{} \\
\cline { 1 - 2 } $\mathbf{2 5 . 0 3}^{\circ}$ & 1.284 & \multirow{2}{*}{1.293} \\
\cline { 1 - 2 } $\mathbf{2 8 . 8 3}^{\circ}$ & 1.284 & \\
\hline $\mathbf{3 2 . 0 3}^{\circ}$ & 1.283 & \\
\hline $\mathbf{3 6 . 0 1}^{\circ}$ & 1.276 & \\
\hline
\end{tabular}

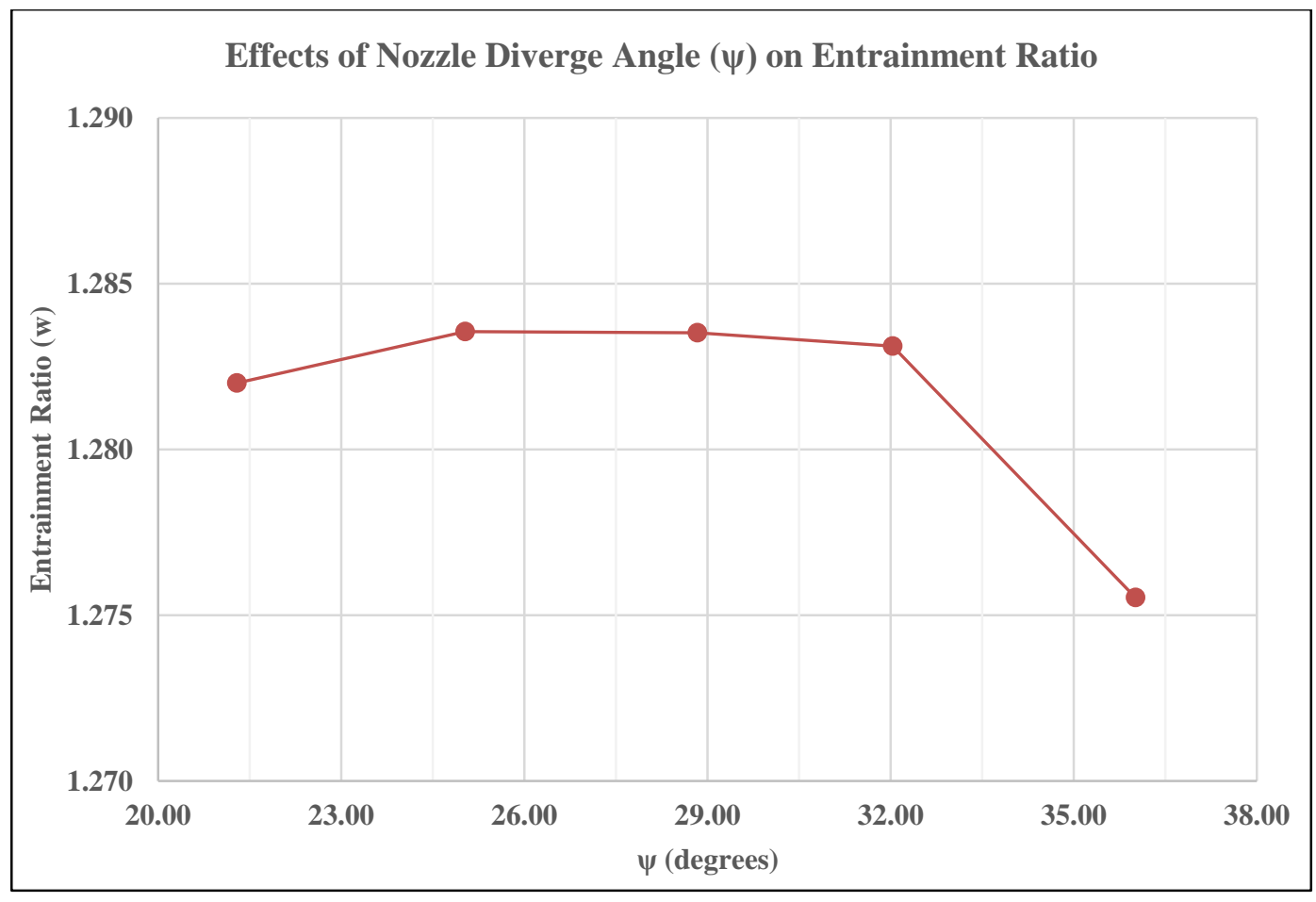

Figure 39. Change of entrainment ratio with nozzle divergence angle 
The corresponding $\psi$ vs entrainment ratio (w) plot where the performance behavior can be examined, is shown for the viscous CFD analyses. As in validation sections, the most effective tool (method of analysis) is selected to be viscous solution of FloEFD, the viscous results are taken into consideration. Looking at the results, (both Table 8 and Figure 39), efficient operational range seems to be in the range of $\sim 25^{\circ}<$ $\psi<\sim 34^{\circ}$.

\subsubsection{Mach Number and Pressure Distribution}

In order to further examine the flow-field, Mach number contours through the system as well as isobars following the start of the mixing process is plotted and compared. More detailed information about the effects of the convergent-divergent nozzle divergence angle to the flow can be observed from Mach number and pressure variations.

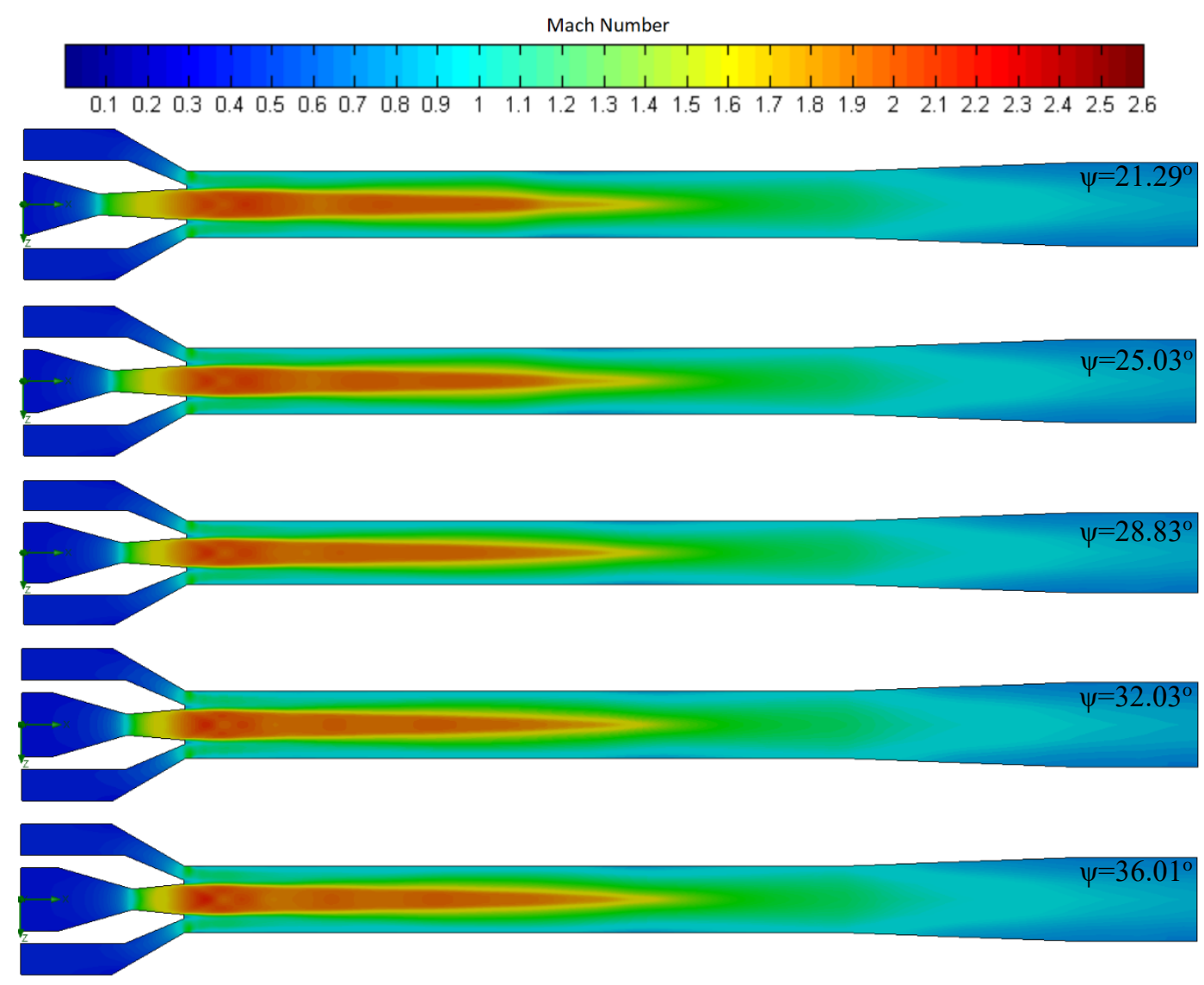

Figure 40. Mach number contours for the given nozzle divergence angles 
As it can be seen from the Mach number contours (Figure 40) there occurs almost no observable effect on Mach number among such different angles, apart from the slight variation of the expansion-compression patterns. In order to reveal these changes, Mach variation through the central streamline is plotted for the entire cases within the same graph and shown in Figure 41.

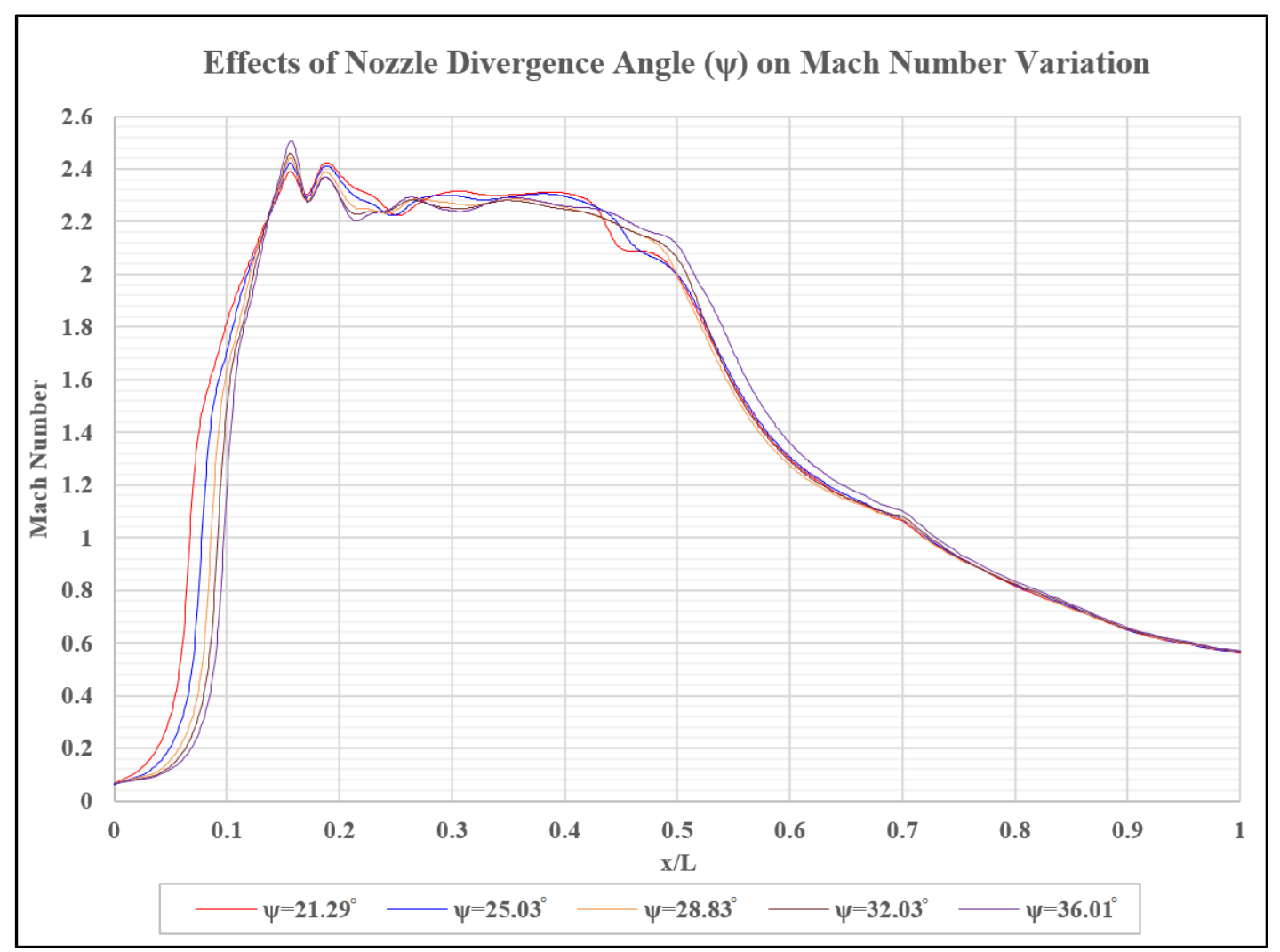

Figure 41. Effects of nozzle divergence angle on Mach number variation along the centerline

Looking at the Mach number vs $\mathrm{x} / \mathrm{L}$ plot (Figure 41), variation of the number and the location of oscillations caused by the expansion-compression waves can be observed further in detail. Following the first two common patterns, locations of the oscillations as well as the amount varies slightly due to different radial velocities of the flow exiting the nozzle from case to case, caused by different divergence angles. Generally, it is accepted that the lesser the radial velocity exiting the nozzle, the more uniform the flow gets. Although in such ejector applications, it may help the mixing of the primary and the secondary flow streams more efficiently. 
Agreeing with the expectations, the results seems to show that an efficient range of nozzle divergence angle should be arranged in order to prevent large amounts of radial velocity of the flow exiting the nozzle (defines the upper limit of $\psi$ ) and in the meantime, to pave the way of efficient mixing process of the primary and the secondary flows (defines the lower limit of $\psi$ ).

The pressure variation of the flow inside the system is also examined as isobars, especially following the start of the mixing process and is plotted in Figure 42.

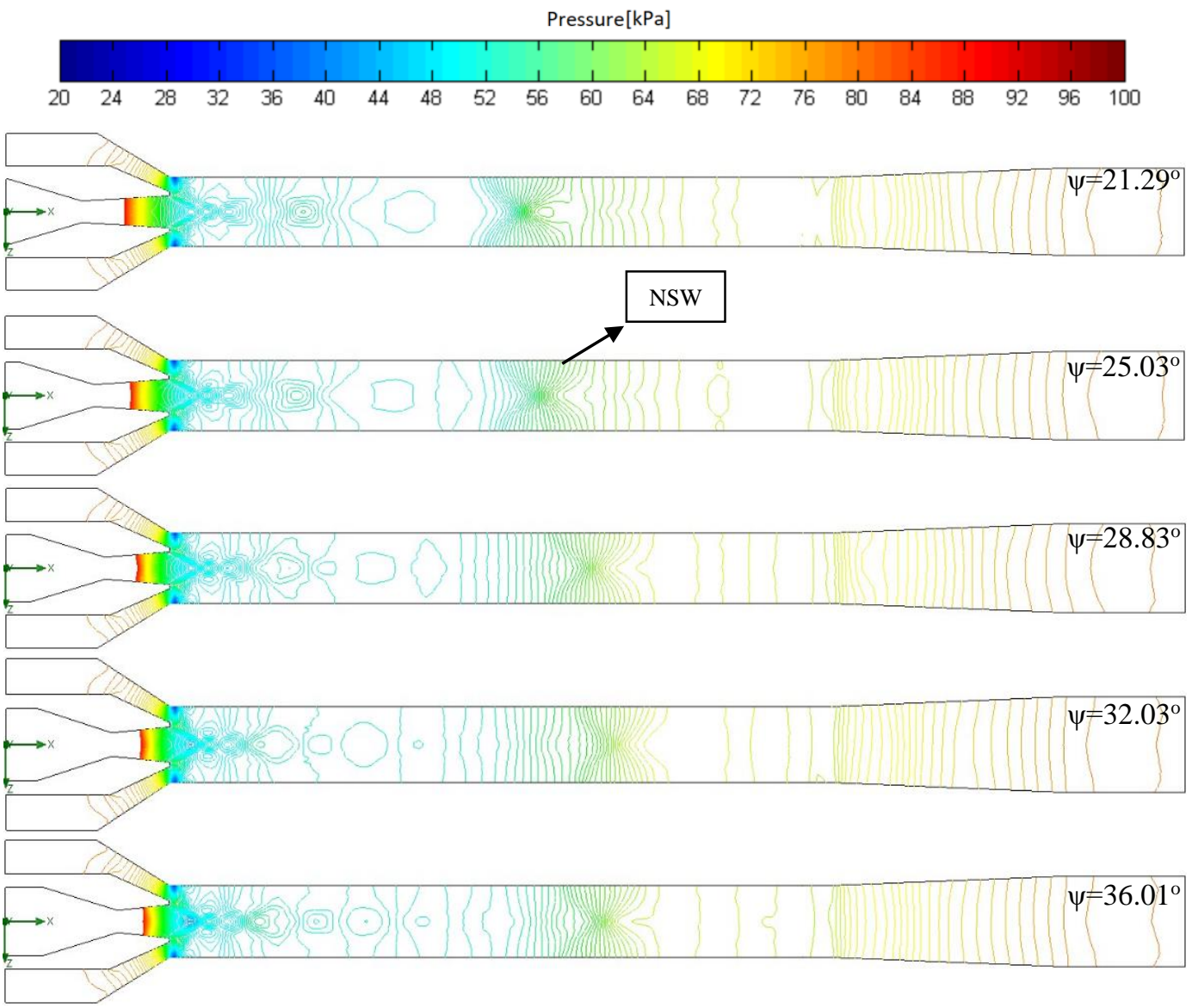

Figure 42. Pressure iso-contours for the corresponding nozzle divergence angles

As one can see from the Figure 42, there are slight changes between these cases. It can be concluded that, higher angles nozzle divergence angles result in quicker mixing, pressure balancing and a large number of expansion-compression patterns, whereas lower angles result in the opposite behaviors. 
It must be noticed that in Figure 42, the legend for pressure variation is limited to 20k100k Pascal in order to observe the mixing and balancing process more clearly and precisely.

Furthermore, pressure variation through the centerline streamline is also plotted in order to ascertain the analysis, which can be spotted in Figure 43. Similarly, slight shifts of the locations of oscillation can be observed from pressure [Pa] vs $\mathrm{x} / \mathrm{L}$ plot in Figure 43.

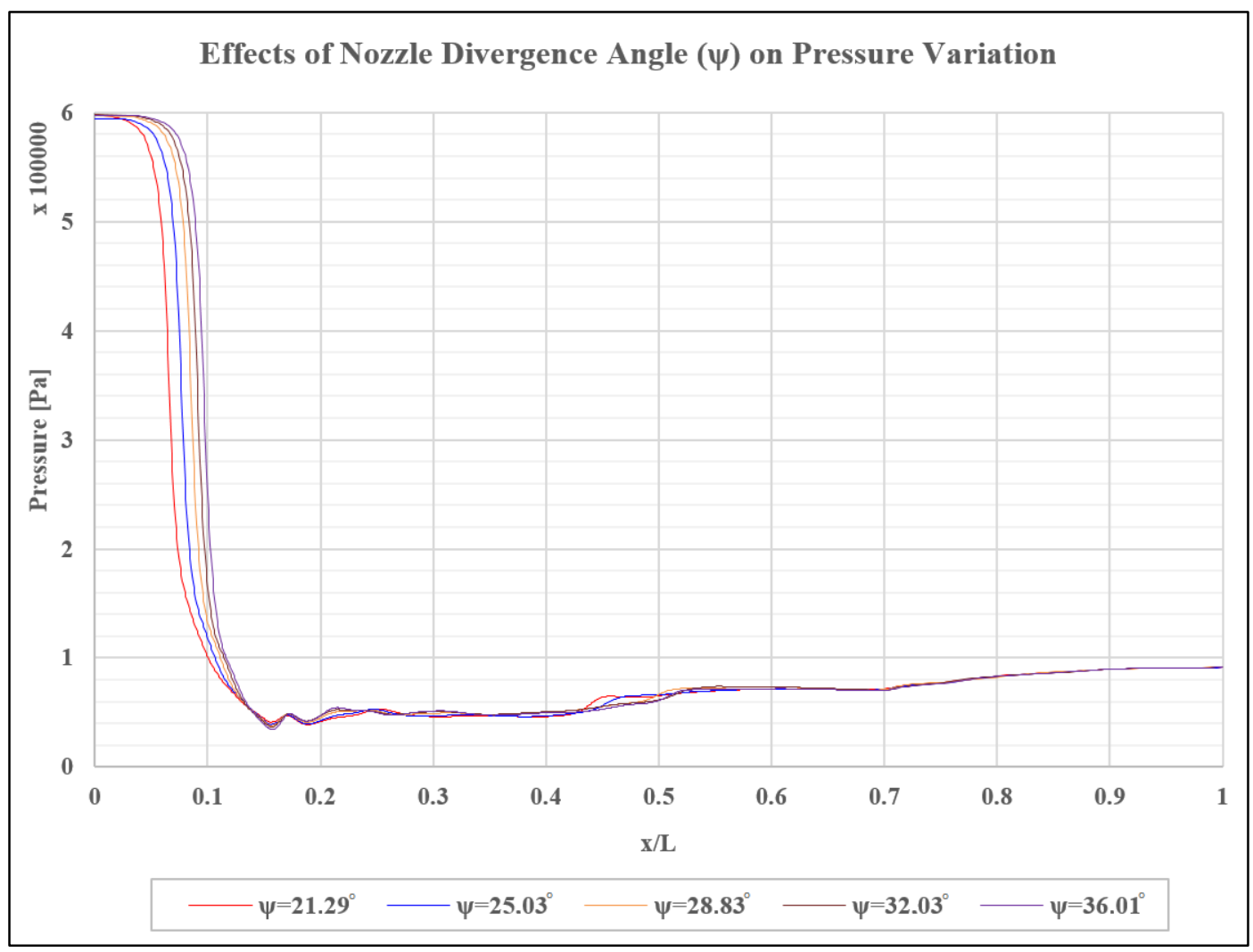

Figure 43. Effects of nozzle divergence angle on pressure variation along the centerline

\subsubsection{Conclusion}

For the whole study, (including entrainment ratio, computational performance, Mach and pressure results) the best and most effective operation is reached for $\psi=32.03^{\circ}$ and is selected for the study and corresponding entrainment ratio is obtained to be 1.283. In the meantime, the efficient operational range is obtained for $25^{\circ}<\psi<34^{\circ}$. 


\subsubsection{Secondary Inlet Inner-wall Angle Analysis ( $\alpha$ )}

In this section, a detailed investigation of the secondary inlet inner-wall angle effects over the flow itself and over the efficiency of the supersonic ejector system, shown as a zoomed view in Figure 44, is performed.

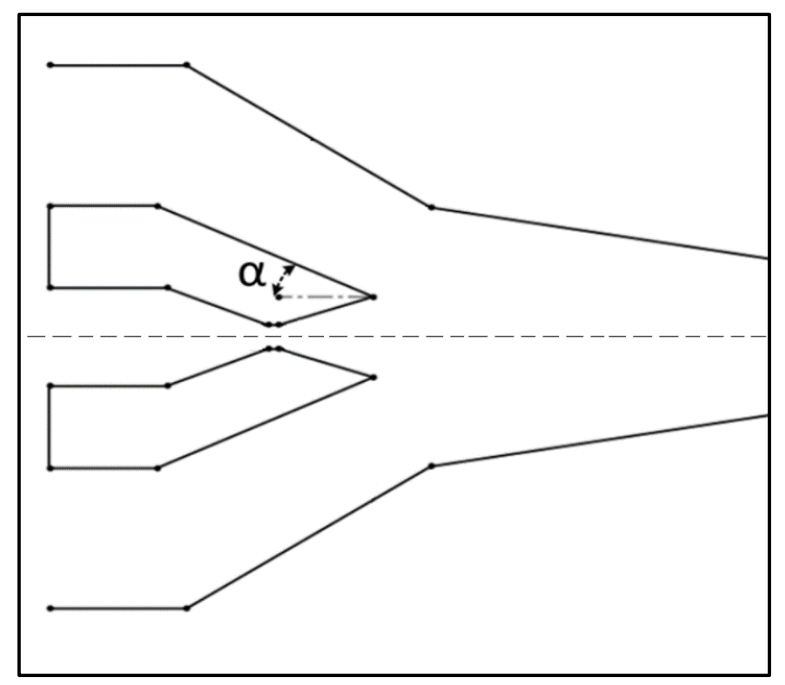

Figure 44. Secondary inlet inner-wall angle illustration

\subsubsection{Entrainment Ratio Analysis}

Entrainment ratio (w) results for the viscous (real wall) CFD studies as well as onedimensional approach is presented in Table 9. The plot of $\alpha$ vs entrainment ratio is plotted, in order to observe and compare the effects clearly.

Table 9. Entrainment ratio results for the corresponding secondary inlet inner-wall angles

\begin{tabular}{|c|c|c|}
\hline $\boldsymbol{\alpha}$ & $\begin{array}{c}\text { CFD Analyses } \\
\text { Entrainment } \\
\text { Ratio (w) }\end{array}$ & $\begin{array}{c}\text { 1-D Approach } \\
\text { Entrainment } \\
\text { Ratio (w) }\end{array}$ \\
\hline $\mathbf{8 . 9 1}^{\circ}$ & 1.311 & \multirow{2}{*}{} \\
\cline { 1 - 2 } $\mathbf{1 0 . 5 7}^{\circ}$ & 1.306 & \multirow{2}{*}{1.293} \\
\hline $\mathbf{1 6 . 7 8}^{\circ}$ & 1.311 & \\
\hline $\mathbf{2 3 . 5 4}^{\circ}$ & 1.283 & \\
\hline $\mathbf{3 3 . 1 6}^{\circ}$ & 1.198 & \\
\hline
\end{tabular}


Looking at the results showing the numerical data (Figure 45), a sharp critical point around $\alpha=16$ degrees can clearly be spotted. Further increase in the angle results performance reduction. One-dimensional approach does not exhibit this behavior and predicts the average of whole cases, as can be observed from Table 9.

One can also observe that the effective range of the secondary inlet inner wall angle for design purposes is taken as $\sim 12^{\circ}<\alpha<\sim 18^{\circ}$ for the entrainment ratio. (Figure 45)

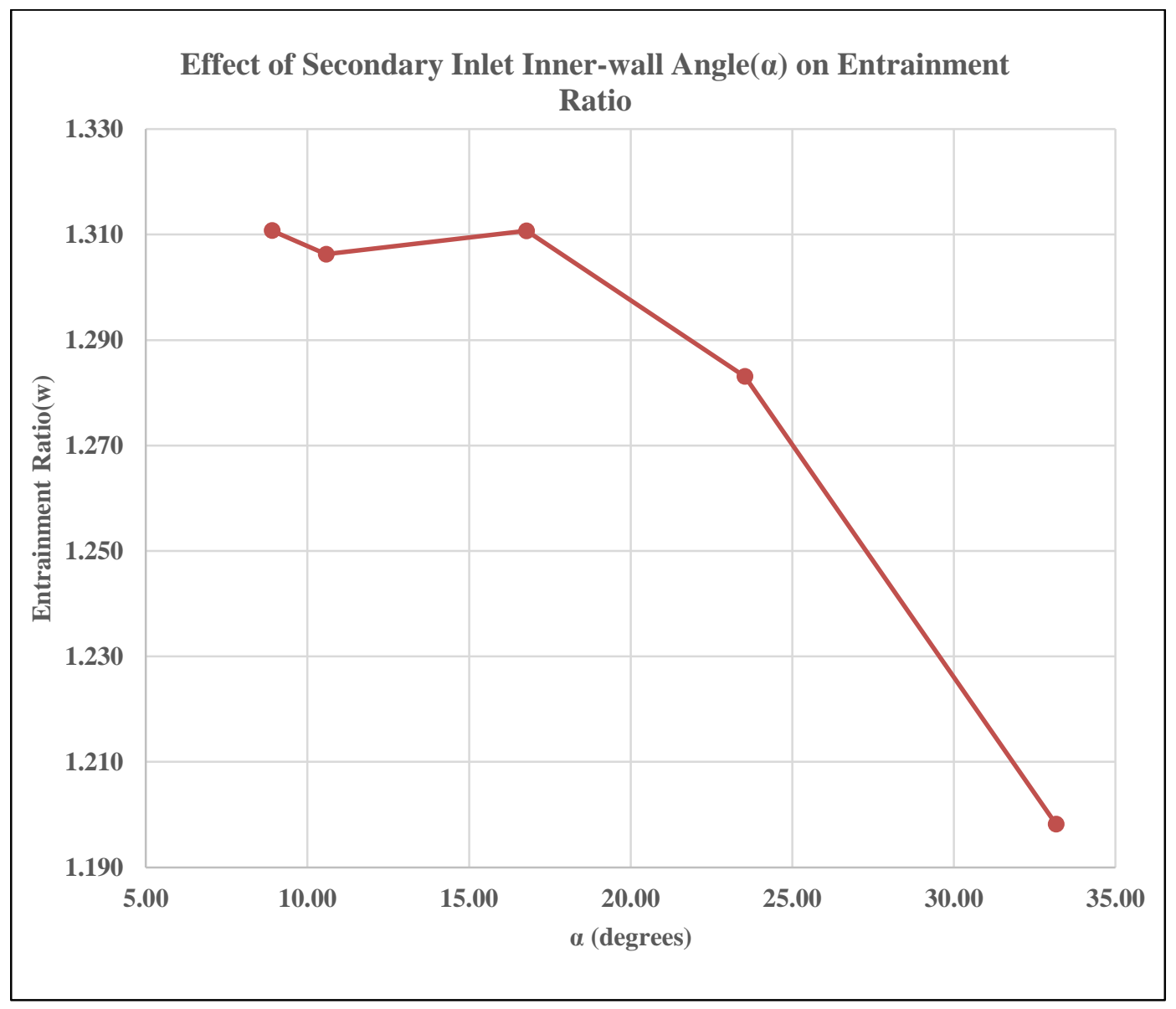

Figure 45. Change of entrainment ratio with secondary inlet inner-wall angle

\subsubsection{Mach Number and Pressure Distribution}

After the entrainment ratio investigation, aero-thermodynamic flow properties are also examined in detail. Mach number contours for each angle $\alpha$ case is presented in Figure 46. Figure 48 shows the corresponding pressure distributions for the same conditions. 
Looking at the Mach contours, one can conclude that the higher the angle $\alpha$ gets, the lower the velocity of the primary flow jet becomes. This may possibly due to the increase in the angle giving more inclined secondary stream that may prevent (block) the primary flow to proceed further developing. Thus, lower velocities are acquired which can be observed in Figure 46.

Mach number variation along the central streamline is plotted for all cases, for close inspection, as shown in Figure 47. Looking at this plot, especially to the first pattern, same comment that higher $\alpha$ results lower velocity can be deduced.

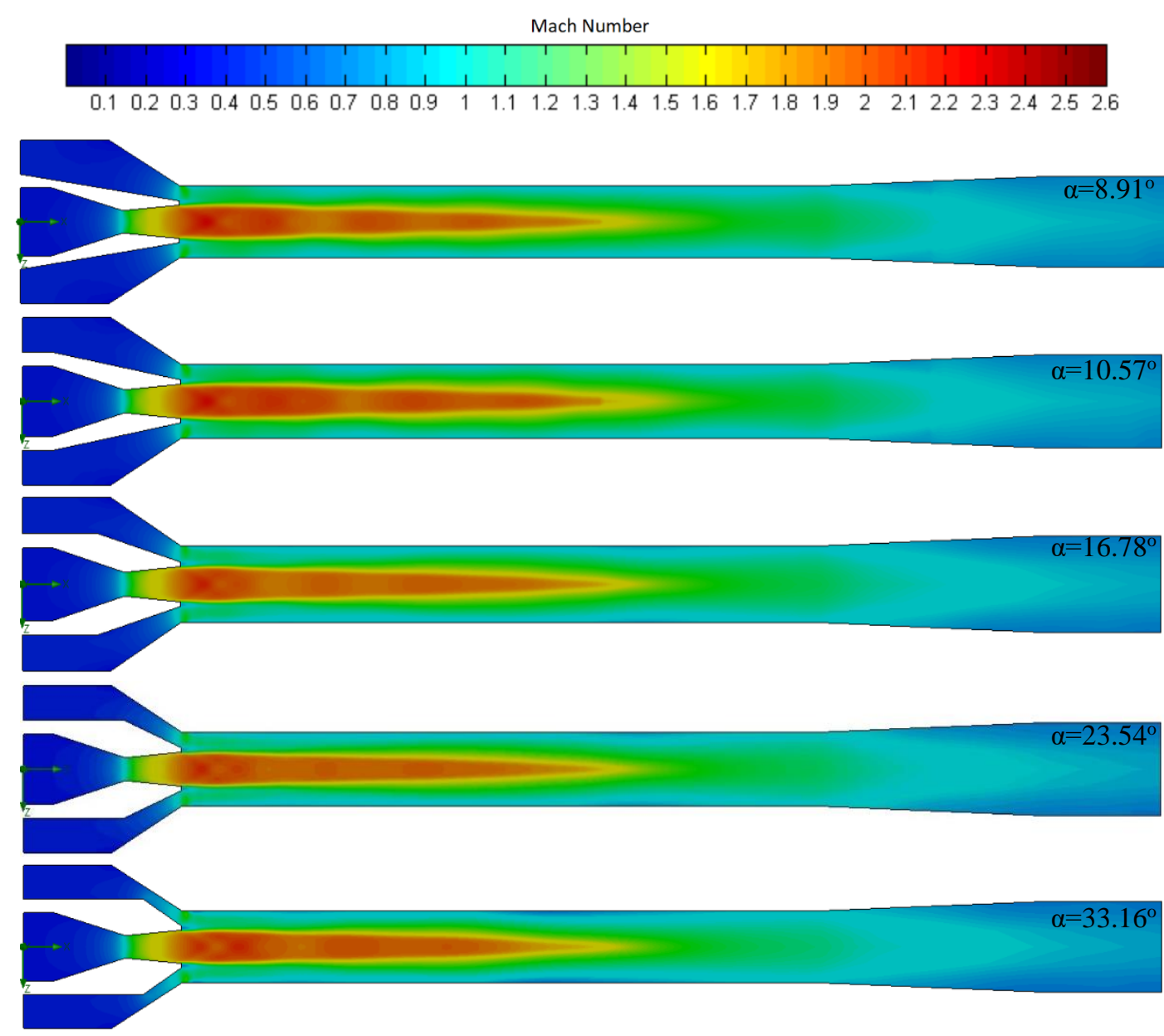

Figure 46. Mach number contours for the corresponding secondary inlet inner-wall angles

Moreover, completely different behavior of mixing for each case can be observed, so it can be concluded that, the radial velocity of the secondary flow or the inclined 
secondary stream has an important effect on the flow properties itself, mixing process as already discussed previously in the entrainment performance section.

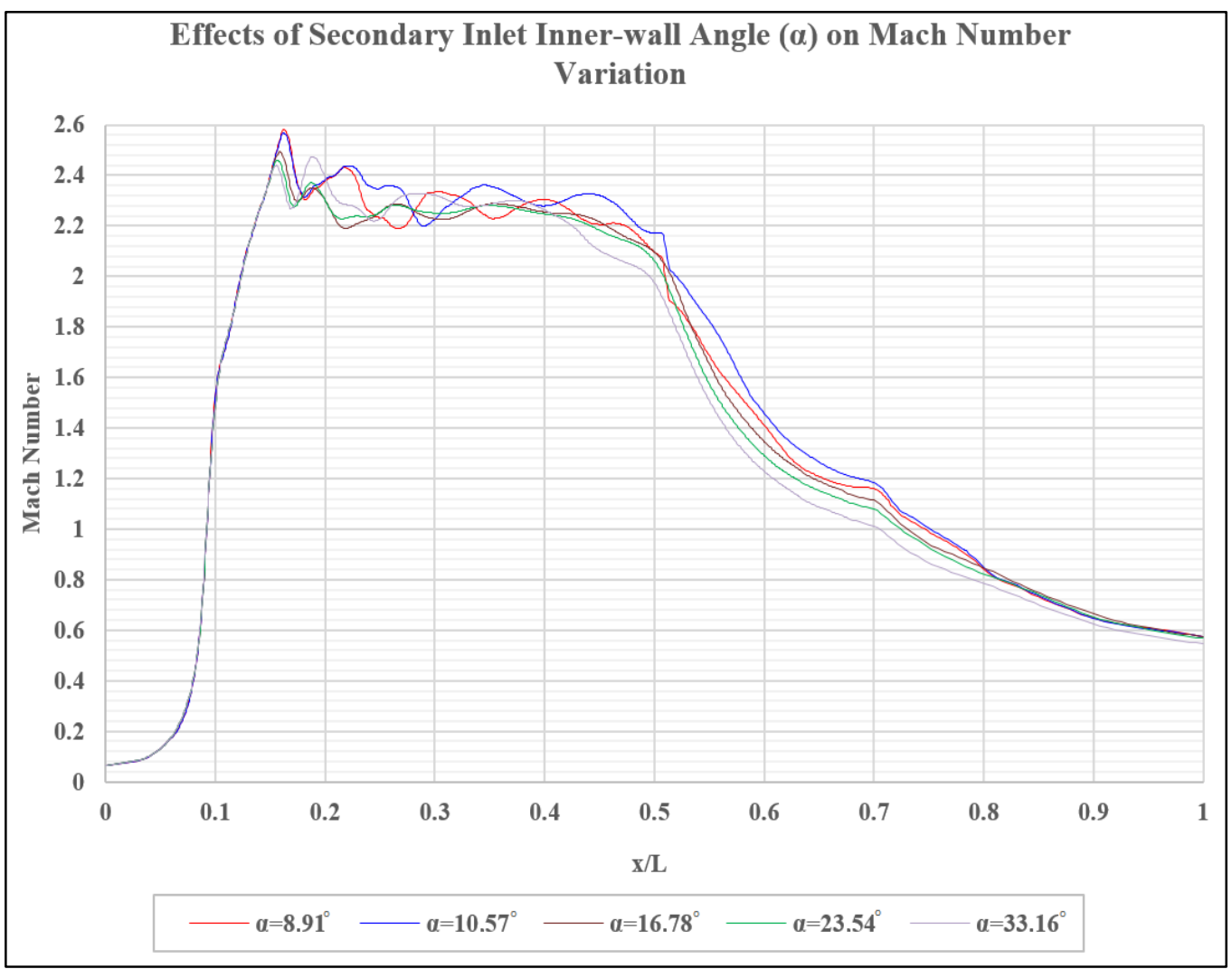

Figure 47. Effects of secondary inlet inner-wall angle on Mach number variation along the centerline

Pressure variation within the system is also studied, and presented as isobars especially within region where the mixing process and pressure recovery is taking place, as well as the plot of pressure variation along the centerline.

As it can clearly be observed from the isobar plots (Figure 48), which is also similar to what was discussed earlier, higher $\alpha$ results in lower velocities, thus higher pressure of the primary stream such that the pressure are developed earlier and earlier mixing can be observed.

This is also the reason for the decreasing entrainment ratio behavior, as the pressure of the vacuum region is increased, such that the entrainment performance is decreased. 


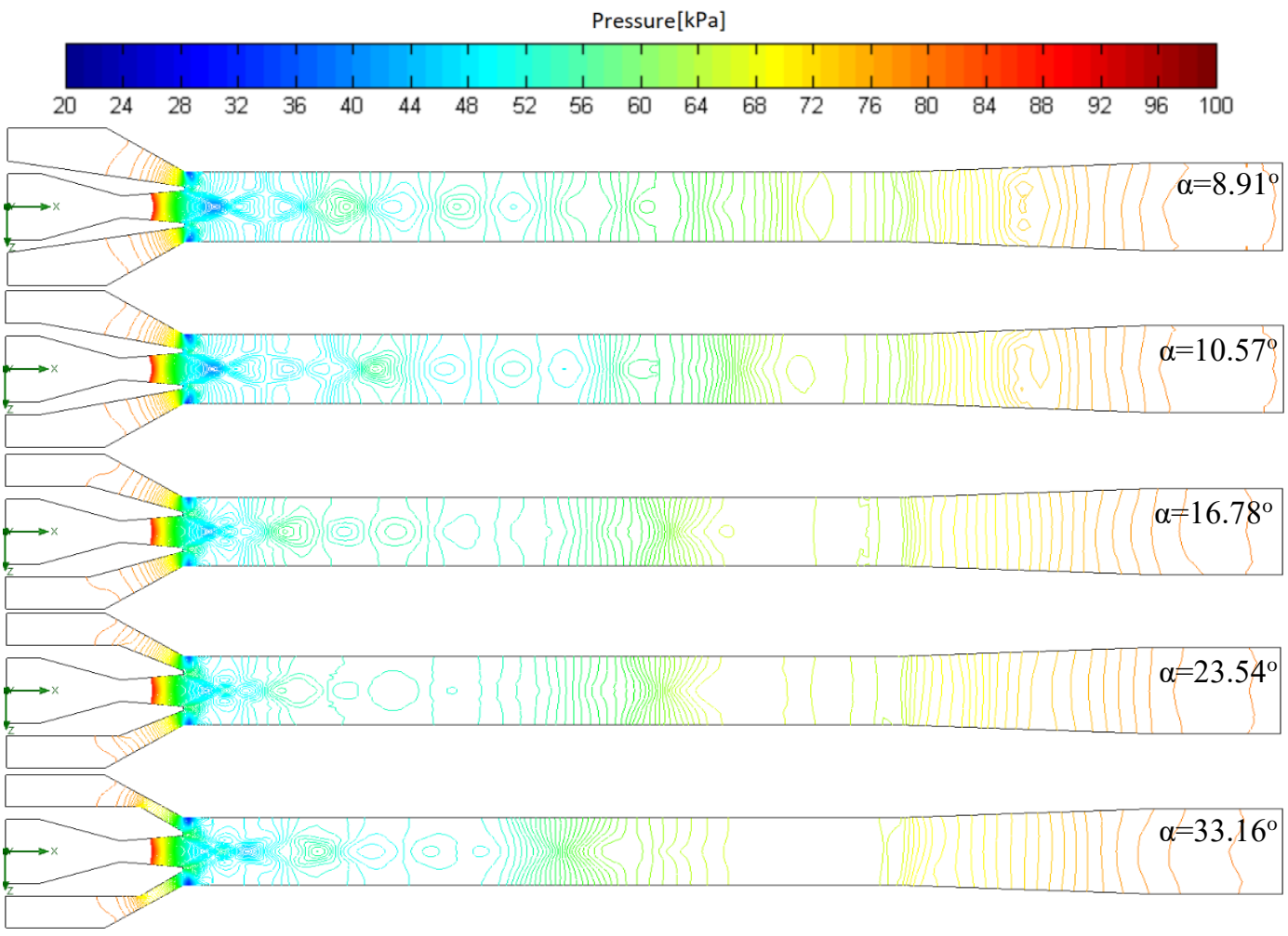

Figure 48. Pressure iso-contours for the corresponding secondary inlet inner-wall angles

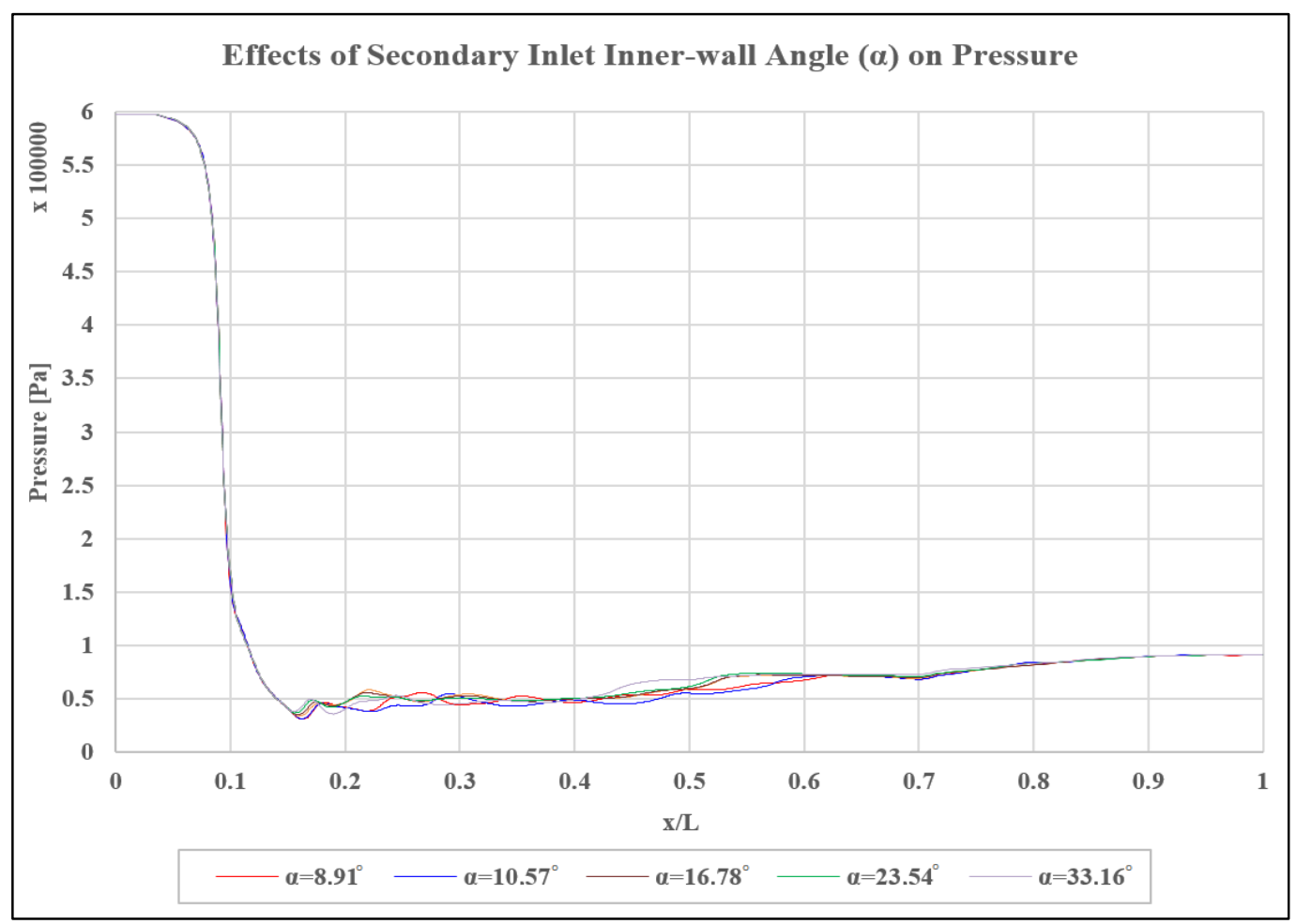

Figure 49. Effects of secondary inlet inner-wall angle along the centerline pressure variation 
Also, as the pressure difference between the primary and the secondary streams becomes larger for low values of $\alpha$, these pressure oscillations (caused by expansioncompression waves) in aero-thermodynamic behaviors of the flow is expected to be stronger, which can be observed from the pressure variation plot shown in Figure 49.

The variation of the centerline pressure versus the non-dimensional $\mathrm{x} / \mathrm{L}$ distance along the downstream direction of the ejector is presented in Figure 49.

\subsubsection{Conclusion}

All these results indicate that the best case for higher entrainment ratio, computational performance and stable mixing process is selected as $\alpha=16.78^{\circ}$ and the entrainment ratio is found to be 1.311. It can also be said that, influential entrainment performance is acquired within the range of secondary inlet inner-wall angle for $\sim 12^{\circ}<\alpha<\sim 18^{\circ}$.

\subsubsection{Secondary Inlet Outer-wall Angle Analysis ( $\beta$ )}

The effect of the outer-wall for the secondary inlet angle is studied and examined, as shown in Figure 50. The effect over the aero-thermodynamic behavior of the fluid can be analyzed.

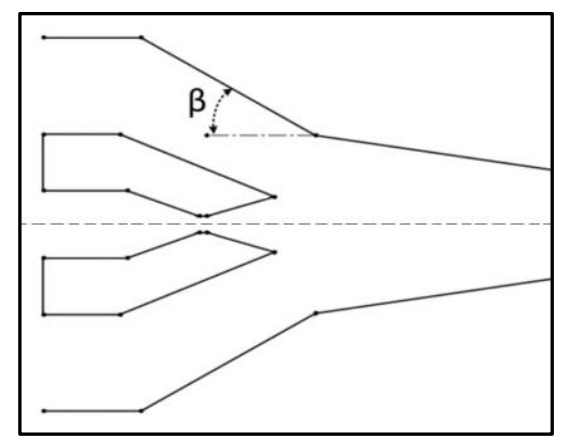

Figure 50. Secondary inlet outer-wall angle illustration

\subsubsection{Entrainment Ratio Analysis}

The results can be observed from Table 10, for numerical analyses as well as the 1-D code outputs. The values in Table 10 are plotted as entrainment ratio vs $\beta$ in Figure 51. 
Table 10. Entrainment ratio results for the corresponding secondary inlet outer-wall angles

\begin{tabular}{|c|c|c|}
\hline $\boldsymbol{\beta}$ & $\begin{array}{c}\text { CFD Analyses } \\
\text { Entrainment } \\
\text { Ratio (w) }\end{array}$ & $\begin{array}{c}\text { 1-D Approach } \\
\text { Entrainment } \\
\text { Ratio (w) }\end{array}$ \\
\hline $\mathbf{1 6 . 1 3}^{\circ}$ & 1.302 & \multirow{2}{*}{} \\
\cline { 1 - 2 } $\mathbf{2 0 . 2 8}^{\circ}$ & 1.320 & \multirow{2}{*}{1.293} \\
\hline $\mathbf{2 5 . 4 1}^{\circ}$ & 1.320 & \\
\hline $\mathbf{3 1 . 1 6}^{\circ}$ & 1.311 & \\
\hline $\mathbf{3 6 . 4 6}^{\circ}$ & 1.297 & \\
\hline $\mathbf{4 7 . 9 4}^{\circ}$ & 1.263 & \\
\hline
\end{tabular}

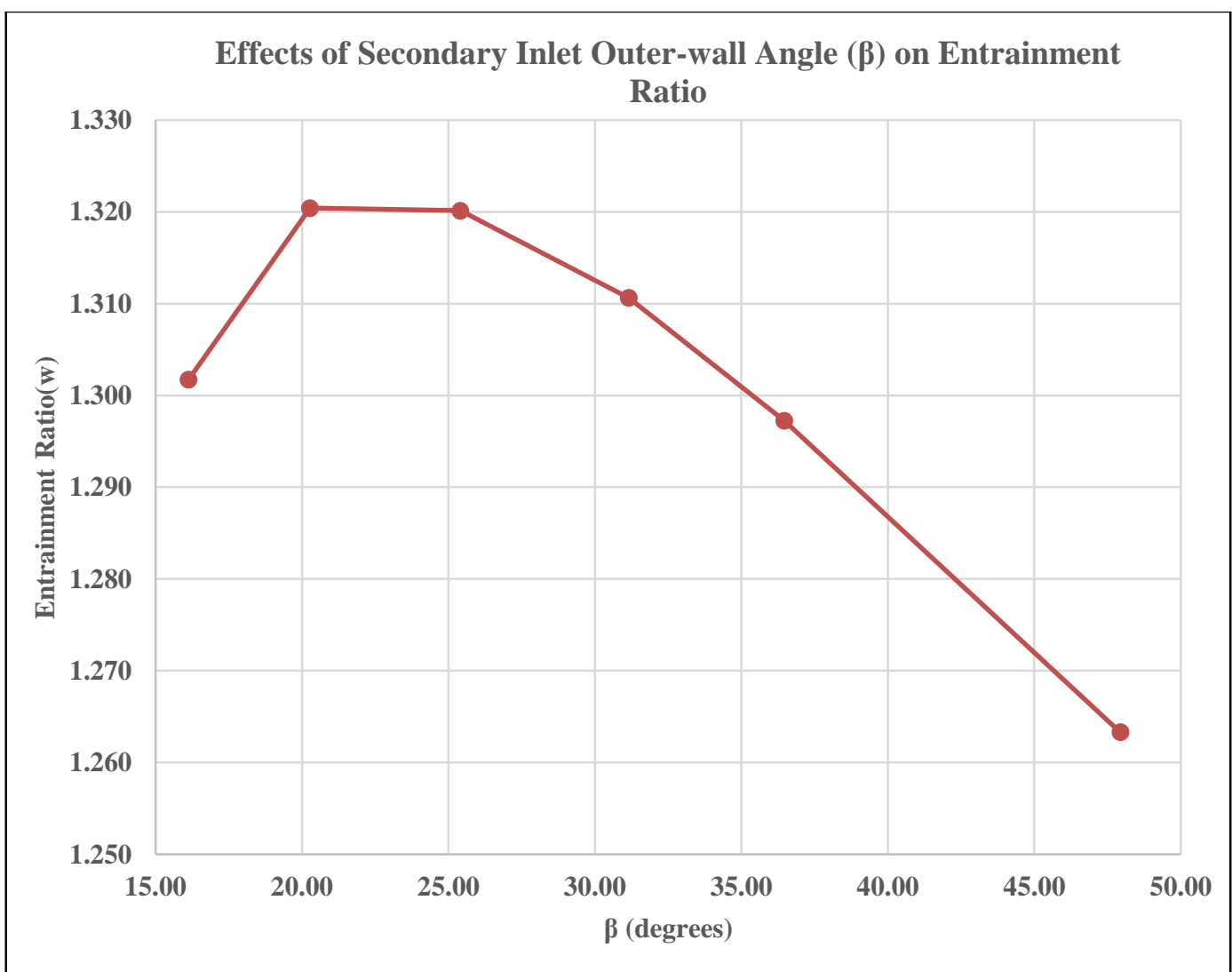

Figure 51. Change of entrainment ratio with secondary inlet outer-wall angle

As one can clearly observe from Figure 51, there forms an efficient entrainment ratio range between $\sim 18^{\circ}<\beta<\sim 30^{\circ}$ for the whole CFD analyses. For entrainment ratio, the 
maximum entrainment ratio is obtained for the secondary inlet outer-wall angle of $\beta=20.28^{\circ}$.

\subsubsection{Mach Number and Pressure Distribution}

In order to obtain finer and more detailed information, the Mach contours of each trial as well as the pressure iso-contours are plotted for the entrainment ratios, shown in Figure 52 andFigure 54.

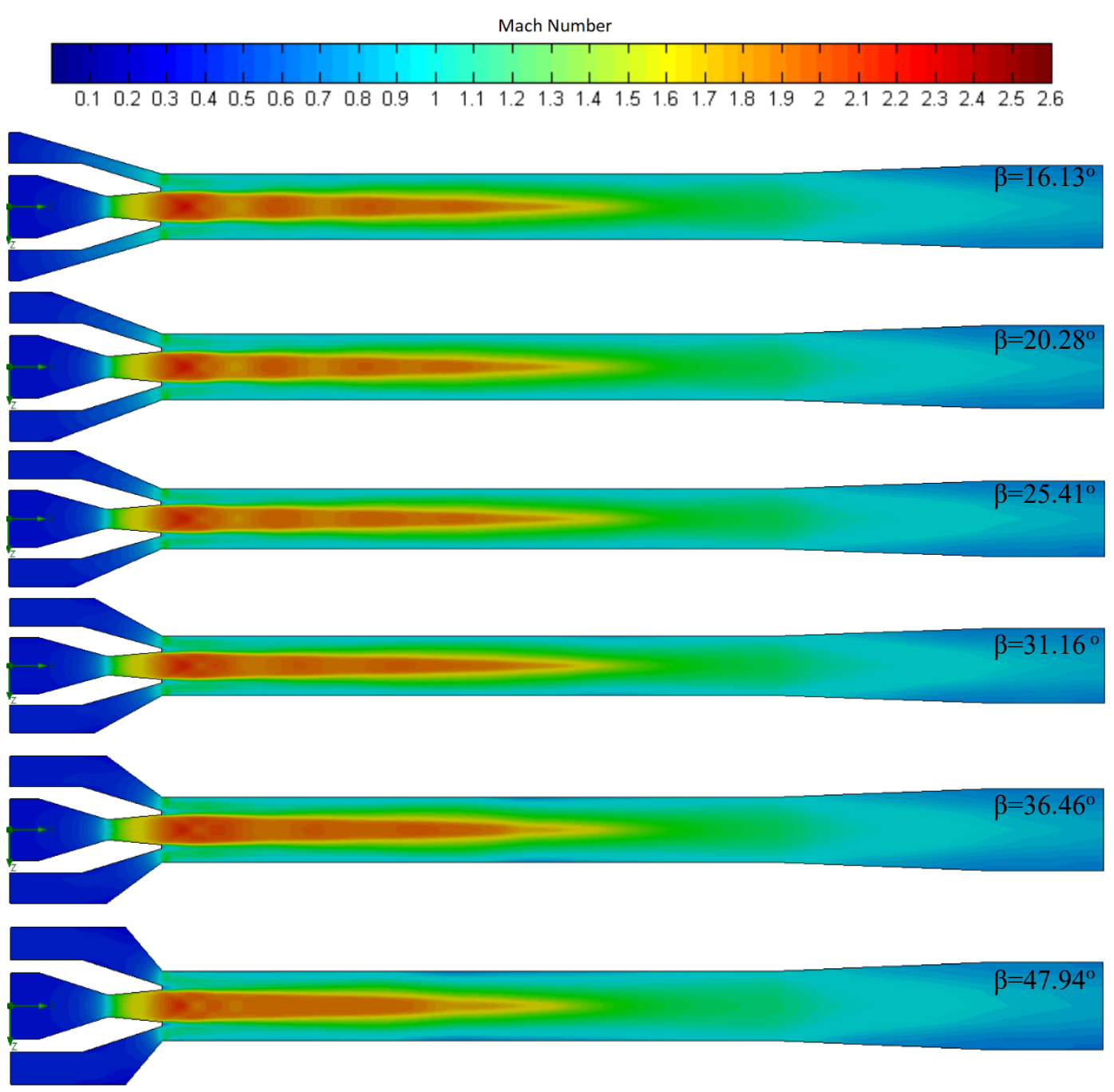

Figure 52. Mach number contours for the corresponding secondary inlet outer-wall angles

Similar to the previous section studies, the secondary inlet outer-wall angle $\beta$ has significant effects and limitations on the velocity and pressure distribution, over the 
primary stream jet. This can be explained the same way as the effect of angle $\alpha$, and the blockage of the secondary stream to the primary flow. The radial velocity of the secondary flow arises with increasing angle $\beta$.

The plot of Mach number as a function of $\mathrm{x} / \mathrm{L}$ along the central line for all values are graphed in Figure 53.

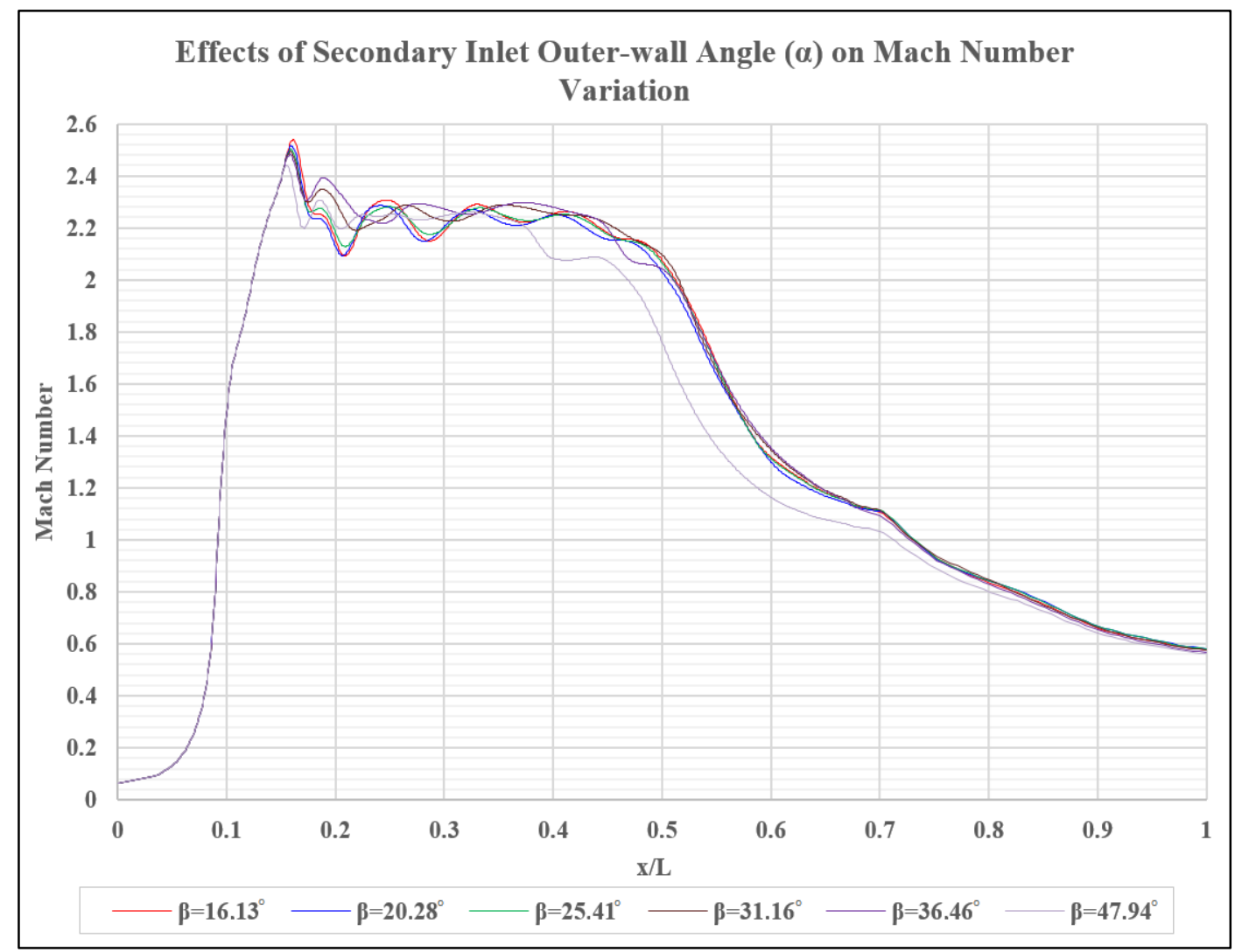

Figure 53. Effects of secondary inlet outer-wall angle on Mach number variation along the centerline

The pressure iso-contours within the critical region of the system is plotted in Figure 54. Similar comments can be made for pressure distributions. Patterns and mixing periods can be observed from these plots.

With increasing $\beta$ values, the difference between the primary and the secondary air stream is increased and the effect is demonstrated visually on the pressure distributions. 
The limitations on the pressure legend (from 20k to $100 \mathrm{k}$ Pascal) is set in order to capture more precisely the information of pressure variation through the mixing and discharging process of the flow.
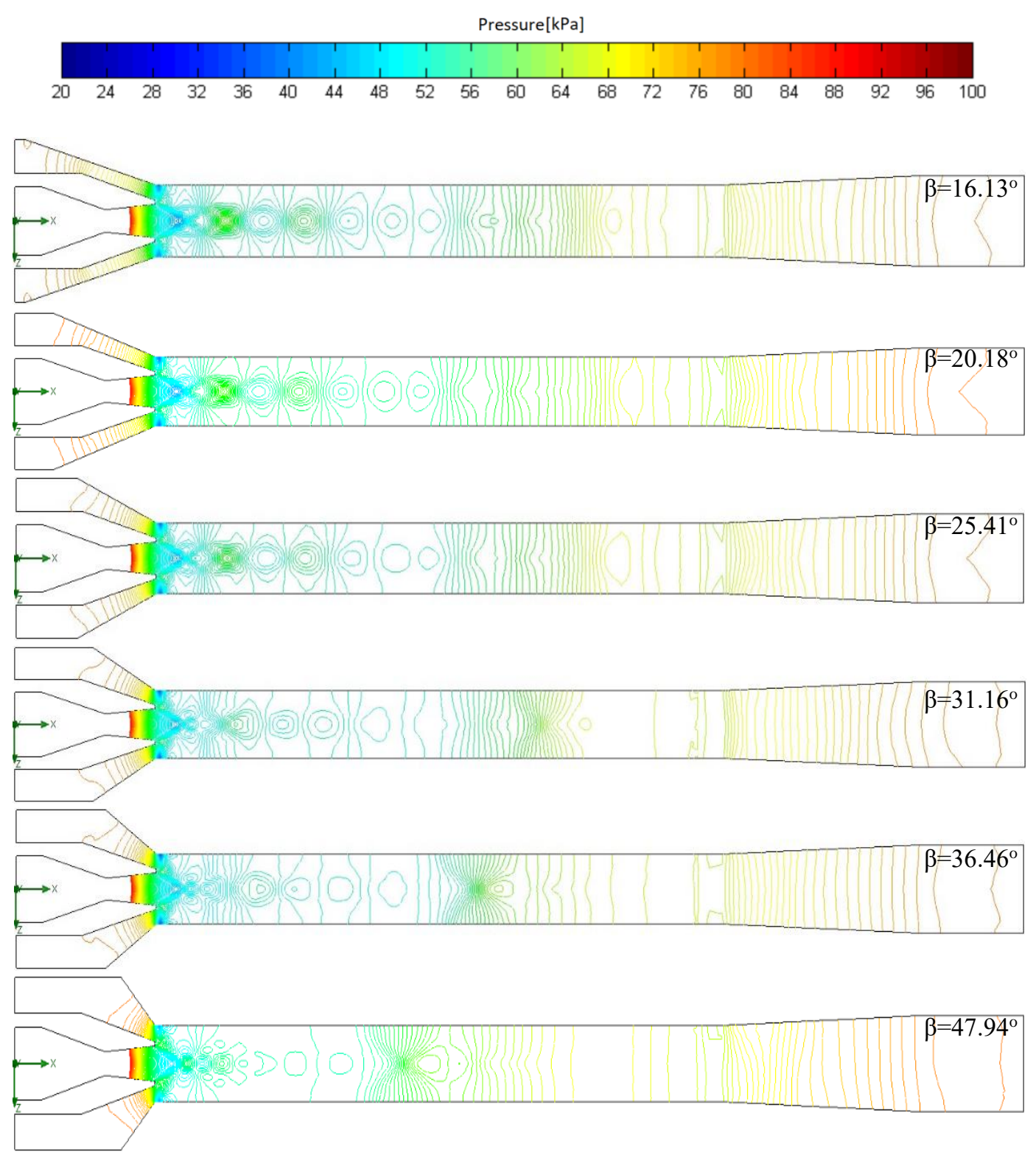

Figure 54. Pressure iso-contours for the corresponding secondary inlet outer-wall angles

The pressure behavior of the flow along the centerline is plotted in Figure 55. Looking at the plot, higher values of vacuum for lower values of $\beta$ can clearly be observed. 
Therefore, the higher performance of the ejector system is expected to occur with the lower values of $\beta$. This comment is partially shown in the entrainment ratio section except for the angles lower than $\sim 18^{\circ}$ (i.e. $\beta<\sim 18^{\circ}$ ).

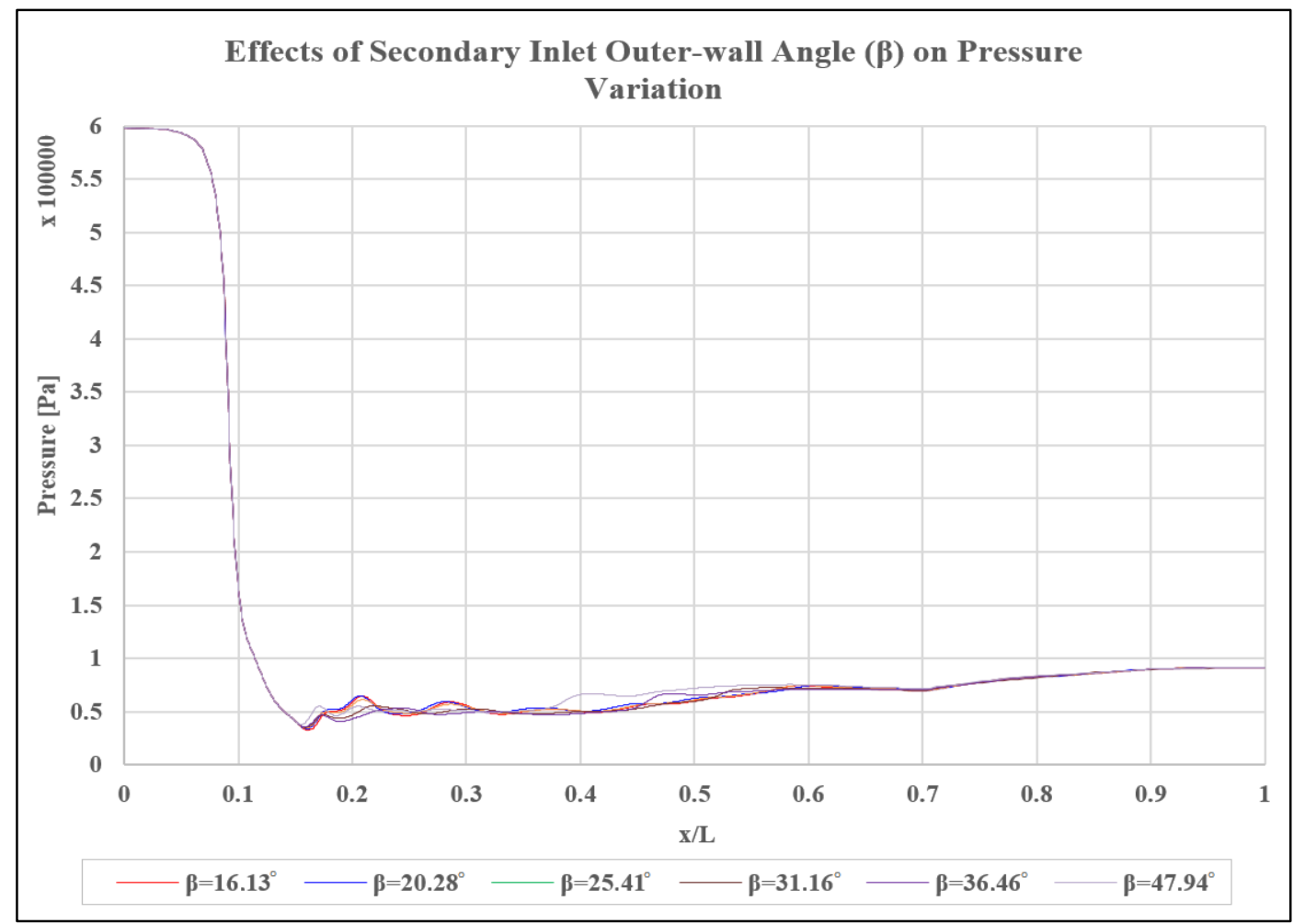

Figure 55. Effects of secondary inlet outer-wall angle along the centerline pressure variation

\subsubsection{Conclusion}

The secondary inlet outer-wall angle $(\beta)$ is concluded to give the best case for an efficient operation, is selected for value of $\beta=20.28^{\circ}$ degrees with corresponding entrainment ratio of 1.320 . The range of $\sim 18^{\circ}<\beta<\sim 30^{\circ}$ is observed to be an efficient operational range.

\subsubsection{Gap Length Analysis $\left(L_{g a p}\right)$}

In this part of the study, the distance between the exit of the convergent-divergent nozzle and the start of the mixing chamber, is called the "gap length" and is shown in Figure 56. 
This distance effects significantly the behavior of the flow inside the mixing region [18]. The effect of this distance will be investigated and the effective operational range and the entrainment ratio maximization will be performed.

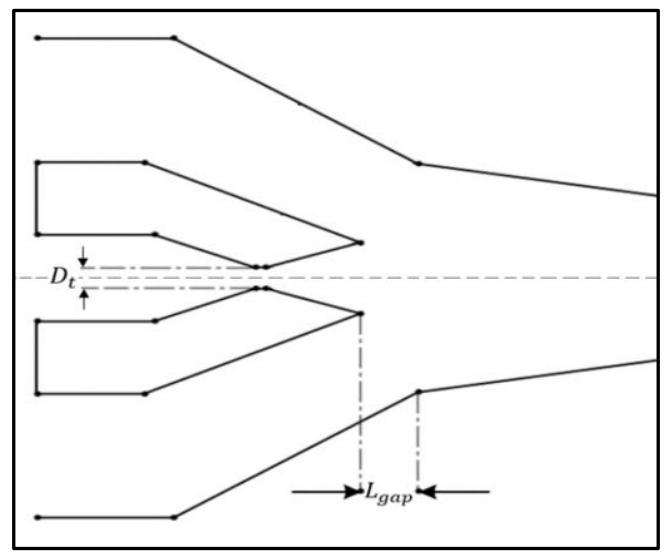

Figure 56. Gap length illustration

\subsubsection{Entrainment Ratio Analysis}

The effect of the "gap length" on the entrainment ratio is examined and the corresponding results performed by numerical analyses as well as with 1-D analysis are presented in Table 11.

Table 11. Entrainment ratio results for the corresponding gap lengths

\begin{tabular}{|c|c|c|}
\hline $\begin{array}{c}L_{\text {gap }} / D_{t} \\
\text { (Gap Length / } \\
\text { Throat Diameter) }\end{array}$ & $\begin{array}{c}\text { CFD Analyses } \\
\text { Entrainment } \\
\text { Ratio (w) }\end{array}$ & $\begin{array}{c}\text { 1-D Approach } \\
\text { Entrainment } \\
\text { Ratio (w) }\end{array}$ \\
\hline $\mathbf{0 . 0 0}$ & 1.320 & 1.293 \\
\hline $\mathbf{0 . 3 0}$ & 1.461 & 1.576 \\
\hline $\mathbf{0 . 5 9}$ & 1.507 & 1.871 \\
\hline $\mathbf{0 . 8 9}$ & 1.501 & 2.187 \\
\hline $\mathbf{1 . 1 8}$ & 1.501 & 2.489 \\
\hline $\mathbf{1 . 4 8}$ & 1.438 & 2.872 \\
\hline
\end{tabular}

Throughout this study, the "gap length" is non-dimensionalized by the diameter of the nozzle throat i.e. $L_{g a p} / D_{t}$. 
The most significant and noticeable change for the performance of the supersonic ejector system is observed in this region. This is due to the cross-sectional area of the secondary flow at the intersection of the primary and the secondary flow. The location where these two streams meet has a significant effect on the performance of the system.

The effect of gap on the entrainment ratio behavior is shown as a plot in Figure 57. The numerical study indicates first a significant increase then a slight decrease as the gap length is increased. This behavior is due to the saturation of the system and the disability of the system to handle any extra fluid of the complex mixing process.

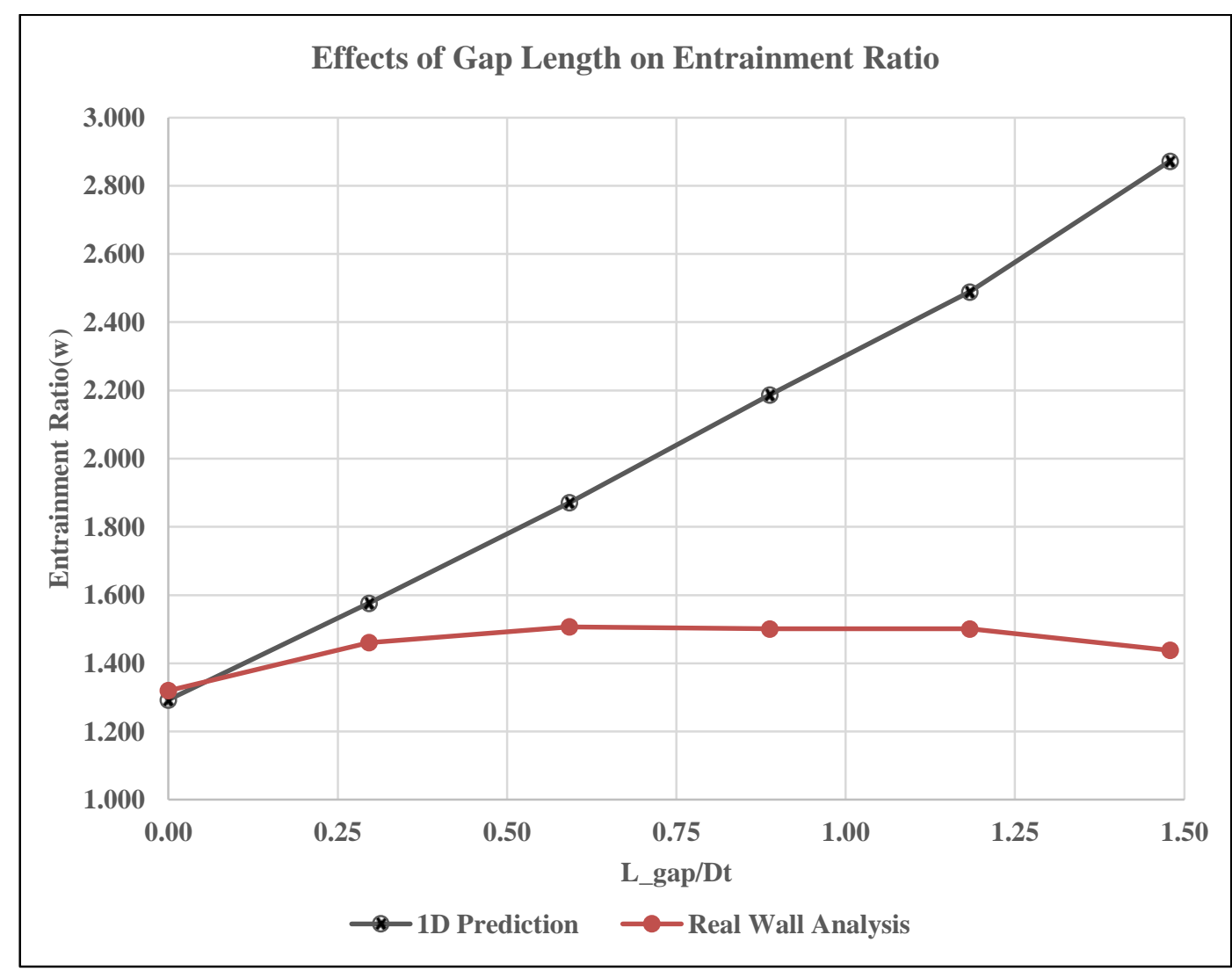

Figure 57. Change of entrainment ratio with gap length for both 1-D calculations and the viscous (real wall) results

The 1-D FORTRAN code was developed such that, the supersonic ejector system operates ideally and the calculations are performed with equations, such that a 
continuous, linear and a proportional increase in the entrainment is expected with increasing gap length. In agreement with these expectations, such behavior is expected. The higher this gap length gets, the further the difference between the 1-D predictions and the numerical analyses becomes, due to the assumption of ideal behavior and equations within the code.

\subsubsection{Mach Number and Pressure Distribution}

More detailed investigation of the Mach number and pressure distributions within the ejector system is studied and the contours of Mach number and pressure are presented.

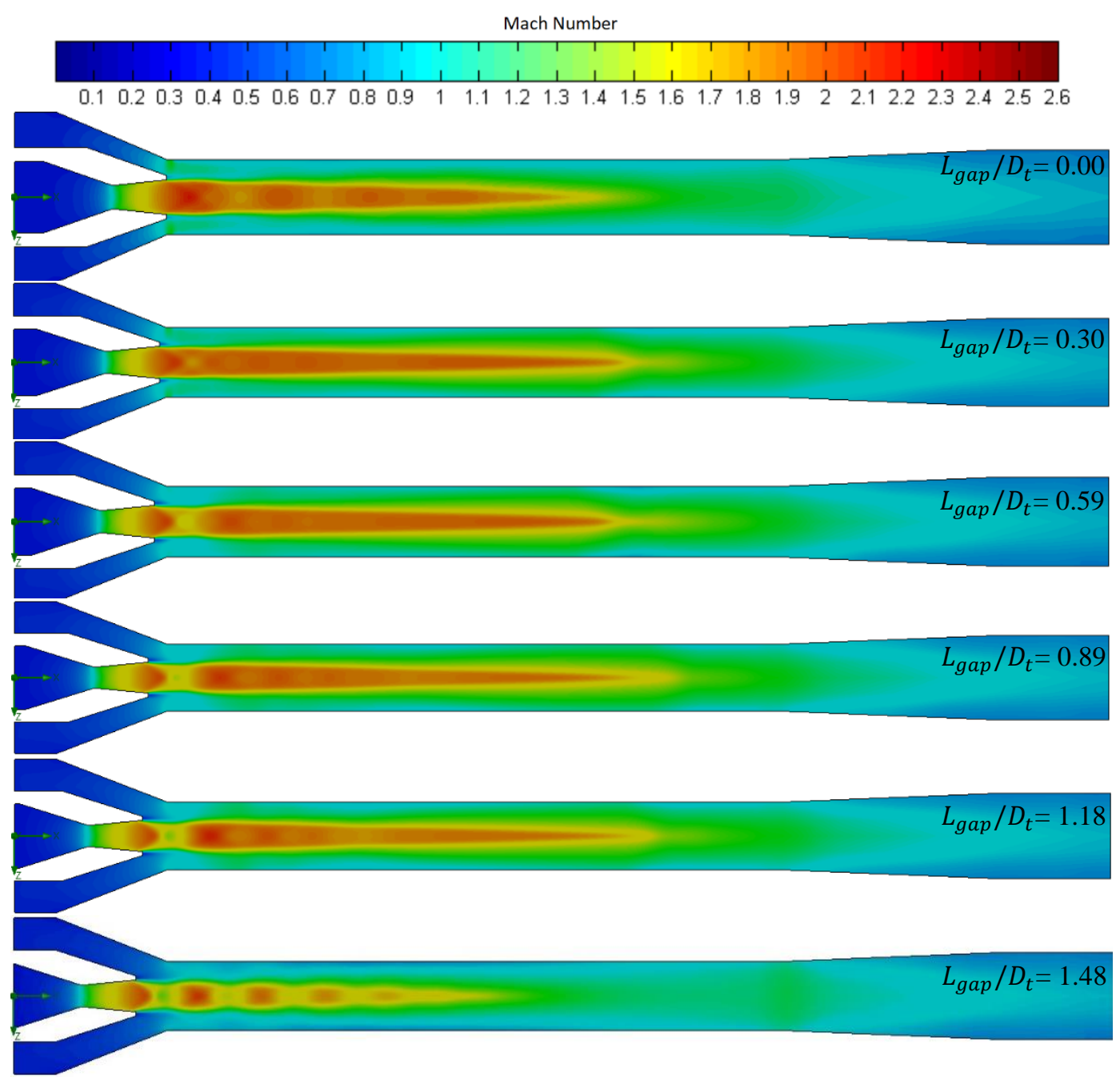

Figure 58. Mach number contours for the indicated ratio values for the corresponding gap lengths 


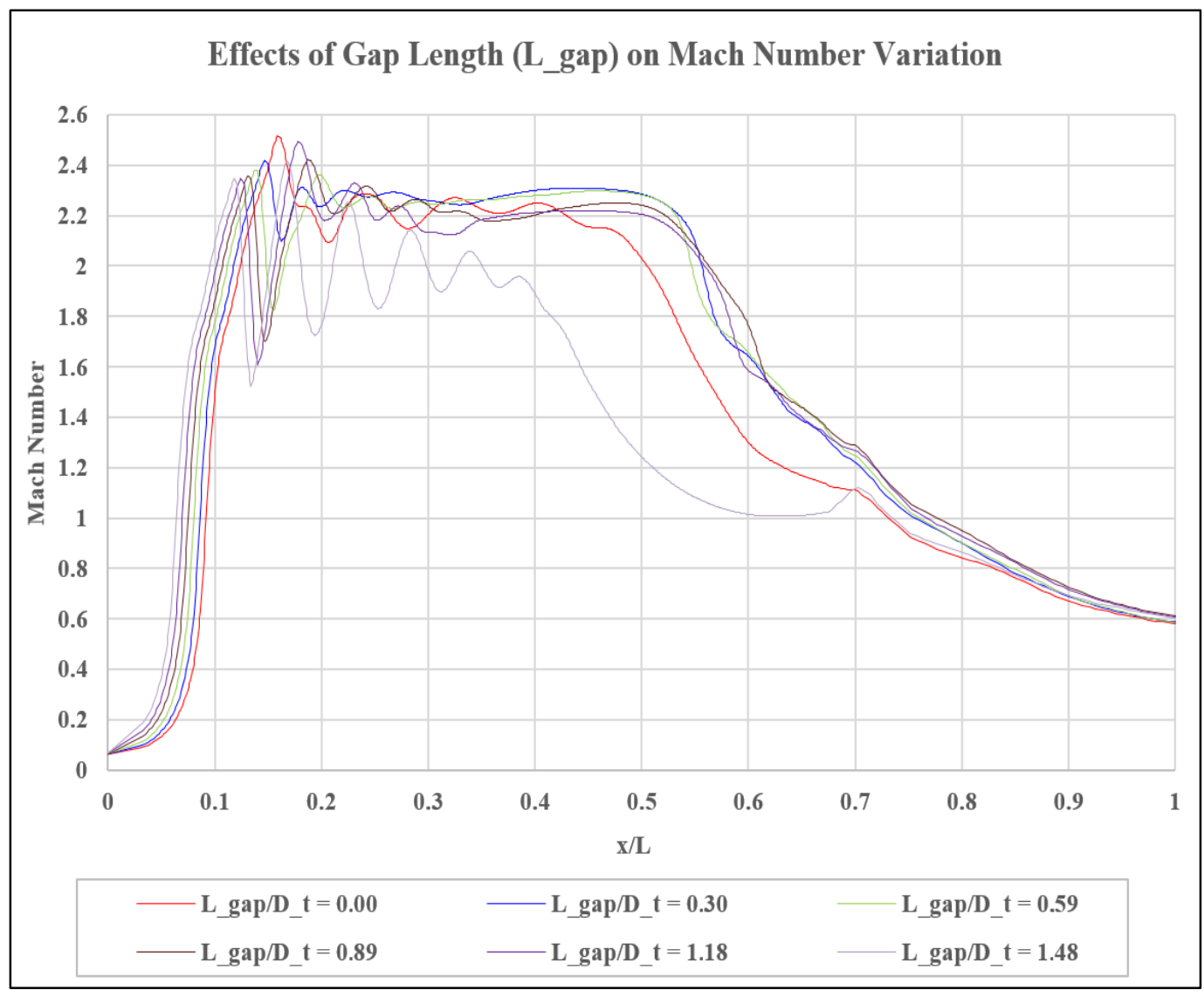

Figure 59. Effects of gap length on Mach number variation along the centerline

Furthermore, the pressure contours within the system is plotted for each case, in order to observe the pressure variations, especially in the mixing region Figure 60.

Stronger expansion and compression patterns can clearly be observed for higher gap length together with higher number of pressure oscillations Figure 60.

In addition to stronger patterns, the value of pressure at the location where the two streams reach an equilibrium increases so that a shock is formed for all gap values except for $\mathrm{Lgap}_{\mathrm{g}}=0$, within the mixing throat region, during the pressure recovery. (i.e. pressure balance with that of the discharge)

Variation of pressure along the centerline is plotted as a function of $\mathrm{x} / \mathrm{L}$ for each gap length values in Figure 61. 


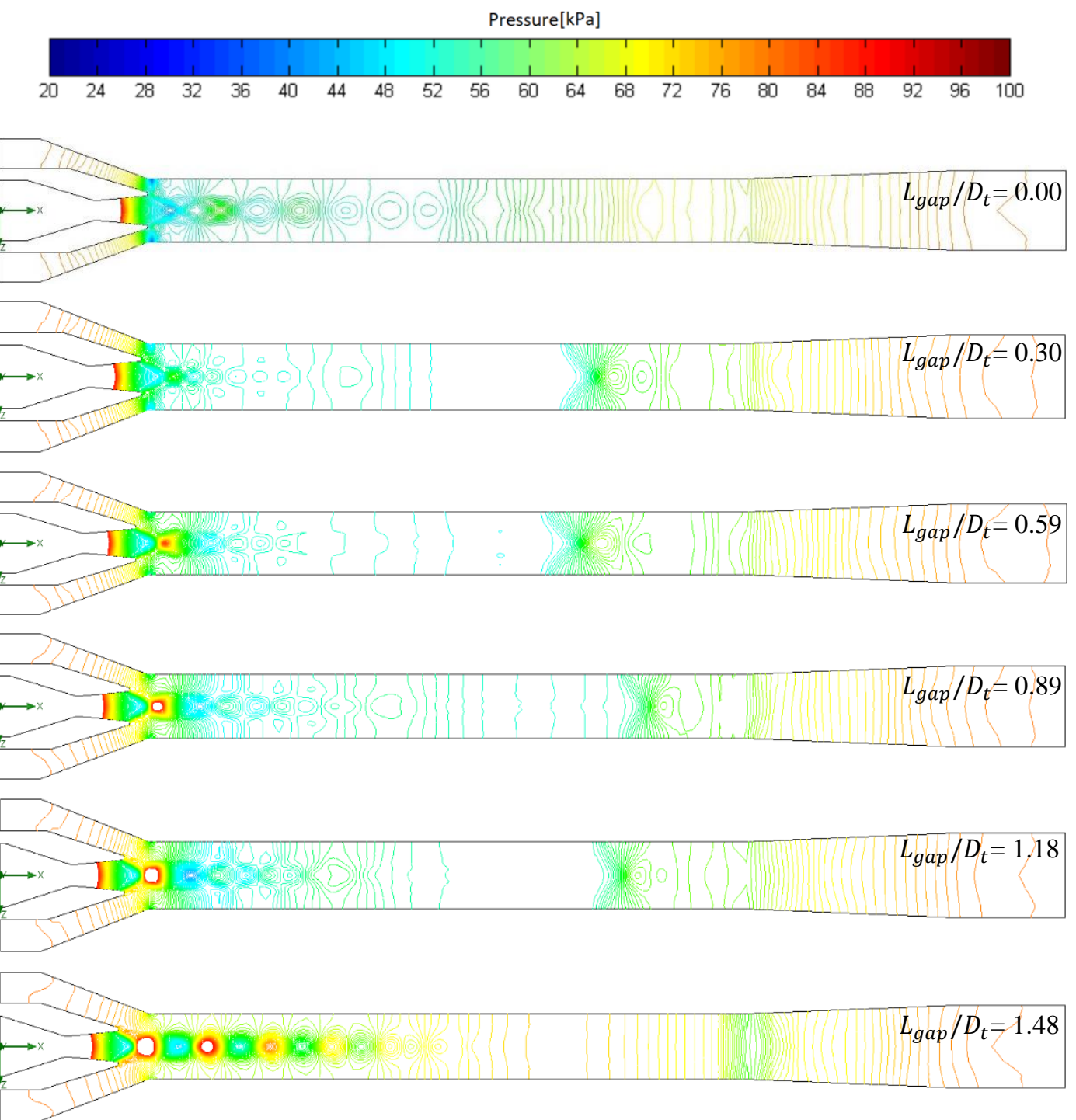

Figure 60. Pressure iso-contours for the corresponding gap lengths

\subsubsection{Conclusion}

As a result the gap length analysis performed in this section, the gap length of $2 \mathrm{~mm}$, $L_{\text {gap }} / D_{t}=0.59$, is selected as the most appropriate value among the other test case values.

The corresponding value for the entrainment ratio is found to be 1.507 . The efficient operational range of $L_{\text {gap }} / D_{t}$ is observed to be between $\sim 0.50<L_{\text {gap }} / D_{t}<\sim 0.90$. 


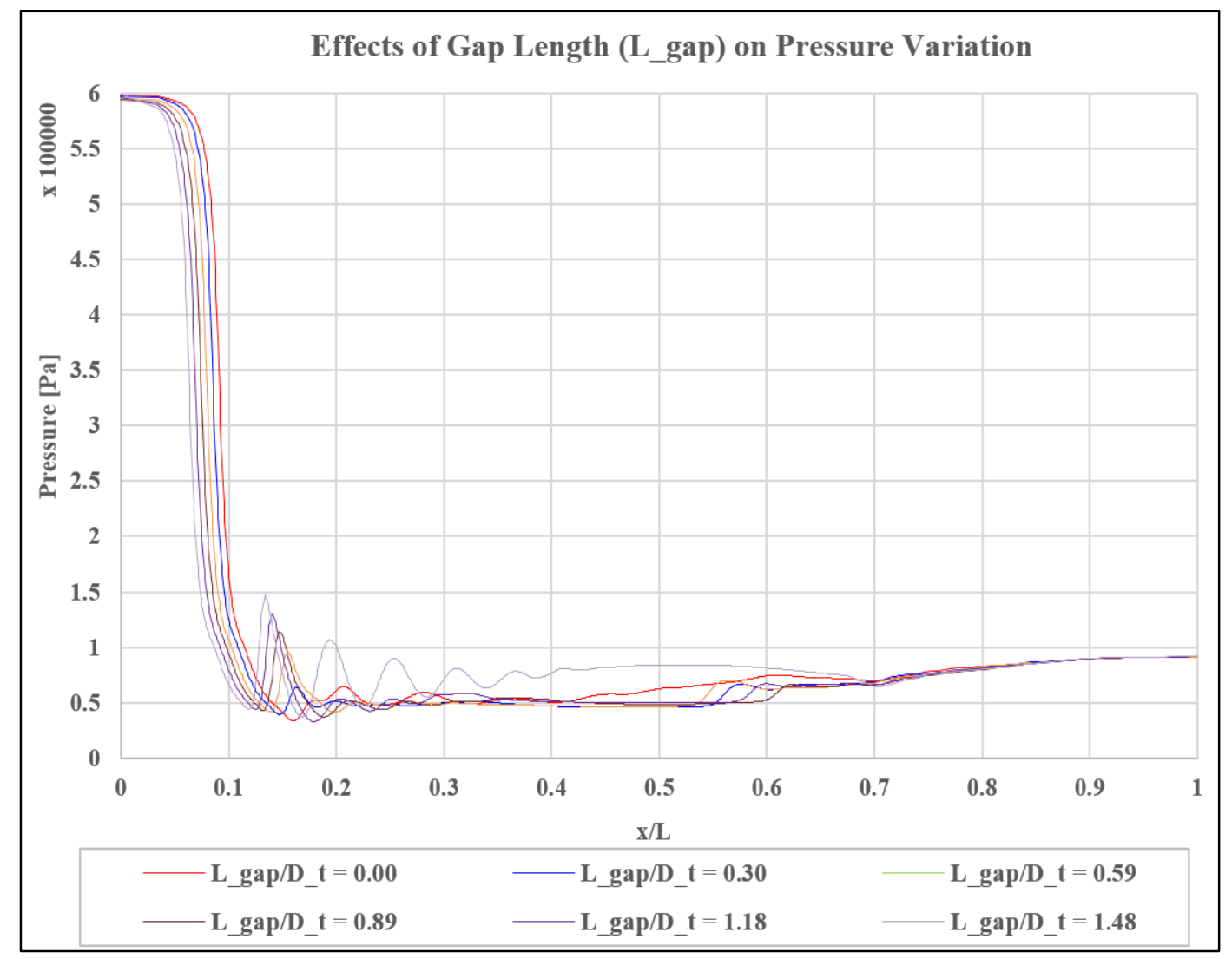

Figure 61. Effects of gap length on pressure variation along the centerline

\subsubsection{Mixing Convergence Angle Analysis ( $\theta$ )}

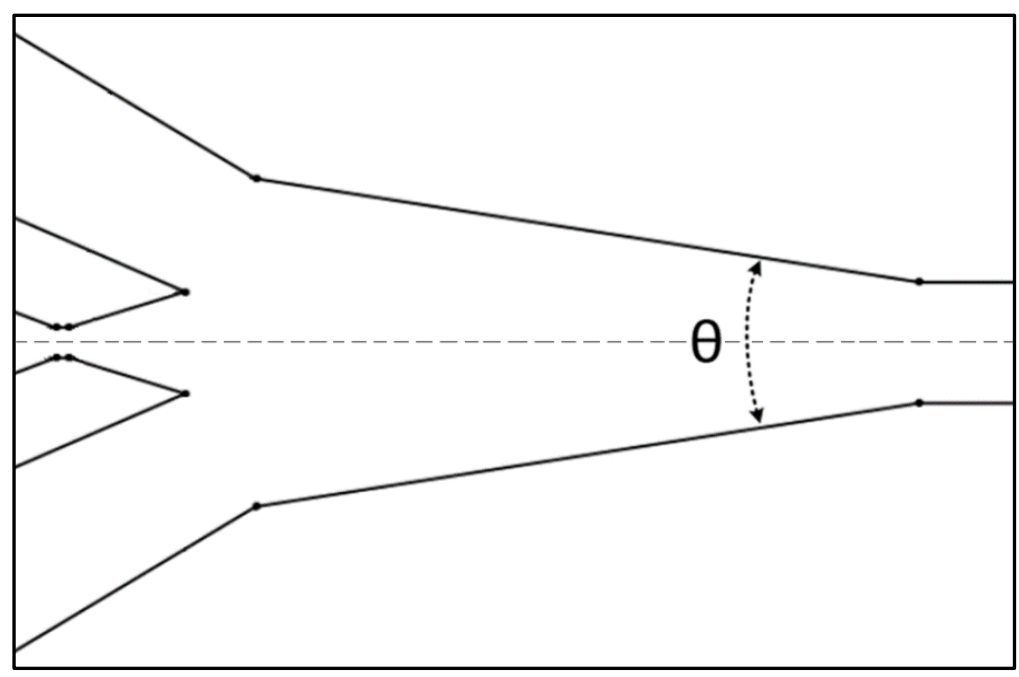

Figure 62. Mixing convergence angle illustration 
In this section, the mixing chamber convergence angle, which is depicted in Figure 62 is investigated and analyzed.

Also, it must be noticed that by keeping other parameters fixed including the crosssectional areas and varying this angle changes the length of the mixing chamber as well.

\subsubsection{Entrainment Ratio Analysis}

The computed results can be observed from Table 12, showing the numerical analyses as well as the 1-D code results.

Table 12. Entrainment ratio results for the corresponding mixing convergence angles

\begin{tabular}{|c|c|c|}
\hline $\boldsymbol{\theta}$ & $\begin{array}{c}\text { CFD Analyses } \\
\text { Entrainment } \\
\text { Ratio (w) }\end{array}$ & $\begin{array}{c}\text { 1-D Approach } \\
\text { Entrainment } \\
\text { Ratio (w) }\end{array}$ \\
\hline $\mathbf{0 . 0 5 9}^{\circ}$ & 1.450 & \\
\hline $\mathbf{0 . 0 6 4}^{\circ}$ & 1.507 & \multirow{2}{*}{1.871} \\
\hline $\mathbf{0 . 0 7 0}^{\circ}$ & 1.507 & \\
\hline $\mathbf{0 . 0 7 6}^{\circ}$ & 1.506 \\
\hline $\mathbf{0 . 0 8 4}^{\circ}$ & 1.501 \\
\hline $\mathbf{0 . 0 9 6}^{\circ}$ & 1.499 \\
\hline $\mathbf{0 . 1 0 8}^{\circ}$ & 1.498 \\
\hline
\end{tabular}

The values that are also shown, is plotted as entrainment ratio vs $\beta$ in Figure 63. The numerical results indicate that, one can clearly observe the efficient range of mixing convergence angle $\theta$ between $\sim 0.063^{\circ}$ and $\sim 0.075^{\circ}$, which provides entrainment ratio values of over 1.505 .

From the entrainment results, the most efficient value of $\theta$ seems to be $0.070^{\circ}$ for the ejector system. 


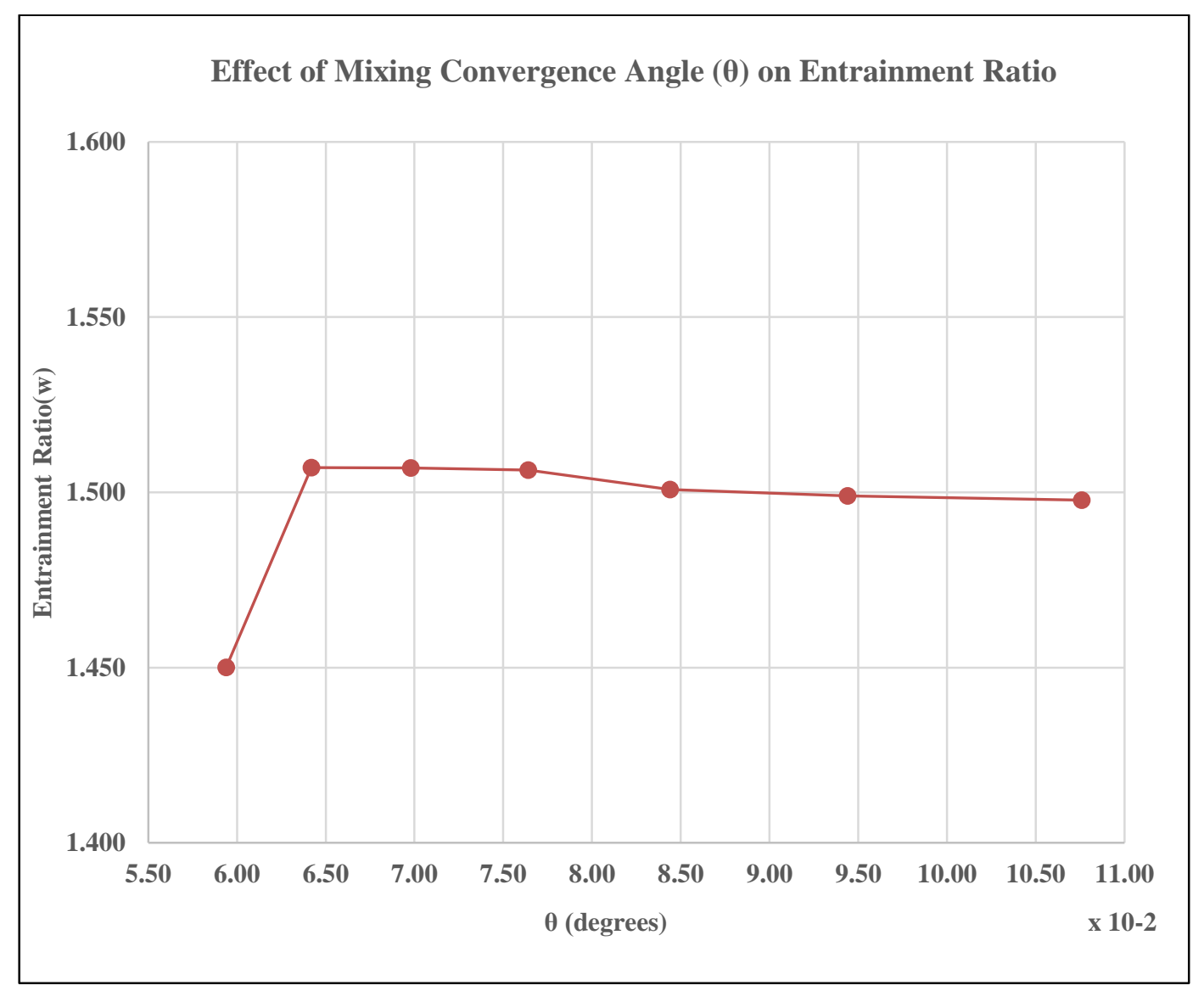

Figure 63. Change of entrainment ratio with mixing convergence angle

\subsubsection{Mach Number and Pressure Distribution}

From theoretical point of view, the mixing convergence angle and therefore the mixing chamber length have a significant effect on how well and proper the primary and secondary streams are mixed. In this respect, Mach number and pressure variations are investigated in detail for different angles and the results are presented in this section.

The Mach number pseudo-colored contours are formed for different $\theta$ angles and the results are presented in Figure 64. As noted previously, study is performed in such a way that, all the remaining parameters are kept unaltered while the mixing angle is varied. Looking at the Mach number contours, the variation in the mixing chamber length (thus the length of the overall supersonic ejector system) is the first thing to notice. 


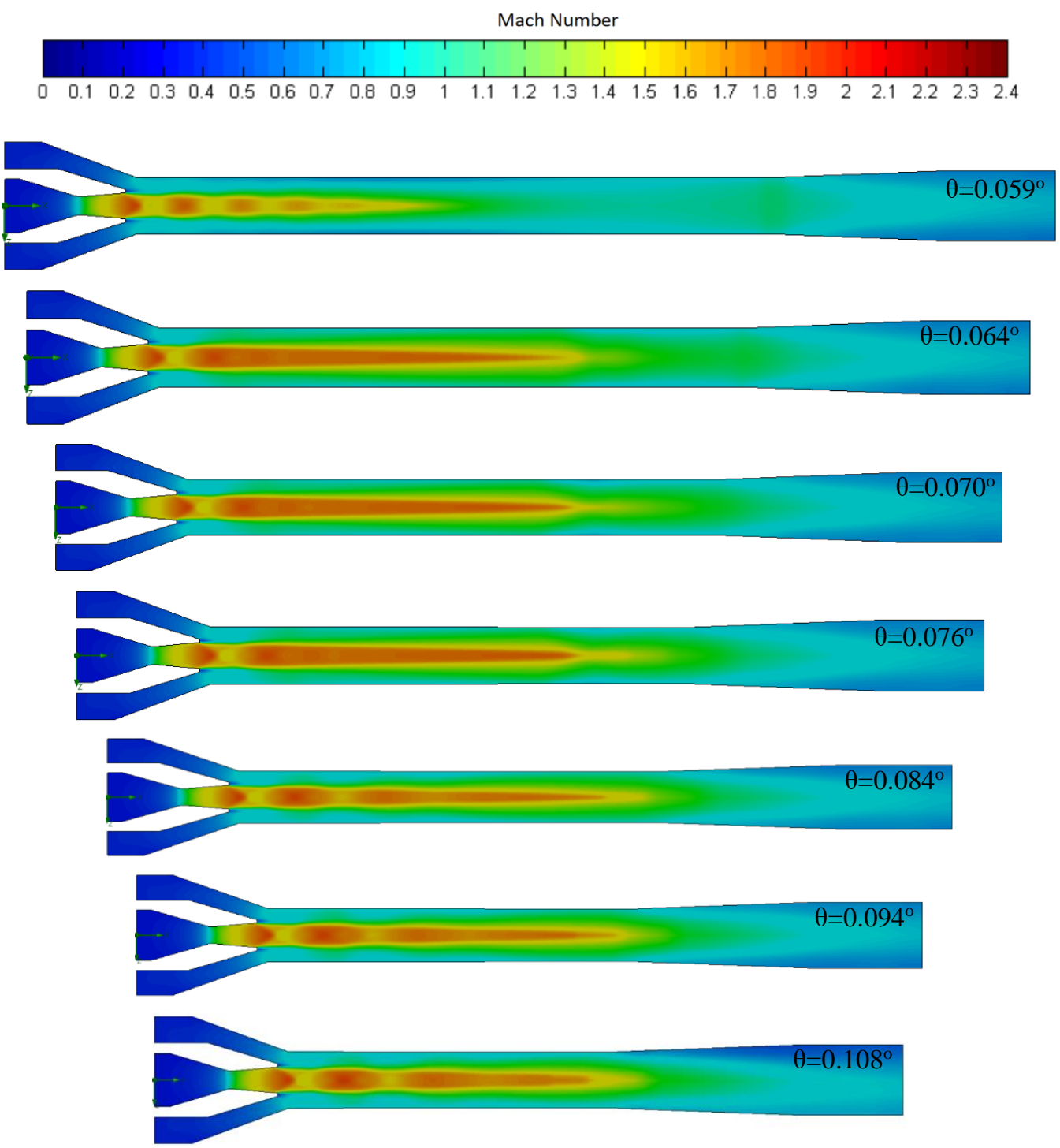

Figure 64. Mach number contours for the corresponding mixing convergence angles

Apart from the $\theta=0.059^{\circ}$ and $0.108^{\circ}$, the overall behavior of the flow stays practically the same with minor changes (slightly sharper expansion and compression patterns with an increase in $\theta$ ). For $\theta=0.059^{\circ}$, it can be commented that the system is unnecessarily long which may have adverse and negative effect on the mixing process as shown in the entrainment ratio study. On the other hand, for $\theta=0.108^{\circ}$, the length of the mixing region is not long enough for the streams for effectively mixing, where the flow separation and its attachment at the downstream location of the system can clearly be observed. 
Mach number distribution along the centerline is plotted for each $\theta$ case and the results are given in Figure 65.

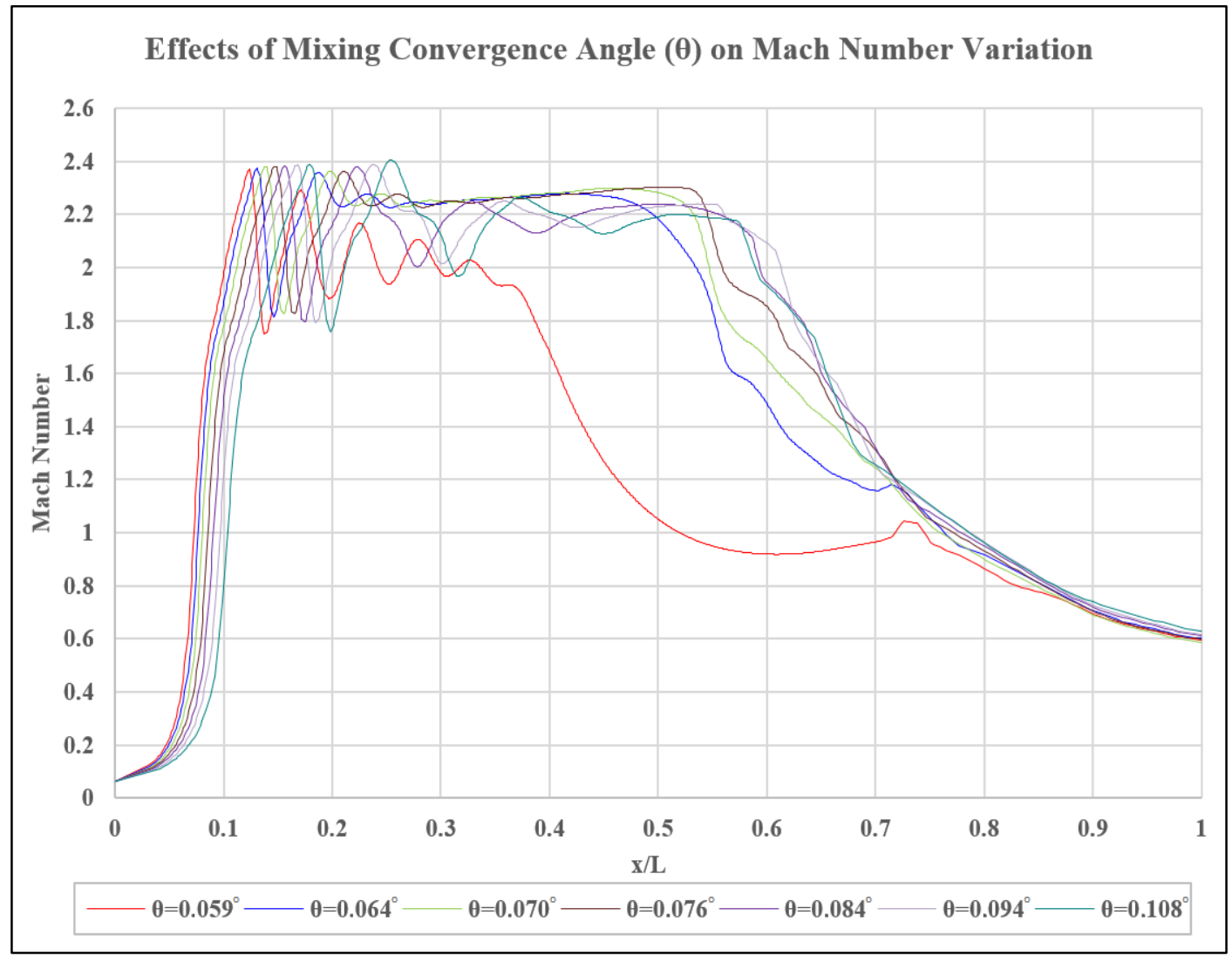

Figure 65. Effects of mixing convergence angle on Mach number variation along the centerline

Another apparent fact is that the upper limit of Mach number within the system is kept at 2.4 (It was up to 2.6 in previous sections) for the present cases due to the selection of the most effective gap length. Despite the decrease of Mach number (thus increase in pressure or decrease in vacuum level), higher cross- sectional area of the primary and the secondary stream at the intersection results in more influential entrainment ratios.

Furthermore, the behavior of the pressure variation in flow is also examined, and the constant pressure lines are plotted within the system for the characterization of the flow within the mixing region. 


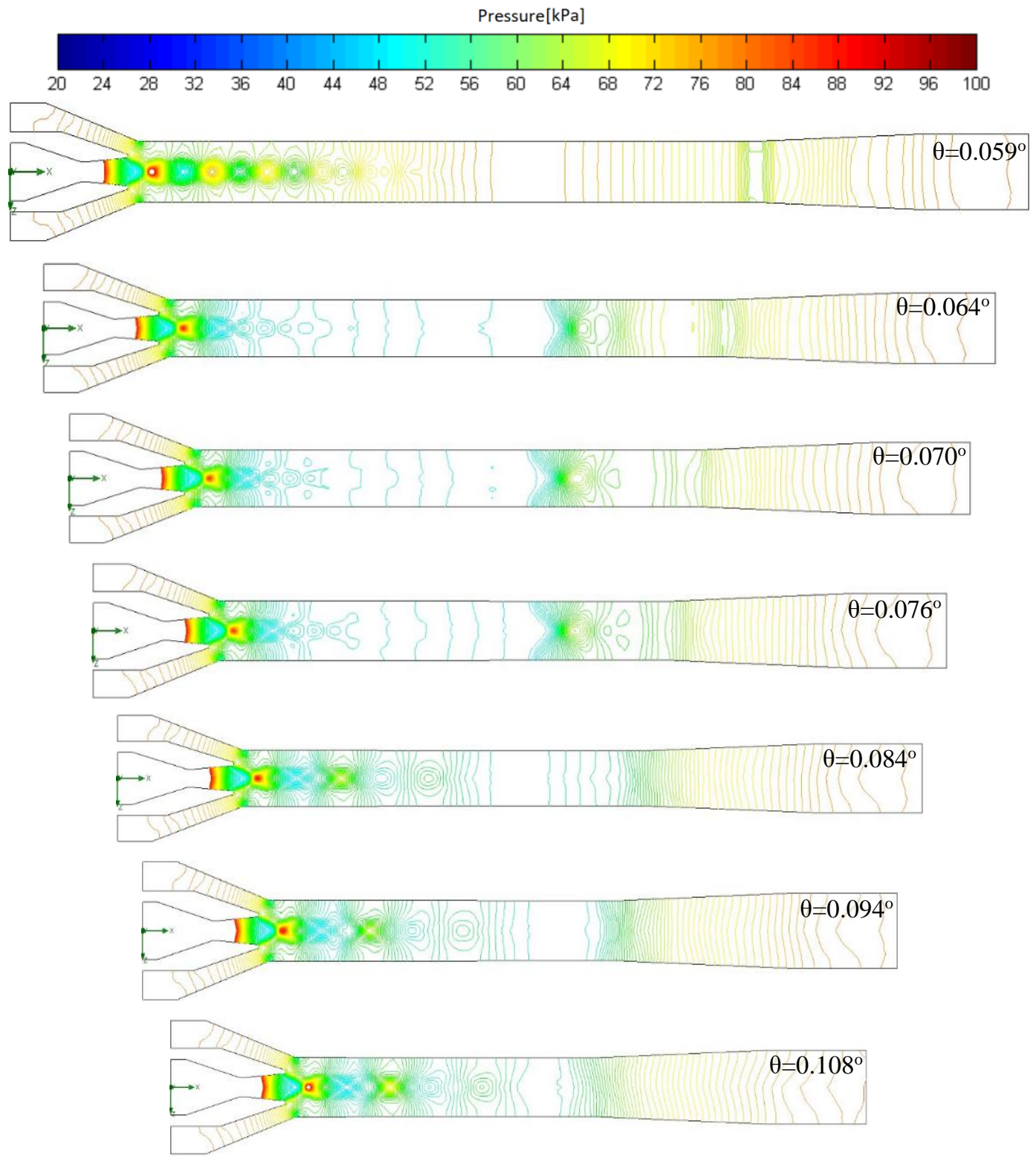

Figure 66. Pressure iso-contours for the corresponding mixing convergence angles

Correspondingly, sharper and stronger flow patterns can clearly be observed from the pressure contours, Figure 66. Additionally, for the angles (trials) analyzed as the efficient operational range for $\theta, \sim 0.063^{\circ}<\theta \sim 0.075^{\circ}$, a normal shock wave is formed at the downstream location of the mixing region.

Slight shifts of the curves on both the Mach number and pressure variation along the centerline, Figure 64 and Figure 66, are due to the non-dimensional x/L length distance 
which shows that the ratio of a location to the overall length and as the total length of the ejector system is changed in the present study.

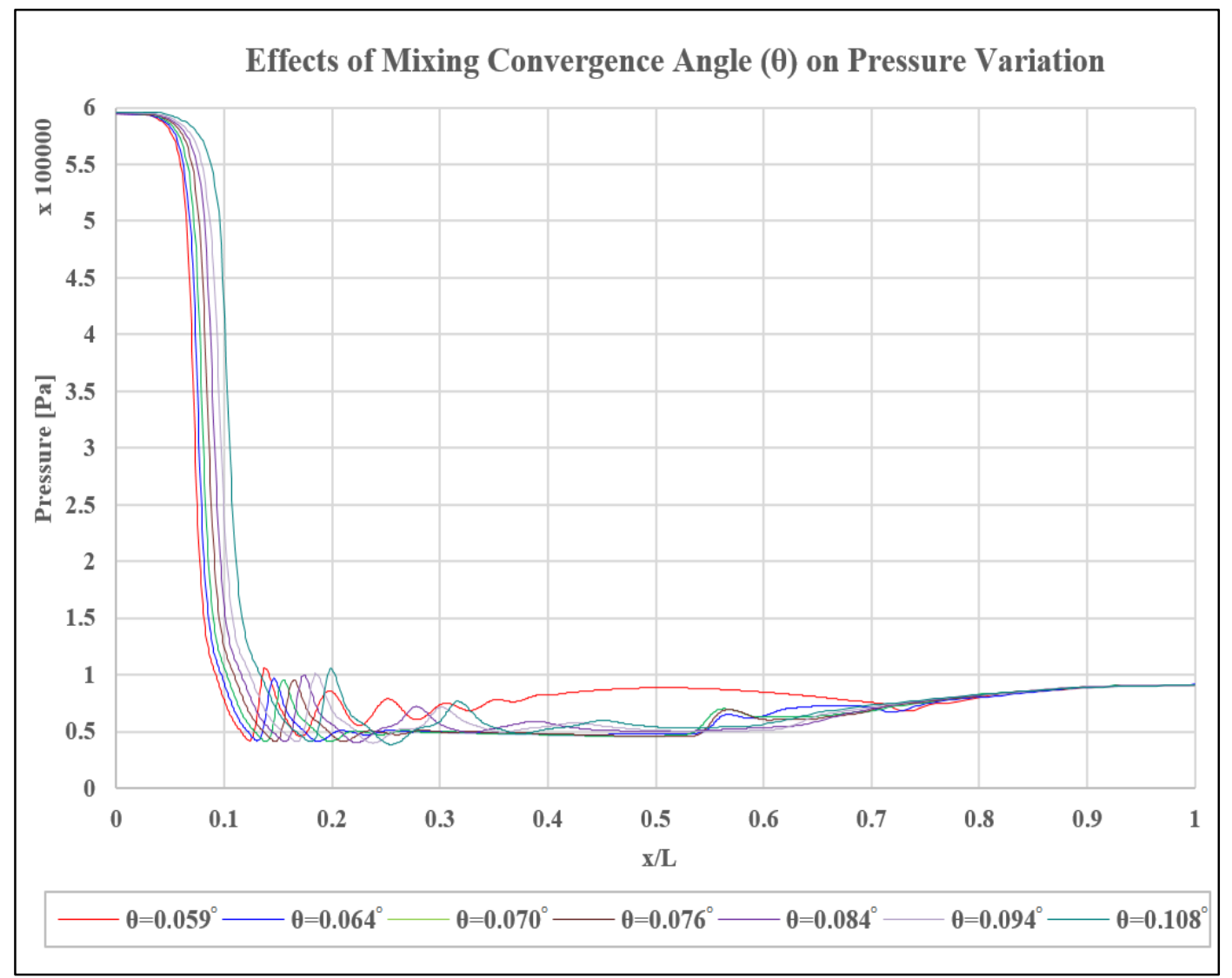

Figure 67. Effects of mixing convergence angle on pressure variation along the centerline

This study shows that, for the current supersonic ejector model, proper geometrical model is the "constant-pressure mixing" approach rather than the "constant-area mixing" approach for the entrainment ratio study as well as for the analyses of the flow characteristics giving the most efficient results for a converging duct during mixing.

\subsubsection{Conclusion}

At the end of the mixing chamber angle analysis, it can be concluded that the most appropriate value of $\theta$ is selected to be $0.070^{\circ}$, and the entrainment ratio is found to be 1.507. In addition, it can also be concluded that, for the best operation of the ejector, the angle $\theta$ should be selected within the range of $\sim 0.063^{\circ}<\theta<\sim 0.075^{\circ}$. 


\subsubsection{Length of Mixing Throat Section Analysis $\left(L_{t 2}\right)$}

This section covers the investigation of the effect of the length of the mixing throat, which is also called as the second throat, for the performance analysis of an ejector system as shown in Figure 68. This study is performed by inspecting the system responses with changing lengths the throat while other geometrical parameters are kept unchanged.

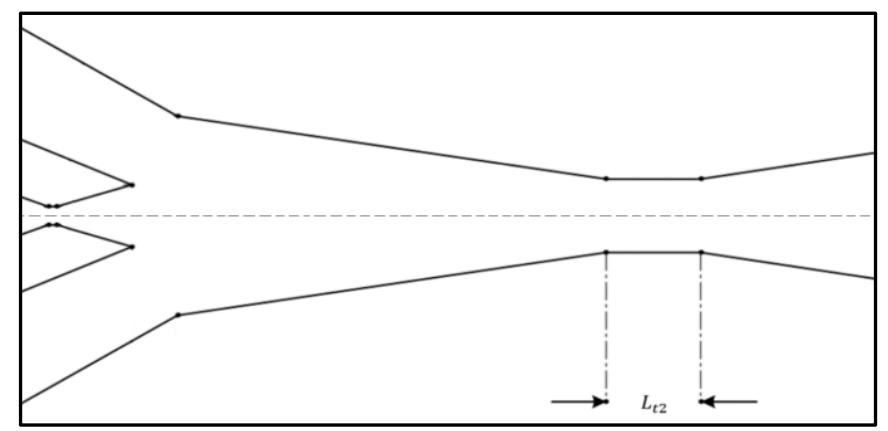

Figure 68. Mixing throat length illustration

\subsubsection{Entrainment Ratio Analysis}

By means of entrainment performance, the computed results for both numerical and one dimensional studies are presented in Table 13.

Table 13. Entrainment ratio results for the corresponding mixing throat lengths

\begin{tabular}{|c|c|c|}
\hline $\begin{array}{c}L_{t 2} / D_{t} \\
\text { (mix-throat length/noz- } \\
\text { throat diameter) }\end{array}$ & $\begin{array}{l}\text { CFD Analyses } \\
\text { Entrainment } \\
\text { Ratio (w) } \\
\end{array}$ & $\begin{array}{l}\text { 1-D Approach } \\
\text { Entrainment } \\
\text { Ratio (w) }\end{array}$ \\
\hline 0.00 & 1.505 & \multirow{8}{*}{1.871} \\
\hline 0.59 & 1.512 & \\
\hline 1.78 & 1.501 & \\
\hline 2.96 & 1.507 & \\
\hline 5.92 & 1.510 & \\
\hline 8.88 & 1.518 & \\
\hline 14.79 & 1.526 & \\
\hline 23.67 & 1.419 & \\
\hline
\end{tabular}


The length ratios used in this analysis refers to $0,2,6,10,20,30,50$ and $80 \mathrm{~mm}$ of mixing throat lengths respectively.

The corresponding plot for the entrainment ratios as a function of $L_{g a p} / D_{t}$ is shown in Figure 69. Looking at the numerical analysis results shown in Figure 69, variation of performance up to $L_{g a p} / D_{t}$ of $\sim 15$ is observed.

It can be commented that if the cost-efficiency is the main concern, then this variation can be discarded and the system can be designed accordingly. However, as the current study is concentrated on the efficient system performance, the effective mixing throat length range is observed as $L_{t} / D_{t}$ equals from $\sim 5$ to $\sim 15$ and it can be said that the best case appears to be for $L_{t 2} / D_{t}=14.79$ case (which is $L_{t 2}=50$ millimeters).

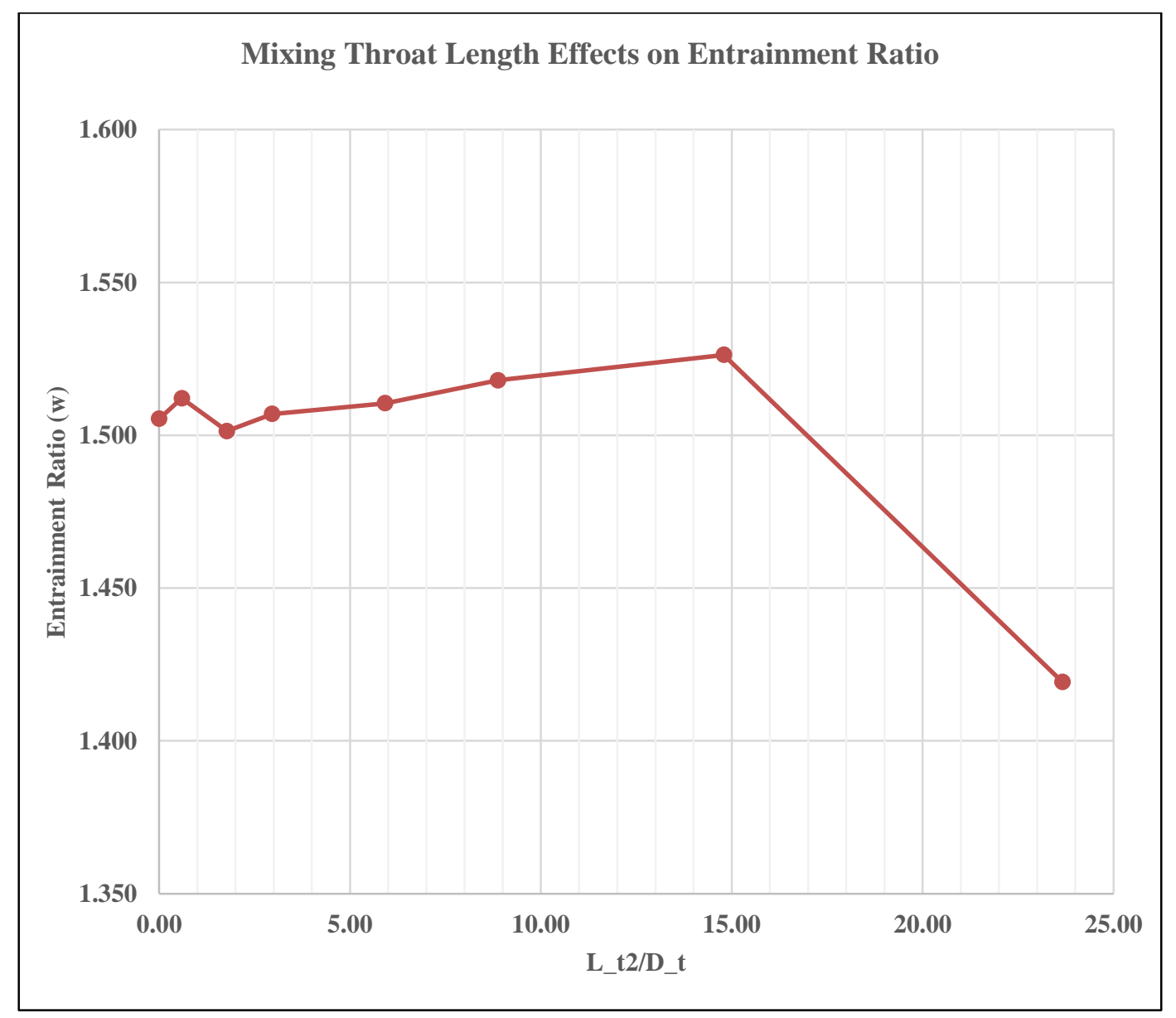

Figure 69. Change of entrainment ratio with the mixing throat length 


\subsubsection{Mach Number and Pressure Distribution}

Mach number and pressure characteristics variation length of the second throat is investigated. Study is performed by presenting and comparing the pseudo-colored isocontour contributions as well as the plots of the pressure and Mach versus the $\mathrm{x} / \mathrm{L}$ distance for each case.

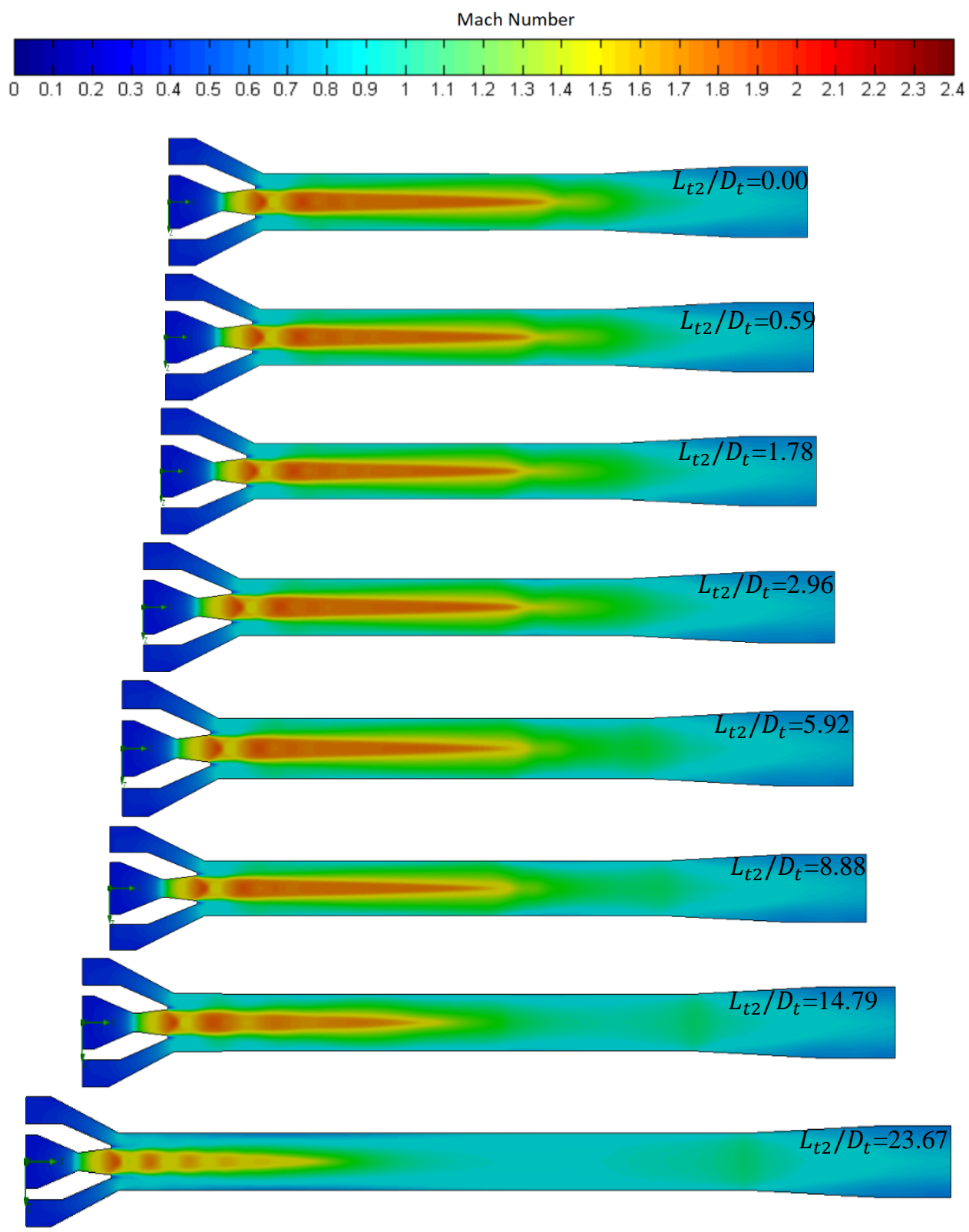

Figure 70. Mach number contours for the corresponding mixing throat lengths 
Apart from the last trial of Figure 70, cases are observed to be identical, with the exception of slight differences in the pattern strengths and the sharpness.

Further investigation of Mach number variation along the central line with $\mathrm{x} / \mathrm{L}$ distance is given in Figure 71.

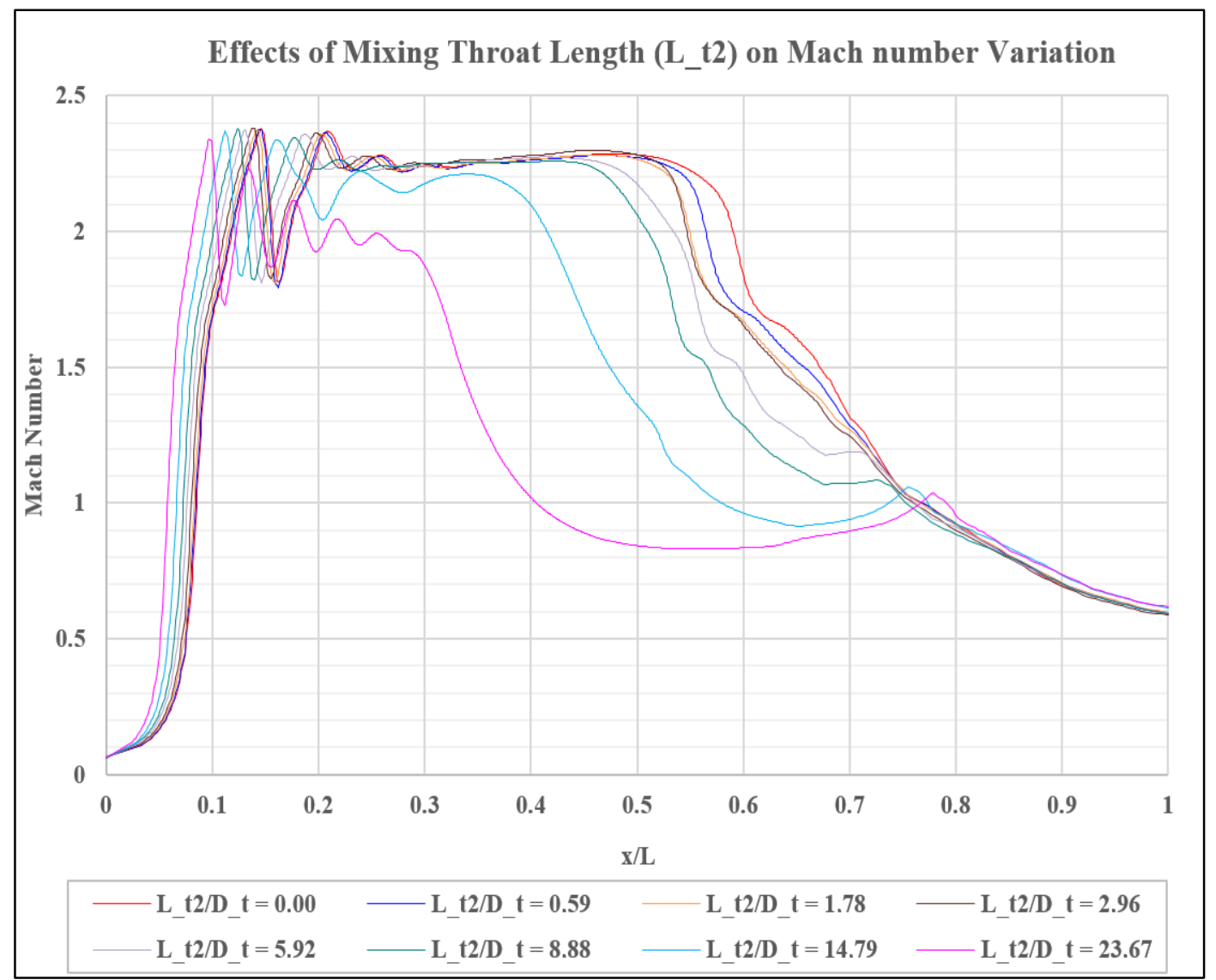

Figure 71. Effects of the mixing throat length on Mach number variation along the centerline

As stated previously, all cases, except the $L_{t 2} / D_{t}=23.67$ case together with the most efficient case of entrainment performance, that is $L_{t 2} / D_{t}=14.79$, gives identical results.

It can be said that, as the length of the throat region increases, entrainment ratio has an increasing trend and when $L_{t 2} / D_{t}=23.79$, it can be noted due to such over-increase one may face additional problems. (i.e. flow blockage or additional shocks etc.) This 
difference for $L_{t 2} / D_{t}=14.79$ can be explained with larger entrainment capability of the system while making the mixing process tougher.

Further increasing the length of the throat region yields pressure variation along the ejector system with the mixing throat length alteration, Figure 72.

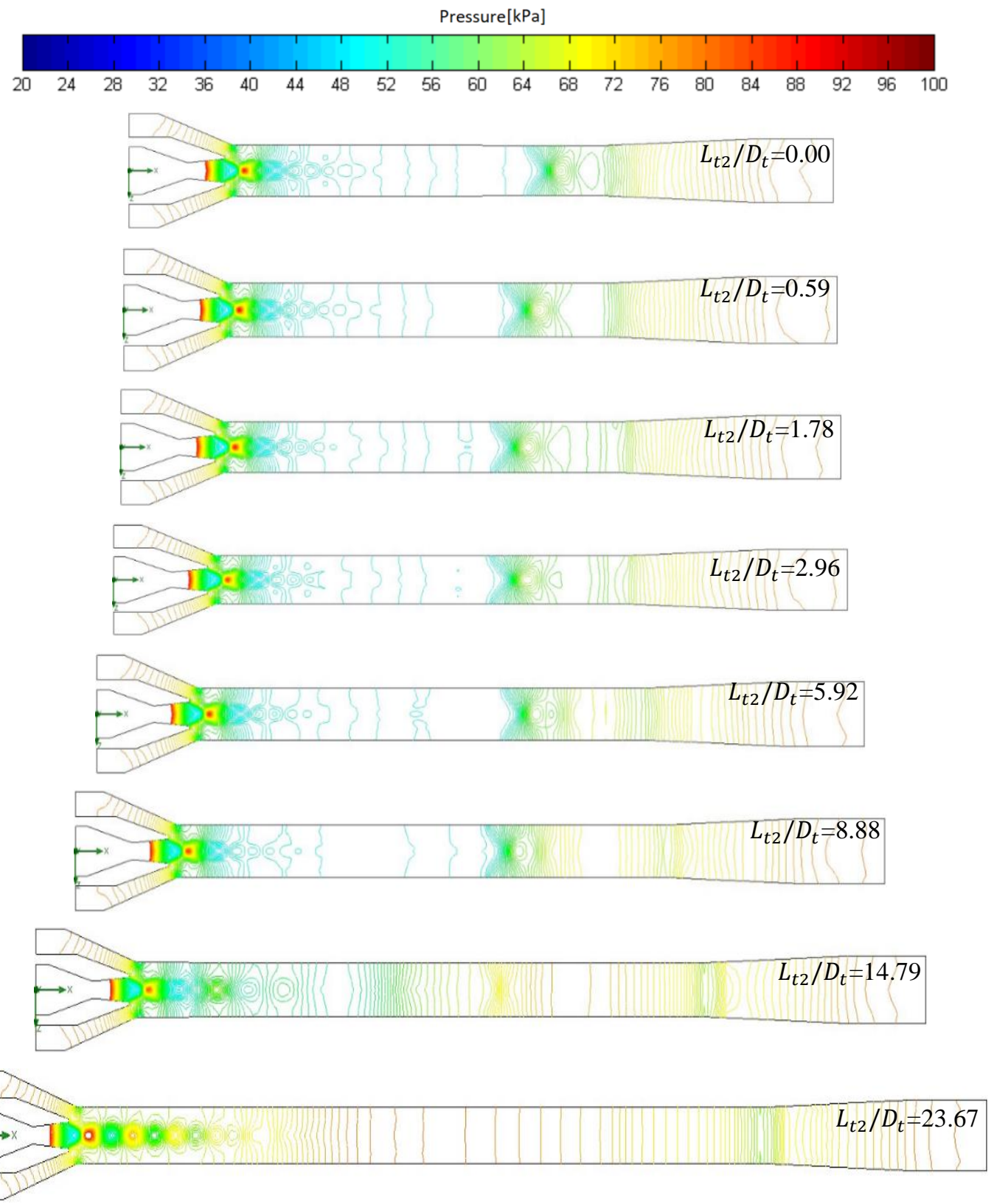

Figure 72. Pressure iso-contours for the ratio values indicated for the corresponding mixing throat lengths 
Looking at the Figure 72, almost no change can be observed as the non-dimensional mixing throat length exceeds a certain value i.e. 10. Thus as the length for which the streams are mixed is increased, (for the current study, 50 and $80 \mathrm{~mm}$ cases,) Figure 72 pressure characteristics of the flow changes considerably. Increase in the entrainment performance is also presented, which may be the main cause of such variation of the flow characteristics.

Pressure variation along the centerline as a function of $\mathrm{x} / \mathrm{L}$ is presented in following plot, Figure 73.

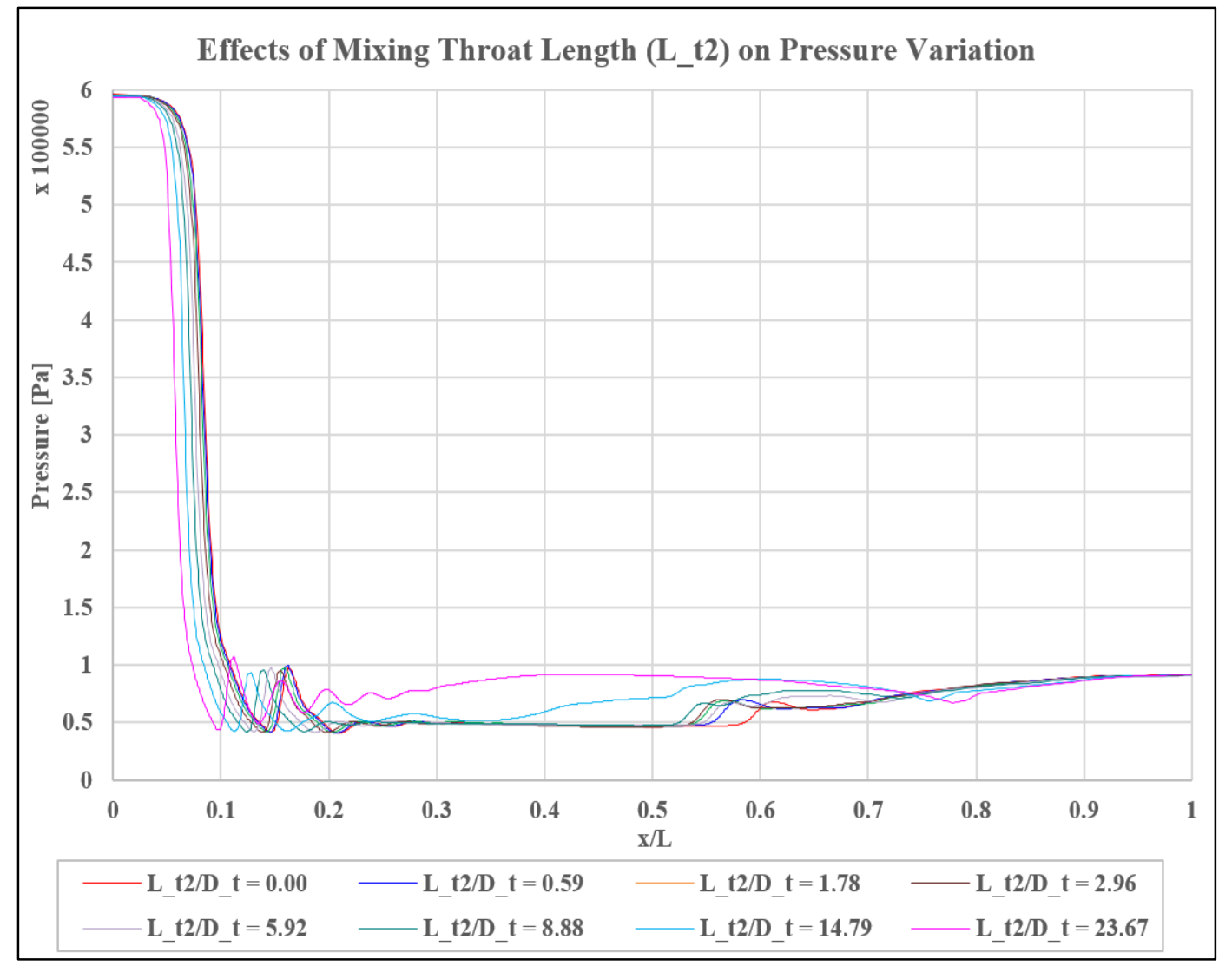

Figure 73. Effects of mixing throat length on pressure variation along the centerline

\subsubsection{Conclusion}

In this present study, the most influential geometrical parameters is found to be $L_{t 2} / D_{t}=14.79$ which corresponds to a mixing throat length of $50 \mathrm{~mm}$ with a 
corresponding value of entrainment ratio of 1.526. A slight alteration of the entrainment ratio is observed, so that, low values of mixing length below $L_{t 2} / D_{t}=\sim 15$ is applicable, when the cost-efficiency limit is taken into consideration. The effective entrainment results are observed between the range of $\sim 5<L_{t 2} / D_{t}<\sim 15$.

\subsubsection{Diffuser Divergence Angle Analysis ( $\Phi)$}

The last but not the least, the diffuser geometry is investigated and is presented within this section. The angle at which the diffuser walls diverge, $\Phi$, is varied and the characteristics of the flow and the changes in the properties are examined. Similar to the mixing convergence angle, changing the angle which can be visualized from Figure 74 while keeping all the remaining dimensions fixed, alters the overall length of the diffuser.

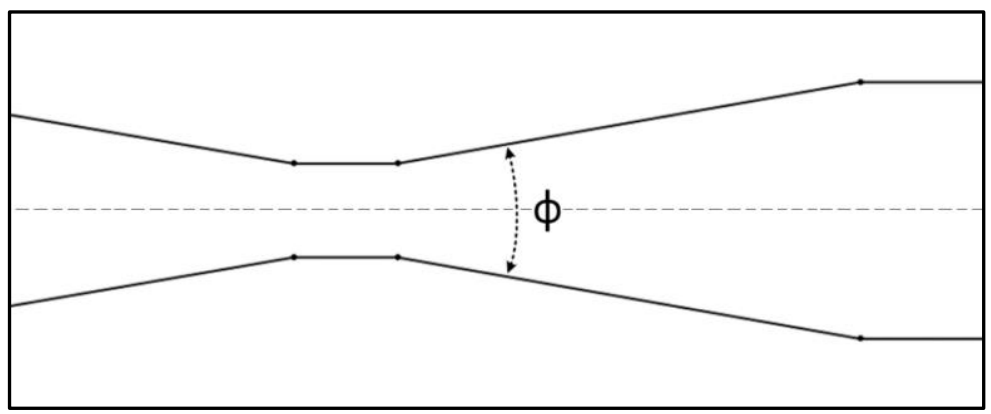

Figure 74. Diffuser divergence angle illustration

\subsubsection{Entrainment Ratio Analysis}

The computed results by the CFD method and the 1-D method are shown as a table in Table 14 along with the plot showing the computed entrainment ratio values versus the angle $\Phi$ for the diffuser as given in Figure 75.

The presented angles refer to the diffuser lengths of $75,65,45,35,25$ and 15 millimeters respectively. The highest entrainment is obtained for the case of $\Phi=2.38^{\circ}$.

However, as in the previous section, if the performance boost of negligible amounts is not as prominent as the cost-efficiency matters, one can design the diffuser section 
between the angles of $\Phi$ from $\sim 2.3^{\circ}$ up to $\sim 8^{\circ}$ corresponding to the diffuser lengths of between $\sim 20 \mathrm{~mm}$ to $\sim 70 \mathrm{~mm}$ for the current case.

Table 14. Entrainment ratio results for the corresponding diffuser divergence angles

\begin{tabular}{|c|c|c|}
\hline$\Phi$ & $\begin{array}{c}\text { CFD Analyses } \\
\text { Entrainment } \\
\text { Ratio (w) }\end{array}$ & $\begin{array}{c}\text { 1-D Approach } \\
\text { Entrainment } \\
\text { Ratio (w) }\end{array}$ \\
\hline $\mathbf{2 . 0 6}^{\circ}$ & 1.432 & \\
\hline $\mathbf{2 . 3 8}^{\circ}$ & 1.531 & \multirow{2}{*}{1.871} \\
\hline $\mathbf{2 . 8 1}^{\circ}$ & 1.531 & \\
\hline $\mathbf{4 . 4 2}^{\circ}$ & 1.526 & \\
\hline $\mathbf{6 . 1 8}^{\circ}$ & 1.524 \\
\hline $\mathbf{1 0 . 2 9}^{\circ}$ & 1.516 \\
\hline
\end{tabular}

As stated above, the highest entrainment performance is achieved for $\Phi=2.38^{\circ}$ and the corresponding entrainment ratio calculated to be 1.532 . The efficient operational range determined to be $\sim 2.3^{\circ}<\Phi<\sim 2.8^{\circ}$.

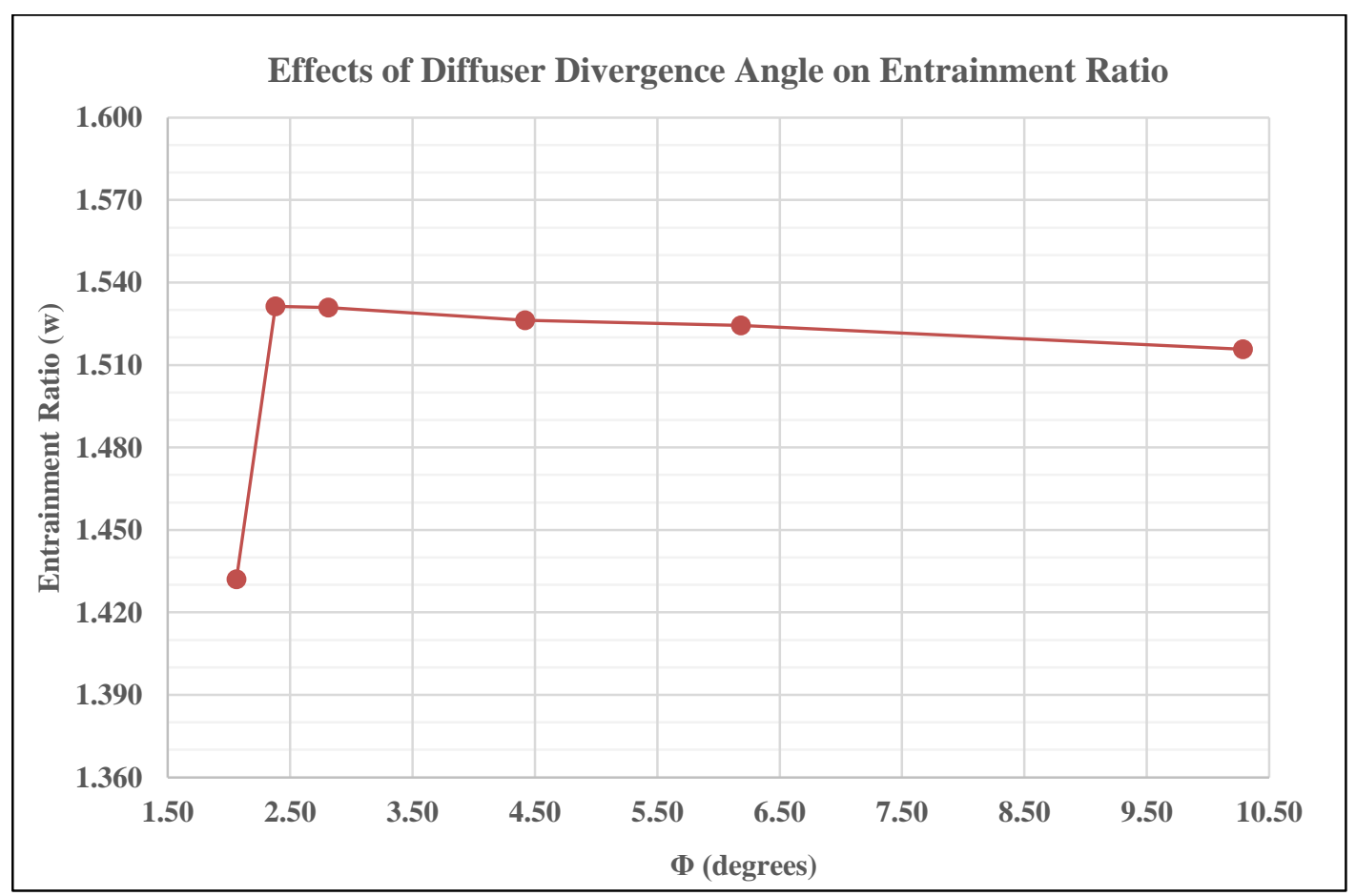

Figure 75. Change of entrainment ratio with diffuser divergence angle 


\subsubsection{Mach Number and Pressure Distribution}

In a similar manner, the aero-thermodynamic investigation of the system is performed as a function of the objective angle and the computed results showing the corresponding Mach number contours are presented in Figure 76.

For values of the diffuser divergence angle (for the current scenario, $\Phi=2.06^{\circ}$ ), no significant change can be observed from Figure 76.

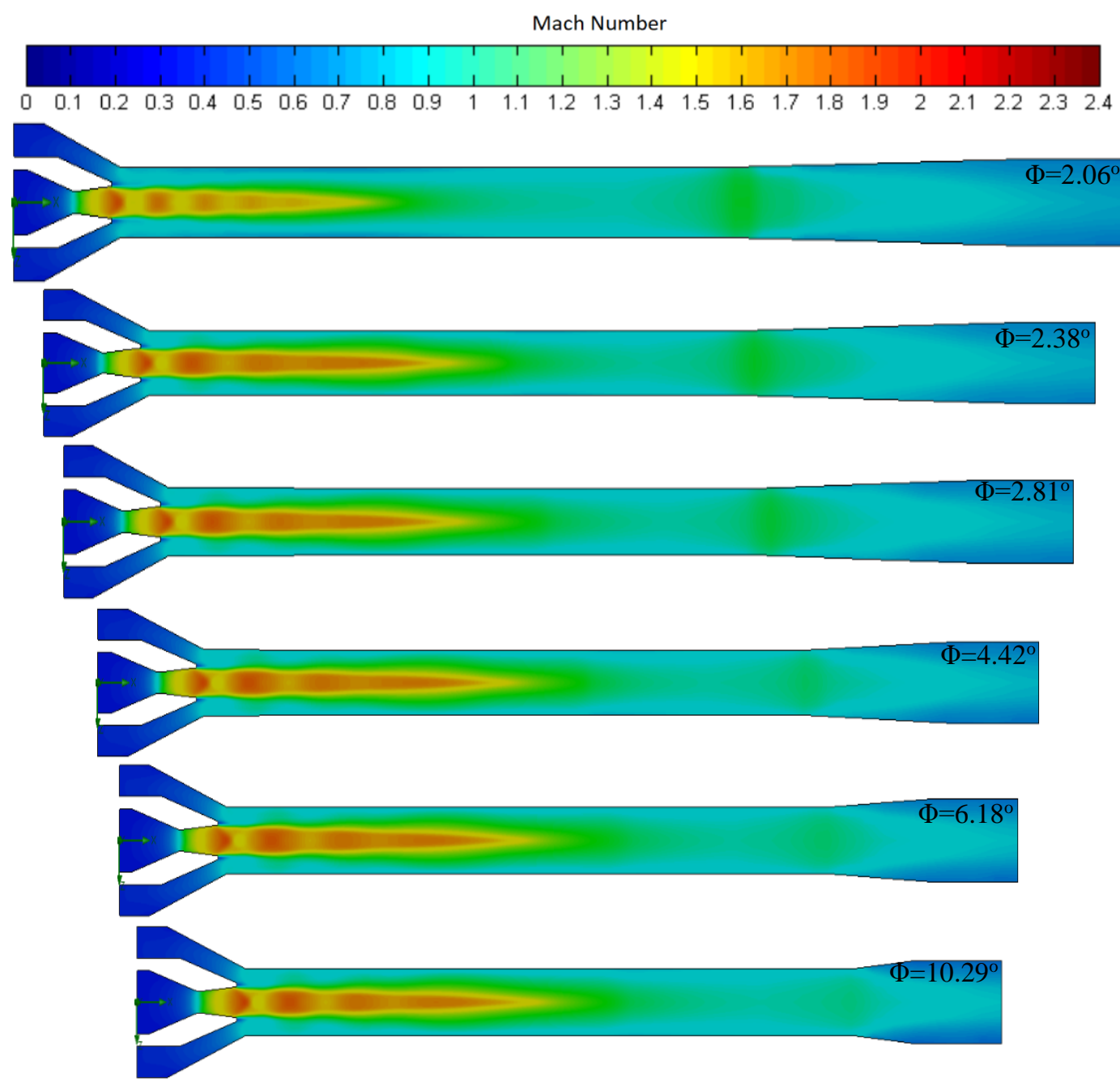

Figure 76. Mach number contours for the corresponding diffuser divergence angles

Looking at the Figure 76, one can observe the differences in the flow patterns with that of the remaining cases. The entrainment performance is presented and an increase in 
the entrainment ratio with decreasing angle and a sharp drop in the entrainment ratio for values of $\Phi>\sim 2.3^{\circ}$ is observed corresponding to the diffuser length of $\sim 70 \mathrm{~mm}$.

Therefore, it can be concluded that a particular value of such angle is prominent in order for the complication-free operation.

Resemblance stated previously can again clearly be observed in Figure 77 which shows the variation of Mach number along the centerline. Curve shifts monitored, are due to the increase in total length of the ejector system. In these graphs the $\mathrm{x}$-axis refers to $\mathrm{x} / \mathrm{L}$ where $\mathrm{L}$ is the total length of the ejector.

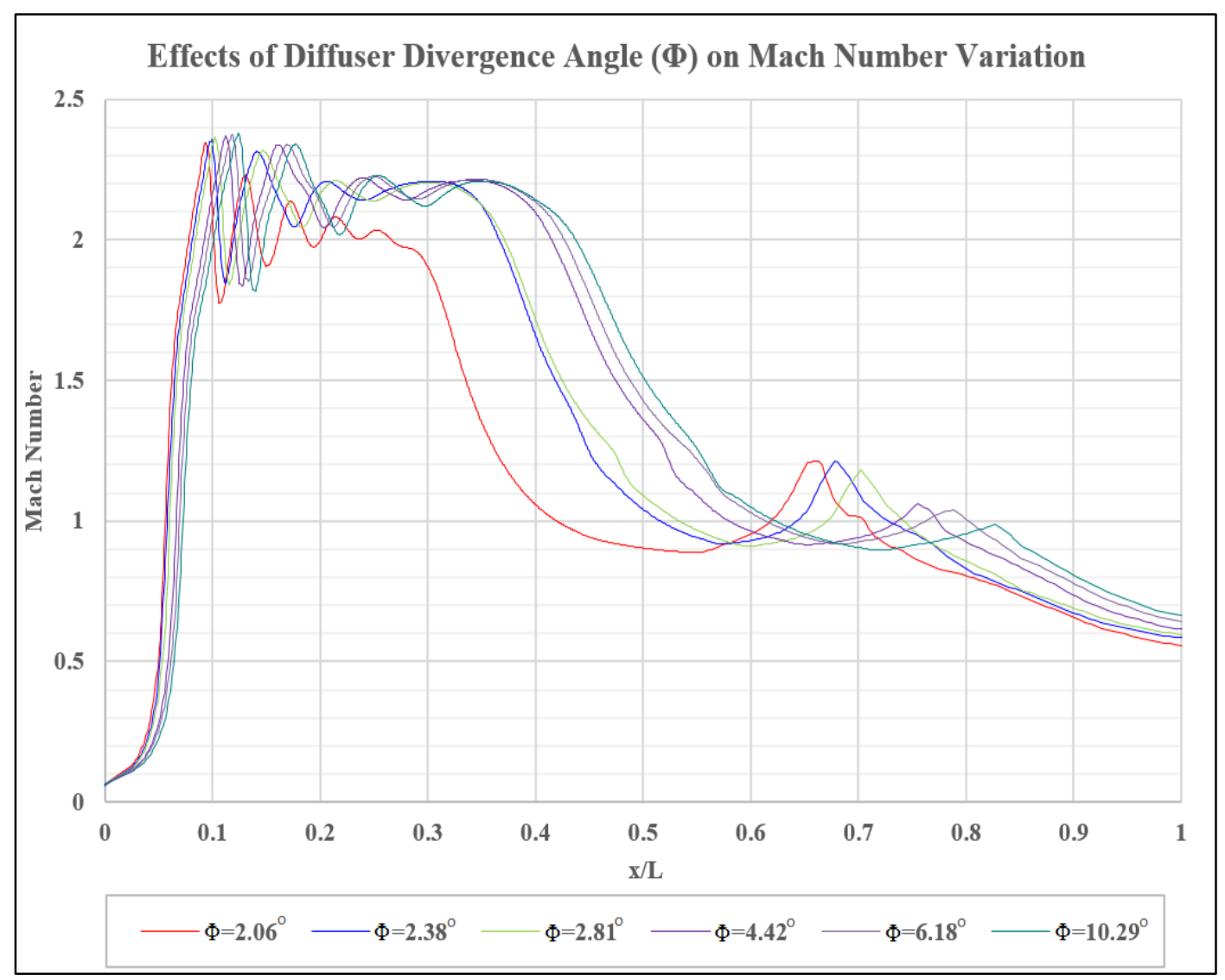

Figure 77. Effects of diffuser divergence angle on Mach number variation along the centerline

For the pressure variation analysis, again similar comments can be made, as of the Mach number distribution along the axis of the ejector. From the $\Phi$ of $2.06^{\circ}$ case in 
Figure 78, it is observed that the shock-cell patterns are more apparent giving more distinctive pressure variations along the axis of the ejector.
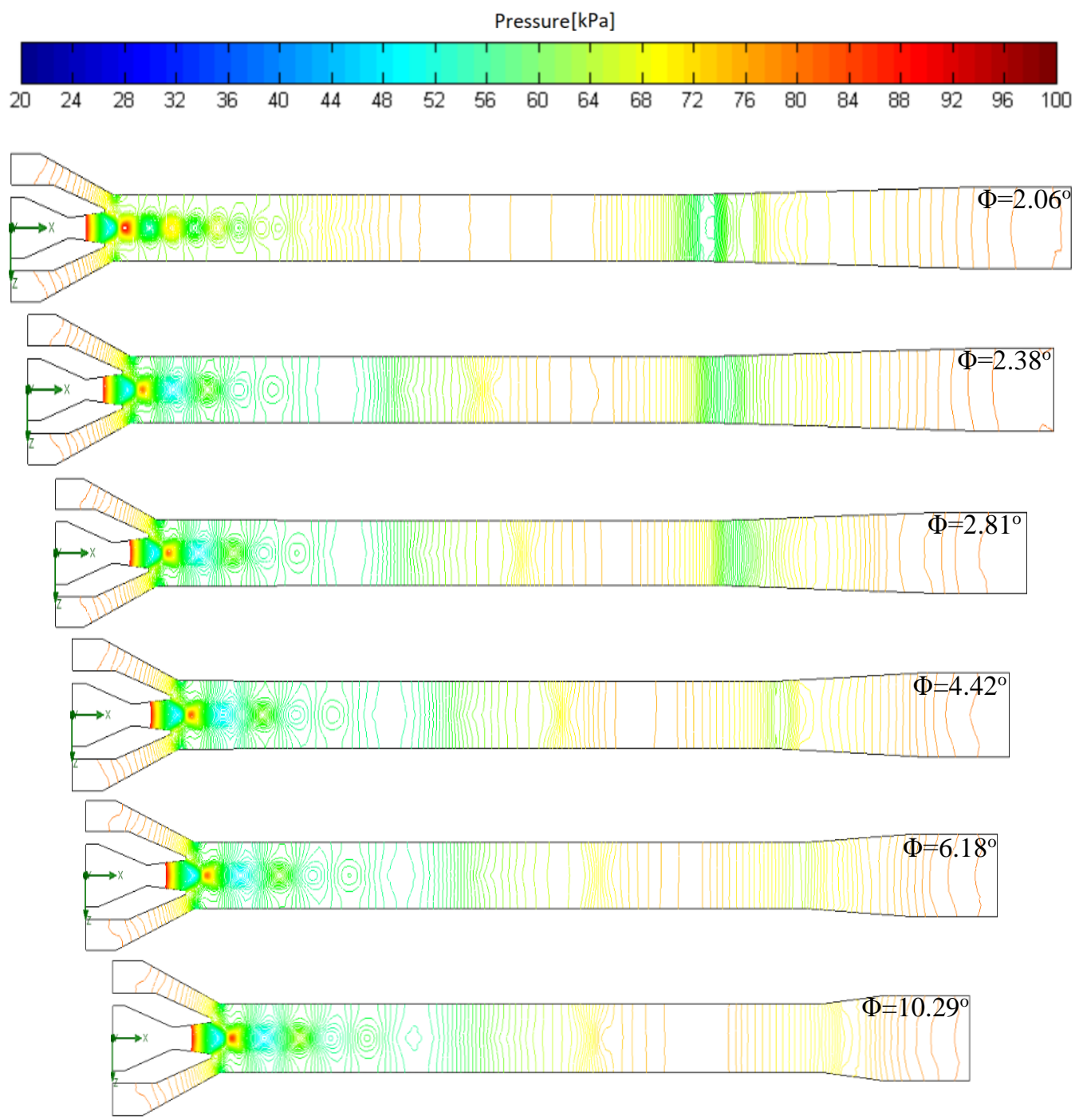

Figure 78. Pressure iso-contours for the corresponding diffuser divergence angles

Pressure variation through the system is studied and presented in Figure 79 as pressure variation contours along the central line of the ejector.

Looking at the plot shown in Figure 79, the pressure variation along the axis of the ejector, once again, almost identical form of Mach number fluctuations, as can be observed. 


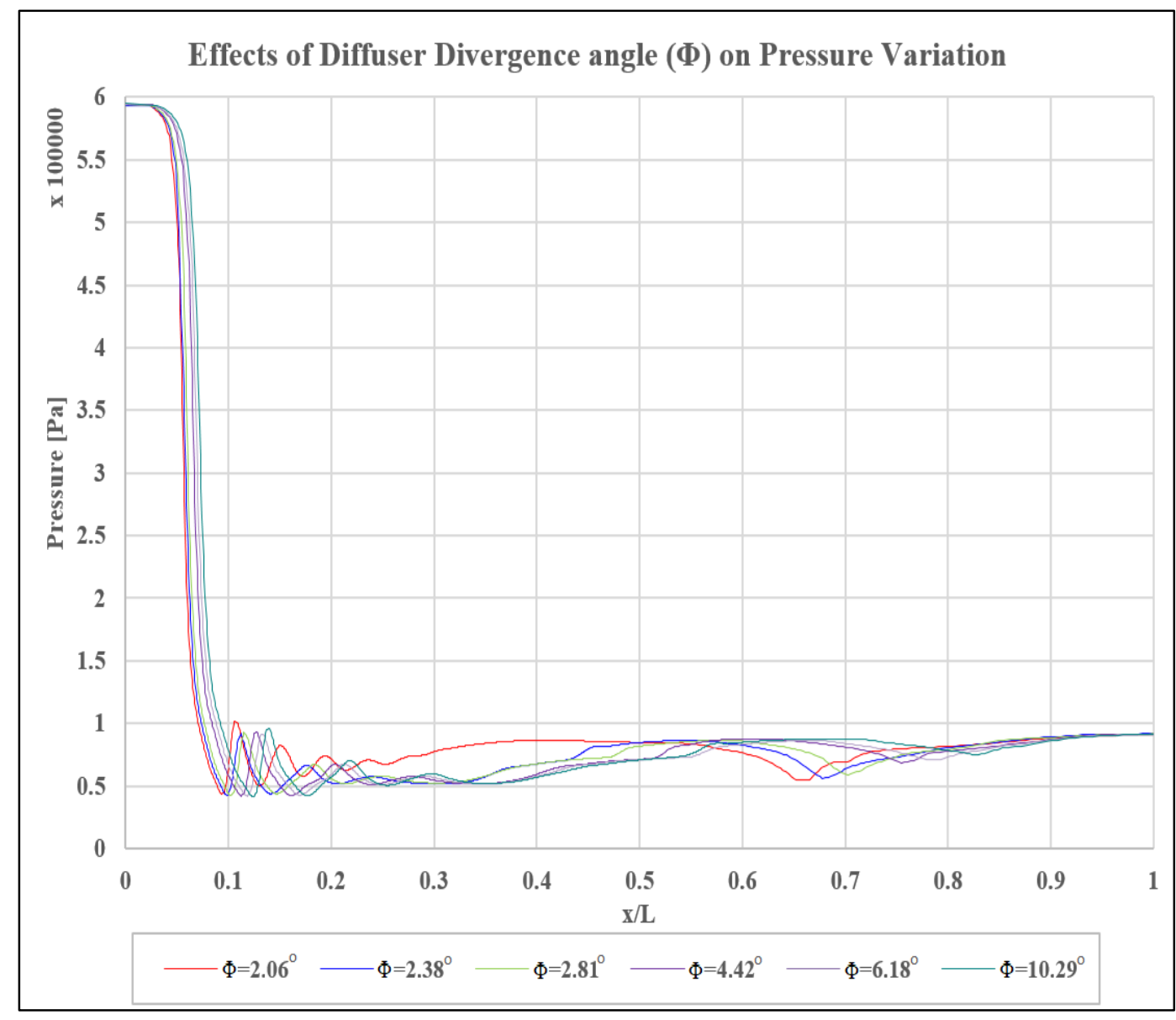

Figure 79. Effects of diffuser divergence angle on pressure variation along the centerline

\subsubsection{Conclusion}

The best and the most effective case for entrainment performance is found for a divergence angle of $\Phi=2.38^{\circ}$ and the entrainment ratio of 1.531 .

Although, the investigation of the diffuser segment of the ejector system boosts the performance, we can conclude that the performance of the ejector for best entrainment performance is insensitive to the diffuser angle, since there is no appreciable difference observed in the pressure variation along the axis.

However, if the cost is the main concern, then since increasing the angle results in an increase in the length of the ejector, it will also increase the cost of the system. 


\subsection{Outcomes of the Study}

The overall outcome of the present study is to enhance the performance of the ejector by improving the entrainment ratio by modifying the geometry of the ejector system. By simply playing with the geometrical parameters, it is observed that the flow characteristic for the primary and the secondary streams are significantly modified which in return effect the overall entrainment performance of the ejector system.

Table 15 gives the progressive enhancement of the entrainment ratio through the whole study, only by changing the geometrical parameters.

Table 15. Overall ejector performance enhancement

\begin{tabular}{|c|c|}
\hline Step \# & Entrainment Ratio (w) \\
\hline$\# \mathbf{1}$ & 1.283 \\
\hline$\# \mathbf{2}$ & 1.311 \\
\hline$\# \mathbf{3}$ & 1.321 \\
\hline$\# \mathbf{4}$ & 1.507 \\
\hline \#5 & 1.507 \\
\hline$\# \mathbf{6}$ & 1.526 \\
\hline$\# \mathbf{7}$ & 1.532 \\
\hline
\end{tabular}

Analyses step number refers the corresponding section of the geometry of the ejector system given previously in the thesis; i.e. 1: convergent-divergent nozzle divergence angle study, 2: secondary inlet inner-wall angle study, 3: secondary inlet outer-wall angle study, 4: gap length study, 5: mixing chamber convergence angle study, 6: mixing throat length study and 7: diffuser divergence angle study.

The values given in Table 15 shows that, notable improvements on the performance can be achieved. Besides, even the resultant entrainment ratio may be further improved if a multi-parameter optimization study is performed, since these parameters are intercorrelated. 
Looking at the table and the discussion of individual sections, we can conclude that the gap length variation causes a significant boost on entrainment ratio whereas the mixing chamber convergence angle has the least effect.

As a result, over $20 \%$ increase can be achieved without any alterations on the working fluid properties of the system and solely by modifying the geometrical parameters of the design. 


\section{CHAPTER 5}

\section{CONCLUSION AND FUTURE WORK}

\subsection{Conclusion}

The main objective of this thesis was to design an efficient double-flux supersonic air ejector system. In order to determine the performance of an ejector and its associated "entrainment ratio", both a 1-D calculation and a numerical CFD computation are performed. Since the performance of an ejector systems are strongly dependent on the design, this thesis focuses on maximizing the entrainment ratio by modifying the angles and the lengths of the critical segments of the ejector, without altering the properties of the working fluids.

Firstly, a 1-D FORTRAN code is developed which gives brief preliminary flow properties as well as the dimensions of a dummy ejector geometry. The code is simply based on conservation equations, with isentropic relations along with ideal mixing assumptions. Then, in order to determine the distribution of the flow field within this geometry of the ejector, computational fluid dynamics (CFD) methods are used. Two well-known commercial CFD codes, "ANSYS Fluent" and "FloEFD", are used for this purpose.

In the first instance, the validity of the methods and tools are analyzed using two separate test geometries of ejector taken from the literature. Four test cases are investigated. These two commercial CFD codes are used, along with the k-epsilon realizable turbulence model and SST k-omega turbulence model are implemented to ANSYS Fluent solver and both the ideal wall and the real wall assumptions are applied 
to the FloEFD solver, and the 1-D FORTRAN code calculations for the same test cases are performed. Corresponding results are compared with the experimental and numerical results available in the literature and found that, apart from the ideal wall assumption of FloEFD where the wall effects are neglected and the flow is treated as inviscid, the computations are in agreement with the expectations. As a result, it is decided that the use of the commercial software package Solidworks Flow Simulation (FloEFD) together with the CAD tool are found to be more convenient since the geometrical and operational aspects of the system can be investigated in a single package throughout the study. Using such a tool makes the preparation of the model geometry and performing the computational analyses for the overall study, advantageous taking into account the effort and the computational rapidity.

Once the methods and tools are validated, investigation of the effects of the design on the performance of a double-flux supersonic air ejector system as well as the maximization of the performance are realized. During the study, the aerothermodynamic properties of the working fluids are unaltered. The angles and the lengths of the critical segments are introduced separately and is modified in order to obtain the progress in performance of entrainment ratio. The effect of geometry modifications on the flow characteristics are also observed using the CFD methods.

Analyses corresponding to the modifications of the convergent-divergent nozzle divergence angle, secondary inlet inner-wall angle, secondary inlet outer-wall angle, gap length, mixing chamber convergence angle, mixing throat length and diffuser divergence angle respectively are observed using the CFD method. Gap length variation results in a significant boost of the entrainment ratio whereas the mixing chamber convergence angle has practically no effect. An enhancement of almost $20 \%$ in entrainment performance is obtained solely by modifying the ejector's critical segments without changing the operating conditions. However, it is also deduced that during these modifications, the complex flow structure through the system, especially within the mixing region, should not be disregarded for a thorough performance maximization and an efficient ejector operation. 
As a result, it can be concluded that the geometry of the ejector has a prominent effect on its performance as much as its operating conditions and they drastically influence the characteristics of the flow inside the ejector. Therefore, performing similar design modifications one can reach the desired performance characteristics for the ejector without modifying the properties of the working fluids and the environmental conditions.

\subsection{Future Work}

For the future improvements of the present study, following topics can be proposed;

- Experimentation including the pressure, temperature and mass flow rate measurements may be performed. This pressure and temperature measurements covers both measurements at the wall and/or along the centerline which is uncommon and quite challenging to achieve without disturbing the flow since i.e. a rigid rod has to be placed along the centerline of the ejector for the measurements. Therefore, different techniques on predicting the operation, the improvements etc. may be achieved.

- Specific topics related to the ejector systems may be investigated such as constant-area and constant pressure mixing assumptions since there is no apparent advantage of one over the other. A more detailed investigation on the flow characteristics on these approaches and the corresponding design alternatives may be evaluated.

- On the other hand, the off-design performance investigation of the ejector may be performed since these ejector systems usually operates for a wide range of working conditions. Therefore, an optimal ejector design covering a range of working conditions may be achieved.

- Multi-flux ejector systems may be investigated and the corresponding advantages or disadvantages may be evaluated.

- Ejector operations with alternative working fluids may be investigated therefore; suitable operations of the ejector may be achieved. 
- Transient behavior of the ejector systems may be investigated, covering the starting or unstarting of such system. The starting or unstarting loads can be evaluated and corresponding issues or the improvements may be performed. 


\section{REFERENCES}

[1] C. Liao, "Gas Ejector Modeling for Desing and Analysis," College Station, 2013.

[2] W. Chen, K. Xue, H. Chen, D. Chong and J. Yan, "Experimental and Numerical Analysis on the Internal Flow of Supersonic Ejector Under Different Working Modes," Heat Transfer Engineering, pp. 1-11, 2017.

[3] L. Cheng, "Operation of Steam Ejectors in Series," Montreal, 1961.

[4] Daneshmand, S.; Aghanajafi, C.; Bahrami, A.;, "Analytical and Experimental Methods of Design for Supersonic Two-Stage Ejectors," World Academy of Science, Engineering and Technology, vol. 3, no. 2, 2009.

[5] R. Manikanda Kumaran, P. K. Vivekand, T. Sundararajan, K. Kumaresan and D. Raja Manohar, "Analysis of Diffuser and Ejector Performance in a High Altitude Test Facility," in 45th AIAA/ASME/SAE/ASEE Joint Propulsion Conference \& Exhibit, Denver, 2009.

[6] S. Rajkumar, G. Eswar phani kumar and J. K. Ganesan, "Second Throat Diffuser System at Different Back Pressure for High Altitude Test," International Research Journal of Engineering and Technology (IRJET), vol. 4, no. 1, pp. 75-80, 2017.

[7] J. B. Rose, G. R. Jinu and C. J. Brindha, "A Numerical Optimization of High Altitude Testing Facility for Wind Tunnel Experiments," Chineese Journal of Aeronautics, vol. 28, no. 3, pp. 636-648, 2015.

[8] R. Manikanda Kumaran, P. Vivekand, T. Sundararajan, K. Kumaresan and D. Raja Manohar, "Optimization of Second Throat Ejectors for High-Altitude Test Facility," Journal of Propulsion and Power, vol. 25, no. 3, pp. 697-706, 2009.

[9] V. Dvorak, "Shape Optimization of Supersonic Ejector for Supersonic Wind Tunnel," Applied and Computational Mechanics, vol. 4, pp. 15-24, 2010.

[10] "Trisonic Test Section Cologne (TMK)," [Online]. Available: www.dlr.de/as/en.

[11] J. C. Dutton and B. F. Carroll, "Optimal Supersonic Ejector Designs," Journal of Fluids Engineering-Transactions of the American Society of Mechanical Engineers, vol. 108, pp. 414-420, 1986.

[12] Y. Bartosiewicz, Z. Aidoun, P. Desevaux and Y. Mercadier, "Numerical and Experimental Investigations on Supersonic Ejectors," International Journal of Heat and Fluid Flow, vol. 26, pp. 56-70, 2005. 
[13] van Eeden, Pierre; Ercolani, Dario;, "A Method for Prediction of Gas/Gas Ejector Performance," ILF Beratende Ingenieure GmbH, 2013.

[14] A. Mattos and R. Medronho, "Optimization of a Supersonic Ejector Coupled with a CFD Analysis," in AIChE Annual Meeting, 2012.

[15] S. Croquer, S. Poncet and N. Galanis, "Coupled Thermodynamic And CFD Approaches Applied to a Supersonic Air Ejector," 16th International Refrigeration and Air Conditioning Conference, 2016.

[16] J. Gagan, K. Smierciew, D. Butrymowicz and J. Karwacki, "Comparative Study of Turbulence Models in Application to Gas Ejectors," International Journal of Thermal Sciences, pp. 9-15, 2014.

[17] Maghsoodi, A.; Ahmadikia, H.; Dadvar, M.; , "A New 1D Model for Supersonic Ejector Performance Evaluation at Critical and Sub-critical Operational Modes," International Journal of Air-Conditioning and Refrigration, vol. 22, no. 1, 2014.

[18] F. Yamamoto, Y. lemoto, C. Kinugasa and N. Heya, "Performance of Subsonic Air Ejector with Multiple Nozzles : Effects of Dimensions of Nozzle Spacing and Parallel Part of Diffuser," Transactions of the Society of Heating,Air-conditioning and Sanitary Engineers of Japan, vol. 8, no. 21, pp. 23-30, 1983.

[19] S. Watanawanavet, "Optimization of a High-Efficiency Jet Ejector by Computational Fluid Dynamics Software," College Station, 2005.

[20] J. H. Hart, "Supersonic Ejector Simulation and Optimisation," Sheffield, 2002.

[21] A. Mittal, R. Gopalapillai, V. Lijo and H. Kim, "Starting Transients in Vacuum EjectorDiffuser System," Journal of Propulsion and Power, vol. 30, pp. 1213-1223, 2014.

[22] McGovern, Ronan K.; Bulusu, Kartik V.; Antar, Mohammed A.; Lienhard V, John H.; "One-dimensional Model of an Optimal Ejector and Parametric Study of Ejector Efficiency," in 25th International Conference on Efficiency, Cost, Optimization and Simulation of Energy Conversation Systems and Processes (ECOS 2012), 2012.

[23] Huang, B. J.; Chang, J. M.;, "Empirical Correlation for Ejector Design," International Journal of Refrigeration, vol. 22, pp. 379-388, 1999.

[24] J. M. Meyers, "Over- and Under-expanded Nozzles and Nozzle Configurations," [Online]. Available: http://www.cems.uvm.edu/ jmmeyers/ME239/Slides/04\%20\%200ver\%20and\%20Under\%20Expansions\%20and\%20Nozzle\%20Configurations\%2 0v1.pdf. 
[25] M. V. Srisha and G. Jagadeesh, "Observations on the Non-mixed Length and Unsteady Shock Motion in a Two-Dimensional Supersonic Ejector," Physics of Fluids, vol. 26, no. 3, 2014.

[26] P. Desevaux, "A Method for Visualizing the Mixing Zone Between Two Co-Axial Flows in an Ejector," Optics and Lasers in Engineering, vol. 35, pp. 317-323, 2001.

[27] D. Guariglia, "Shock-Cell Noise Investigation on a Subsonic/Supersonic Coaxial Jet," Roma, 2017.

[28] H.-D. Kim, T. Setoguchi, S. Yu and S. Raghunathan, "Navier-Stokes Computations of the Supersonic Ejector-Diffuser System with a Second Throat," Journal of Thermal Science, vol. 8, p. 79, 1999.

[29] D. T. Daniel, "A General Simulation of an Air Ejector Diffuser System," Knoxville, 2010.

[30] Y. M. Antonio, C. Périlhon, G. Descombes and C. Chacoux, "Thermodynamic Modelling of an Ejector with Compressible Flow by a One-Dimensional Approach," Entropy, vol. 4, pp. 599-613, 2012.

[31] S. Ghorbanian and S. J. Nejad, "Ejector Modeling and Examining of Possibility of Replacing Vacuum Pump in Vacuum Production Systems," International Journal of Chemical Engineering and Applications, vol. 2, no. 2, pp. 91-97, 2011.

[32] J. Archalous, "Mathematical model of ejector and experimental verification," 31. Setkani Kateder Mechaniky Tekutin a Termomechaniky, pp. 26-28, 2012.

[33] N. Hall, "Isentropic Flow Equations - NASA," 05 May 2015. [Online]. Available: https://www.grc.nasa.gov/www/k-12/airplane/isentrop.html.

[34] N. Hall, "Rocket Thrust Equations - NASA," 05 May 2015. [Online]. Available: https://www.grc.nasa.gov/www/k-12/airplane/rktthsum.html.

[35] W. Hongqiang, L. Zhongliang, H. Bing and L. Yanxia, "Numerical Investigation of the Influences of Mixing Chamber Geometries on Steam Ejector Performance," The International Journal on the Science and Technology of Desalting and Water Purification, vol. 353, pp. 15-20, 2014.

[36] C. Shi, H. Chen, W. Chen, S. Zhang, D. Chong and J. Yan, "1D Model to Predict Ejector Performance at Critical and Sub-critical Operation in the Refigeration System," Clean, Efficient and Affordable Energy for a Sustainable Future: The 7th International Conference on Applied Energy (ICAE2015), vol. 75, pp. 1477-1483, 2015. 
[37] N. Hall, "Normal Shock Wave Equations - NASA," 05 May 2015. [Online]. Available: https://www.grc.nasa.gov/www/k-12/airplane/normal.html.

[38] J. M. A. Dandachi, "Steam Air Ejector Performance and Its Dimensional Parameters," Loughborough, 1990.

[39] L. Su, "CFD Simulation and Shape Optimization of Supersonic Ejectors for Refrigeration and Desalination," Engineering and Applied Science Theses \& Dissertations, 2015.

[40] O. Lamberts, P. Chatelain and Y. Bartosiewicz, "Experimental and Numerical Analysis of the Flow within a Supersonic Ejector," in Proceedings of CHT-17 ICHMT International Symposium on Advances in Computational Heat Transfer, Napoli, 2017.

[41] Z. Zhang, W. Zhang, Z. J. Zhai and Q. Y. Chen, "Evaluation of Various Turbulence Models in Predicting Airflow and Turbulence in Enclosed Environments by CFD: Part 2-Comparison with Experimental Data from Literature," HVAC\&R Research, vol. 13, no. 6, pp. 871-886, 2007.

[42] B. Elhub, "Review of Ejector Desgn Parameters and Geometry for Refrigeration and Air Conditioning Application," Computer Applications in Environmental Sciences and Renewable Energy, pp. 54-66, 2014.

[43] J. D. Anderson Jr., Fundementals of Aerodynamics, 5th ed., McGraw-Hill Education, 2010. 


\section{APPENDIX A}

\section{TEMPERATURE AND PRESSURE EFFECTS ON THE ENTRAINMENT PERFORMANCE}

In this section, the entrainment ratio behavior when the temperatures or the pressures of the primary and the secondary working fluids are different is analyzed.

To begin with, the ratio of the primary fluid jet stagnation temperature $\left(T_{01}\right)$ to the secondary fluid jet temperature $\left(T_{02}\right)$ is altered since the idea behind is the difference between the energies of such streams, and the resulting entrainment ratio is presented, including the one-dimensional analyses as well as the CFD analyses.

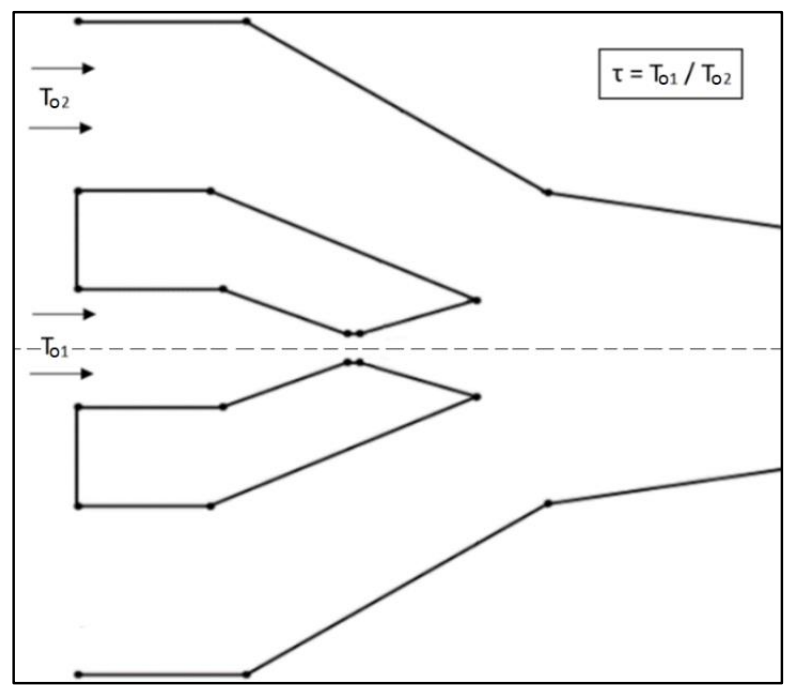

Figure 80. Operation illustration - additional study I - stagnation temperatures of the corresponding working fluids

The visual demonstration of such study can be observed in Figure 80 . Throughout the study, the ratio of the temperatures is changed while the rest of the parameters, properties as well as the geometry of the configuration are kept unaltered. 
The results obtained are presented in Table 16 along with the plot of the entrainment ratio with respect to the temperature ratios in Figure 81.

Table 16. Entrainment ratio results for the corresponding temperature ratios

\begin{tabular}{|c|c|c|}
\hline $\boldsymbol{\tau}=\mathbf{T}_{\mathbf{0} 1} / \mathbf{T}_{\mathbf{0} 2}$ & $\begin{array}{c}\text { Numerical Analyses } \\
\text { Entrainment Ratio }(\mathbf{w})\end{array}$ & $\begin{array}{c}\text { 1-D Approach } \\
\text { Entrainment Ratio }(\mathbf{w})\end{array}$ \\
\hline $\mathbf{1 . 1 8}$ & 1.197 & 1.602 \\
\hline $\mathbf{1 . 3 5}$ & 1.238 & 1.713 \\
\hline $\mathbf{1 . 4 4}$ & 1.362 & 1.769 \\
\hline $\mathbf{1 . 6 1}$ & 1.532 & 1.871 \\
\hline $\mathbf{1 . 7 3}$ & 1.590 & 1.939 \\
\hline $\mathbf{1 . 9 6}$ & 1.684 & 2.059 \\
\hline $\mathbf{2 . 1 3}$ & 1.753 & 2.147 \\
\hline $\mathbf{2 . 3 0}$ & 1.817 & 2.232 \\
\hline
\end{tabular}

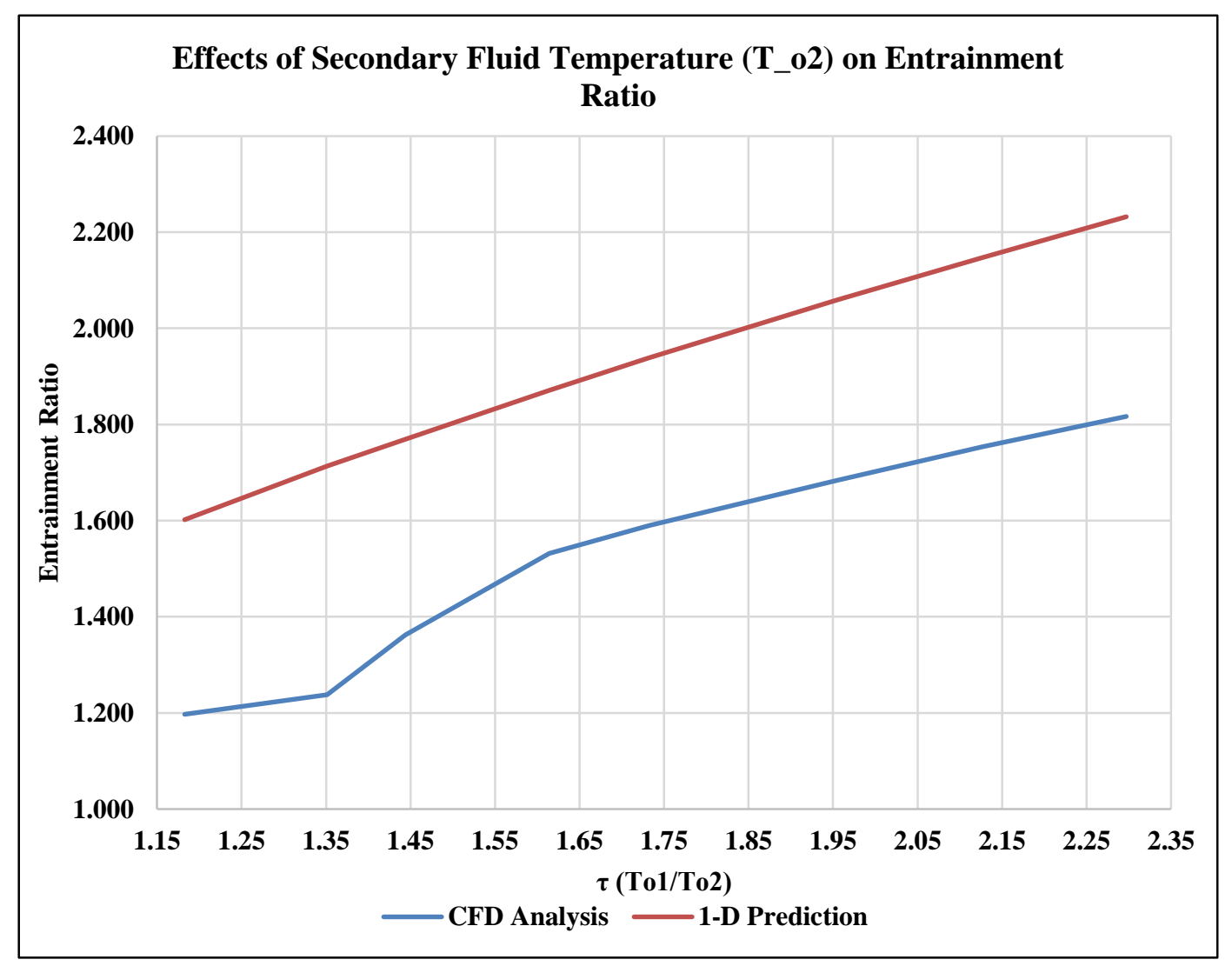

Figure 81. Change of entrainment ratio with the primary fluid temperature 
Looking at the results obtained in Figure 81; the temperature ratio of the primary fluid to the secondary fluid has a significant effect on the entrainment performance of a supersonic ejector system. As the ratio $(\tau)$ increases, the secondary flow drained through the system increases, due to the fact that the energy of the primary supplied fluid is greater, in the similar way as the ability to entrain. Hence, it can be said that, scaling the ratio of the supplied working fluid to the fluid to be vacuumed out, is another way to improve the entrainment performance of a supersonic ejector system.

One can explicitly observe that, both of the methods are based on the one-dimensional approach and the numerical CFD analysis, give results with almost similar entrainment trends by altering the primary fluid temperature. The amount of difference in between the methods is due to the fact that is already discussed in section of "Gap Length Analysis".

This is followed by the investigation of the entrainment ratio behavior when the pressures of working fluids are varied and the results are presented.

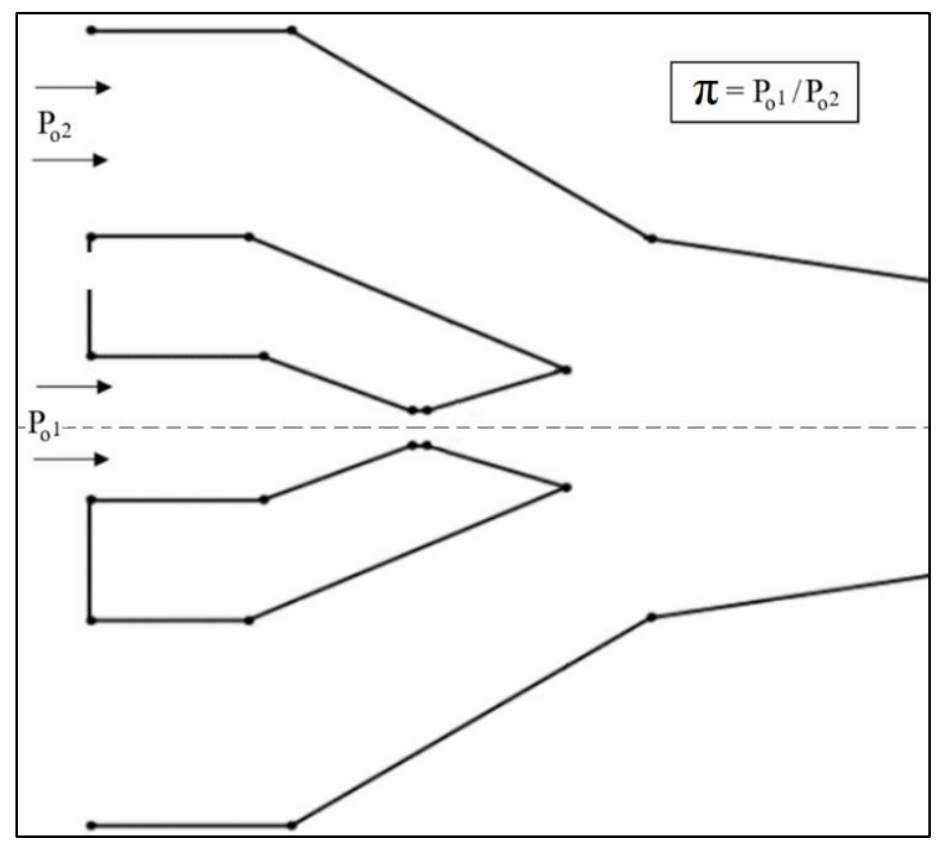

Figure 82. Operation illustration - additional study II - stagnation pressures of the corresponding working fluids 
Since the main parameter for the ejector to operate is the pressure itself, or in other words the pressure energies of the primary and the secondary fluids, such study is performed. The effect of the pressure difference (ratio) is revealed as well as the entrainment performance for the off-design conditions (i.e. different pressures at the primary, secondary or discharge flow openings) can be obtained. The effect of the pressure ratio $(\pi)$ is investigated by two separate means; i.e., $\pi$ is altered by increasing/decreasing either solely the primary pressure $\left(P_{01}\right)$ or solely the secondary pressure $\left(P_{\mathrm{O} 2}\right)$ and observe the different behaviors obtained as distinct from the previous section ( 0 - temperature ratio - $T_{o 1} / T_{o 2}$ - effects investigation).

Table 17. Entrainment ratio results for the corresponding pressure ratio values - primary stagnation pressure $\left(P_{o 1}\right)$ varied

\begin{tabular}{|c|c|c|}
\hline$\pi=P_{\mathbf{~} 1} / P_{\mathbf{~} 2}$ & $\begin{array}{c}\text { CFD Analyses } \\
\text { Entrainment Ratio }(\mathbf{w})\end{array}$ & $\begin{array}{c}\text { 1-D Approach } \\
\text { Entrainment Ratio (w) }\end{array}$ \\
\hline $\mathbf{4 . 6 0}$ & 1.421 & 2.659 \\
\hline $\mathbf{5 . 1 4}$ & 1.370 & 2.417 \\
\hline $\mathbf{5 . 6 9}$ & 1.402 & 2.195 \\
\hline $\mathbf{6 . 0 2}$ & 1.403 & 2.069 \\
\hline $\mathbf{6 . 5 6}$ & 1.532 & 1.871 \\
\hline $\mathbf{7 . 6 6}$ & 1.263 & 1.497 \\
\hline $\mathbf{7 . 8 8}$ & 1.231 & 1.420 \\
\hline $\mathbf{8 . 2 1}$ & 1.180 & 1.313 \\
\hline $\mathbf{8 . 7 5}$ & 1.104 & 1.126 \\
\hline $\mathbf{9 . 3 0}$ & 1.035 & 0.928 \\
\hline $\mathbf{9 . 8 5}$ & 0.970 & 0.704 \\
\hline
\end{tabular}

Looking at the results obtained in Figure 83, the ratio of primary fluid's total pressure to that of the secondary fluid's, defined as $\pi$, has significant effects on the entrainment performance of a supersonic ejector system. Pressure ratio $(\pi)$ values for the on-design case, the performance reduction can clearly be observed. As $\pi$ gets larger, pressure at the nozzle-exit (vacuum region) gets larger as well, thus the pressure difference 
between the secondary flow and the vacuum region is reduced, which results in a drop in the entrainment performance.

On the other hand, as $\pi$ gets smaller, the energy thus the ability of the system to entrain is attenuated; so, aside from the on-design condition, the system cannot operate effectively due to these concerns. Therefore, the ejector system should be designed considering such aspects.

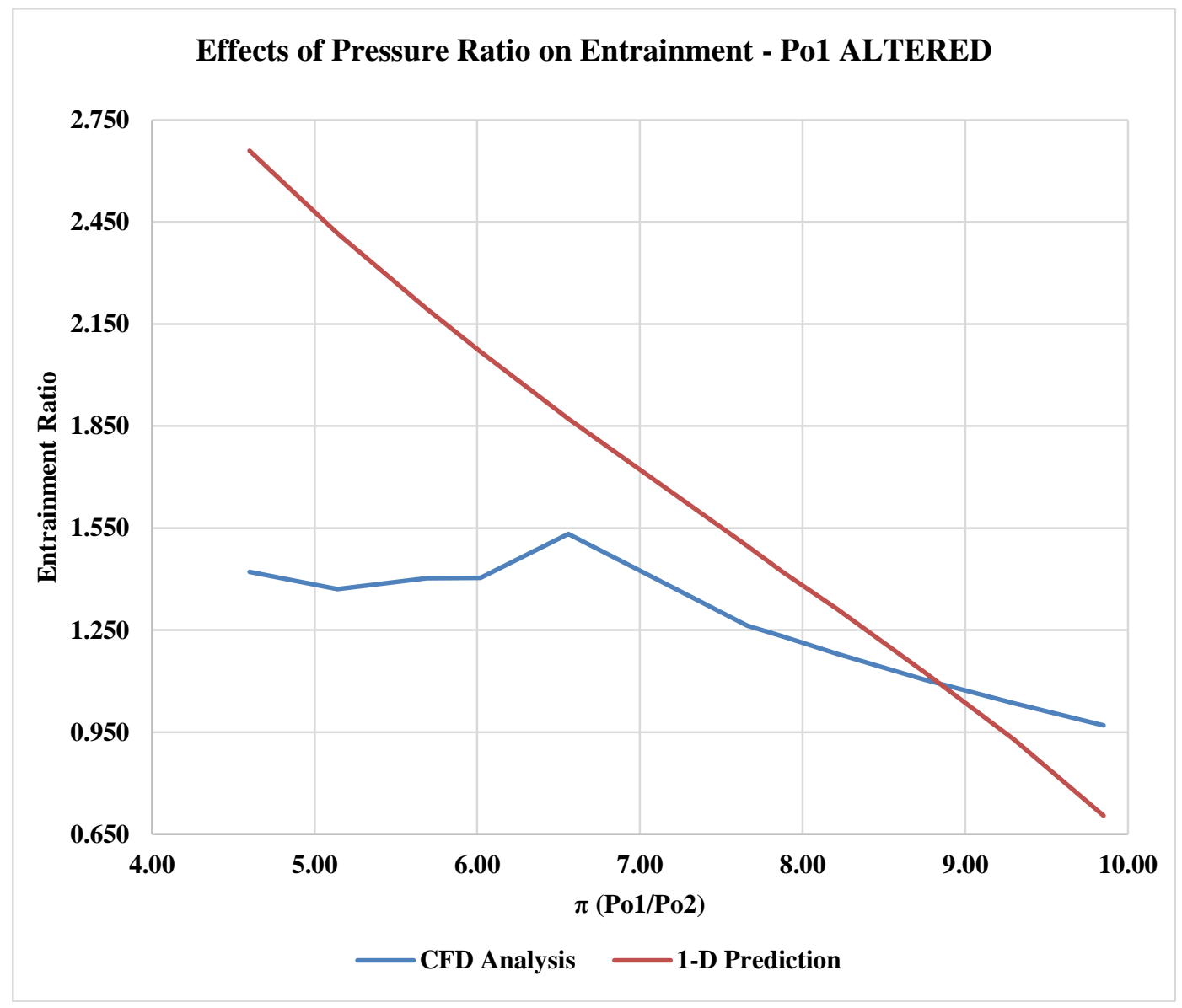

Figure 83. Change of entrainment ratio with the pressure ratio $\pi\left(P_{01}\right.$ altered)

The reason behind is the energy of the entrained fluid gets so low that it gets harder and harder to be vacuumed out or set in motion. At some certain point, despite the mathematics tells us it is possible (1-D approach), the physics of the operation within the ejector system shows the reality. 
Table 18. Entrainment ratio results for the corresponding pressure ratios - secondary stagnation pressure $\left(P_{o 2}\right)$ varied

\begin{tabular}{|c|c|c|}
$\pi=\boldsymbol{P}_{\mathbf{0 1}} / \boldsymbol{P}_{\mathbf{0} 2}$ & $\begin{array}{c}\text { CFD Analyses } \\
\text { Entrainment Ratio }(\mathbf{w})\end{array}$ & $\begin{array}{c}\text { 1-D Approach } \\
\text { Entrainment Ratio (w) }\end{array}$ \\
\hline $\mathbf{3 . 8 2}$ & 2.486 & 3.056 \\
\hline $\mathbf{4 . 1 4}$ & 2.289 & 2.885 \\
\hline $\mathbf{4 . 5 5}$ & 2.081 & 2.683 \\
\hline $\mathbf{5 . 0 0}$ & 1.894 & 2.478 \\
\hline $\mathbf{5 . 4 1}$ & 1.809 & 2.308 \\
\hline $\mathbf{5 . 8 3}$ & 1.689 & 2.143 \\
\hline $\mathbf{6 . 1 9}$ & 1.583 & 2.008 \\
\hline $\mathbf{6 . 5 6}$ & 1.532 & 1.871 \\
\hline $\mathbf{7 . 0 6}$ & 1.259 & 1.699 \\
\hline $\mathbf{7 . 4 1}$ & 1.187 & 1.581 \\
\hline $\mathbf{7 . 5 0}$ & 1.170 & 1.550 \\
\hline $\mathbf{7 . 5 9}$ & -0.059 & 1.518 \\
\hline $\mathbf{7 . 6 9}$ & -0.076 & 1.485 \\
\hline $\mathbf{7 . 7 9}$ & -0.092 & 1.451 \\
\hline $\mathbf{8 . 0 0}$ & -0.130 & 1.380 \\
\hline $\mathbf{8 . 8 2}$ & -0.275 & 1.101 \\
\hline $\mathbf{9 . 5 2}$ & -0.388 & 0.841 \\
\hline & & \\
\hline
\end{tabular}

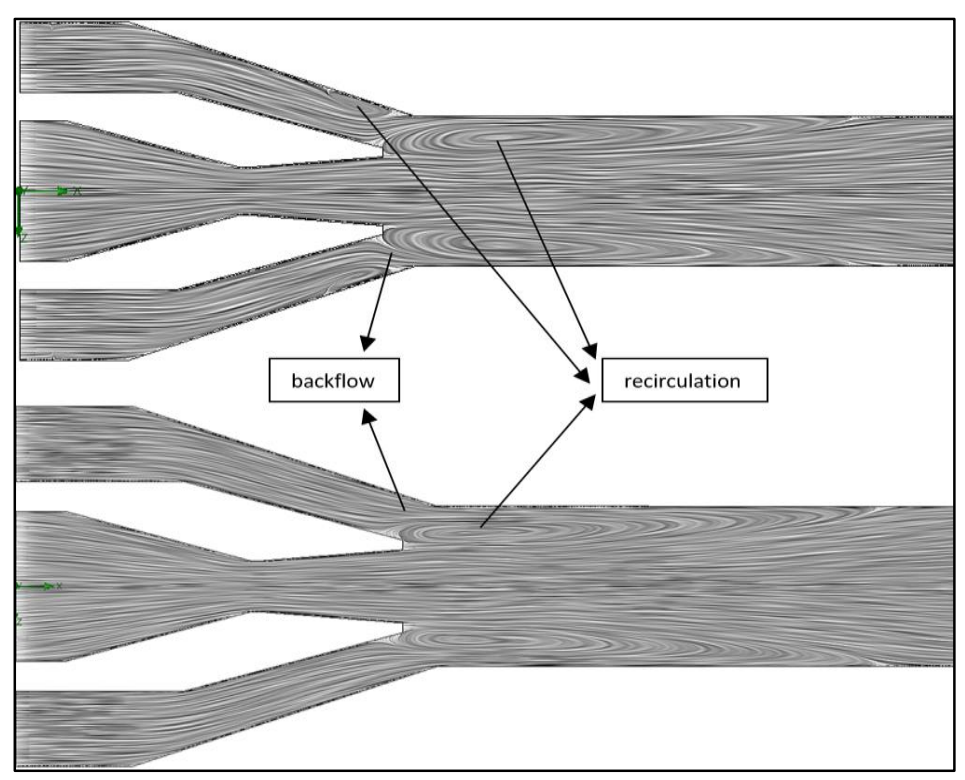

Figure 84. Streamlines for $\pi=7.59$ (upper) and $\pi=9.52$ (lower) 


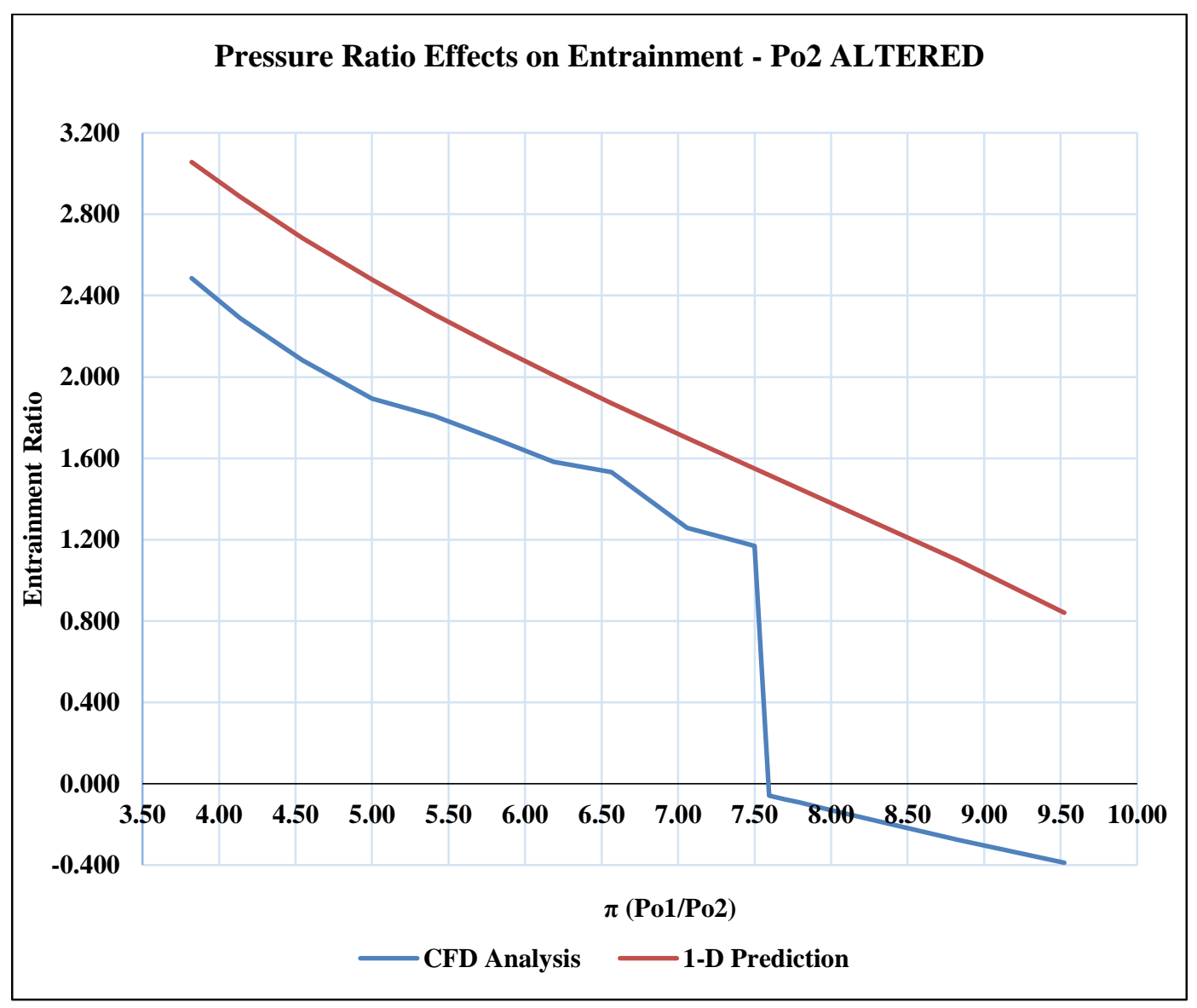

Figure 85 . Change of entrainment ratio with the pressure ratio $\pi\left(P_{o 2}\right.$ altered)

In order to further reveal the difference between the entrainment performance when merely the pressure of the primary fluid is altered and merely the pressure of the secondary fluid is altered separately, entrainment performance as a function of $\pi$ $=P_{01} / P_{02}$ is plotted in Figure 86.

Therefore, one can conclude that, decreasing the pressure ratio results in an increase of the entrainment, yet how the pressure ratio to be altered should be carefully decided considering the performance map of such.

Taking these results into consideration, modifications on the primary stagnation pressure $\left(P_{1}\right)$ will not yield significant profit, even result in performance reduction, apart from the on-design condition; since the convergent-divergent nozzle is designed and flow operation (i.e. vacuum level) is arranged by taking such on-design condition 
into account. On the other hand, increasing the secondary pressure $\left(P_{\mathrm{O} 2}\right)$ (thus decreasing the pressure ratio $-\pi$ ), is observed to be an efficient way to enhance the ejector performance, possibly until the rest of the geometry handles the processing flow throughout, i.e. pressure recovery, over-mass flow rate etc.

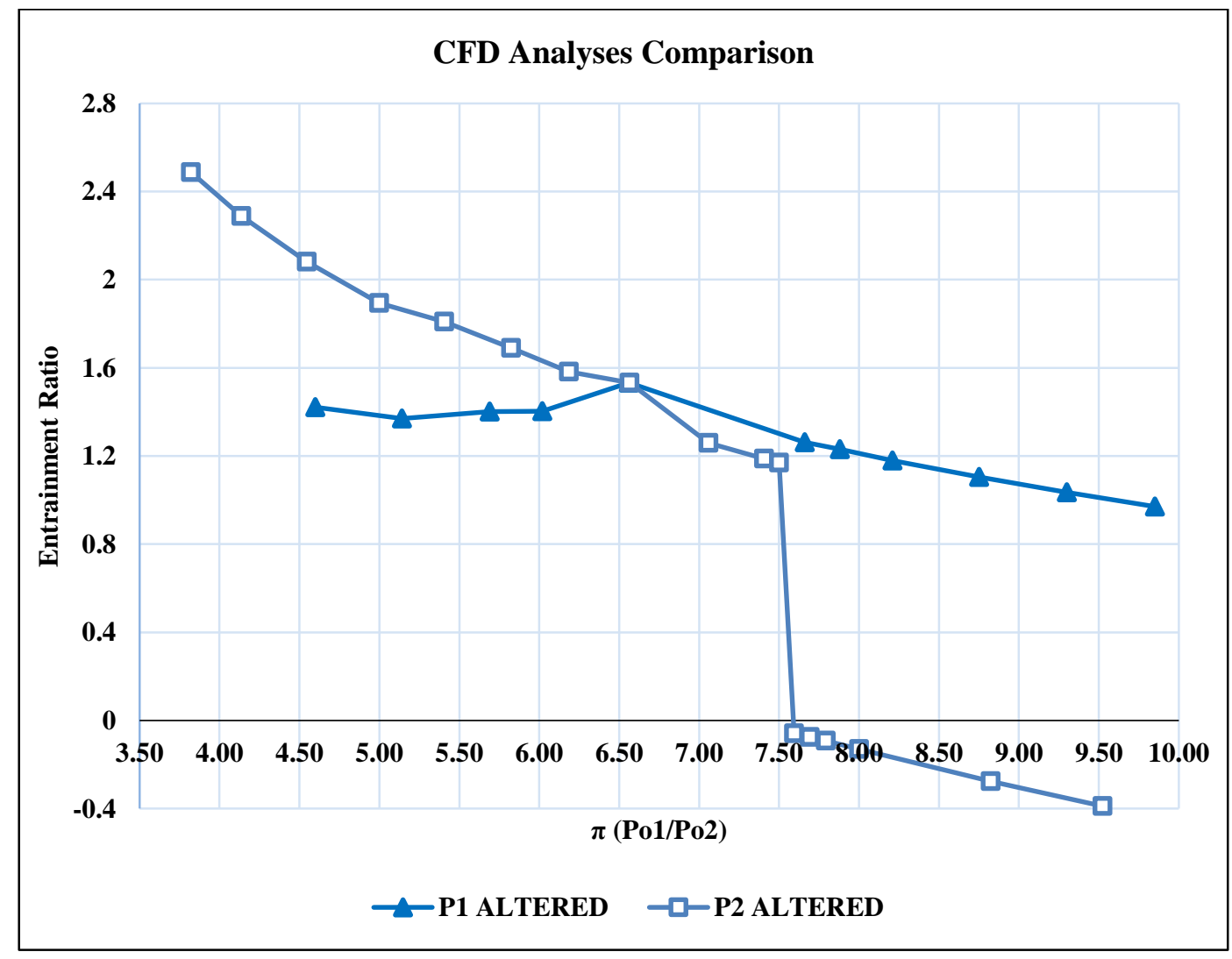

Figure 86. Entrainment performance versus pressure ratio $(\pi)$ comparison for both $P_{o 1}$ and $P_{o 2}$ altered cases 


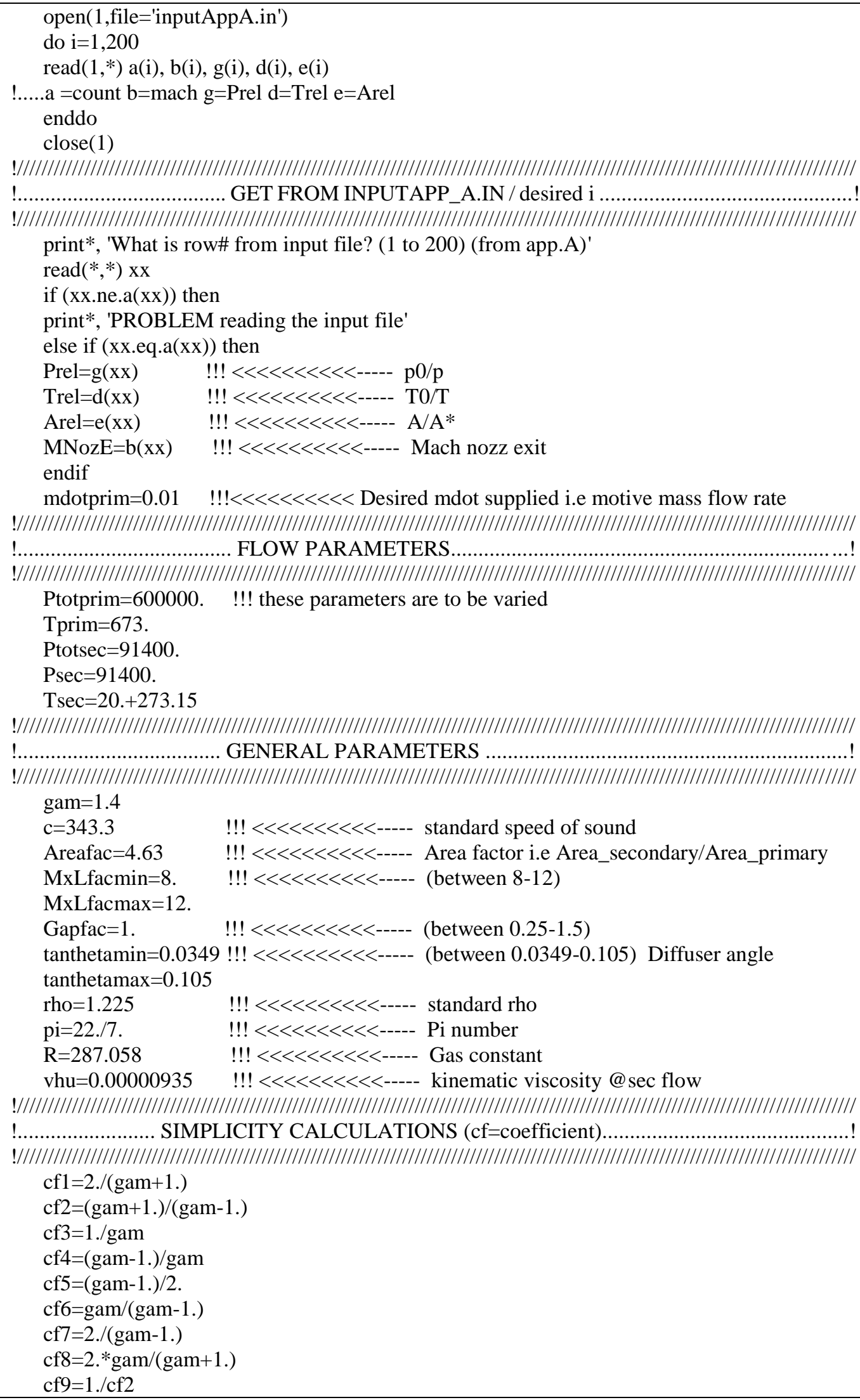




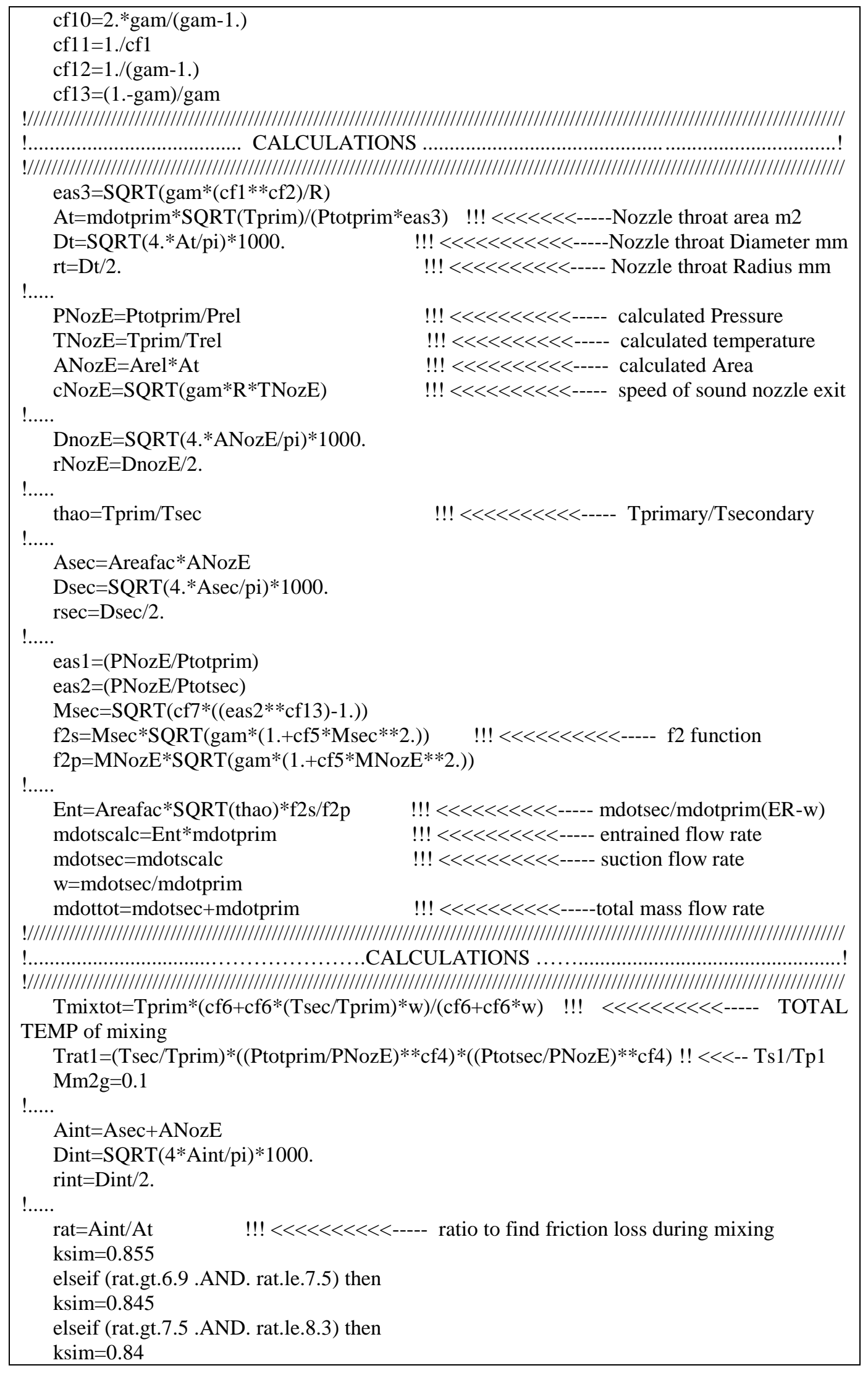




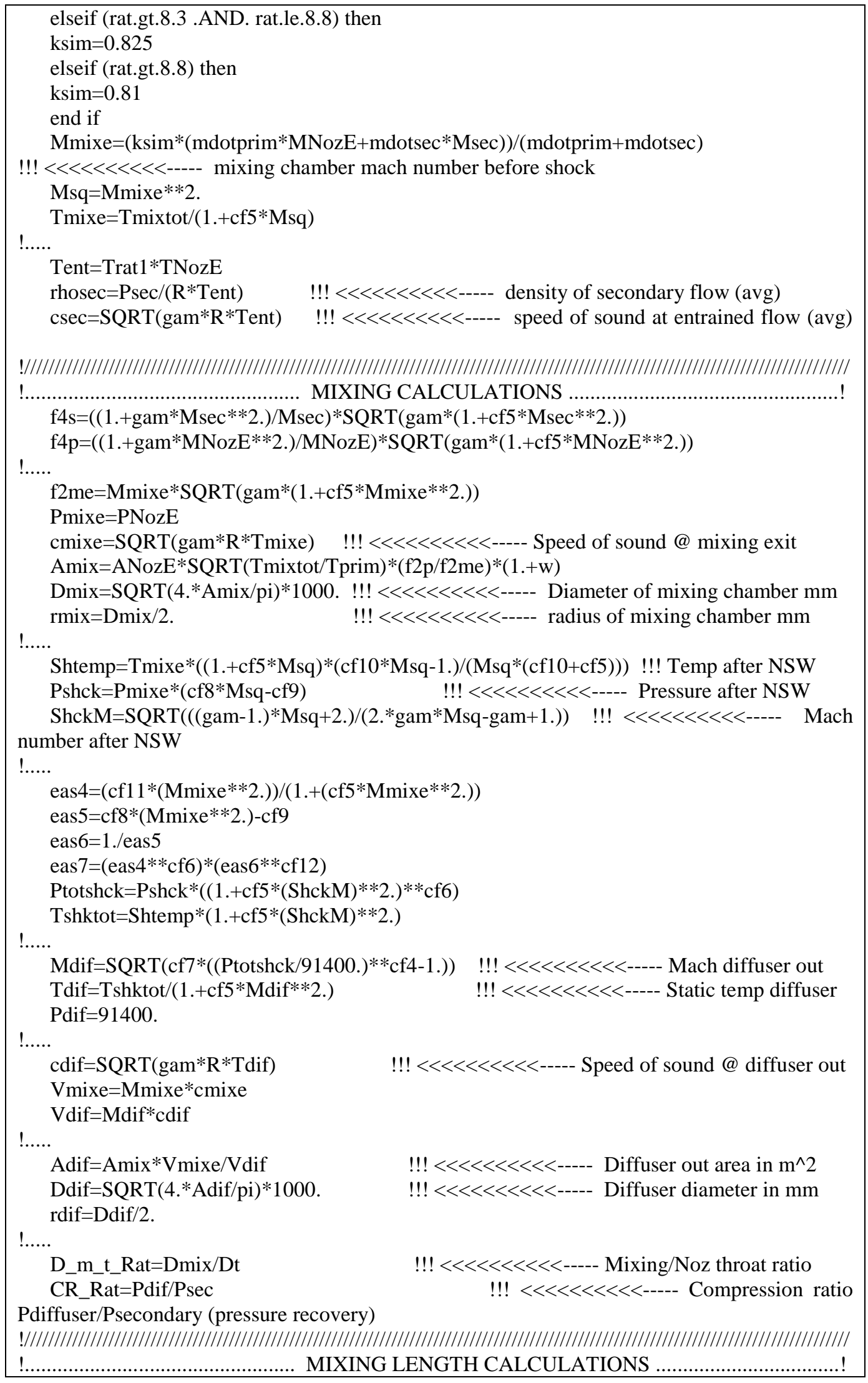




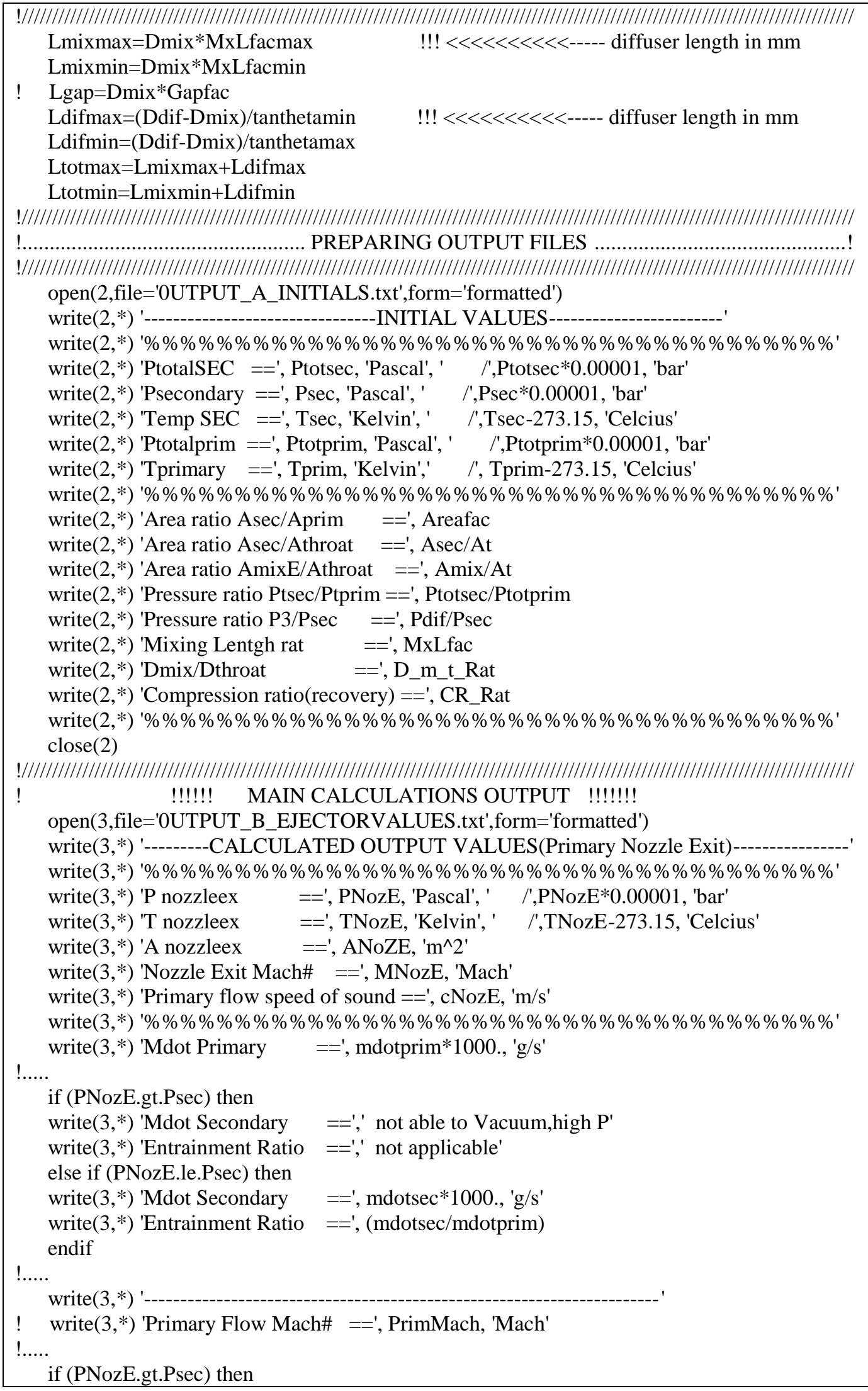


write( $3, *)$ 'NOT APPLICABLE'

else if (PNozE.le.Psec) then

write $(3, *)$ 'Secondary Flow Mach\# ==', Msec, 'Mach'

write $(3, *)$ 'Secondary Flow density ==', rhosec, 'kg/m3'

write $(3, *)$ 'Secondary Flow speedofsound ==', csec, 'm/s'

write $(3, *)$ '

write $(3, *)$ 'Mixing Flow Mach @exit==', Mmixe, ' Mach'

write $(3, *)$ 'Mixing Flow Temp @exit ==', Tmixe, 'Kelvin', ' I',Tmixe-273.15, 'Celcius'

write $(3, *)$ 'Mixing Flow Press @exit==', Pmixe, 'Pascal', ' I',Pmixe*0.00001, 'bar'

write $(3, *)$ 'Mixed Flow speedofsound ==', cmixe, 'm/s'

write $(3, *)$ '

write $(3, *)$ 'Mach after NSW ==', ShckM, ' Mach'

write $(3, *)$ 'Temp. aft. Normal Shock ==', Shtemp, 'Kelvin', ' /',Shtemp-273.15, 'Celcius'

write $(3, *)$ 'Pres. aft. Normal Shock ==', Pshck, 'Pascal', ' /',Pshck*0.00001, 'bar'

write $(3, *)$ '

write $\left(3,{ }^{*}\right)$ 'Diff speedofsound ==', cdif, 'm/s'

write $(3, *)$ 'Mach diffu out', Mdif

write $(3, *)$ 'Temp tot after NSW', Tshktot

write $(3, *)$ 'tmixtot', Tmixtot

write $(3, *)$ 'i', xx

write $(3, *)$ 'Pdiff out', Pdif

endif

!.....

write( $\left.3{ }^{*}\right)^{\prime} \% \% \% \% \% \% \% \% \% \% \% \% \% \% \% \% \% \% \% \% \% \% \% \% \% \% \% \% \% \% \% \% \% \% \% \% \% \% '$

! $\quad$ write $(3, *)$ 'Secondary Flow Reynolds\# ==', Rey

close(3)

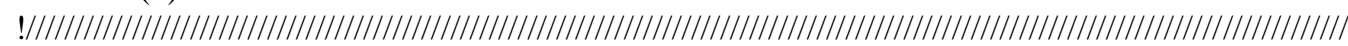

! CALCULATIONS OUTPUT

open(5,file='0UTPUT_C_DIMENSIONS_CONSTANT_PRESSURE.txt')

write(5,*) '----------------CONSTANT PRESSURE MIXING-

write $\left(5,{ }^{*}\right.$ ) $\% \% \% \% \% \% \% \% \% \% \% \% \% \% \% \% \% \% \% \% \% \% \% \% \% \% \% \% \% \% \% \% \% \% \% \% \%$ '

write $(5, *)$ 'DIMENSION PARAMETERS FOR 3D ANALYSIS'

write $(5, *)$ 'Area of the Noz Throat $==$ ', At, ' $\mathrm{m}^{\wedge} 2$ '

write $(5, *)$ 'Area mixing chamber $==$ ', Amix, ' $\mathrm{m}^{\wedge} 2^{\prime}$

write $(5, *)$ 'Area nozzle exit ==', ANozE, ' $\mathrm{m}^{\wedge} 2^{\prime}$

write $(5, *)$ 'Area secondary ==', Asec, ' $\mathrm{m}^{\wedge} 2^{\prime}$

write $(5, *)$ 'Area diffuserout toAtm ==', Adif, ' $\mathrm{m}^{\wedge} 2$ '

write $(5, *)$ '

write $\left(5,{ }^{*}\right)$ 'Diameter of Nozz exit ==', DnozE, 'mm', ' r ==',rnoze, 'mm'

write $(5, *)$ 'Diameter of Nozz throat==', Dt, 'mm', ' $r==', r t$, 'mm'

write $(5, *)$ 'Diameter of Mixing ==', Dmix, 'mm', ' $\mathrm{r}==$ ',rmix, 'mm'

write $(5, *)$ 'Diameter of Intersect. ==', Dint, 'mm', ' $r==$,rint, 'mm'

write $(5, *)$

write $(5, *)$ 'MIXING CHAMB LENGTH ==', Lmixmax, 'mm', ' <---->', Lmixmin, 'mm' write $(5, *)$ 'DIFFUSER LENGTH ==', Ldifmax, 'mm', ' <---->', Ldifmin, 'mm'

! $\quad$ write $(5, *)$ 'Nozzle-Mix inlet dist $==$ ', Lgap, 'mm'

write $(5, *)$ 'TOTAL LENGTH MIX+DIF ==', Ltotmax, 'mm', ' <---->', Ltotmin, 'mm' write $(5, *)$ '

write $(5, *)$ 'Diameter of Sec inlet ==', (Dmix-DNozE), 'mm',' r ==', (rmix-rNozE), 'mm' write $(5, *)$ 'Diameter of Diffuser ==', Ddif, 'mm',' $\mathrm{r}==$ ', rdif, 'mm'

write $\left(5,{ }^{*}\right.$ ) $\% \% \% \% \% \% \% \% \% \% \% \% \% \% \% \% \% \% \% \% \% \% \% \% \% \% \% \% \% \% \% \% \% \% \%$ ' close (5)

print *,'Entrainment Ratio = ', w

stop

end 
The corresponding input file that is "inputAppA.in" which includes the aerothermodynamic properties of a C-D nozzle (i.e.isentropic flow relations) obtained from the literature [43] is presented below. It has the information about the flow properties correlative to the desired Mach number at the exit of the C-D nozzle along with the area ratio of the nozzle exit to the nozzle throat cross-sections. The code reads the columns in order for the simplification of the calculations, saves the selected row and uses these values for the calculations.

Within the file, five separate columns can be found, and these columns refers to, the column number (i) for the selection, Mach number, the ratio of the total pressure to the static pressure $\left(\mathrm{P}_{0} / \mathrm{P}\right)$, the ratio of the total temperature to the static temperature $\left(\mathrm{T}_{0} / \mathrm{T}\right)$ at the exit of the C-D nozzle, and the ratio of C-D nozzle exit area to the throat area $\left(\mathrm{A} / \mathrm{A}^{*}\right)$ respectively [43]. Thus, the file has the aero-thermodynamic parameters for the desired Mach number at the exit of the nozzle from Mach 0 up to Mach 20, but considering the current study, only the range of Mach 1 up to Mach 4.75 is presented.

\begin{tabular}{|lllll|}
\hline 50.00 & 1.00 & 1.893 & 1.2000 & 1.000 \\
51.00 & 1.02 & 1.938 & 1.2081 & 1.000 \\
52.00 & 1.04 & 1.985 & 1.2164 & 1.001 \\
53.00 & 1.06 & 2.033 & 1.2247 & 1.003 \\
54.00 & 1.08 & 2.083 & 1.2333 & 1.005 \\
55.00 & 1.10 & 2.135 & 1.2420 & 1.008 \\
56.00 & 1.12 & 2.189 & 1.2509 & 1.011 \\
57.00 & 1.14 & 2.245 & 1.2599 & 1.015 \\
58.00 & 1.16 & 2.303 & 1.2691 & 1.020 \\
59.00 & 1.18 & 2.363 & 1.2785 & 1.025 \\
60.00 & 1.20 & 2.425 & 1.2880 & 1.030 \\
61.00 & 1.22 & 2.489 & 1.2976 & 1.037 \\
62.00 & 1.24 & 2.556 & 1.3075 & 1.043 \\
63.00 & 1.26 & 2.625 & 1.3175 & 1.050 \\
64.00 & 1.28 & 2.697 & 1.3277 & 1.058 \\
65.00 & 1.30 & 2.771 & 1.3380 & 1.066 \\
66.00 & 1.32 & 2.847 & 1.3484 & 1.075 \\
67.00 & 1.34 & 2.927 & 1.3591 & 1.084 \\
\hline
\end{tabular}




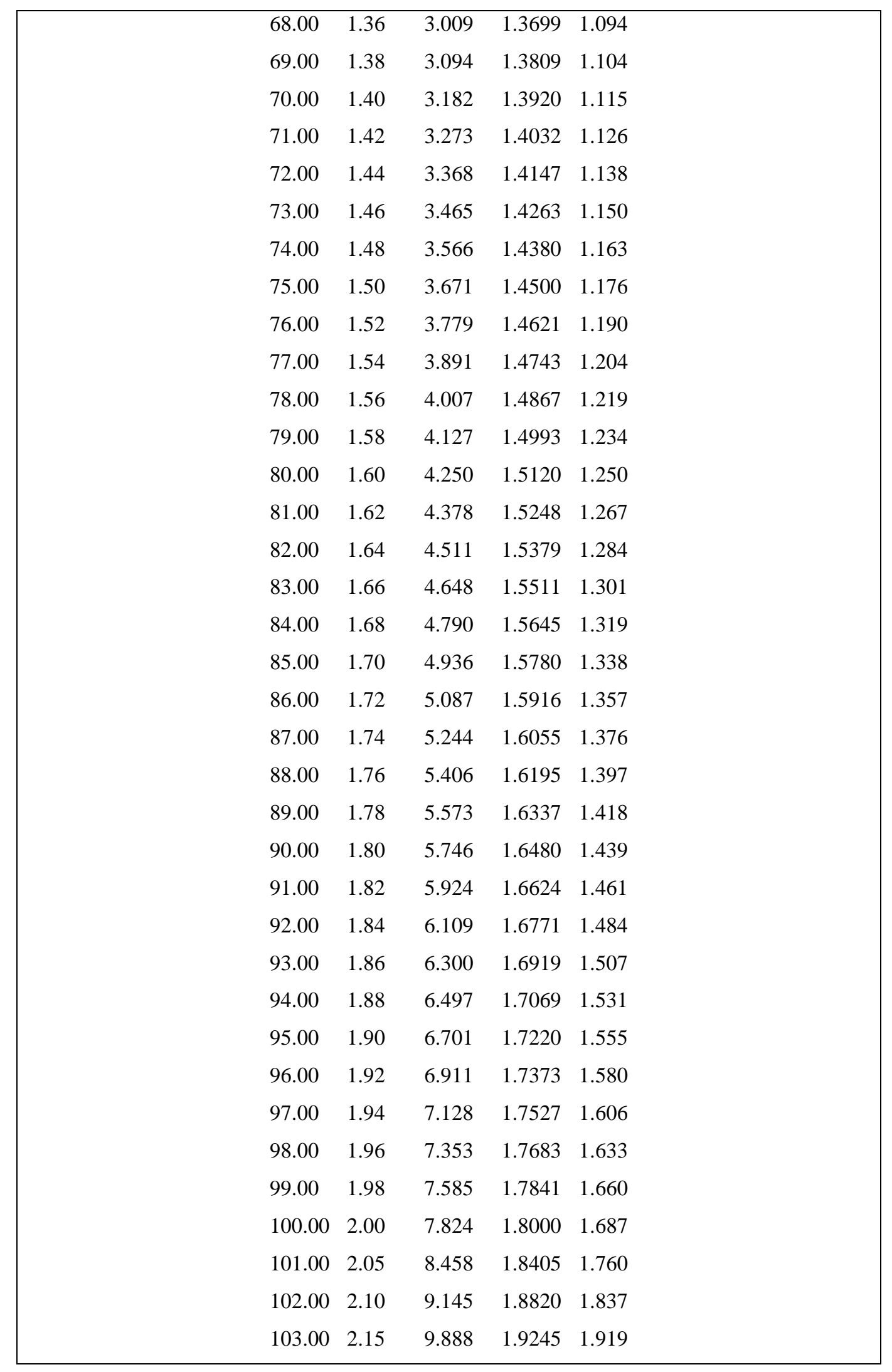




\begin{tabular}{|c|c|c|c|c|}
\hline 104.00 & 2.20 & 10.690 & 1.9679 & 2.005 \\
\hline 105.00 & 2.25 & 11.560 & 2.0123 & 2.096 \\
\hline 106.00 & 2.30 & 12.500 & 2.0578 & 2.193 \\
\hline 107.00 & 2.35 & 13.520 & 2.1044 & 2.295 \\
\hline 108.00 & 2.40 & 14.620 & 2.1520 & 2.403 \\
\hline 109.00 & 2.45 & 15.810 & 2.2007 & 2.517 \\
\hline 110.00 & 2.50 & 17.090 & 2.2502 & 2.637 \\
\hline 111.00 & 2.55 & 18.470 & 2.3006 & 2.763 \\
\hline 112.00 & 2.60 & 19.950 & 2.3519 & 2.896 \\
\hline 113.00 & 2.65 & 21.560 & 2.4046 & 3.036 \\
\hline 114.00 & 2.70 & 23.280 & 2.4579 & 3.183 \\
\hline 115.00 & 2.75 & 25.140 & 2.5125 & 3.338 \\
\hline 116.00 & 2.80 & 27.140 & 2.5680 & 3.500 \\
\hline 117.00 & 2.85 & 29.290 & 2.6246 & 3.671 \\
\hline 118.00 & 2.90 & 31.590 & 2.6819 & 3.850 \\
\hline 119.00 & 2.95 & 34.070 & 2.7404 & 4.038 \\
\hline 120.00 & 3.00 & 36.730 & 2.7999 & 4.235 \\
\hline 121.00 & 3.05 & 39.590 & 2.8606 & 4.441 \\
\hline 122.00 & 3.10 & 42.650 & 2.9221 & 4.657 \\
\hline 123.00 & 3.15 & 45.930 & 2.9846 & 4.884 \\
\hline 124.00 & 3.20 & 49.440 & 3.0480 & 5.121 \\
\hline 125.00 & 3.25 & 53.200 & 3.1126 & 5.369 \\
\hline 126.00 & 3.30 & 57.220 & 3.1780 & 5.629 \\
\hline 127.00 & 3.35 & 61.520 & 3.2445 & 5.900 \\
\hline 128.00 & 3.40 & 66.120 & 3.3120 & 6.184 \\
\hline 129.00 & 3.45 & 71.030 & 3.3805 & 6.480 \\
\hline 130.00 & 3.50 & 76.270 & 3.4500 & 6.790 \\
\hline 131.00 & 3.55 & 81.870 & 3.5205 & 7.113 \\
\hline 132.00 & 3.60 & 87.840 & 3.5920 & 7.450 \\
\hline 133.00 & 3.65 & 94.200 & 3.6645 & 7.802 \\
\hline 134.00 & 3.70 & 101.000 & 3.7382 & 8.169 \\
\hline 135.00 & 3.75 & 108.200 & 3.8125 & 8.552 \\
\hline 136.00 & 3.80 & 115.900 & 3.8881 & 8.951 \\
\hline 137.00 & 3.85 & 124.100 & 3.9648 & 9.366 \\
\hline 138.00 & 3.90 & 132.800 & 4.0423 & 9.799 \\
\hline 139.00 & 3.95 & 142.000 & 4.1204 & 10.250 \\
\hline
\end{tabular}




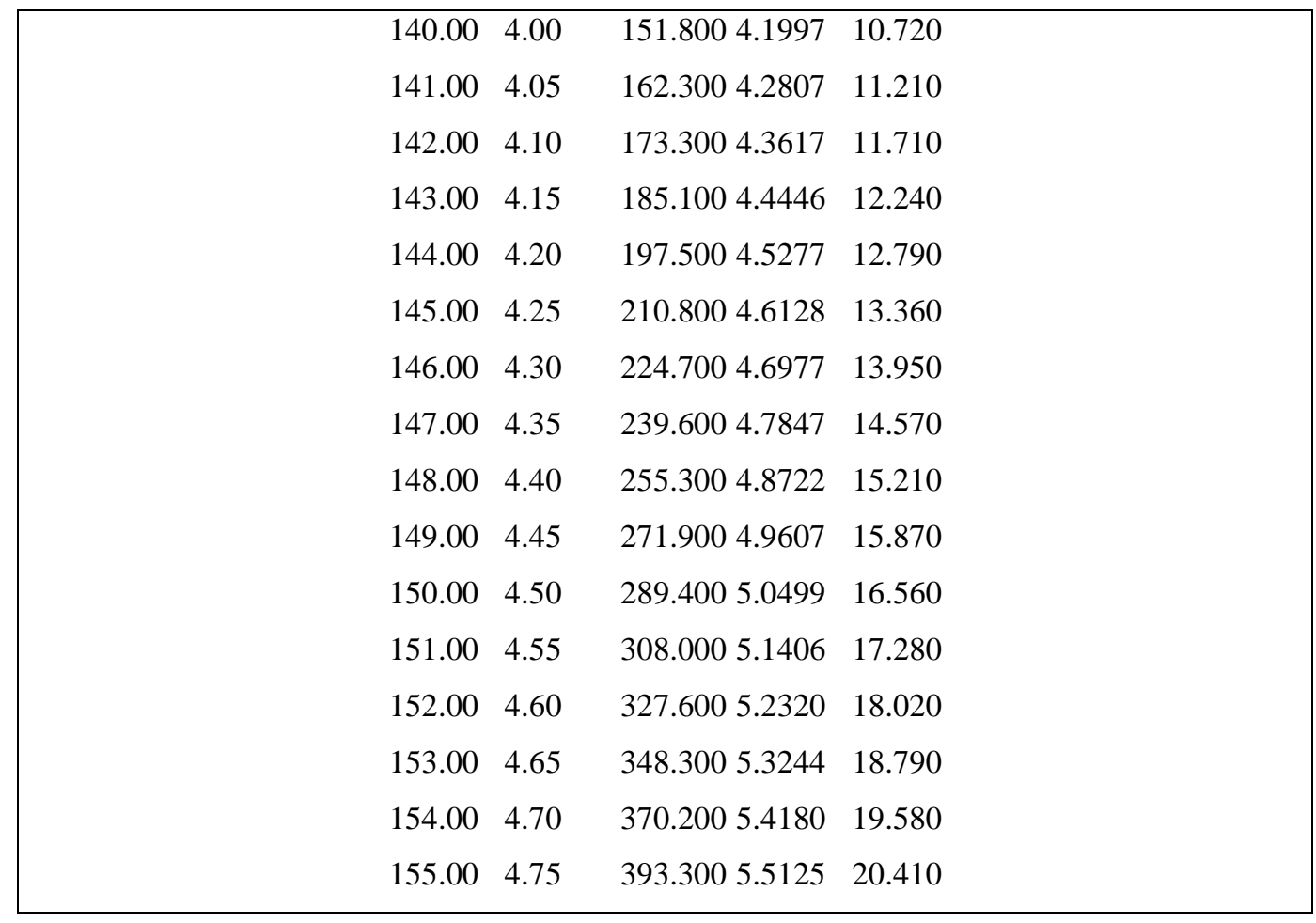

